UNIVERSIDADE DE SÃO PAULO

Instituto de Física.

\title{
Vacâncias em Nanotubos de Carbono: Propriedades Eletrônicas, Estruturais e de Transporte
}

\author{
José Eduardo Padilha de Sousa
}

Orientador:

Prof. Dr. Adalberto Fazzio

Dissertação apresentada ao Instituto de Física para a obtenção do título de Mestre em Ciências.

Banca Examinadora:

Prof. Dr. Adalberto Fazzio (IFUSP)

Prof. Dr. Gustavo Martini Dalpian (UFABC)

Profa. Dra. Maria Cecilia Barbosa da Silveira Salvadori (IFUSP)

São Paulo

2008 
FICHA CATALOGRÁFICA

Preparada pelo Serviço de Biblioteca e Informação do Instituto de Física da Universidade de São Paulo

Sousa, José Eduardo Padilha de

Vacâncias em Nanotubos de Carbono: Propriedades

Eletrônicas, Estruturais e de Transporte - 2008

Dissertação (Mestrado) - Universidade de São Paulo. Instituto de Física - Depto. de Física dos Materiais e Mecânica

Orientador: Prof. Dr. Adalberto Fazzio

Área de Concentração: Física

Unitermos: 1. Física da Matéria Condensada; 2. Física Computacional; 3. Estrutura Eletrônica; 4. Transporte de Elétrons; 5. Materiais Nanoestruturados. 
... "We're living in a world where all we see if the tip of the iceberg, the classical tip of an immense quantum mechanical iceberg ...

... What makes up things are not more things ... but what make up things are idea, concepts, information"...

Fred Alan Wolf 



\section{Agradecimentos}

Primeiramente, gostaria de agradecer à Deus, por tudo, pela saúde que tive durante todo o mestrado, pela clareza nas idéias, por ter colocado pessoas maravilhosas na minha minha vida durante este período e por eu não ter passado mal nenhum dia por ter ficado tantas noites em claro estudando.

Agradeço muito aos meus pais por toda a força e motivação, por todas as passagens de ônibus que me pagaram para que pudesse ir para Colorado, pelas compras que eu fazia antes de vir para São Paulo, mas principalmente por todo amor, carinho e uma dedicação incondicional que sempre tiveram comigo.

Gostaria de agradecer à minha namorada e noiva Ana Paula, por todo o carinho, elogios e amor dedicado durante todo o meu mestrado. Além de agradecer, gostaria de dedicar esta dissertação à ela.

Gostaria de agradecer muito aos meus colegas e amigos, tanto amizades que fiz aqui em São Paulo, quanto amigos da minha cidade natal. Em especial, gostaria de agradecer 3 pessoas que tiveram uma grande contribuição para o desenvolvimento desse mestrado. Primeiro o Jeverson, por ter perdido um bom tempo me ensinando a mexer com Linux e com o VASP e por todas as discussões que tivemos sobre física, agradeço também ao Matheus por todas as discussões sobre física que foram muito importantes e também ao Alexandre, também por discussões muito importantes sobre física e pelas contas de transporte que ele fez. Agradeço também à todos os alunos do grupo SAMPA.

Agradeço ao professor José Roque, por ter sido meu orientador - não oficial durante todo mestrado, sempre me ajudando muito a compreender o universo que eu estava inserido.

Por fim, agradeço muito ao meu orientador, Adalberto Fazzio, primeiramente por me aceitar como aluno de mestrado e depois pela paciência, pelo empenho que teve comigo em me ensinar e me motivar a estudar física. Se não fosse por ele, hoje não saberia nada do que sei sobre a área do meu mestrado.

Agradeço à CAPES pelo apoio financeiro. 



\section{Resumo}

O principal objetivo dessa dissertação de mestrado é o estudo das propriedades estruturais e eletrônicas de um dos materiais mais promissores para a nanoeletrônica, os nanotubos de carbono, na presença de defeitos do tipo vacâncias.

Os defeitos estudados neste trabalho são as monovacâncias e multivacâncias em nanotubos de carbono armchair $(5,5)$. Para isso, realizamos cálculos quânticos de primeiros princípios baseados na teoria do funcional da densidade.

Primeiramente, foi realizado um estudo sistemático das monovacâncias variando a sua concentração, para que possamos entender qual é a influência da dis-

tância entre esses defeitos no sistema. A partir de $14.784 \AA$ o efeito do potencial inserido pela vacância praticamente é desprezível. Seguindo essa sistemática, observamos também que a partir de $19.712 \AA$ a interação elástica entre defeitos é desprezível. Em todas as estruturas de bandas ocorre o surgimento de bandas de impureza, caracterizadas por uma localização de carga no defeito, principalmente no "dangling bond".

Utilizando o procedimento NEB (nudge elastic band) obtivemos um valor de $0.55 \mathrm{eV}$ para a barreira de migração da vacância. Esse valor fornece um tempo aproximado de $0.156 \mathrm{~ms}$ a $300 \mathrm{~K}$, para que a vacância salte de um sítio para outro na rede do nanotubo. Tendo isso, determinamos que a monovacância é um defeito que apresenta uma grande mobilidade no sistema, o que pode eventualmente ocorrer de uma encontrar-se com outras, formando sistemas maiores, como clusters de monovacâncias ou multivacâncias.

Seguindo o nosso objetivo, realizamos um estudo sistemático das multivacâncias. Determinamos todas as reconstruções desses defeitos, nas quais observamos que as multivacâncias de índice par, apresentavam somente pentágonos e uma região central, e em contrapartida as de índice ímpar apresentavam pentágonos, uma região central e um dangling bond na sua estrutura final. Definidas as estruturas e as energias das multivacâncias, calculamos suas propriedades eletrônicas, onde é notório que a influência desses defeitos é muito mais drástica que as monovacâncias, devido a sua grande extensão no sistema.

Realizamos cálculos de transporte eletrônico para todos os sistemas, utilizando o método de funções de Green fora do equilíbrio (NEGF-DFT), desenvolvido no 
nosso grupo. A partir desses cálculos, observamos que todos os defeitos modificam a estrutura eletrônica do sistema, uns mais outros menos, mas até para as multivacâncias maiores como a hexavacância, o sistema mantém o seu caráter metálico. Através das técnicas de funções de Green, mostramos que quando estamos utilizando condições periódicas de contorno há uma surgimento de minigap's espúrios. Estes não aparecem quando o vínculo de simetria translacional é quebrado via técnicas de funções de Green. 


\begin{abstract}
The main purpose of this dissertation is the study of the electronic and structural properties in the presence of different types of vacancies, in one of the most promising materials for nanoelectronics, carbon nanotubes.

The defects studied in this work are monovacancy and multivacancies in $(5,5)$ armchair carbon nanotubes. For that purpose perform quantum ab initio calculations based on density functional theory (DFT).

Firstly, was made a systematic study of monovacancies varying its concentration, so we can understand what is the influence of the distance between these defects in the system. Undergoes reconstruction pentagon nonagon from $14.784 \AA$ on words the effect of the potential created by the vacancy is practically negligible. Following this systematic approach, we also found that from $19.712 \AA$ the structural interaction between the defects tends to zero. In all band structures one observes impurity bands, characterized by charge localization in the defect, mainly in the dangling bond.

Using the NEB (nudge elastic band) procedure we obtained a value of $0.55 \mathrm{eV}$ for the migration barrier of the monovacancy. This value provides an approximate time of $0.156 \mathrm{~ms}$ at $300 \mathrm{~K}$ for the vacancy to jump from one site to another on the nanotube network. Hence, we determined that the monovacancy presents a great mobility in the system, which may possibly inccur in two ore more vacancies merging with others to form a larger defect, such as clusters of monovacancies or a hole multivacancy.

Following our goal, we conducted a systematic study of multivacancies. We determined all reconstructions of these defects. We observed that multivacancies with and even number of carbon atoms removed had only pentagons and a central region. In contrast the CNT with and odd numbers of carbon atoms removed have pentagons, a central region and a dangling bond in its final structure. Once we have defined the structures and the energies of the multivacancies, we calculated their electronic properties. It is clear that the influence of these defects is much more drastic than the monovacancy, due to the size of the defect in the system.

We calculated the electronic transport for all systems, using a non-equilibrium Green's functions method (NEGF-DFT), developed in our group. From these
\end{abstract}


calculations, we observed that all the defects alter the electronic structure of the system, but even for the largest multivacancy, the system maintains its metallic character. Using the Green's functions techniques, we show that the use of periodic boundary conditions leads to the emergence of spurious mini-gap's. These do not appear when the translational symmetry is broken using Green's function approach and a true open system is considered. 


\section{Sumário}

Resumo vi

Abstract viii

1 Introdução 1

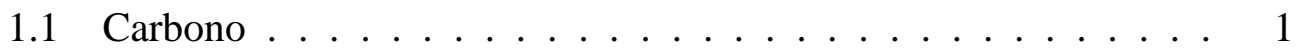

1.2 Formas Alotrópicas do Carbono $\ldots \ldots \ldots \ldots$

1.2 .1 Grafite . . . . . . . . . . . . . . . 4

1.2 .2 Diamante . . . . . . . . . . . . . . 7

1.2 .3 Fulerenos . . . . . . . . . . . . . . 8

1.2.4 Nanoespumas de Carbono . . . . . . . . . . . . . 10

1.3 Nanotubos de Carbono . . . . . . . . . . . . . . . . . . . 11

1.3.1 Classificação dos Nanotubos de Carbono . . . . . . . . 12

1.3.2 Vetor Quiral: $C_{h} \ldots \ldots \ldots \ldots \ldots$

1.3.3 Vetor Translacional: T . . . . . . . . . . . . . . 16

1.3.4 Vetor de Simetria:R . . . . . . . . . . . . . . . . 19

1.3.5 Célula Unitária e Zonas de Brillouin . . . . . . . . . . 23

1.4 Crescendo nanotubos . . . . . . . . . . . . . . . . . . 25

1.4 .1 Ablação a Laser . . . . . . . . . . . . . . . . . . . . 26

1.4 .2 Descarga de Arco . . . . . . . . . . . . . . . . . . 26

1.4.3 Deposição Química de Vapor . . . . . . . . . . . . . . 27

1.5 Microscopia Eletrônica . . . . . . . . . . . . . . . . . . . . . . 29

1.5.1 Microscopia de Tunelamento . . . . . . . . . . . . . 31

1.5.2 Microscopia de Força Atômica . . . . . . . . . . . . . . 31 
3 Formalismo Teórico 39

3.1 Introdução . . . . . . . . . . . . . . . . . . . . . . . . . 39

3.2 Teoria do Funcional da Densidade . . . . . . . . . . . . . . 41

3.3 Aproximação de Born-Oppenheimer . . . . . . . . . . . . . . . 44

3.4 Teoremas de Hohenberg-Kohn . . . . . . . . . . . . . . . 46

3.4.1 Primeiro Teorema de HK: Prova da Existência . . . . . . 47

3.4.2 Segundo Teorema de HK: Princípio Variacional . . . . . . 52

3.5 A Abordagem de Kohn-Sham . . . . . . . . . . . . . . . . . . . 54

3.5.1 Orbitais e Sistema Referêncial Não-Interagente . . . . . . 54

3.5.2 As Equações de Kohn-Sham . . . . . . . . . . . . . . 59

3.6 O Funcional de Troca e Correlação, $E_{x c}[\rho]$ e Suas Aproximações $L D A$ e $G G A \ldots \ldots \ldots$

3.6.1 A Aproximação Local da Densidade - LDA . . . . . . . . 64

3.6.2 A Aproximação Generalizada do Gradiente - GGA . . . . 65

3.7 Condutância e Corrente: Via Funções de Green Fora do Equilíbrio - NEGF . . . . . . . . . . . . . . . . . . . 67

4 Resultados - Caracterização do Sistema Puro $\quad 80$

5 Resultados - Monovacância $\quad 87$

5.1 Formação da Monovacância . . . . . . . . . . . . . . . . . . 87

5.2 Energia de Formação das Monovacâncias . . . . . . . . . . . . . 91

5.3 Bandas de Energia e Densidade de Estados . . . . . . . . . . . 96

5.4 Densidade de Estados da Monovacância Isolada . . . . . . . . . . 101

5.5 Potencial das Monovacâncias . . . . . . . . . . . . . . . 105

5.6 Propriedades de Transporte das Monovacâncias . . . . . . . . . . 111

5.7 Mobilidade da Monovacância . . . . . . . . . . . . . . . . . 113

5.8 Conclusões - Monovacâncias . . . . . . . . . . . . . . . . . . 116

6 Resultados - Multivacâncias $\quad 120$

6.1 Sistemas Estudados . . . . . . . . . . . . . . . . . . . . . 121

6.2 Divacâncias . . . . . . . . . . . . . . . . . . . 122 
6.2.1 Energia de Formação e Reconstrução para as Divacâncias 123

6.2.2 Bandas de Energia e Densidade de Estados - Condições Periódicas de Contorno . . . . . . . . . . . . . . 125

6.2.3 Densidade de Estados e Transporte - Defeito Isolado . . . 127

6.3 Trivacâncias . . . . . . . . . . . . . . . . 132

6.3.1 Energia de Formação e Reconstrução para as Trivacâncias 133

6.3.2 Bandas de Energia e Densidade de Estados - Condições Periódicas de Contorno . . . . . . . . . . . . . . 134

6.3.3 Densidade de Estados e Transporte - Defeito Isolado . . . 136

6.4 Tetravacância . . . . . . . . . . . . . . . . . 137

6.4.1 Energia de Formação e Reconstrução da Tetravacância . . 137

6.4.2 Bandas de Energia e Densidade de Estados - Condições Periódicas de Contorno . . . . . . . . . . . . . 138

6.4.3 Densidade de Estados e Transporte - Defeito Isolado . . . 139

6.5 Pentavacância . . . . . . . . . . . . . . . . . . . . 141

6.5.1 Energia de Formação da Pentavacância . . . . . . . . . . 142

6.5.2 Bandas de Energia e Densidade de Estados - Condições Periódicas de Contorno . . . . . . . . . . . . . . . 142

6.5.3 Densidade de Estados e Transporte - Defeito Isolado . . . 144

6.6 Hexavacância . . . . . . . . . . . . . . . . . . 145

6.6.1 Energia de Formação . . . . . . . . . . . . . . . . 145

6.6.2 Bandas de Energia e Densidade de Estados - Condições Periódicas de Contorno . . . . . . . . . . . . . . . . 146

6.6.3 Densidade de Estados e Transporte - Defeito Isolado . . . 147

6.7 Estabilidade dos Defeitos . . . . . . . . . . . . . . . . . . . . . 149

6.8 Conclusões - Multivacâncias . . . . . . . . . . . . . . . . . 164

7 Conclusões Gerais 172

A Multivacâncias Lineares $\quad 174$

A.1 Tetravacância Linear . . . . . . . . . . . . . . . . . . . . . . . . 174

A.1.1 Reconstrução e Energia de Formação da Tetravacância Linear . . . . . . . . . . . . . . . 175 
A.1.2 Bandas de Energia e Densidade de Estados - Condições Periódicas de Contorno . . . . . . . . . . . . . 175

A.1.3 Densidade de Estados e Transporte Eletrônico - Defeito Isolado . . . . . . . . . . . . . . . . . . . . 177

A.2 Pentavacância Linear . . . . . . . . . . . . . . . . . . . 178

A.2.1 Reconstrução e Energia de Formação da Pentavacância Linear . . . . . . . . . . . . . . . . 178

A.2.2 Bandas de Energia e Densidade de Estados - Condições Periódicas de Contorno . . . . . . . . . . . . . . . 179

A.3 Hexavacância Linear ． . . . . . . . . . . . . . . . . . . 180

A.3.1 Reconstrução e Energia de Formação da Hexavacância Linear . . . . . . . . . . . . . . . . . . 181

A.3.2 Bandas de Energia e Densidade de Estados - Condições Periódicas de Contorno . . . . . . . . . . . . . . 182

A.4 Conclusões e Perspectivas . . . . . . . . . . . . . . . . . . . 183

B Trabalhos Relacionados com a Dissertação 186 $\begin{array}{lr}\text { Referências Bibliográficas } & 188\end{array}$ 


\section{Capítulo 1}

\section{Introdução}

"O carbono é um material que contribui fortemente para a vida dos seres humanos e este tem sido envolvido com várias descobertas científicas. Ele é 'Um velho mas um novo material'. As pesquisas envolvendo o carbono, sempre resultam em novas descobertas", disse o professor Endo, que desenvolveu um método para a produção de nanotubos de carbono em larga escala.

Um átomo de carbono apresenta uma abilidade extraordinária de fazer ligações com outros átomos de carbono e com vários outros tipos de átomos, resultando numa vasta gama de cadeias e anéis, que é a base de toda uma ciência, denominada de química orgânica.

\subsection{Carbono}

Carbono (do latim carbo), é um elemento químico, com símbolo C, de número atômico 6 (6 prótons e 6 elétrons) e massa atômica 12 u. É sólido à temperatura 
ambiente e dependendo das condições de formação pode ser encontrado na natureza em diversas formas alotrópicas: - carbono amorfo; - cristalino na forma do grafite ou diamante. Ele pertence ao grupo (ou família) 14 (anteriormente chamada $4 A$ ).

O carbono é o pilar básico da química orgânica. Hoje em dia, se conhece mais de 10 milhões de compostos baseados no carbono, sendo ele parte fundamental de todos os seres vivos.

É um elemento notável por várias razões. Suas formas alotrópicas incluem, surpreendentemente, uma das substâncias mais frágeis e baratas (o grafite) e uma das mais duras e caras (o diamante). Além disso, apresenta uma grande afinidade para combinar-se quimicamente com outros átomos, incluindo átomos de carbono que podem formar largas cadeias. O seu pequeno raio atômico lhe permite formar cadeias múltiplas onde com o oxigênio forma o dióxido de carbono, vital para o crescimento das plantas. Quando ligado ao hidrogênio forma numerosos compostos denominados, genericamente, hidrocarbonetos, essenciais para a indústria e o transporte, na forma de combustíveis derivados de petróleo e gás natural. Quando combinado com oxigênio e hidrogênio, o carbono forma uma grande variedade de compostos como os ácidos graxos, essenciais para a vida, e os ésteres que dão sabor às frutas. Além disso, ele fornece através do ciclo carbono-nitrogênio, grande parte da energia produzida pelo Sol e outras estrelas. 


\subsection{Formas Alotrópicas do Carbono}

Hoje em dia são conhecidas várias formas alotrópicas do carbono, além da fase amorfa. Temos o grafite, o diamante, os fulerenos, nanotubos, as nanoespumas [1], entre outras. A forma amorfa não chega a adotar uma estrutura cristalina macroscópica. Ela está presente na maioria dos carvões e na fuligem.

Em condições normais de pressão e temperatura, o carbono adota a forma de grafite onde cada átomo está unido a outros três em um plano composto de células hexagonais. Neste estado, 3 elétrons se encontram em orbitais híbridos planos $s p^{2}$ e o quarto em um orbital $p$.

As duas formas de grafite conhecidas, são a alfa (hexagonal) e beta (romboédrica), onde apresentam propriedades físicas idênticas. Os grafites naturais contém mais de $30 \%$ de forma beta, enquanto o grafite sintético contém unicamente a forma alfa. A forma alfa pode transformar-se em beta através de procedimentos mecânicos, e esta recristalizar-se na forma alfa por aquecimento acima de $1000^{\circ} \mathrm{C}$.

Devido à delocalização dos elétrons do orbital $\pi$, o grafite é condutor de eletricidade, propriedade que permite seu uso em processos de eletrólise. Ele é um material frágil e as diferentes camadas encontram-se unidas por forças de Van der Waals, sendo relativamente fácil que umas deslizem sobre as outras, propriedade essa que torna o grafite um bom lubrificante.

Sob pressões elevadas, o carbono adota a forma de diamante, onde cada átomo está unido a outros quatro, com os 4 elétrons em orbitais $s p^{3}$, como nos hidrocarbonetos. O diamante apresenta a mesma estrutura cúbica que o silício e o ger- 
mânio, e devido à resistência da ligação química carbono-carbono, é junto com o nitreto de boro (BN) a substância mais dura conhecida na natureza. Sob certas condições, o carbono cristaliza como lonsdaleíta, uma forma similar ao diamante, porém hexagonal, encontrado nos meteoros.

O orbital híbrido $s p^{1}$, que forma ligações covalentes, só é de interesse na química, manifestando-se em alguns compostos como, por exemplo, o acetileno.

Os fulerenos têm uma estrutura similar à do grafite, porém o empacotamento hexagonal se combina com pentágonos (e, possivelmente, heptágonos), o que curva os planos e permite o aparecimento de estruturas de forma esférica, elipsoidal e cilíndrica. A forma mais convencional é constituída por 60 átomos de carbono, apresentando uma estrutura tridimensional similar a uma bola de futebol. As propriedades dos fulerenos ainda não foram determinadas por completo, continuando a serem amplamente investigadas.

A esta família pertencem também os nanotubos de carbono, de forma cilíndrica, rematados em seus extremos por hemiesferas (fulerenos). Constituem um dos primeiros produtos industriais da nanotecnologia. Hoje em dia investiga-se a sua aplicabilidade em fios de nanocircuitos, já que, por ser derivado do grafite, possui algumas configurações que conduzem eletricidade em toda sua extensão.

\subsubsection{Grafite}

Grafite ou grafita é um dos alótropos do carbono. O grafite é um condutor e pode ser usado, por exemplo, como os eletrodos de uma lâmpada elétrica. 


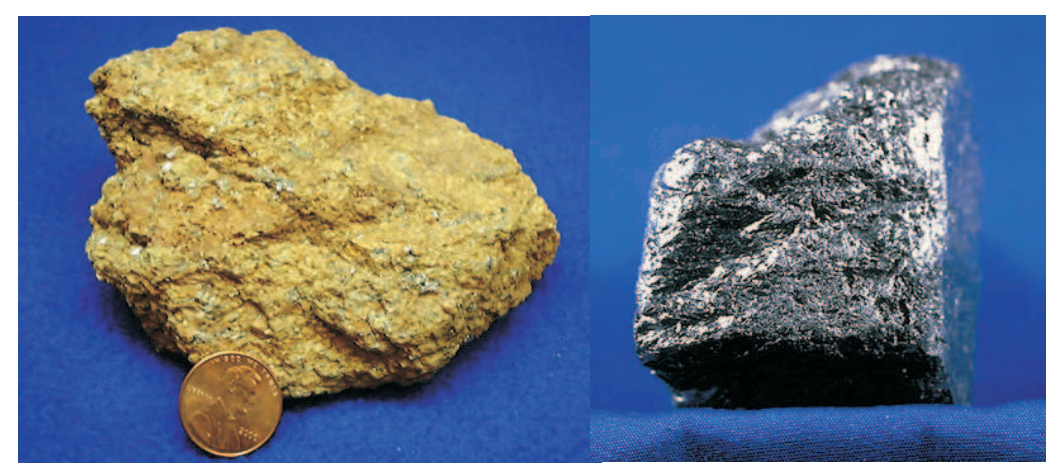

Figura 1.1: Foto: (a) Minério de grafite - grafita; (b) Pedra de grafite.

O grafite possui múltiplas e importantes aplicações industriais, embora seja conhecido popularmente por sua utilização como componente do lápis. As primeiras minas de grafite foram descobertas em 1400 na Bavaria, hoje uma região da Alemanha, mas foi somente no final de século XVIII, que o químico Karl Wilhelm Scheele comprovou cientificamente, que o grafite é composto por um único elemento, ou seja, ele é uma forma alotrópica do carbono.

A condutividade e outras propriedades físicas do grafite, como plano de clivagem e características lubrificantes, são provenientes do arranjo dos átomos no material, formando estruturas em forma de folhas (folhas de grafeno), onde os átomos de carbono apresentam uma hibridização do tipo $s p^{2}$. Os átomos estão organizados como hexágonos, semelhante à organização dos favos numa colméia onde cada vértice é ocupado por um átomo de carbono. O comprimento médio das ligações é de $1.412 \AA$ [2].

As folhas de grafeno são ligadas por ligações fracas, do tipo Van der Walls, com uma distância entre elas de $3.14 \AA$ [2], sendo esse acoplamento fraco res- 
ponsável pela sua característica lubrificante. Essas camadas de folhas de grafeno encontram-se sempre deslocadas uma em relação a outra, de modo que três átomos de cada hexágono de uma camada encontra-se sempre no centro dos hexágonos da camada adjacente, conforme ilustrado na figura (1.2).

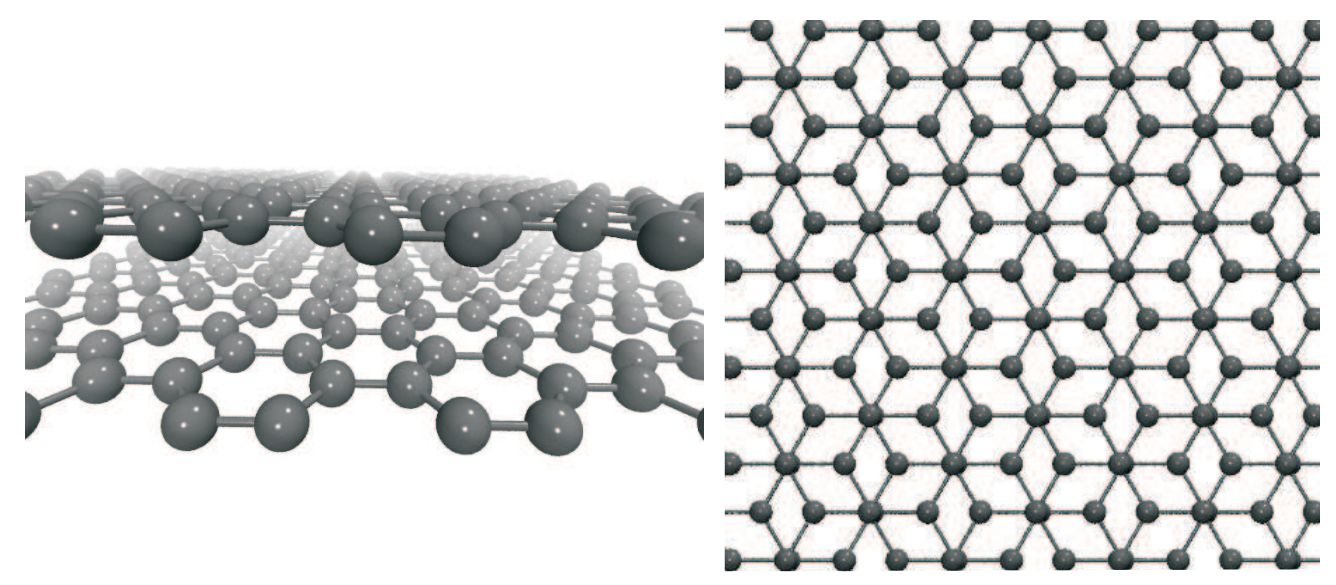

Figura 1.2: Ilustração das folhas de grafeno formando o grafite.

O conjunto de orbitais $p$, perpendiculares ao plano de cada folha, formam estados delocalizados, semelhante à ligação metálica. Uma única folha de grafeno é considerada um semicondutor de gap zero, onde a banda de condução e de valência se tocam nos seis pontos correspondentes aos vértices do hexágono da sua rede recíproca. Porém, no grafite, como esses estados são delocalizados, ocorre uma superposição dos estados, tornando o material metálico.

A condutividade no grafite se dá ao longo das folhas, de forma que no sólido, há uma variação da condutividade dependendo da posição em que esta é medida (mais alta ao longo das folhas e menor perpendicularmente a estas). 


\subsubsection{Diamante}

O diamante é uma outra forma alotrópica do carbono, mas ao contrário do grafite, os elétrons do carbono hibridizam-se na forma $s p^{3}$, onde cada átomo faz quatro ligações nas direções de um tetraedro regular. A rede formada é cúbica de face centrada com dois átomos na base, um em $(0,0,0)$ e outro em $(a / 4, a / 4, a / 4)$, onde $a$ é o parâmetro de rede, com valor $3.57 \AA$ e comprimento da ligação entre os átomos de carbono de $1.56 \AA$ [2]. Esta ligação é extremamente rígida, surgindo dai o principal motivo da sua dureza.

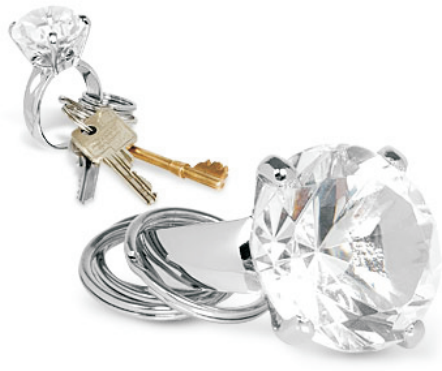

(a)

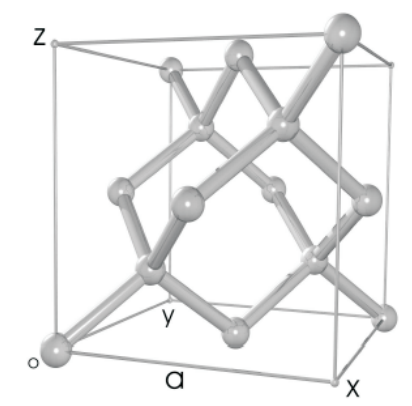

(b)

Figura 1.3: (a) Diamante lapidado; (b) Rede cristalina do diamante.

Ao contrário do grafite, o diamante é um material isolante, ou seja possui um gap entre a banda de condução e valência, com valor 5.4eV [3]. A transparência do diamante é devido a ele possuir um gap de energia grande, onde nenhuma onda eletromagnética na região do visível é absorvida pelo cristal. 


\subsubsection{Fulerenos}

Os fulerenos são a terceira forma mais estável do carbono, depois do diamante e do grafite. Foram descobertos recentemente, em 1985 por Kroto, Curl e Smalley [4], tornando-se populares entre os químicos, tanto pela sua beleza estrutural quanto pela sua versatilidade para a síntese de novos compostos químicos. Foram chamados de "buckministerfullerene"em homenagem ao arquiteto R. Buckminister Fuller que inventou a estrutura do domo geodésico.

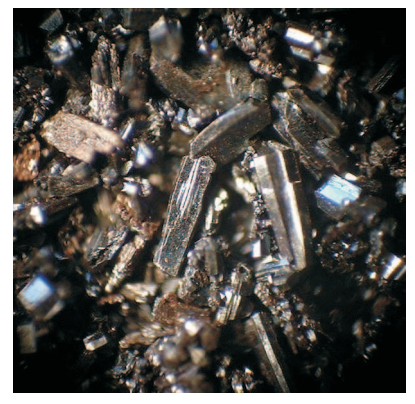

(a)

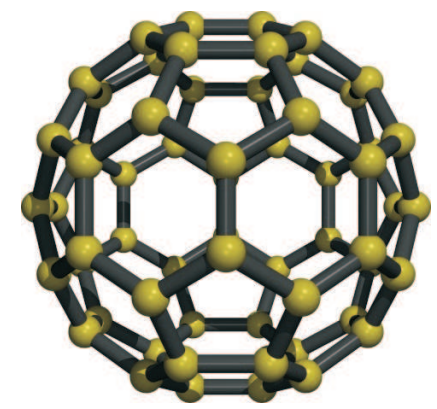

(b)

Figura 1.4: Foto: (a) Estrutura cristalina formada pelo buckministerfullerene; (b)Fulereno $C_{60}$.

O fulereno $C_{60}$ possui forma de uma bola de futebol (domo geodésico) composta por 12 pentágonos e 20 hexágonos. Sua formula química é $C_{60}$. Os hexágonos mantém a planaridade (como no grafite que é plano por apresentar somente hexágonos) enquanto que cada pentágono inicia um ângulo de curvatura, sendo necessários 12 pentágonos para fechar a superfície sobre si mesma, formando a bola.

Na figura (1.5) temos outras formas de fulerenos, formados por diferentes 
quantidades de átomos de carbono, como o fulereno $C_{20}$, que apresenta somente 12 pentágonos e nenhum hexágono.
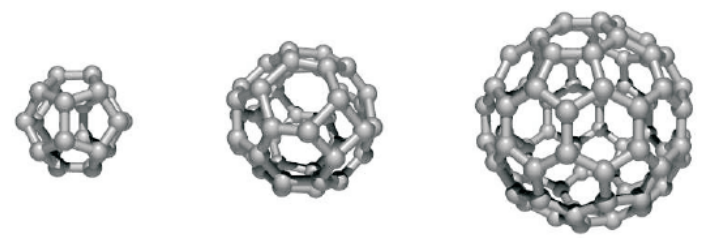

(a)

(b)

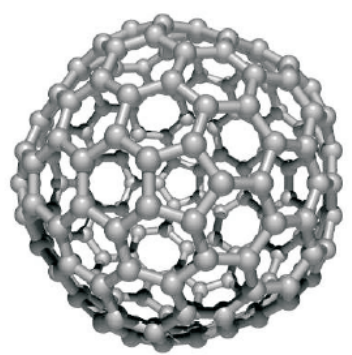

(d)

(c)

Figura 1.5: (a) $C_{20}$; (b) $C_{40}$; (c) $C_{40}$; (c) $C_{80}$; (d) $C_{180}$.

A descoberta dos fulerenos ocorreu em setembro de 1985, quando um grupo de cientistas, principalmente H. W. Kroto e R. E. Smalley, obtiveram uma série de estruturas químicas com 44 a 90 átomos de carbono, aparecendo em maior concentração aquelas com 60 átomos de carbono. Eles foram observados a partir do bombardeamento de raios laser sobre um alvo de grafite a uma temperatura de $104^{\circ} \mathrm{C}$. A descoberta do novo alótropo do carbono rendeu a estes cientistas o Prêmio Nobel de Química em 1996. 


\subsubsection{Nanoespumas de Carbono}

As nanoespumas de carbono são consideradas hoje em dia a quinta forma alotrópica do carbono. Foram descobertas em 1997 por Andrei V. Rode, et all [1]. Este sistema consiste de clusters de baixa densidade de carbono, que juntos formam uma estrutura tridimensional forte.

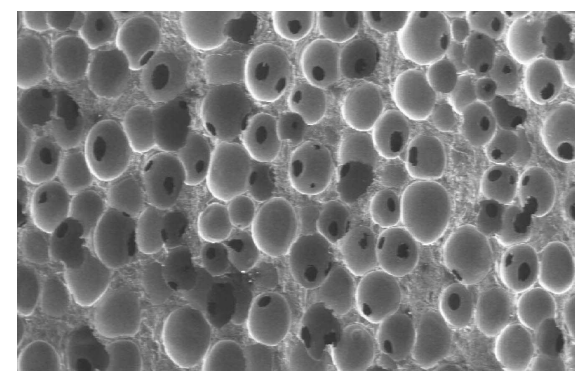

Figura 1.6: Nanoespuma de carbono

Cada cluster possui cerca de 6 nanômetros de largura e são compostos por cerca de 4000 átomos de carbono ligados como no grafite - porém com folhas que possuem curvatura negativa devido a inclusão de heptagons entre os padrões regulares hexagonais. Isto é o contrário do que acontece no caso do buckminsterfullerenes, onde as folhas de carbono possuem curvatura positiva, devido à inclusão de pentágonos.

A estrutura de uma nanoespuma, é semelhante à de um aerogel, mas com $1 \%$ da sua densidade. Ao contrário dos aerogels, as nanoespumas de carbono são má condutoras elétricas. 


\subsection{Nanotubos de Carbono}

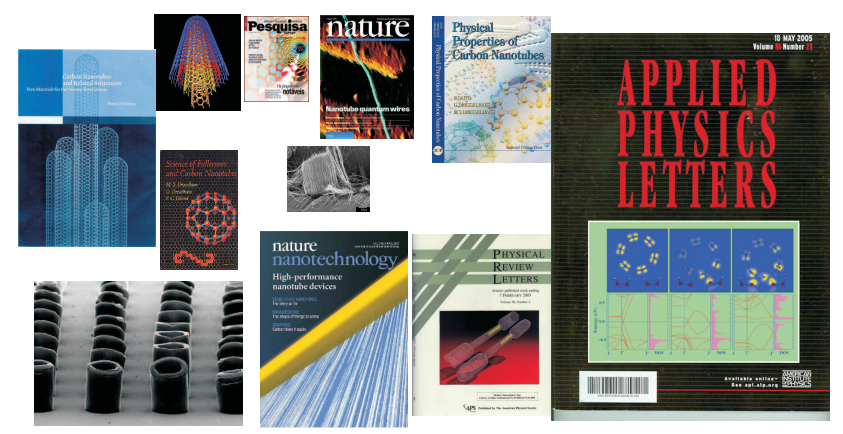

Figura 1.7: Nanotubos de Carbono - Objeto de grande importância na comunidade científica.

Os nanotubos de carbono foram inicialmente descobertos como um produto secundário na síntese dos fulerenos. Em 1991, Iijima observou com um TEM (microscópico de transmissão eletrônica) objetos tubulares numa amostra de fulerenos produzidos via descarga de arco. As primeiras imagens obtidas mostraram que os "tubulos de fulereno"consistiam de várias camadas cilíndricas, separadas pela distância típica de interações de Van der Waals entre as folhas de grafeno $(\approx 3.14$ Å). Hoje, essas moléculas são chamadas de nanotubos de carbono de paredes múltiplas - multi-wall carbon nanotube (MWCNT). Antecipando-se às evidências experimentais, M. Dresselhaus e R. Smalley ${ }^{1}$ propuseram em 1990 um modelo teórico simples de um nanotubo de parede única, descrito por uma folha de grafeno enrolada sob uma forma cilíndrica e fechada por hemisférios de fulereno. Apenas em 1993 é que foi sintetizado pela primeira vez um tubo de parede única, com o uso de catalisadores metálicos [5,6], chamado então de single-wall carbon

\footnotetext{
${ }^{1} 1$ DoD Workshop 1990 in Washington about Carbon-Carbon materials
} 
nanotubes (SWCNT). O trabalho pioneiro de Iijima [7] de 1991, uniu previsões teóricas e evidências experimentais onde deu início a um campo de pesquisa que vem progredindo rapidamente. Um exemplo importante dentro da realidade nacional são as Redes Temáticas de Nanotecnologia envolvendo pesquisadores de vários estados, onde muitos desses pesquisam as propriedades desses nanotubos ${ }^{2}$.

Um nanotubo de carbono single-wall pode ser descrito por uma folha de grafeno enrolada em uma forma cilíndrica tendo uma estrutura unidimensional com uma simetria axial, geralmente exibindo uma conformação espiral, chamada quiralidade. A quiralidade, como iremos definir nesse capítulo, é dada por um único vetor chamado vetor quiral. Para especificar a estrutura dos nanotubos de carbono, nós iremos definir alguns vetores importantes, que são derivados do vetor quiral.

\subsubsection{Classificação dos Nanotubos de Carbono}

Um nanotubo "single-wall"é definido como uma folha de grafeno com um formato cilíndrico, com um diâmetro em torno de $0.7-10.0 \mathrm{~nm}^{3}$, entretanto a maioria nos nanotubos single-wall observados possuem diâmetros $<2 \mathrm{~nm}$. Se negligenciarmos os dois finais dos nanotubos de carbono e observarmos o aspecto da razão do cilindro (isto é, comprimento/diâmetro, que é da ordem de $10^{4}-10^{5}$ ), esses nanotubos podem ser considerados como nanoestruturas unidimensionais.

Um fato interessante e essencial sobre a estrutura dos nanotubos de carbono

\footnotetext{
${ }^{2}$ Um exemplo de uma rede dessas, é a Rede Theo-Nano - Web Site : http://www.fmt.if.usp.br/ theonano/

${ }^{3}$ Muitos dos nanotubos observados experimentalmente são estruturas multi-wall
} 
$(6,6)$
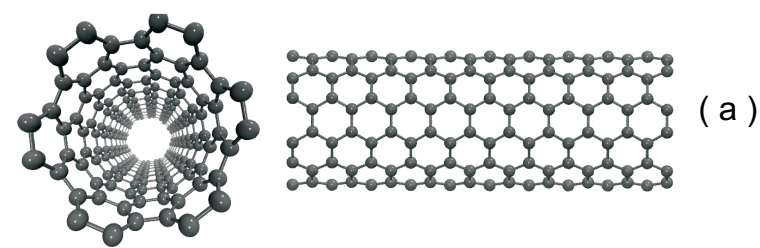

$(8,0)$
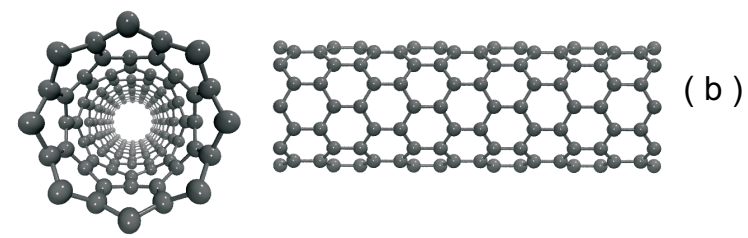

$(6,3)$
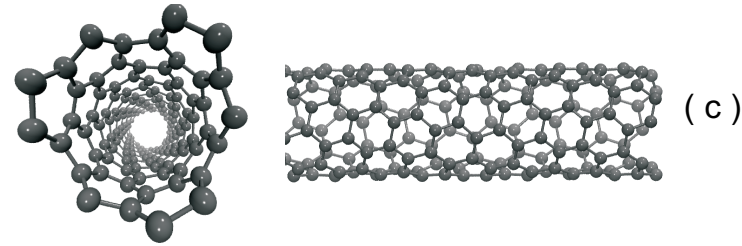

Figura 1.8: Classificação dos nanotubos de carbono: (a) Armchair, (b) zigzag, e (c) quiral. A partir dessa figura, podemos claramente ver a orientação dos hexágonos na rede com relação ao eixo do nanotubo.

é a orientação dos hexágonos (anéis de carbono) na rede, com relação ao eixo do nanotubo. Três exemplos de nanotubos single-wall (SWCNT) são mostrados na figura (1.8). Dessa figura, podemos ver que a direção dos hexágonos na rede, pode ser tomada arbitrariamente, sem nenhuma distorção dos hexágonos, exceto a distorção da curvatura do nanotubo de carbono.

A primeira classificação de simetria é se o nanotubo é quiral (non-symmorphic) ou não quiral (symmorphic). Um nanotubo não quiral é definido por um tubo cuja imagem possui uma estrutura idêntica à original. Existem somente dois casos de nanotubos não quirais; nanotubos armchair e zig-zag, que são mostrados na figura (1.8(a) e (b)), respectivamente. Os nomes armchair e zig-zag vem da forma da seção transversal do anel, como mostrado no final de cada tubo na figura (1.8)(a) e 
(b), respectivamente. Nanotubos quirais exibem uma simetria espiral cuja imagem não pode ser superposta à primeira. A quiralidade axial é comumente discutida em conexão com atividade óptica. Nós temos então uma variedade de geometrias para os nanotubos de carbono que podem possuir vários diâmetros e quiralidades.

\subsubsection{Vetor Quiral: $C_{h}$}

A estrutura de um nanotubo de carbono single-wall é especificado pelo vetor quiral $\vec{C}_{h}(\overrightarrow{O A}$ na figura 1.9$)$ que corresponde a uma seção do nanotubo perpendicular ao seu eixo (daqui para frente nós chamaremos de equador do tubo). Na figura (1.9) nós mostramos a folha de grafeno, em que $\overrightarrow{O B}$ é a direção do eixo do tubo, e a direção de $\overrightarrow{O A}$ corresponde ao equador. Considerando os eixos cristalográficos equivalentes $O, A, B$ e $B^{\prime}$, e enrolando-se a folha de grafeno, os pontos $A$ e $B$ coincidem (e os pontos $B$ e $B^{\prime}$ coincidem). Assim, é possível a construção de um modelo de nanotubo de carbono. Os vetores $\overrightarrow{O A}$ e $\overrightarrow{O B}$ definem o vetor quiral $\overrightarrow{C_{h}}$ e o vetor de translação $\vec{T}$, respectivamente, como será explicado. Este

vetor quiral $\vec{C}_{h}$ pode ser expresso pelos vetores unitários no espaço real $\vec{a}_{1}$ e $\vec{a}_{2}$ (ver figura (1.9) da rede hexagonal:

$$
\vec{C}_{h}=n \vec{a}_{1}+m \vec{a}_{2}, \quad(n, m \in \mathbb{N}, 0 \leq|m| \leq n)
$$

O vetor quiral mostrado na figura (1.9) é $(4,2)$. Um nanotubo armchair corresponde ao caso $n=m$, ou seja $\vec{C}_{h}=(n, m)$, e um nanotubo zig-zag corresponde ao caso $m=0$, ou $\vec{C}_{h}=(n, 0)$. Todos os outros vetores quirais $(n, m)$ corre- 
spondem a nanotubos quirais. Devido a simetria hexagonal da rede, nós devemos considerar somente $0<|m|<n$ em $\vec{C}_{h}$ para nanotubos quirais.

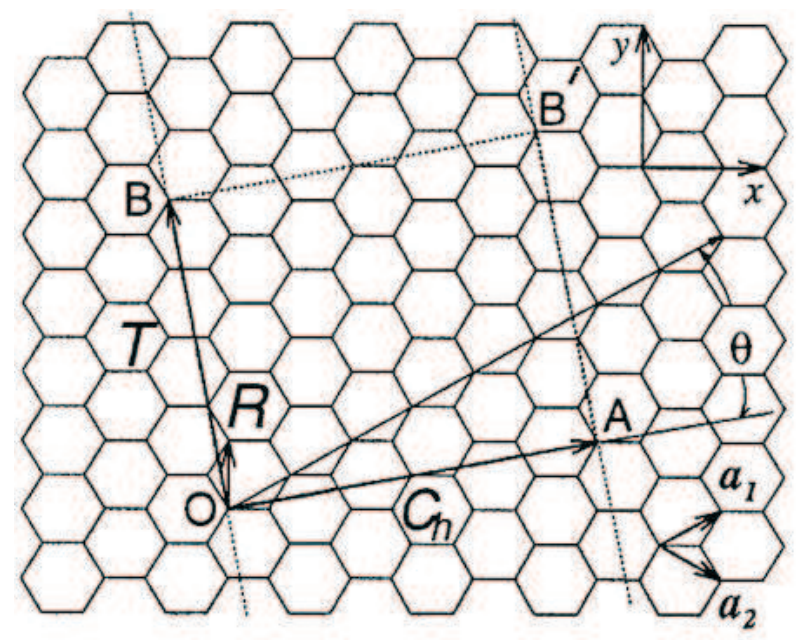

Figura 1.9: Rede hexagonal de um nanotubo de carbono desenrolada. Quando nós conectamos os sítios $O$ e $A$, e $B$ e $B^{\prime}$, um nanotubo de carbono pode se construído. $\overrightarrow{O A}$ e $\overrightarrow{O B}$ definem o vetor quiral $\vec{C}_{h}$ e o vetor translacional $\mathbf{T}$ do nanotubo, respectivamente. $\mathrm{O}$ retângulo $O A B^{\prime} B$ definem a célula unitária para o nanotubo de carbono. $\mathrm{O}$ vetor $\mathbf{R}$ denota o vetor de simetria (ver seção 1.3.4). A figura corresponde à $\vec{C}_{h}=(4,2)$, $d=d_{R}=2, \mathbf{T}=(4,-5), N=28, \mathbf{R}=(1,-1)$.

O diâmetro do nanotubo de carbono, $d_{t}$, é dado por $L / \pi$, em que $L$ é o comprimento da circunferência do nanotubo de carbono:

$$
d_{t}=L / \pi, \quad L=\left|\vec{C}_{h}\right|=\sqrt{\vec{C}_{h} \cdot \vec{C}_{h}}=a \sqrt{n^{2}+m^{2}+n m}
$$

É claro aqui, que $\vec{a}_{1}$ e $\vec{a}_{2}$ não são ortogonais um ao outro, assim o produto interno entre $\vec{a}_{1}$ e $\vec{a}_{2}$ nos dá:

$$
\vec{a}_{1} \cdot \vec{a}_{1}=\vec{a}_{2} \cdot \vec{a}_{2}=\vec{a}^{2}, \quad \vec{a}_{1} \cdot \vec{a}_{2}=\frac{a^{2}}{2}
$$


onde a constante da rede hexagonal $a=1.44 \AA \times \sqrt{3}=2.49 \AA^{4}$. Por exemplo, o diâmetro do nanotubo armchair $(5,5)$ é $d_{t}=6.88 \AA$.

O ângulo quiral $\theta$ (ver figura (1.9)) é definido como o ângulo entre os vetores $\vec{C}_{h}$ e $\vec{a}_{1}$, com valores de $\theta$ no range de $0 \leq|\theta| \leq 30^{\circ}$, por causa da simetria hexagonal da rede. $\mathrm{O}$ ângulo quiral $\theta$ denota o ângulo de inclinação dos hexágonos com respeito à direção do eixo do nanotubo de carbono e especifica a simetria espiral. O ângulo quiral $\theta$ é definido tomando-se o produto interno de $\vec{C}_{h}$ e $\vec{a}_{1}$, que nos dá uma expressão para o $\cos \theta$ :

$$
\cos \theta=\frac{\vec{C}_{h} \cdot \vec{a}_{1}}{\left|\vec{C}_{h}\right|\left|\vec{a}_{1}\right|}=\frac{2 n+m}{2 \sqrt{n^{2}+m^{2}+n m}}
$$

assim relacionando o ângulo $\theta$ aos inteiros $(n, m)$ definidos na equação (1.1). Em particular, nanotubos zigzag e armchair correspondem à $\theta=0^{\circ}$ e $\theta=30^{\circ}$, respectivamente.

\subsubsection{Vetor Translacional: $\mathrm{T}$}

O vetor translacional $\mathbf{T}$ é definido como ser um vetor unitário de um nanotubo de carbono $1 D$. O vetor $\mathbf{T}$ é paralelo ao eixo do nanotubo e normal ao vetor quiral $\vec{C}_{h}$ na rede hexagonal desenrolada na figura (1.9). O vetor da rede T mostrado como $\overrightarrow{O B}$ na figura (1.9) pode ser expresso em termos dos vetores da base $\vec{a}_{1}$ e $\vec{a}_{2}$ como:

\footnotetext{
${ }^{4} \mathrm{O}$ comprimento da ligação $C-C$ do grafite é $1.42 \AA$. No caso dos nanotubos de carbono, o comprimento da ligação $C-C$ é um pouco maior que a do grafite: $1.44 \AA$.
} 


$$
\mathbf{T}=t_{1} \vec{a}_{1}+t_{2} \vec{a}_{2} \equiv\left(t_{1}, t_{2}\right), \quad \text { (onde } t_{1}, t_{2} \text { são inteiros ) }
$$

$\mathrm{O}$ vetor translacional $\mathbf{T}$ corresponde ao primeiro ponto da rede da folha de grafeno $2 D$ por onde o vetor $\overrightarrow{O B}$ passa (normal ao vetor quiral $\vec{C}_{h}$ ). É claro que $t_{1}$ e $t_{2}$ não devem possuir um divisor em comum, exceto a unidade. Usando $\vec{C}_{h} \cdot \mathbf{T}=0$ e as equações $(1.1),(1.3)$ e (1.5) nós obtemos as expressões para $t_{1} \mathrm{e}$ $t_{2}$ que são dadas por:

$$
t_{1}=\frac{2 m+n}{d_{R}}, \quad t_{2}=-\frac{2 n+m}{d_{R}}
$$

onde $d_{R}$ é o maior divisor comum de $(2 m+n)$ e $(2 n+m)$ (gcd). Introduzindo também $d$ como sendo o maior divisor comum entre $n$ e $m$, então $d_{R}$ pode ser relacionado com $d$ por: ${ }^{5}$

$$
d_{R}= \begin{cases}d & \text { se } n-m \text { não for um múltiplo de } 3 d \\ 3 d & \text { se } n-m \text { é um múltiplo de } 3 d\end{cases}
$$

No caso da figura (1.9), onde $\vec{C}_{h}=(4,2)$, nós temos $d=d_{R}=2, \mathbf{T}=$ $(4,-5)$. O comprimento do vetor translacional $T$, é dado por:

\footnotetext{
${ }^{5}$ Esta relação é obtida pelo uso repetido do fato de que quando dois inteiros, $\alpha$ e $\beta$ ( $\alpha>\beta$ ), possuem um divisor em comum, $\gamma$, então $\gamma$ também é um divisor comum de $(\alpha-\beta)$ e $\beta$ (Lei de Euclides). Quando nós denotamos o maior divisor comum como $\gamma=\operatorname{gcd}(\alpha, \beta)$, nós obtemos:$$
d_{R}=\operatorname{gcd}(2 m+n, 2 n+m)=\operatorname{gcd}(2 m+n, n-m)=\operatorname{gcd}(3 m, n-m)=\operatorname{gcd}(3 d, n-m)
$$

que nos dá a equação (1.7) 


$$
T=|\mathbf{T}|=\sqrt{3} L / d_{R}
$$

onde o comprimento da circunferência, $L$, do nanotubo é dado pela equação (1.2). Nós notamos que $T$ é muito reduzido quando $(n, m)$ possui um divisor em comum ou quando $(n-m)$ é um múltiplo de $3 d$. De fato, para o nanotubo armchair $\vec{C}_{h}=$ $(5,5)$, nós temos $d_{R}=3 d=15, \mathbf{T}=(1,-1)$ [Figura (1.8)-(a)], enquanto que para o nanotubo zigzag $\vec{C}_{h}=(9,0)$ nós temos $d_{R}=d=9$, e $\mathbf{T}=(1,-2)$ [Figura (1.8)-(b)]

A célula unitária do nanotubo de carbono $1 D$ é o retângulo $O A B^{\prime} B$ definido pelos vetores quirais $\vec{C}_{h}$ e T (ver figura (1.9)), enquanto que os vetores $\vec{a}_{1}$ e $\vec{a}_{2}$ definem a área da célula unitária do grafite $2 D$. Quando a área da célula unitária do nanotubo de carbono $\left|\vec{C}_{h} \times \mathbf{T}\right|$ (onde o símbolo $\times$ denota o produto vetorial) é dividida pela área do hexágono $\left(\left|\vec{a}_{1} \times \vec{a}_{2}\right|\right)$, nós obtemos o número de hexágonos por célula unitária $N$ como uma função de $n$ e $m$ na equação (1.1) dado por: ${ }^{6}$

$$
N=\frac{\left|\vec{C}_{h} \times \mathbf{T}\right|}{\left|\vec{a}_{1} \times \vec{a}_{2}\right|}=\frac{2\left(n^{2}+m^{2}+n m\right)}{d_{R}}=\frac{2 L^{2}}{a^{2} d_{R}}
$$

onde $L$ e $d_{R}$ são dados pelas equações (1.2) e (1.7), respectivamente. Nós denotamos que cada hexágono contém dois átomos de carbono. Então existem $2 \mathrm{~N}$

\footnotetext{
${ }^{6}$ Para vetores da célula unitária não ortogonais, o cálculo usando o produto vetorial fica mais fácil usando o produto interno, desde que o produto vetorial de vetores unitários são dados por:

$$
\vec{a}_{1} \times \vec{a}_{1}=\vec{a}_{2} \times \vec{a}_{2}=0 \quad \text { e }\left|\vec{a}_{1} \times \vec{a}_{2}\right|=\sqrt{3} a^{2} / 2
$$

onde $\left|\vec{a}_{1} \times \vec{a}_{2}\right|$ corresponde a área o paralelogramo gerado por $\vec{a}_{1}$ e $\vec{a}_{1}$. A área do paralelogramo é igual à área do hexágono.
} 
átomos de carbono (ou $2 p_{z}$ orbitais) em cada célula unitária do nanotubo de carbono.

\subsubsection{Vetor de Simetria:R}

Nós denotamos os vetores dos sítios dos átomos de carbono dentro da célula unitária $1 D$ do nanotubo de carbono por $i$ vezes o vetor $\mathbf{R}$, ou seja, $i \mathbf{R}$, onde $i$ é um inteiro $(i=1 \ldots N)$. Quando $i \mathbf{R}$ sai da célula unitária, nós deslocamos ele de maneira que pertença à célula unitária, através de translações de um número inteiro dos vetores $\vec{C}_{h}$ ou $\mathbf{T}$, usando condições periódicas de contorno. O vetor $\mathbf{R}$ é usado para gerar as coordenadas dos átomos de carbono no nanotubo.

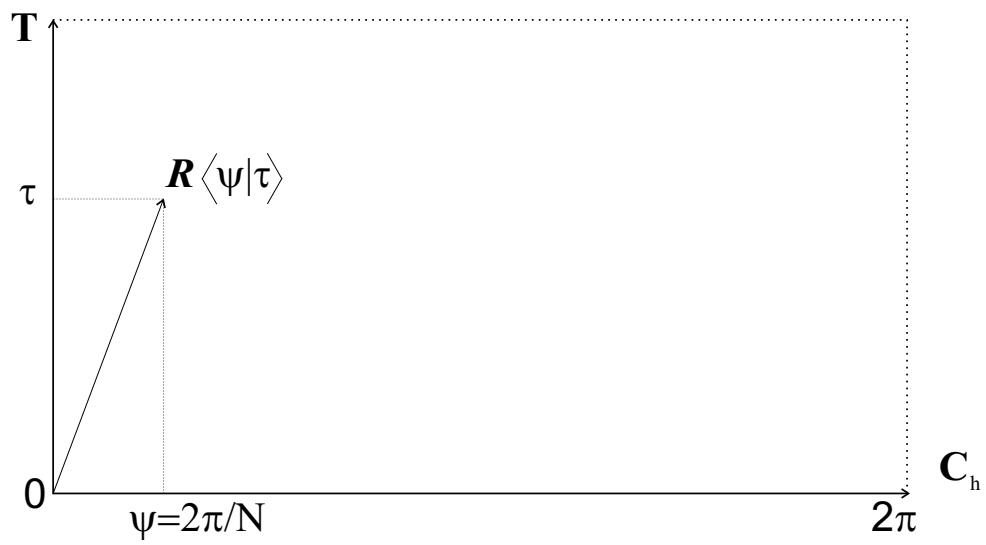

Figura 1.10: Operação de simetria do grupo espacial, $\mathbf{R}=\langle\psi \mid \tau\rangle$, em que $\psi$ denota o ângulo de rotação ao redor do eixo do nanotubo e $\tau$ é uma translação na direção do vetor de translação $\mathbf{T}$, como especificado pelo vetor de simetria $\mathbf{R}$ na equação (1.16). Note que $N \psi=2 \pi$ e $N \tau=M T$.

É convencional expressar o vetor $\mathbf{R}$ em termos das suas projeções nos vetores

ortogonais $\vec{C}_{h}$ e T da célula unitária do nanotubo, como mostrado na figura (1.10). O vetor de simetria $\mathbf{R}$ é então definido como o vetor local (mostrado na figura (1.9) 
como $\overrightarrow{O R}$ ) possuindo as menores componentes na direção de $\vec{C}_{h}$, e $\mathbf{R}$ é expresso em termos de $\vec{a}_{1}$ e $\vec{a}_{2}$ como:

$$
\mathbf{R}=p \vec{a}_{1}+q \vec{a}_{2} \equiv(p, q), \quad(p, q \text { são inteiros })
$$

onde $p$ e $q$ não possuem um divisor em comum exceto pela unidade. ${ }^{7}$ A componente $\vec{C}_{h}$ de $\mathbf{R}$, ou $\vec{C}_{h} \cdot \mathbf{R}$, é proporcional ao valor de $\mathbf{T} \times \mathbf{R}$ dada por: ${ }^{8}$

$$
\mathbf{T} \times \mathbf{R}=\left(t_{1} q-t_{2} p\right)\left(\vec{a}_{1} \times \vec{a}_{2}\right)
$$

onde $\left(t_{1} q-t_{2} p\right)$ do lado direito da equação (1.11) é um inteiro. Nós selecionamos $p$ e $q$ de $\mathbf{R}$ para formar o menor vetor local $(i=1)$, tal que

$$
t_{1} q-t_{2} p=1, \quad(0<m p-n q \leq N)
$$

A solução da equação (1.12) para $p$ e $q$ é única e determinada se $t_{1}$ e $t_{2}$ da equação (1.5) não possuírem um divisor em comum exceto pela unidade. A segunda condição na equação (1.12), $0<m p-n q \leq N$, onde isso surge do fato que $\mathbf{R}$ existe dentro da célula unitária $1 D$ do nanotubo, então

\footnotetext{
${ }^{7} \mathrm{Se} p$ e $q$ possuem um divisor em comum, $r$, então $\mathbf{R} / r$ deve possuir uma componente menor na direção de $\vec{C}_{h}$ faz com $\mathbf{R}$

${ }^{8}$ Daqui por diante nós iremos utilizar com frequiência as relações entre os produtos internos e vetoriais do vetor $\mathbf{R}$ com os dois vetores ortogonais $\vec{C}_{h}$ e T, para obter:

$$
\frac{\vec{C}_{h} \cdot \mathbf{R}}{L}=\frac{|\mathbf{R} \times \mathbf{T}|}{T}, \quad \text { ou } \frac{\mathbf{T} \cdot \mathbf{R}}{T}=\frac{\left|\vec{C}_{h} \times \mathbf{R}\right|}{L}
$$

onde $L$ e $T$ são dados pelas equações (1.2) e (1.8), respectivamente. Aqui nós assumimos que $\mathbf{R}$ esteja entre $\vec{C}_{h}$ e T, como na figura 1.10 .
} 


$$
0<\frac{\mathbf{R} \cdot \mathbf{T}}{T^{2}}=\frac{\left|\vec{C}_{h} \times \mathbf{R}\right|}{L T}=\frac{m p-n q}{N}<1
$$

usando as equações (1.2), (1.8) e (1.9). Similarmente, usando as equações (1.6) e (1.9), nós obtemos outra condição necessária, surgindo de que $\mathbf{R}$ deve estar dentro da célula unitaria $1 D$ :

$$
0<\frac{\mathbf{R} \cdot \vec{C}_{h}}{L^{2}}=\frac{|\mathbf{R} \times \mathbf{T}|}{L T}=\frac{t_{1} q-t_{2} p}{N} \leq 1
$$

e da equação (1.14), nós temos a condição,

$$
0<t_{1} q-t_{2} p \leq N
$$

Desde que a primeira condição da equação (1.12) satisfaz a equação (1.14), não é necessário adicionar à definição de $\mathbf{R}$, como explicado anteriormente.

Para determinar a localização dos $N$ vetores $i \mathbf{R},(i=1 \ldots N)$ dos sítios da célula unitária do nanotubo, nós usamos a expressão $i\left(t_{1} q-t_{2} p\right)=i$ para cada $i$, e observamos que o valor máximo de $i\left(t_{1} q-t_{2} p\right)$ se torna $N$. Usando o fato ${ }^{9}$ que a componente $\vec{C}_{h}$ de $N \mathbf{R}$ é sempre igual à $\left|\vec{C}_{h}\right|=L$, os vetores $i \mathbf{R}$ definem $N$ sítios inequivalentes na célula unitária do nanotubo, e então terá diferentes valores para suas projeções ao longo da direção de $\vec{C}_{h}$. Conseqüentemente $i \mathbf{R},(i=1 \ldots N)$,

\footnotetext{
${ }^{9}$ Este fato pode ser demonstrado como se segue:

$$
\frac{N \mathbf{R} \cdot \vec{C}_{h}}{L}=\frac{N|\mathbf{R} \times \mathbf{T}|}{T}=\frac{2 L^{2}}{d_{R} a^{2}} \frac{\sqrt{3} a^{2}}{2} \frac{d_{R}}{\sqrt{3} L}=L
$$
}

onde nós fizemos o uso das equações (1.8) e (1.9). 
gera unicamente $N$ diferentes sítios de átomos na célula unitária do nanotubo. ${ }^{10}$.

De um ponto de vista físico, o vetor $\mathbf{R}$ consiste de uma rotação ao redor do eixo do tubo de um ângulo $\psi$ combinado com uma translação $\tau$ na direção de $\mathbf{T}$, e reflete a operação básica do grupo de simetria de um nanotubo quiral, denotado por $R=\langle\psi \mid \tau\rangle$ e mostrado na figura (1.10). O significado físico do vetor $\mathbf{R}$ é que a projeção de $\mathbf{R}$ no vetor quiral $\vec{C}_{h}$ nos dá o ângulo $\psi$ escalado por $L / d_{t}$ (ver equação (1.2)), enquanto que a projeção de $\mathbf{R}$ em $\mathbf{T}$ nos dá a translação $\tau$ da operação básica de simetria do grupo espacial $1 D$ do nanotubo de carbono. Os inteiros $(p, q)$ denotam as coordenadas alcançadas quando a operação de simetria $\langle\psi \mid \tau\rangle$ age em um átomo em $(0,0)$, isto é, $\langle\psi \mid \tau\rangle(0,0)=(p, q)$. Se $\langle\psi \mid \tau\rangle$ é uma operação de simetria para o nanotubo, então $\langle\psi \mid \tau\rangle^{2},\langle\psi \mid \tau\rangle^{3}, \ldots,\langle\psi \mid \tau\rangle^{N}$ são todas as operações de simetrias distintas de um grupo Abeliano denotado por $C_{N}$, onde $\langle\psi \mid \tau\rangle^{N}=E$ é a operação de identidade.

Tomando os produtos vetoriais indicados por $\mathbf{R} \times \vec{C}_{h}$ e $\mathbf{R} \times \mathbf{T}$ e usando as equações (1.8), (1.9), e (1.12), nós obtemos as expressões para o comprimento $\tau$ e o ângulo de rotação $\psi$, como segue:

\footnotetext{
${ }^{10}$ Nota-se que da definição de $\mathbf{R}$ é diferente da descrita por Jishi et al. [8]. A definição de $\mathbf{R}$, dada aqui é independente ou não de $d=1$. A seguir, a equação (1.12) pode ser generalizada como

$$
t_{1} q-t_{2} p=Q, \quad(1 \leq Q \leq N)
$$

onde os inteiros $Q$ e $N$ não possuem um divisor comum exceto pela unidade. Se $Q$ e $N$ possuírem um divisor em comum, $d_{Q}$, então $\left(N / d_{Q}\right) \mathbf{R}$ se tornaria localmente equivalente à $O$. Os maiores valores possíveis de $Q$ correspondem ao $\mathbf{R}$ definido por Jishi et al. [8]. Aqui nós usamos a notação para o vetor de simetria $\mathbf{R}$ definido na equação (1.12)
} 


$$
\begin{aligned}
\tau & =\frac{\left|\mathbf{R} \times \vec{C}_{h}\right|}{L}=\frac{(m p-n q)\left|\overrightarrow{a_{1}} \times \vec{a}_{2}\right|}{L}=\frac{(m p-n q) T}{N} \\
\psi & =\frac{|\mathbf{T} \times \mathbf{R}|}{T} \frac{2 \pi}{L}=\frac{d_{R}\left(t_{1} q-t_{2} p\right)}{\sqrt{3} L} \frac{\sqrt{3} a^{2}}{2}=\frac{2 \pi}{N}
\end{aligned}
$$

e usando tais definições, o ângulo de rotação $\psi$ se torna $2 \pi / N$, onde $N$ é o número de hexágonos na célula unitária $1 D$ do nanotubo dado pela equação (1.9).

Referindo-se à figura (1.10), a operação de simetria $\langle\psi \mid \tau\rangle^{N}$ traz o ponto $O$ da rede à um ponto equivalente $C$, onde

$$
N \mathbf{R}=\vec{C}_{h}+M \mathbf{T}
$$

e onde

$$
M \equiv m p-n q
$$

é um inteiro que denota o número de vetores T que são necessários para se obter a distância de $O$ à $N \mathbf{R}$.

\subsubsection{Célula Unitária e Zonas de Brillouin}

A célula unitária de um nanotubo de carbono no espaço real é dada por um

retângulo gerado pelo vetor quiral $\vec{C}_{h}$ e pelo vetor de translação T, como mostrado em $O A B^{\prime} B$ na figura (1.9). Desde que existem $2 N$ átomos de carbono na célula unitária , nós teremos $N$ pares de bandas eletrônicas de ligação $\pi$ e antiligação $\pi^{*}$. 


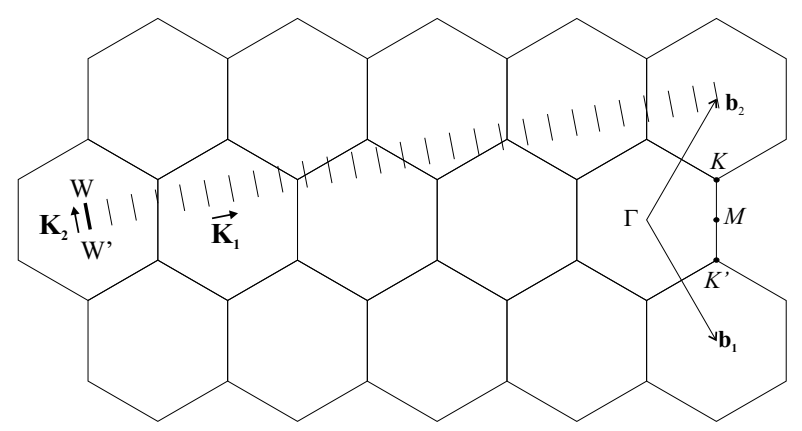

Figura 1.11: A zona de Brillouin para um nanotubo de carbono é representada pelo segmento de linha $W W^{\prime}$ que é paralelo à $\mathbf{K}_{2}$. Os vetores $\mathbf{K}_{1}$ e $\mathbf{K}_{2}$ são os vetores da rede recíproca, correspondentes a $\vec{C}_{h}$ e $\mathbf{T}$, respectivamente.

Expressões para os vetores da rede recíproca $\mathbf{K}_{2}$ ao longo do eixo do nanotubo e $\mathbf{K}_{1}$ ao longo da direção radial ${ }^{11}$ são obtidos da relação $\mathbf{R}_{i} \mathbf{K}_{j}=2 \pi \delta_{i j}$, onde $\mathbf{R}_{i}$ e $\mathbf{K}_{j}$ são, respectivamente, os vetores da rede no espaço real e recíproco. Então, usando as equações (1.6), (1.9), e as relações

$$
\begin{aligned}
\vec{C}_{h} \cdot \mathbf{K}_{1}=2 \pi, & \mathbf{T} \cdot \mathbf{K}_{1}=0, \\
\vec{C}_{h} \cdot \mathbf{K}_{2}=0, & \mathbf{T} \cdot \mathbf{K}_{2}=2 \pi
\end{aligned}
$$

nós obtemos as expressões para $\mathbf{K}_{1}$ e $\mathbf{K}_{2}$ :

$$
\mathbf{K}_{1}=\frac{1}{N}\left(-t_{2} \vec{b}_{1}+t_{1} \vec{b}_{2}\right), \quad \mathbf{K}_{2}=\frac{1}{N}\left(m \vec{b}_{1}-n \vec{b}_{2}\right)
$$

onde $\vec{b}_{1}$ e $\vec{b}_{2}$ são os vetores da rede recíproca do grafite bidimensional. Na figura (1.11), nós mostramos os vetores da rede recíproca, $\mathbf{K}_{1}$ e $\mathbf{K}_{2}$, para um nano-

\footnotetext{
${ }^{11}$ Desde que os nanotubos são materiais unidimensionais, somente $\mathbf{K}_{2}$ é um vetor da rede recíproca. $\mathbf{K}_{1}$ nos dá valores discretos de $k$ na direção de $\vec{C}_{h}$.
} 
tubo quiral $\vec{C}_{h}=(4,2)$. A primeira zona de Brillouin deste material unidimensional é o segmento de linha $W W^{\prime}$. Desde que $N \mathbf{K}_{1}=-t_{2} \vec{b}_{1}+t_{1} \vec{b}_{2}$ corresponde a um vetor da rede recíproca do grafite bidimensional, dois vetores de onda que diferem por $N \mathbf{K}_{1}$ são equivalentes. Desde que $t_{1}$ e $t_{2}$ não possuem um divisor em comum exceto pela unidade (ver 1.3.3), nenhum dos $N-1$ vetores $\mu \mathbf{K}_{1}$ (onde $\quad \mu=1, \ldots, N-1$ ) são vetores da rede recíproca do grafite bidimensional. Então os $N$ vetoes de onda $\mu \mathbf{K}_{1}(\mu=0, \ldots, N-1)$ dão origem a $k$ vetores, como indicado pelos $N=28$ segmentos de linhas paralelas na figura (1.11), que surgem dos vetores de onda quantizados, associados com as condições periódicas de contorno em $\vec{C}_{h}$. O comprimento de todas as linhas paralelas na figura (1.11)é $2 \pi / \mathbf{T}$, que é o comprimento da primeira zona de Brillouin unidimensional. Para os $N$ valores discretos dos vetores $k, N$ bandas de energia unidimensionais irão aparecer. Por causa da simetria translacional de $\mathbf{T}$, nós temos vetores de ondas contínuos de $\mathbf{K}_{2}$ para um nanotubo de carbono de comprimento infinito. Entretanto, para um nanotubo de comprimento finito $L_{t}$, o espaçamento entre os vetores de onda é $2 \pi / L_{t}$; este espaçamento entre os vetores de onda tem sido observado experimentalmente [9].

\subsection{Crescendo nanotubos}

Os nanotubos de carbono podem ser sintetizados de várias maneiras. As três mais comuns são: "Laser Ablation", "descarga de arco"e "deposição química por vapor"(CVD). Todos os três processos usam os mesmos ingredientes, porém 
de maneiras diferentes: Uma fonte de carbono, que pode ser tanto sólida como gasosa, um método para aquecer o carbono que será liberado da fonte e tornálo disponível para o crescimento dos nanotubos, e um material catalizador para iniciar o processo do crescimento (o método de descarga de arco só necessita de catalizador quando forem produzir nanotubos de parece simples (SWCNT)).

\subsubsection{Ablação a Laser}

A primeira síntese eficiente por este método, produzindo mais de $70 \%$ de SWCNT, foi realizada em 1996 [10]. Este resultado foi obtido em um setup como mostrado na figura (1.12-a). Um alvo feito de $1.2 \%$ de átomos de Cobalto-Níquel e $98.8 \%$ de átomos de carbono são aquecidos em um forno a $1200^{\circ} \mathrm{C}$. Dois pulsos de laser evaporam parte do alvo. A fuligem, contendo os nanotubos, é carregada ao longo do interior do forno por um fluxo de gás de argônio. Assim, a fuligem é coletada para fora do forno por uma ponta refrigerada a água. Na figura (1.12-b) nós observamos uma imagem SEM de um amontoado de SWCNT, criados por "laser ablation". Os tubos criados a partir desse método, precisam ser separados um dos outros por um outro método para serem caracterizados.

\subsubsection{Descarga de Arco}

Pouco tempo após o método de "laser ablation"ser publicado, outro método para sintetizar grandes quantidade de nanotubos foi descoberto: $\mathrm{O}$ método do arco de carbono [12]. Duas barras de carbono, são operadas a uma pressão de $a \approx 500$ Torr He com um fluxo de $5-15 \mathrm{ml} / \mathrm{s}$ de um gás frio. As barras são 


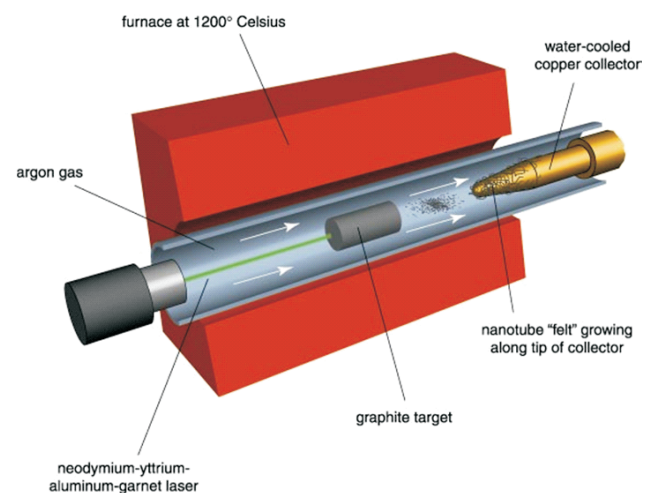

( a )

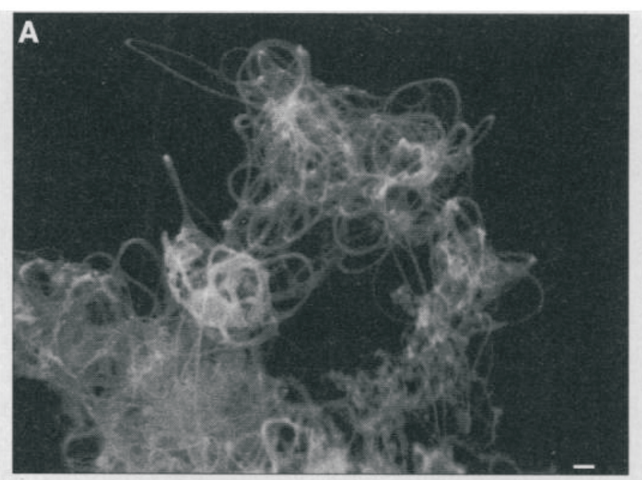

(b)

Figura 1.12: (a) Figura esquemática de um setup para "laser ablation". Dois pulsos de laser evaporam parte do alvo de grafite. Os CNT são carregados, juntamente com o restante da fuligem, por um fluxo de gás de Argônio até um coletor. (b) Exemplo de como os nanotubos são coletados da fuligem a partir desse processo de crescimento. Os nanotubos coletados, precisam de um pós processamento, só assim, depois de separados que os tubos podem ser montados em um dispositivo e caracterizados [11].

separadas umas das outras por $\approx 1 \mathrm{~mm}$ e é aplicado uma tensão entre elas de $20-25 \mathrm{~V}$, criando uma corrente de $50-120 \mathrm{~A}$ que flui entre elas. Este aparato vaporiza o carbono em um plasma $\left(>3000^{\circ} C\right)$ e os nanotubos de carbono são depositados no eletrodo negativo. Barras de carbono puras nos fornecem somente nanotubos de carbono de múltiplas camadas (MWCNT), enquanto que barras de carbono dopadas com um metal catalizador como, $\mathrm{Co}, \mathrm{Ni}, \mathrm{Fe}, \mathrm{Y}$ e $\mathrm{Mo}$ produzem nanotubos de camada única (SWCNT). Os nanotubos criados através de descarga de arco também necessitam de um pós processamento para serem caracterizados. A figura (1.13), exemplifica o aparato experimental de descarga de arco.

\subsubsection{Deposição Química de Vapor}

O método de deposição química por vapor, difere dos métodos de "laser ablation"e descarga por arco, por não utilizar uma fonte de carbono sólida. Neste 


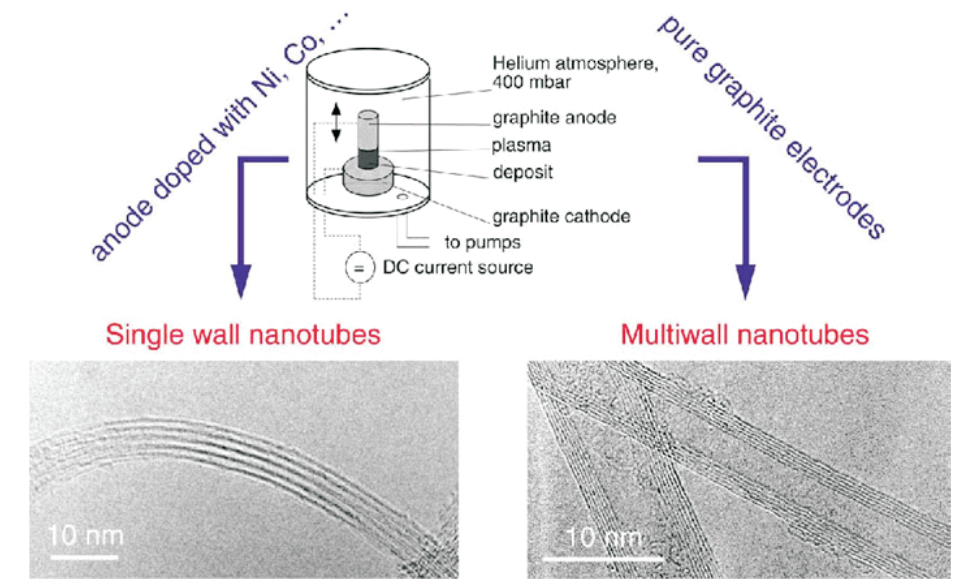

Figura 1.13: Aparato de descarga de arco. Em um setup de descarga de arco uma voltagem DC é aplicada através de um pequeno gap, induzindo uma correste através do gap. Isso vaporiza o carbono em um plasma e a fuligem de CNT é criada no eletrodo negativo. MWCNT são criados a partir de eletrodos puros. E SWCNT são criados a partir de eletrodos dopados com uma pequena quantidade de algum metal catalizador [13].

método, o carbono é gasoso, onde as principais fontes incluem o metano, o monóxido de carbono e o acetileno, que são separados por uma fonte externa de energia, isto é, ou um plasma ou por uma resistência aquecida. Os carbonos reativos difundem-se através da superfície de um dispositivo, onde existem partículas catalizadoras, ou seja, onde partículas de $N i, F e$ ou $C o$ já haviam sido previamente depositadas. Os átomos de carbono grudam-se às partículas catalizadoras e dependendo dos parâmetros de crescimento, podem começar a crescer tanto SWCNT ou MWCNT. A vantagem da CVD é a possibilidade de um processo em larga escala, simples e controlado, que pode ter um bom controle da espessura e comprimento dos tubos. A figura (1.14), mostra um esquema do aparato experimental utilizado nesse experimento. 

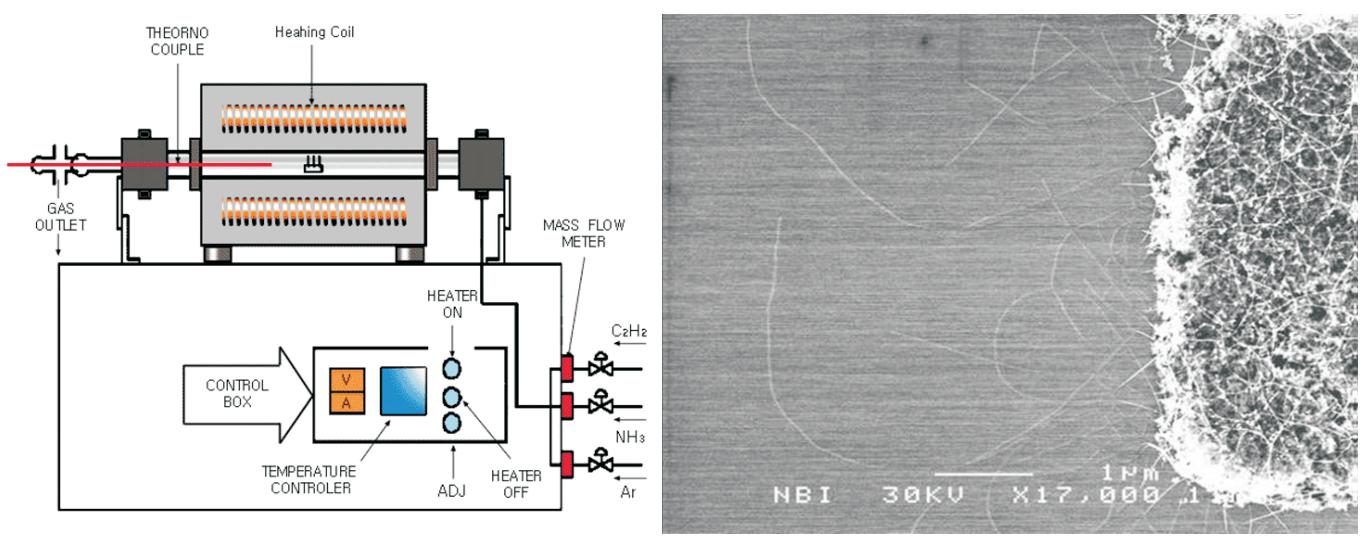

Figura 1.14: (a) Esquema de um forno de CVD. Um gás contendo carbono, por exemplo metano, é introduzido dentro do forno e aquecido até uns $900^{\circ} \mathrm{C}$. O gás aquecido libera os átomos de carbono. O carbono se difunde através da superfície da amostra, onde já havia sido previamente depositado partículas de um material catalizador, para iniciar o processo de crescimento. (b) Exemplos de nanotubos de carbono crescidos em um forno de CVD. [13]

\subsection{Microscopia Eletrônica}

A compreensão da estrutura básica que é composta a matéria, tem se apresentado ao longo do tempo como um desafio aos estudiosos. A partir do momento em que se compreende a estrutura básica da matéria, pode-se compreender suas propriedades, e assim, levar a uma mudança controlada de nosso ambiente. Os primeiros instrumentos utilizados para estudar a estrutura atômica foram os microscópios ópticos, porém esses possuem a limitação do comprimento de onda da luz visível. As primeiras imagens de átomos foram obtidas com o microscópio de campo iônico, inventado por Erwin Müller. Outro método pelo qual podemos obter imagens de átomos é através do microscópio eletrônico de varredura(SEM), que é apenas capaz de trabalhar no vácuo, onde a resolução chega à escalas nanométricas $\left(1 \mathrm{~nm}=10^{-9} \mathrm{~m}\right)$ mas, em geral, essa técnica possui efeitos des- 
trutivos para a amostra. Além disso, um SEM não é capaz de dar uma boa informação sobre profundidades. Os mais novos desenvolvimentos nesta área são microscópios de varredura, ou SPM (Scanning Probe Microscope) que na realidade são grupos de instrumentos compostos basicamente de uma sonda, cerâmicas piezoelétricas para posicionar o objeto, circuitos de realimentação para controlar a posição vertical da sonda e um computador para mover os scanners de varredura, armazenar dados e os convertê-los em imagens por meio de softwares específicos. Há diversos tipos de microscópios de varredura: o de tunelamento ou STM (Scanning Tunneling Microscope), o de força atômica ou AFM (Atomic Force Microscope) e o de campo próximo ou SNOM (Scanning Near-Field Optical Microscope). O STM foi inventado por Gerd Binnig e Heinrich Rohrer, da IBM de Zurich, em 1981 e foi o primeiro instrumento capaz de gerar imagens reais de superfícies com resolução atômica. Em 1986 seus inventores ganharam o Prêmio Nobel de Física [14]. Depois dos primeiros relatos [14-16], vários trabalhos sobre a técnica foram desenvolvidos, registrando-se imagens atômicas de superfícies de semicondutores, assim como moléculas adsorvidas quimicamente [17]. Dessa maneira a espectroscopia de varredura por tunelamento (STS : Scanning Tunneling Spectroscopy) [18], a qual mede a condutância de tunelamento versus a voltagem de polarização em uma posição específica da ponta, começou a proporcionar informações da estrutura eletrônica local da superfície, com uma resolução em escala atômica. A partir de uma modificação do microscópio de tunelamento, combinado com um profilômetro Stylus (aparelho para medir rugosidade em es- 
cala microscópica) Binnig, Quate e Gerber [19], desenvolveram o AFM em 1986.

\subsubsection{Microscopia de Tunelamento}

A ponta de um microscópio de tunelamento (STM) é colocada a uma distância de poucos angstroms da superfície condutora, de tal modo que a função de onda de ambos se sobreponham. Em seguida, uma pequena voltagem é aplicada permitindo uma probabilidade finita de tunelamento entre a ponta e o substrato. A ponta do microscópio está ligada a um tubo piezoelétrico que, ao receber uma voltagem, deforma-se modificando a posição de sua ponta. Quando a ponta passa pela superfície a distância ponta-superfície varia, a corrente de tunelamento e o

movimento piezoelétrico fornecem a topologia da amostra. É possível daí, determinar o diâmetro de um nanotubo de carbono através da altura dele. A corrente de tunelamento é proporcional à densidade eletrônica local na energia de Fermi do nanotubo. $\mathrm{O}$ vácuo entre a ponta e o tubo, forma uma barreira conveniente para permitir um fluxo constante de corrente $I$, enquanto que a voltagem $V$ é varrida. Na figura (1.15), temos um exemplo de um equipamento de STM.

\subsubsection{Microscopia de Força Atômica}

O microscópio de força atômica (AFM) também é importante. A variação de altura da ponta permite que a superfície da amostra seja reconstruída. Uma grande vantagem do AFM é que as amostras não condutoras também podem ser medidas e nanotubos de carbono podem ser manipulados e arranjados no substrato. O uso de nanotubos de carbono como ponta desses microscópios, conforme a figura (1.16) 


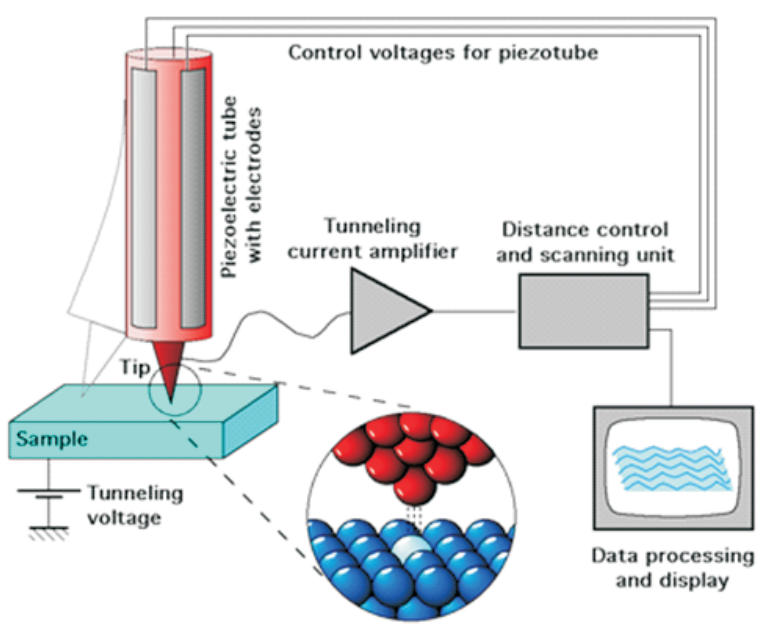

( a )

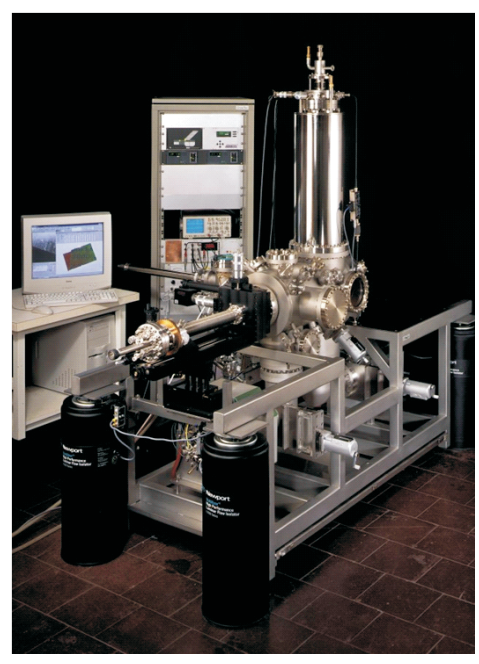

( b )

Figura 1.15: (a) Esquema de funcionamento de um microscópio de tunelamento. (b) Foto de um microscópio de tunelamento.

é uma aplicação muito importante, ou seja, o uso dos tubos aumentam o poder de resolução do sistema para poucos nanômetros e fornecem uma ponta altamente rígida e bem definida, devido a estrutura unidimensional dos nanotubos.

Além disso, a vida média das pontas feitas de nanotubos de carbono são maiores que as dos materiais utilizados convencionalmente, pois quando essa ponta é pressionada no substrato, ela se dobra antes de quebrar. No seu processo de fabricação elas são tanto coladas em uma ponta convencional de AFM, quanto crescidas diretamente a partir de uma ponta de silicone, conforme a figura (1.17). 


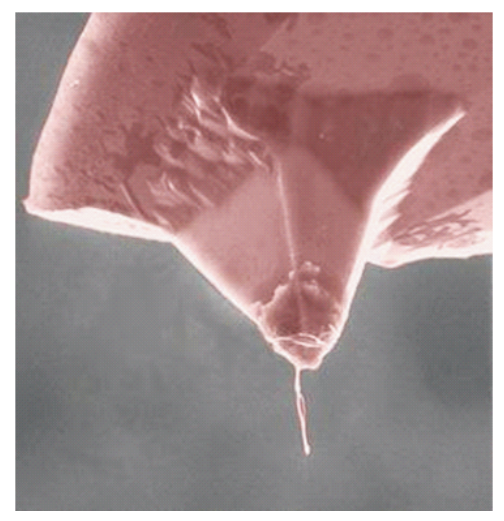

Figura 1.16: Ponta de um microscópio de força atômica. É utilizado nesta ponta um nanotubo de carbono.

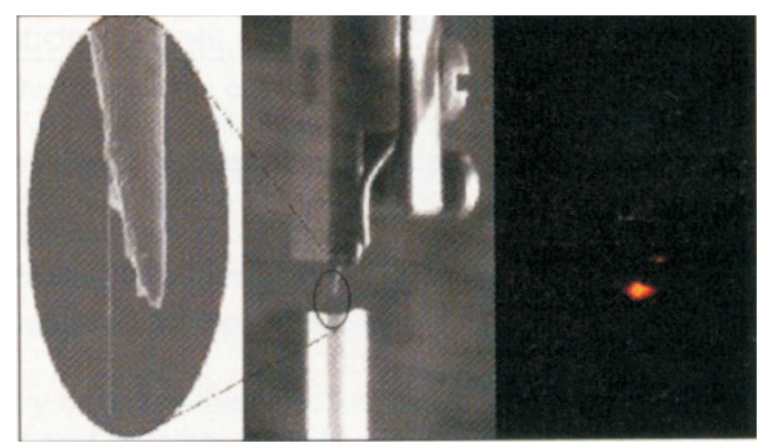

Figura 1.17: Detalhe de um outro tipo de ponta de um microscópio de força atômica, onde também é utilizado um nanotubo de carbono. 


\section{Capítulo 2}

\section{Motivação do Trabalho}

A presença de desordem e defeitos em sólidos nanoestruturados normalmente é um fenômeno indesejável. Porém, recentes experimentos de irradiação em materiais nanoestruturados demonstraram que tais defeitos ou desordem, podem possuir efeitos benéficos [20].

Quando sistemas como nanotubos de carbono, nanofios, grafeno, nanofitas, entre outros, são estudados utilizando radiação tanto por ions ou por elétrons, pode ocorrer que estas partículas podem criar defeitos e deteriorar o material, ou seja, criar vários tipos de defeitos na rede de tais materiais. Tais defeitos que a radiação provoca, como a desordem, já são bem conhecidos e possuem aplicações interessantes, porém não em sistemas nanoestruturados, mas sim em sistemas na forma de bulk. Dentre os mais importantes podemos destacar a implantação iônica em semicondutores [21].

Continuando com esse pensamento sobre a análise de sistemas com radiação, é esperado que os efeitos presentes no bulk devam aparecer também nos 
nanosistemas. O que recentemente é observado, é que este método pode causar efeitos benéficos em tais materiais, como um exemplo disso, podemos citar a auto organização e reconstrução de sistemas carbonosos. A estrutura e morfologia atômica de nanotubos de carbono e materiais afins, podem ser adaptadas por irradiação [22-28] e podem também ser interconectadas de uma maneira controlada. [22-30]

Como já citamos anteriormente, na seção de microscopia eletrônica, os nanotubos de carbono podem ser modificados pelas pontas de microscópios STM e AFM, como também podem ser modificados por feixes de partículas, como irradiação por elétrons ou ions. Quando se trata os nanotubos de carbono com feixes de partículas, a principal resposta deste sistema é uma auto organização e reconstrução. Dessa maneira, é muito importante saber como os nanotubos de carbono reconstroem-se, ou seja, qual a estrutura resultante a partir da presença desses defeitos.

Uma das principais razões da pesquisa intensiva desses defeitos em nanotubos de carbono, tanto de camada única (SWCNT's) como de múltipla camadas (MWCNT's) [7], é que tanto suas propriedades mecânicas, quanto eletrônicas são modificadas pela presença desses defeitos. Algo mais bonito nisso, é que existe uma física muito rica e intrigante desses sistemas na presença de defeitos, que é a capacidade dessas estruturas se reorganizarem, como não ocorre em nenhum outro material. Novas ligações se formam ao redor do defeito, criando-se uma rede, porém coerente, que preserva muitas das propriedades originais do sistema. $\mathrm{O}$ nosso 
primeiro objetivo, é estudar o defeito do tipo vacância, a mais simples possível, que é a monovacância, pois em uma situação ideal, este seria o primeiro defeito formado devido ao choque das partículas que utilizamos para analisar o sistema. Assim, realizaremos um estudo sistemático das monovacâncias em nanotubos de carbono armchair, variando-se a densidade desses defeitos, com o intuito principal de encontrar uma densidade mínima, tal que poderemos observar explicitamente o efeito de somente um defeito no nanotubo.

Continuando a nossa motivação para o desenvolvimento dessa dissertação, podemos retornar ao que estávamos falando antes, ou seja, quando se analisa os nanotubos de carbono a partir de feixes de radiação. Conforme citamos anteriormente, em uma situação ideal, seria criada monovacância, porém podem ser criados outros tipos de defeitos como multivacâncias [20,31-36], conforme podemos observar na figura (2.1).
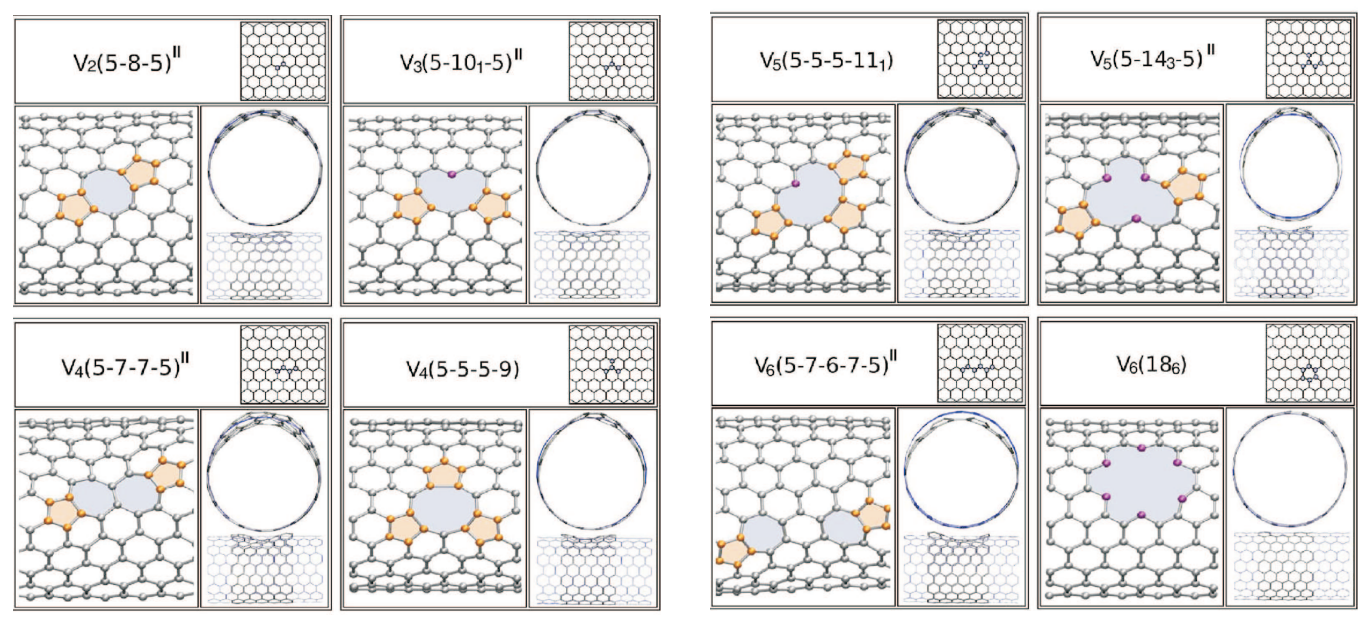

Figura 2.1: Estrutura atômica de multivacâncias em um nanotubo de carbono SWCNT $(10,10)$ dadas por um método DFTB. O nanotubo puro, onde foram retirados os átomos é mostrado no canto superior de cada figura [31] 
Para isso, precisamos saber quais os tipos de defeitos que podem estar presentes nesse sistema.

Tal como em um metal, uma vacância é a ausência de um átomo na rede, mas nos nanotubos, devido ao átomo de carbono possuir hibridização $s p^{2}$, o nanotubo desenvolve uma extensa reconstrução da rede atômica ao redor da vacância [3739], saturando sempre duas dangling bonds vizinhas, formando um pentágono, como mostrado na figura (2.2).

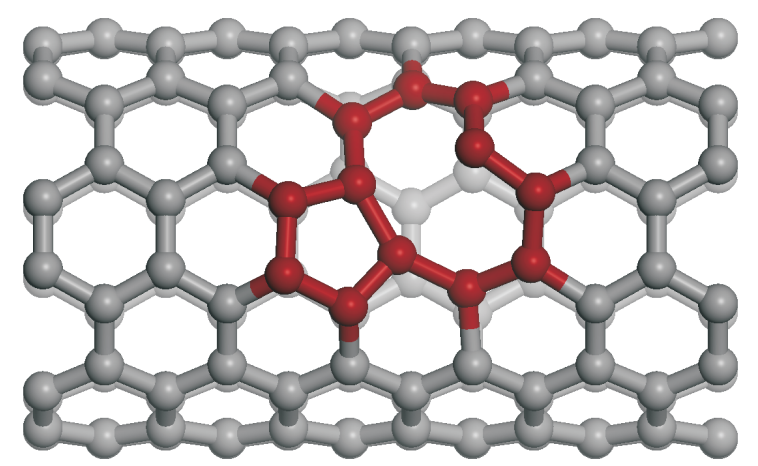

Figura 2.2: Nanotubo de carbono armchair $(5,5)$ na presença de uma monovacância reconstruída.

No grafeno, temos uma boa reconstrução $[40,41]$, porém nos nanotubos de carbono, a reconstrução é muito mais forte devido a curvatura do sistema, ou seja, é muito mais fácil para um nanotubo contrair-se localmente para consertar o buraco formado e para saturar as dangling bonds, que são energéticamente desfavoráveis. A reconstrução é tanto observada nas monovacâncias, como nas divacâncias [39] e multivacâncias [31]. Dessa maneira, podemos dar aos nanotubos de carbono o nome de materiais que se auto curam. 
Várias propriedades importantes são modificadas dos nanotubos na presença desses defeitos, como por exemplo as mecânicas e eletrônicas. Neste trabalho, nós iremos focar nas propriedades eletrônicas. Os defeitos, influenciam muito a estrutura eletrônica dos nanotubos de carbono, devido ao caráter $s p^{2}$ dos átomos de carbono. Novos estados perto do nível de Fermi e localizados nas vacâncias foram previstos [41-43], e confirmados por observações experimentais de STM [44]. Em princípio estes estados localizados, podem ser utilizados para o desenvolvimento de dispositivos eletrônicos baseados em nanotubos de carbono, como por exemplo sensores. [45] Uma outra propriedade muito importante que sofre a influência da presença dos defeitos, é o transporte eletrônico nos nanotubos de carbono, por causa da sua geometria quasi-unidimensional. Normalmente, a resistência dos nanotubos de carbono aumentam na presença desses defeitos [26, 46, 47]. Assim, temos o nosso segundo objetivo, que é estudar as propriedades de transporte eletrônico dessas multivacâncias.

Porém, fora o interesse físico, esses defeitos maiores podem não apresentar nenhum interesse prático, pois eles podem ser instáveis e nunca aparecerem nos nanotubos em condições de aplicabilidade. Assim, o nosso terceiro objetivo, é estudar detalhadamente a estabilidade desses defeitos, para que possamos ter certeza que eles podem ser encontrados, e assim utilizados em alguma aplicação fora somente do interesse do conhecimento físico. 


\section{Capítulo 3}

\section{Formalismo Teórico}

\subsection{Introdução}

Quando iniciamos o curso de graduação em física, logo no seu início ficamos impressionados com o grande número de problemas que a física clássica resolve, mas logo percebemos que ela resolve muito bem problemas somente ao alcance dos nossos olhos. Quando ingressamos no terceiro ano do curso, nos deparamos com um dos primeiros problemas que a física clássica não resolve exatamente, $\mathrm{o}$ famoso problema de três corpos. Aprendemos também que os fenômenos mais lindos da natureza não se apresentam ao alcance de nossos olhos, mais sim no alcance dos poderosos microscópios eletrônicos. Porém nesta época, ainda não tínhamos sido apresentados à mecânica quântica. Quando nos é feito isso, deparamos com uma teoria no mínimo interessante, e logo após resolvermos o átomo de hidrogênio, retorna o sentimento de que a física está toda resolvida e com o pouco que temos de mecânica quântica, já podemos resolver todo o nosso mundo! Porém após uns dias, percebemos que não é tão simples assim e novamente caí- 
mos no abismo dos problemas de se tratar mais de dois corpos ou partículas interagentes.

O nosso sentimento de euforia, as vezes se transforma em um sentimento de decepção. Será que terminaremos o curso de física aprendendo somente a resolver o oscilador harmônico e o átomo de hidrogênio? Sendo mais claro, a grande pergunta é: Como podemos resolver o nosso mundo se ele não é somente feito de osciladores harmônicos e átomos de hidrogênio? Como resolveremos um sistema de muitos elétrons?

Como ainda não sabemos resolver estes problemas exatamente, a resposta pode ser encontrada na maioria das vezes, no grande poder que os físicos possuem de criar teorias matemáticas brilhantes e métodos aproximativos, que descrevem a natureza de uma maneira brilhante e muito realista. Dentre essas teorias de aproximação, temos a teoria de Hartree-Fock (HF). Ela torna factível a abordagem de um problema de $N$ corpos, transformando esse problema de $N$ corpos em $N$ problemas de um só corpo. Nesta teoria, a função de onda $\Psi$ que depende das coordenadas dos $N$ corpos é o objeto fundamental de investigação.

Temos outras teorias como o método da interação de configurações (CI), que é um método variacional pós Hartree-Fock para resolver a equação de Schrödinger não relativística, utilizando a aproximação de Born-Oppenheimer para um sistema quântico multieletrônico. Dois significados são conectadas ao termo interação de configurações. Matematicamente falando, configurações simplesmente descreve a combinação linear de determinantes de Slater usados para função de 
onda. Interação, em termos da especificação da ocupação de orbitais (por exemplo, $\left.(1 s)^{2}(2 s)^{2}(2 p)^{1} \ldots\right)$, significa mistura de diferentes configurações eletrônicas (estados). Porém devido ao longo tempo de CPU e a necessidade de hardwares muito potentes para cálculos $\mathrm{CI}$, o método é limitado à sistemas relativamente pequenos.

Mas ainda temos outro método aproximativo, ou teoria, muito poderosa, que é a Teoria do Funcional da Densidade, DFT, onde o objeto fundamental de investigação é a densidade eletrônica $\rho(\vec{r})$, e não mais a função de onda $\Psi[48,49]$. Com o DFT, ao invés de encontrarmos a função de onda $\Psi$, quando resolvemos a equação de Schrödinger de um sistema de $N$ elétrons, encontramos a densidade eletrônica de tal sistema. Assim, ao invés de escrevermos a equação de Schrödinger dos $N$ elétrons com uma função de onda com $3 N$ variáveis, escrevemos ela como uma equação da densidade eletrônica, com somente 3 variáveis.

Iremos apresentar neste capítulo, uma breve introdução à teoria do funcional da densidade, que é o método que iremos utilizar para a descrição dos nossos sistemas.

\subsection{Teoria do Funcional da Densidade}

No âmbito da mecânica quântica não relativística, a equação fundamental, que nos permite descrever os sistemas físicos, como átomos, moléculas, entre muitos outros sistemas, é a equação de Schrödinger. Ela é definida por um operador

Hamiltoniano $\hat{H}(t)$ que caracteriza o sistema, e o estado onde tal sistema está é 
dado pelo vetor $|\Psi(t)\rangle$. Assim, a equação de Schrödinger dependente do tempo pode ser escrita como:

$$
i \hbar \frac{\partial}{\partial t}|\Psi(t)\rangle=\hat{H}(t)|\Psi(t)\rangle
$$

onde esta equação estabelece uma relação unívoca entre o operador Hamiltoniano $\hat{H}(t)$ e o estado $|\Psi(t)\rangle$. O estado caracterizado pelo vetor $|\Psi(t)\rangle$ contém toda a informação que queremos saber sobre o sistema em estudo. Nos sistemas que iremos estudar, estaremos somente interessados em solução estacionárias desta equação, logo, queremos resolver a equação de Schrödinger independente do tempo, ou seja, o operador Hamiltoniano do sistema não possui uma dependência temporal explícita. Dessa maneira, podemos expressar o nosso vetor de estado $|\Psi(t)\rangle$ como uma combinação de uma parte temporal e uma parte espacial, $|\Psi(t)\rangle=\left|\psi_{j}(t=0)\right\rangle \phi_{j}(t)$, onde $\phi_{j}(t)$, é obtida através de uma separação de variáveis, sendo expressa por:

$$
\phi_{j}(t)=e^{-\frac{i}{\hbar} E_{j} t}
$$

e a parte espacial da nossa equação de autovalores pode ser escrita como:

$$
\hat{H}\left|\psi_{j}\right\rangle=E_{j}\left|\psi_{j}\right\rangle
$$

A solução representada pela equação (3.2) juntamente com as soluções da equação (3.3), formam um conjunto completo, de forma que um estado pode ser 
completamente caracterizado por uma equação escrita da seguinte maneira:

$$
|\Psi(t)\rangle=\sum_{j} C_{j}\left|\psi_{j}\right\rangle e^{-\frac{i}{\hbar} E_{j} t}
$$

sendo assim, nós estamos interessados em resolver a equação (3.3).

Até agora nós sabemos qual é a equação fundamental do sistema e também qual é o Hamiltoniano, onde este pode ser escrito da seguinte forma:

$$
\begin{aligned}
\hat{H} & =-\sum_{A=1}^{N_{a t}} \frac{1}{2 \tilde{M}_{A}} \nabla_{A}^{2}-\sum_{i=1}^{N} \frac{1}{2} \nabla_{i}^{2}-\sum_{A=1}^{N_{a t}} \sum_{i=1}^{N} \frac{Z_{A}}{\left|r_{i}-R_{A}\right|}+\frac{1}{2} \sum_{i \neq j}^{N} \frac{1}{r_{i}-r_{j}} \\
& +\frac{1}{2} \sum_{A \neq B}^{N_{a t}} \frac{Z_{A} Z_{B}}{\left|R_{A}-R_{B}\right|}=\hat{T}_{N}+\hat{T}_{e}+\hat{V}_{N e}+\hat{V}_{e}+\hat{V}_{N}
\end{aligned}
$$

(as constantes numéricas e físicas forma suprimidas nesse Hamiltoniano pois podemos escrever ele no sistema de unidades atômicas, onde a massa do elétron $m_{e}$, a carga do elétron $e$, o raio atômico de bohr $a_{0}$ e a constante de Planck $h$ dividida por $2 \pi$ são todos iguais a 1 ).

Aqui, os termos $\hat{T}_{N}, \hat{T}_{e}, \hat{V}_{N e}, \hat{V}_{e}, \hat{V}_{e}, \tilde{M}_{A}$ e $Z_{A}$, são respectivamente o operador energia cinética nuclear, operador energia cinética dos elétrons, operador energia potencial de atração dos núcleos com os elétrons, operador de energia potencial repulsiva entre os núcleos, operador de energia potencial repulsiva entre os elétrons, massa do núcleo $A$ e carga do núcleo $A$. Este operador Hamiltoniano $\hat{H}$, descreve um sistema de elétrons e núcleos interagentes.

A solução analítica e exata desta equação não é conhecida para nenhum sistema de interesse. Sendo assim, temos que levar em conta algumas aproximações 
para que possamos resolver o nosso problema.

\subsection{Aproximação de Born-Oppenheimer}

Sabe-se que o movimento relativo elétrons-núcleos reflete, evidentemente, o fato de ambos se moverem em relação a algum referencial fixo. Entretanto, como as velocidades eletrônicas são pelo menos mil vezes maiores do que as nucleares, é uma aproximação razoável desprezar os movimentos de rotação e vibração dos núcleos ao se considerar o movimento dos elétrons em relação a estes (ou dos núcleos em relação aos elétrons). Em outras palavras, é razoável considerar que, a cada momento ao longo do movimento rovibracional dos núcleos, a distribuição eletrônica espacial, instantaneamente se ajusta às correspondentes posições nucleares, de modo a manter sempre mínima a energia do sistema.

Esta é a aproximação de Born-Oppenheimer [50,51]. Ela nos permite resolver a equação de Schrödinger, para o movimento eletrônico em relação aos núcleos, considerando estes fixos. Ela permite que a equação de Schrödinger para o movimento eletrônico seja resolvida considerando-se a influência dos núcleos como um potencial dependente somente dependente das suas posições. Esta aproximação produz uma imensa simplificação matemática no estudo quântico das moléculas, introduzindo nos resultados um erro geralmente desprezível quando comparado com outros, criados por outras aproximações freqüentemente usadas.

Assim, como o termo de energia cinética dos núcleos é considerado muito

menor que os demais, $\hat{T}_{N} \rightarrow 0$, o nosso Hamiltoniano pode ser escrito como um 
Hamiltoniano eletrônico mais um termo de energia potencial dos núcleos:

$$
\hat{H}=\hat{H}_{e l}+\hat{V}_{N}
$$

onde $\hat{H}_{e l}$ é dado por

$$
\hat{H}_{e l}=\hat{T}_{e l}+\hat{V}_{N e}+\hat{V}_{e}
$$

Aqui, assumiremos ser válida usar uma hipótese de que as coordenadas nucleares $\left\{R_{1}, R_{2}, \ldots, R_{N_{a t}}\right\}$ entrarão como parâmetros, e o problema em questão será encontrar os estados eletrônicos, que serão representados pela função de onda $\Psi_{e l}\left(r_{1}, r_{2}, \ldots, r_{N} ; R_{1}, R_{2}, \ldots, R_{N_{a t}}\right)$, onde esta notação utilizada indica que a função de onda depende dos parâmetros $\left\{R_{1}, R_{2}, \ldots, R_{N_{a t}}\right\}$ dados. (Para simplificar a notação, utilizaremos $\left.f\left(x^{N}\right) \equiv f\left(x_{1}, x_{2}, \ldots, x_{N}\right)\right)$. Assim nós estamos sempre tentando resolver um problema eletrônico, onde $\Psi_{e l}\left(r^{N} ; R^{N_{a t}}\right) \rightarrow \Psi\left(r^{N}\right)$ e $\hat{H}_{e l} \rightarrow \hat{H}$. Dessa maneira a equação que temos que resolver é:

$$
\begin{aligned}
\hat{H} \Psi_{i}\left(r^{N}\right) & =E_{i} \Psi_{i}\left(r^{N}\right) \\
{\left[\hat{T}_{e}+\hat{V}_{N e}+\hat{V}_{e}\right] \Psi_{i}\left(r^{N}\right) } & =E_{i} \Psi_{i}\left(r^{N}\right)
\end{aligned}
$$

Dado isto, podemos definir a energia total de um sistema caracterizado por um estado $|\Psi\rangle$, sem esquecer de somar a parte da energia potencial entre os núcleos, como:

$$
E_{T}=\langle\Psi|\hat{H}| \Psi\rangle+\frac{1}{2} \sum_{A \neq B}^{N_{a t}} \frac{Z_{A} Z_{B}}{\left|R_{A}-R_{B}\right|}
$$

Após todas essas simplificações, a próxima a ser feita, para entrarmos de fato 
no DFT, é considerar este problema, sobre os olhos da densidade eletrônica e não mais da função de onda. Para isto, definimos a densidade eletrônica da seguinte maneira

$$
\rho(r)=N \int d r_{1} d r_{2} \ldots d r_{N} \Psi^{*}\left(r_{1}, r_{2}, \ldots, r_{N}\right) \Psi\left(r_{1}, r_{2}, \ldots, r_{N}\right)
$$

onde agora, trataremos um sistema de somente 3 graus de liberdade, no lugar de um sistema de $3 N$ graus de liberdade.

Utilizando todos os ingredientes citados acima, entramos agora no DFT, que é formulado a partir de dois teoremas. A seguir iremos definir estes teoremas, que são conhecidos como teoremas de Hohenberg-Kohn.

\subsection{Teoremas de Hohenberg-Kohn}

Embora as origens da teoria do Funcional da Densidade remontem aos trabalhos de Thomas [48], Fermi [49], [52] e Wigner [53], a Teoria do Funcional da Densidade como a conhecemos hoje em dia, nasceu em 1964, com os trabalhos de Hohenberg [54] e Kohn [55].

Os teoremas apresentados nestes dois trabalhos, representam os pilares teóricos fundamentais sobre os quais, toda a teoria moderna do funcional da densidade é sustentado. Nesta seção, introduziremos as idéias dos teoremas de HohenbergKohn, e tentaremos discutir suas consequiências, que nem sempre são tão óbvias e triviais. 


\subsubsection{Primeiro Teorema de HK: Prova da Existência}

O primeiro teorema de Hohenberg-Kohn fornece a prova de que os nossos argumentos dados anteriormente, são de fato, fisicamente justificáveis e plausíveis, ou seja, a densidade eletrônica é o elemento básico do sistema. Para colocar isso de uma maneira um pouco diferente, iremos mostrar que a densidade eletrônica determina por si só o operador Hamiltoniano e dessa maneira todas as propriedades do sistema. A prova inicialmente dada por Hohenberg e Kohn em seus artigos de 1964, é de uma simplicidade tremenda, quase banal, podendo-se até imaginar que foi por isso que demorou quase 40 anos - depois de Thomas e Fermi terem utilizado a densidade eletrônica como um objeto fundamental - para se colocar a densidade eletrônica como uma entidade básica e fundamental, estabelecendo a sua abordagem como um alicerce físico do sistema.

Fazendo referência aos artigos de Hohenberg-Kohn, o primeiro teorema estabelece que:

O potencial externo $v(\vec{r})$ é (a menos de uma constante) um funcional único da densidade $\rho(\vec{r})$; uma vez que, aplicando $v(\vec{r})$ fixa $\hat{H}$, nós vemos que o estado fundamental do sistema de muitas partículas é um funcional único da densidade

$$
\rho(\vec{r}) .
$$

Escrevendo de uma outra maneira, a densidade eletrônica $\rho(\vec{r})$ de um sistema de elétrons interagentes em um campo de potencial externo $v(\vec{r})$, determina uni- 
vocamente esse potencial:

$$
v(\vec{r})=v[\rho(\vec{r})]
$$

portanto, a densidade $\rho(\vec{r})$ do estado fundamental deve conter todas as informações sobre os observáveis do sistema, da mesma maneira que a função de onda. A função de onda também é um funcional único da densidade $(\psi=\psi[\rho])$ [45].

Para provar este primeiro teorema de Hohenberg-Kohn, começamos considerando dois potenciais externos $v_{\text {ext }}$ e $v_{e x t}^{\prime}$, que diferem por mais de uma constante, ${ }^{1}$ mas ambos à mesma densidade eletrônica $\rho(\vec{r})$ associada ao estado não degenerado correspondente às $N$ partículas. Esses dois potenciais externos são parte de duas Hamiltonianas, que são diferentes somente por esses potências externos, $\hat{H}=\hat{T}+\hat{V}_{e e}+\hat{V}_{e x t}$ e $\hat{H}^{\prime}=\hat{T}+\hat{V}_{e e}+\hat{V}_{e x t}^{\prime}$. Obviamente, essas duas Hamiltonianas pertencem a duas funções de onda do estado fundamental que são diferentes, $\Psi$ e $\Psi^{\prime}$, e correspondem a energias do estado fundamental, $E_{0}$ e $E_{0}^{\prime}$, respectivamente, $\operatorname{com} E_{0} \neq E_{0}^{\prime}$. Entretanto, nós assumimos que ambas as funções de onda dão origem à mesma densidade eletrônica ${ }^{2}$. Nós podemos expressar isso esquematicamente como:

$$
V_{\text {ext }} \Rightarrow \hat{H} \Rightarrow \Psi \Rightarrow \rho(\vec{r}) \Leftarrow \Psi^{\prime} \Leftarrow \hat{H}^{\prime} \Leftarrow V_{\text {ext }}^{\prime}
$$

Conseqüentemente, $\Psi$ e $\Psi^{\prime}$, são diferentes, onde podemos usar $\Psi^{\prime}$ como uma

\footnotetext{
${ }^{1}$ Desde que a função de onda e conseqüentemente a densidade de carga são inalteradas se uma constante é adicionada ao potencial, nós devemos exigir desde o início que os dois potenciais devem diferir por não somente uma constante

${ }^{2}$ Isso é bem possível, desde que a prescrição de como uma densidade é construída a partir do quadrado de uma função de onda, isto é, $\rho(\vec{r})=N \int\left|\Psi\left(\vec{x}_{1}, \vec{x}_{2}, \ldots, \vec{x}_{N}\right)\right|^{2} d s_{1} d \vec{x}_{2} \ldots d \vec{x}_{N}$, com certeza não é única
} 
função de onda teste para $\hat{H}$. Então, a partir do princípio variacional, temos:

$$
E_{0}<\left\langle\Psi^{\prime}|\hat{H}| \Psi^{\prime}\right\rangle=\left\langle\Psi^{\prime}\left|\hat{H}^{\prime}\right| \Psi^{\prime}\right\rangle+\left\langle\Psi^{\prime}\left|\hat{H}-\hat{H}^{\prime}\right| \Psi^{\prime}\right\rangle
$$

ou, como os dois operadores Hamiltonianos são diferentes somente pelo potencial externo, temos

$$
E_{0}<E_{0}^{\prime}\left\langle\Psi^{\prime}\left|\hat{T}+\hat{V}_{e e}+\hat{V}_{e x t}-\hat{T}-\hat{V}_{e e}-\hat{V}_{e x t}^{\prime}\right|\right\rangle
$$

o que nos fornece

$$
E_{0}<E_{0}^{\prime}+\int \rho(\vec{r})\left\{V_{e x t}-V_{e x t}^{\prime}\right\} d \vec{r}
$$

Trocando-se as quantidades linha pelas não linha e repetindo os passos anteriores das equações (3.13) até (3.15) nós obtemos a equação correspondente

$$
E_{0}^{\prime}<E_{0}+\int \rho(\vec{r})\left\{V_{e x t}-V_{e x t}^{\prime}\right\} d \vec{r}
$$

Agora, somando as duas equações (3.15) e (3.16), obtemos

$$
E_{0}+E_{0}^{\prime}<E_{0}^{\prime}+E_{0} \quad \text { ou } \quad 0<0
$$

que é claro que é uma inconsistência.

Isso conclui a nossa prova, que não pode haver dois potenciais $V_{e x t}$ diferentes fornecendo a mesma densidade eletrônica do estado fundamental, ou seja, que a densidade do estado fundamental exclusivamente especifica o potencial externo $V_{\text {ext }}$. Usando outras palavras, nós podemos simplesmente especificar à $\rho_{0}$ a pro- 
priedade de conter as informações sobre $\left\{N, Z_{A}, R_{A}\right\}$, e sumarizar isso como

$$
\rho_{0} \Rightarrow\left\{N, Z_{A}, R_{A}\right\} \Rightarrow \hat{H} \Rightarrow \Psi_{0} \Rightarrow E_{0} \text { (e todas as outras propriedades). }
$$

Desde que a energia completa do estado fundamental é uma função da densidade eletrônica do estado fundamental, as suas componentes também devem ser, assim, podemos escrever (onde retornamos com o sub índice ' $N e^{\prime}$, para expressar o tipo de potencial externo presente em nosso caso, que é completamente definido como a atração devido ao núcleo)

$$
E_{0}\left[\rho_{0}\right]=T\left[\rho_{0}\right]+E_{e e}\left[\rho_{0}\right]+E_{N e}\left[\rho_{0}\right]
$$

É conveniente neste ponto, separar essa expressão da energia nas partes dependentes do atual sistema, isto é, a energia potencial devido a atração núcleo-elétron, $E_{N e}\left[\rho_{0}\right]=\int \rho_{0}(\vec{r}) V_{N e} d \vec{r}$, e a parte que é universal, no sentido de que a sua forma é independente de $N, R_{A}$ e $Z_{A}$,

$$
E_{0}\left[\rho_{0}\right]=\underbrace{\int \rho_{0}(\vec{r}) V_{N e} d \vec{r}}_{\text {dependente do sistema }}+\underbrace{T\left[\rho_{0}\right]+E_{e e}\left[\rho_{0}\right]}_{\text {universalmente válida }}
$$

Agrupando as partes que são independentes do sistema em uma nova quantidade, o funcional de Hohenberg-Kohn $F_{H K}\left[\rho_{0}\right]$, nós obtemos

$$
E_{0}\left[\rho_{0}\right]=\int \rho_{0}(\vec{r}) V_{N e} d \vec{r}+F_{H K}\left[\rho_{0}\right]
$$

que define $F_{H K}\left[\rho_{0}\right]$. Em outras palavras, se o funcional de Hohenberg-Kohn é 
alimentado com alguma densidade arbitrária $\rho(\vec{r})$, ele a conecta ao valor esperado $\left\langle\Psi\left|\hat{T}+\hat{V}_{e e}\right| \Psi\right\rangle$. Isso é a soma do operador de energia cinética mais o operador de repulsão elétron-elétron com a função de onda do estado fundamental conectada com esta densidade. (Isto é, entre todas as muitas funções de onda que nos fornecem $\rho$, ele nos fornece a de mais baixa energia),

$$
F_{H K}[\rho]=T[\rho]+E_{e e}[\rho]=\left\langle\Psi\left|\hat{T}+V_{e e}\right| \Psi\right\rangle
$$

Este funcional, $F_{H K}[\rho]$, à primeira vista, nos parece como o Santo Graal da teoria do funcional da densidade. Se soubermos ele exatamente, nós teremos resolvido a equação de Schrödinger, não de uma maneira aproximada, mas exatamente. Esse funcional se aplica muito bem a qualquer sistema, tanto ao átomo de hidrogênio quanto a uma molécula gigante como o DNA! $F_{H K}$, contém o funcional para a energia cinética $T[\rho]$ e para a interação elétron-elétron, $E_{e e}[\rho]$. A forma explícita de ambos esses funcionais, infelizmente, ainda se encontra na escuridão. Entretanto, nós já podemos saber exatamente a parte Coulombiana clássica $J[\rho]$, que nós já a conhecemos bem

$$
E_{e e}[\rho]=\frac{1}{2} \iint \frac{\rho\left(\vec{r}_{1}\right) \rho\left(\vec{r}_{2}\right)}{r_{12}} d \vec{r}_{1} d \vec{r}_{2}+E_{n c l}[\rho]=J[\rho]+E_{n c l}[\rho]
$$

$E_{n c l}[\rho]$, é a contribuição não clássica da interação elétron-elétron, contendo todos os efeitos da correção de auto-interação, exchange e correlação Coulombiana. Não é surpresa nenhuma que encontrar essas formas explicitas para esses funcionais ainda desconhecidos, isto é, $T[\rho]$ e $E_{n c l}[\rho]$, representa o maior desafio na 
teoria do funcional da densidade.

\subsubsection{Segundo Teorema de HK: Princípio Variacional}

Até este ponto, nós estabelecemos que a densidade do estado fundamental é em princípio suficiente para obter todas as propriedades de interesse do sistema. Mas, como é que podemos ter a certeza de que ela é realmente a densidade do estado fundamental que estamos procurando? Uma prescrição formal de como este problema deve ser abordado foi dada pelo segundo teorema, comprovado por Hohenberg e Kohn nos seus trabalhos de 1964. Em palavras simples, este teorema afirma que

$F_{H K}[\rho]$, é o funcional que nos fornece a energia do estado fundamental do sistema. Ele nos fornece a menor energia se e somente se a densidade de entrada for a densidade do estado fundamental, $\rho_{0}$.

Isso trata-se, evidentemente, nada mais nada menos que o nosso velho amigo, o princípio variacional, que no presente contexto pode ser expresso como

$$
E_{0} \leq E[\tilde{\rho}]=T[\tilde{\rho}]+E_{N e}[\tilde{\rho}]+E_{e e}[\tilde{\rho}]
$$

Estabelecendo isso em outras palavras, significa que para uma densidade de teste $\tilde{\rho}$ - que satisfaz as condições de contorno necessárias como $\tilde{\rho}(\vec{r}) \geq 0, \int \tilde{\rho}(\vec{r}) d \vec{r}=$ $N$, e que é associada com algum potencial externo $\tilde{V}_{e x t}$ - a energia obtida a partir do funcional dado na equação (3.19) representa um valor superior à verdadeira energia do estado fundamental $E_{0}$. Teremos $E_{0}$ como resultado, se e somente 
se, inserirmos exatamente a densidade do estado fundamental na equação (3.20). A prova dessa desigualdade, equação (3.24), é feita simplesmente usando-se o princípio variacional.

Vamos recordar a nossa densidade de teste $\tilde{\rho}(\vec{r})$, onde ela define a sua própria Hamiltoniana $\tilde{\hat{H}}$ e conseqüentemente a sua própria função de onda $\tilde{\Psi}$. Essa função de onda, pode ser tomada agora como a nossa função de onda teste para a Hamiltoniana gerada pelo verdadeiro potencial externo. Então,

$$
\langle\tilde{\Psi}|\hat{H}| \tilde{\Psi}\rangle=T[\tilde{\rho}]+V_{e e}[\tilde{\rho}]+\int \tilde{\rho}(\vec{r}) V_{e x t} d \vec{r}=E[\tilde{\rho}] \geq E_{0}\left[\rho_{0}\right]=\left\langle\Psi_{0}|\hat{H}| \Psi_{0}\right\rangle
$$

que é o resultado desejado.

Vamos resumir tudo o que apresentamos anteriormente. Primeiro, todas as propriedades do sistema definido por um potencial externo, são determinadas pela densidade do estado fundamental. Em particular, a energia do estado fundamental associada com a densidade $\rho$ é obtida através do funcional $\int \rho(\vec{r}) V_{N e} d \vec{r}+F_{H K}[\rho]$. Segundo, este funcional alcança seu valor mínimo com respeito a todas as densidades permitidas, se e somente se, a densidade de entrada é a densidade do estado fundamental, isto é, para $\tilde{\rho}(\vec{r}) \equiv \rho_{0}(\vec{r})$. Com certeza, a aplicabilidade deste princípio variacional é limitada à energia do estado fundamental, desde que é aplicada a propriedade de que $E_{0}$ é a menor energia possível do sistema. 


\subsection{A Abordagem de Kohn-Sham}

O que falaremos nessa seção, tem sua origem no segundo maior paper da teoria moderna do funcional da densidade, que foi publicado por volta de um ano depois da contribuição fundamental feita por Hohenberg e Kohn [56], onde neste artigo Kohn e Sham, sugerem uma maneira de como o funcional universal, $F_{H K}[\rho]$, pode ser aproximado. Para isso, Kohn e Sham, introduziram a idéia de sistema referencial não-interagente, criado a partir de um conjunto de orbitais (isto é, funções de um elétron), tal que a maior parte da energia cinética possa ser calculada com uma boa precisão. A partir deste método, muita informação pode ser calculada exatamente, deixando somente uma pequena parte da energia total tendo que ser calculada de maneira aproximada.

Após introduzirmos o esquema de Kohn-Sham, nós iremos discutir algumas de suas principais características. Em particular, iremos desenhar uma linha entre as propriedades que se aplicam o esquema de "Kohn-Sham"e o que acontece com essas propriedades na vida real.

\subsubsection{Orbitais e Sistema Referêncial Não-Interagente}

Recordemos que os teoremas de Hohenberg-Kohn nos permite construir uma teoria de muitos corpos rigorosa, usando a densidade eletrônica como a quantidade fundamental. Nós mostramos anteriormente que neste quadro, a energia do 
estado fundamental de um sistema atômico ou molecular pode ser escrito como

$$
E_{0}=\min _{\rho \rightarrow N}\left(F[\rho]+\int \rho(\vec{r}) V_{N e} d \vec{r}\right)
$$

onde o funcional universal $F[\rho]$ contém as contribuições individuais da energia cinética, da interação clássica de Coulomb e da porção não-clássica devido a correção de auto-interação, troca (isto é, antisimetrica) e os efeitos de correlação eletrônica,

$$
F[\rho(\vec{r})]=T[\rho(\vec{r})]+J[\rho(\vec{r})]+E_{n c l}[\rho(\vec{r})]
$$

De todas essas grandezas, só conhecemos exatamente $J[\rho(\vec{r})]$. Enquanto que a forma explícita das outras grandezas continua sendo um mistério. Nas aproximações de Thomas-Fermi e Thomas-Fermi-Dirac, que não citamos neste trabalho ${ }^{3}$, todos os termos presentes nesses modelos, isto é, a energia cinética, o potencial devido aos núcleos, a repulsão Coulombiana clássica, e no caso do modelo de Thomas-Fermi-Dirac, também a contribuição de troca, são funcionais explícitos da densidade eletrônica, fazendo essas expressões serem bastantes simples. Entretanto, esses métodos baseados no esquema de Thomas-Fermi, incluindo várias outras extensões falham quando lamentavelmente os melhores resultados alvo são mais do que meras tendências. Dentre todos estes resultados devastadores, está a prova rigorosa, baseada no modelo de Thomas-Fermi, que nenhum sistema molecular é estável com respeito aos seus fragmentos [57]! Então, qual o valor

\footnotetext{
${ }^{3}$ Para uma descrição mais detalhada desses assuntos ver o livro, Teoria Quântica de Molécula e Sólidos - Simulação Computacional [51]
} 
para a química, pode eventualmente ter um modelo em que a ligação química nem sequer existe? Olhando-se rapidamente para o modelo de Thomas-Fermi, fica claro que a principal razão para o mal desempenho deste modelo é a forma funcional para a energia cinética possuir uma dependência em $\int \rho^{5 / 3}(\vec{r}) d \vec{r}$. Intuitivamente, também, não estamos surpresos que a relação entre a distribuição espacial dos elétrons, conforme previsto pela densidade eletrônica e suas velocidades, necessárias para a energia cinética, não é trivial. Assim, parece ser crucial encontrar uma forma diferente de se tratar a energia cinética, melhorando o controle da precisão - e isso é exatamente o que Kohn e Sham se propõem a fazer.

Para entender como Kohn e Sham abordaram esse problema, vamos entender um pouco sobre o esquema de Hartree-Fock [51]. Nesse esquema, a nossa função de onda é um único determinante de Slater, $\Phi_{S D}$, construído a partir de $N$ orbitais. O determinante de Slater pode ser visto de duas maneiras. Primeiro como a verdadeira função de onda de $N$ elétrons no método de Hartree-Fock, e segundo como a função de onda exata para um sistema fictício de $N$ elétrons não-interagentes (ou seja, elétrons que se comportam como férmions sem carga, e conseqüentemente não interagem uns com os outros via repulsão Coulombiana), se movendo em um potencial efetivo, $V_{H F}$. Para este tipo de função de onda, a energia cinética pode ser expressa exatamente como

$$
T_{H F}=-\frac{1}{2} \sum_{i}^{N}\left\langle\Xi_{i}\left|\nabla^{2}\right| \Xi_{i}\right\rangle
$$

Os orbitais $\Xi_{i}$ de Hartree-Fock que aparecem na expressão (3.28), são esco- 
lhidos de maneira que o valor esperado para a energia, $E_{H F}$, seja mínimo

$$
E_{H F}=\min _{\Phi_{S D} \rightarrow N}\left\langle\Phi_{S D}\left|\hat{T}+\hat{V}_{N e}+\hat{V}_{e e}\right| \Phi_{S D}\right\rangle
$$

Agora, temos que estabelecer a parte mais importante, que é a conexão disto com a teoria do funcional da densidade, que é valida para férmions não-interagentes, para que possamos calcular a maior fração da energia cinética do nosso sistema interagente.

O próximo passo é muito importante. Nós sabemos que as funções de onda exatas para o sistema de férmions não-interagentes são os determinantes de Slater ${ }^{4}$. Assim, será possível estabelecer um sistema referencial não-interagente, com uma Hamiltoniana em que introduziremos um potencial local efetivo, $V_{S}(\vec{r})$

$$
\hat{H}_{S}=-\frac{1}{2} \sum_{i}^{N} \nabla_{i}^{2}+\sum_{i}^{N} V_{S}\left(\vec{r}_{i}\right)
$$

Desde que esse operador Hamiltoniano não contém nenhuma interação elétronelétron ele também descreve um sistema não-interagente. Conseqüientemente, a nossa função de onda do estado fundamental é representada por um determinante de Slater (vamos mudar a notação, representando agora $\Phi_{S D}$ por $\Theta_{S}$ e $\Xi$ por $\phi$,

\footnotetext{
${ }^{4}$ Isso é verdade se estivermos lidando com um sistema não degenerado, mas caso o sistema for degenerado, a função de onda será uma combinação linear destes determinantes de Slater.
} 
para evitar uma confusão entre as quantidades do modelo de Hartree-Fock)

$$
\Theta_{S}=\frac{1}{\sqrt{N} !}\left|\begin{array}{cccc}
\phi_{1}\left(\vec{x}_{1}\right) & \phi_{2}\left(\vec{x}_{1}\right) & \ldots & \phi_{N}\left(\vec{x}_{1}\right) \\
\phi_{1}\left(\vec{x}_{2}\right) & \phi_{2}\left(\vec{x}_{2}\right) & & \phi_{N}\left(\vec{x}_{2}\right) \\
\vdots & \vdots & & \vdots \\
\phi_{1}\left(\vec{x}_{N}\right) & \phi_{2}\left(\vec{x}_{N}\right) & \ldots & \phi_{N}\left(\vec{x}_{N}\right)
\end{array}\right|
$$

onde os orbitais $\phi_{i}$, são determinados por

$$
\hat{f}^{K S} \phi_{i}=\epsilon_{i} \phi_{i}
$$

com o operador de um elétron de Kohn-Sham, $\hat{f}^{K S}$ definido como

$$
\hat{f}^{K S}=-\frac{1}{2} \nabla^{2}+V_{S}(\vec{r})
$$

Para evitar uma confusão entre estes orbitais e os da teoria de Hartree-Fock, eles são usualmente denominados de orbitais de Kohn-Sham, ou simplesmente orbitais de KS. A conexão, deste sistema artificial, com o que estamos realmente interessados, é agora estabelecida pela escolha do potencial efetivo $V_{S}$, tal que a densidade resultante a partir da soma do módulo dos quadrados dos orbitais $\left\{\phi_{i}\right\}$, é exatamente igual a densidade do estado fundamental do nosso sistema alvo, ou seja, o sistema real de elétrons interagentes

$$
\rho_{S}(\vec{r})=\sum_{i}^{N} \sum_{s}\left|\phi_{i}(\vec{r}, s)\right|^{2}=\rho_{0}(\vec{r})
$$




\subsubsection{As Equações de Kohn-Sham}

Retornaremos agora à nossa idéia inicial: encontrar a melhor maneira para determinar a energia cinética. A idéia de Kohn-Sham era que se nós não somo capazes de determinar de uma maneira precisa a energia cinética, através de uma forma funcional exata, nós deveríamos ser um pouco menos ambiciosos, e tentar calcular esta energia cinética de uma maneira aproximada, porém a mais próxima da energia cinética exata. Eles sugeriram que utilizássemos a expressão (3.28) para obter a energia cinética exata do sistema referencial não-interagente com a mesma densidade do sistema real e interagente

$$
T_{S}=-\frac{1}{2} \sum_{i}^{N}\left\langle\phi_{i}\left|\nabla^{2}\right| \phi_{i}\right\rangle
$$

Com certeza a energia cinética do sistema não-interagente não é igual a energia cinética do sistema interagente, mesmo se os sistemas compartilharem da mesma densidade, isto é, $T_{S} \neq T$. Kohn e Sham representaram isso, introduzindo-se uma separação do funcional $F[\rho]$ da seguinte maneira

$$
F[\rho(\vec{r})]=T_{S}[\rho(\vec{r})]+J[\rho(\vec{r})]+E_{X C}[\rho(\vec{r})]
$$

onde $E_{X C}$, é a tão chamada energia de troca e correlação, definida na equação (3.36) como

$$
E_{X C}[\rho] \equiv\left(T[\rho]-T_{S}[\rho]\right)+\left(E_{e e}[\rho]-J[\rho]\right)=T_{C}[\rho]+E_{n c l}[\rho]
$$


A parte residual da verdadeira energia cinética, que não está incluída em $T_{C}$, é simplesmente adicionada à contribuição eletrostática não-clássica. Em outras palavras, a energia de troca e correlação, é um funcional que contém tudo que é desconhecido, um tipo de lata de lixo, onde colocamos tudo o que não sabemos tratar exatamente. É importante dizer, que apesar de seu nome ser funcional de troca e correlação, ele contém não somente a parte não clássica da correção dos efeitos de auto-interação, troca e correlação, que são contribuições devido à energia potencial do sistema, mas também uma parte pertencente à energia cinética do sistema. Como indicado pela relação entre os orbitais e a densidade, equação (3.34), $T_{S}$ também é um funcional da densidade. Uma maneira complementar de olhar para isso, é observar que a expressão para a energia do sistema nãointeragente contém somente duas componentes: a energia cinética e a energia devido à interação com o potencial externo. A partir do teorema de HohenbergKohn, a energia total deve ser um funcional da densidade. Da mesma maneira que a energia de interação com o potencial externo é um funcional da densidade, $T_{S}$, necessariamente tem que ser um funcional da densidade. Mas note, que novamente nós não temos uma expressão onde a densidade entre explicitamente em $T_{s}$ - o que aparece na equação (3.35) são os orbitais de KS e não a densidade.

Até ai tudo bem, mas antes de avançar com este conceito, nós devemos saber como podemos determinar os orbitais em nosso sistema não-interagente. Em outras palavras: como nós podemos definir $V_{S}$, tal que ele realmente nos proporcione um determinante de Slater que caracterize exatamente a mesma densidade que o 
nosso verdadeiro sistema? Para resolver esse problema, escrevemos a expressão para a energia do sistema interagente, em termos da separação descrita na equação (3.36), destacando a dependência dos orbitais como indicada nas equações (3.34)

$$
\begin{aligned}
E[\rho(\vec{r})] & =T_{S}[\rho]+J[\rho]+E_{X C}[\rho]+E_{N e}[\rho] \\
& =T_{S}[\rho]+\frac{1}{2} \iint \frac{\rho\left(\vec{r}_{1}\right) \rho\left(\vec{r}_{2}\right)}{r_{12}} d \vec{r}_{1} d \vec{r}_{2}+E_{X C}[\rho]+\int V_{N e} \rho(\vec{r}) d \vec{r} \\
& =-\frac{1}{2} \sum_{i}^{N}\left\langle\phi_{i}\left|\nabla^{2}\right| \phi_{i}\right\rangle+\sum_{i}^{N} \sum_{j}^{N} \iint\left|\phi_{i}\left(\vec{r}_{1}\right)\right|^{2} \frac{1}{r_{12}}\left|\phi_{j}\left(\vec{r}_{2}\right)\right|^{2} d \vec{r}_{1} d \vec{r}_{2} \\
& +E_{X C}[\rho(\vec{r})]-\sum_{i}^{N} \int \sum_{A}^{Z} \frac{Z_{A}}{r_{1 A}}\left|\phi_{i}\left(\vec{r}_{1}\right)\right|^{2} d \vec{r}_{1}
\end{aligned}
$$

Aqui, podemos ver que o único termo que não podemos dar uma forma explicita, isto é, o grande mistério, é com certeza o termo de troca e correlação, $E_{X C}$. Da mesma maneira que é feita com a aproximação de Hartree-Fock, aplicamos o princípio variacional e fazemos a seguinte pergunta: quais condições devem ter os orbitais $\left\{\phi_{i}\right\}$ para que a expressão da energia seja minimizada perante o vínculo usual de que $\left\langle\phi_{i} \mid \phi_{j}\right\rangle=\delta_{i j}$ ? As equações, que resultam como resposta a esta questão são (para uma descrição mais detalhada da obtenção destas equações ver Parr e Yang, 1989 [58], ou Teoria Quântica de Moléculas e Sólicos, Adalberto Fazzio [51])

$$
\begin{array}{r}
\left(-\frac{1}{2} \nabla^{2}+\left[\int \frac{\rho\left(\vec{r}_{2}\right)}{r_{12}} d \vec{r}_{2}+V_{X C}\left(\vec{r}_{1}\right)-\sum_{A}^{Z} \frac{Z_{A}}{R_{1 A}}\right]\right) \phi_{i} \\
=\left(-\frac{1}{2} \nabla^{2}+V_{\text {eff }}\left(\vec{r}_{1}\right)\right) \phi_{i}=\epsilon_{i} \phi_{i}
\end{array}
$$


Se compararmos essa equação, com as equações de uma partícula do nosso sistema não interagente, iremos ver imediatamente que a expressão entre colchetes, isto é, $V_{e f f}$, é idêntico ao $V_{S}$ da equação (3.33)

$$
V_{s}(\vec{r}) \equiv V_{e f f}(\vec{r})=\int \frac{\rho\left(\vec{r}_{2}\right)}{r_{12}} d \vec{r}_{2}+V_{X C}\left(\vec{r}_{1}\right)-\sum_{A}^{M} \frac{Z_{A}}{r_{1 A}}
$$

Assim, uma vez que sabemos as várias contribuições na equação (3.40), teremos uma idéia do potencial $V_{S}$ que precisaremos inserir nas equações de uma partícula, que irá nos determinar os orbitais e conseqüentemente a densidade do estado fundamental através da aplicação da expressão da energia (3.38). Devemos notar que $V_{\text {eff }}$ também depende da densidade, como os orbitais também dependem, assim, as equações de Kohn-Sham devem ser resolvidas de maneira autoconsistente.

O termo $V_{X C}$, da equação (3.40), que é proveniente da energia de troca e correlação, precisa de alguns comentários a mais desde que que nós não sabemos como é a forma explícita desta energia. Assim, $V_{X C}$, é definido como a derivada funcional do funcional $E_{X C}[\rho]$ com respeito a $\rho$, ou seja

$$
V_{X C} \equiv \frac{\delta E_{X C}}{\delta \rho}
$$

É muito importante, notar que se forem conhecidas as formas exatas para $E_{X C}$ e $V_{X C}$, a estratégia de Kohn-Sham irá nos fornecer a energia exata, ou seja, o auto valor correto do operador Hamiltoniano $\hat{H}$ da equação de Schrödinger. Devemos notar, que até agora, nenhum tipo de aproximação foi feita. Em princípio, o de- 
senvolvimento de Kohn-Sham é exato! As aproximações somente entram, quando temos que decidir qual será a forma dos funcionais para a energia de troca e correlação e o potencial correspondente à esta. O objetivo central da teoria moderna do funcional da densidade é então encontrar melhores e melhores aproximações para os funcionais de troca e correlação. A seguir, iremos dar uma noção de duas aproximações para estes funcionais, conhecidas como Aproximação Local da Densidade - LDA - (do inglês Local Density Approximation) e Aproximação Generalizada do Gradiente - GGA - (do inglês Generalized Gradient Approximation).

\subsection{O Funcional de Troca e Correlação, $E_{x c}[\rho]$ e Suas Aproximações $L D A$ e $G G A$}

O esquema de Kohn-Sham, mapeia um problema de elétrons interagentes, sujeitos a um potencial $V(r)$, em um problema de elétrons não interagentes, sujeitos

a um potencial externo $V_{\text {ext }}(r)$. Toda a complexidade do sistema, é inserido no funcional energia de troca e correlação, como mencionamos anteriormente, onde associado a este funcional temos o potencial definido pela equação (3.41).

O que a DFT garante, é que estes potenciais existem e podem ser definidos. Neste trabalho, usaremos dois tipos de aproximações, que também já foram citadas, LDA e GGA. A seguir, iremos expor as idéias básicas desses tipos de aproximações. 


\subsubsection{A Aproximação Local da Densidade - LDA}

Nesta seção, iremos introduzir o modelo de um sistema que aproxima o funcional de troca e correlação baseando-se em um gás uniforme de elétrons. Ou seja, os elétrons se movem em um sistema que localmente é carregado positivamente, mas que o ensemble total é elétricamente neutro. Tanto o número de elétrons quanto o volume do sistema são considerados ir para o infinito, enquanto que a densidade eletrônica do sistema permanece finita, ou seja, $N \rightarrow \infty, V \rightarrow \infty$ e $N / V=\rho$ e mantém o seu valor constante em qualquer lugar. Fisicamente, tal situação representa um metal ideal, consistindo de um cristal ideal com os elétrons de valência, e os caroços iônicos positivos.

A razão pela qual um gás uniforme de elétrons possui um lugar proeminente na teoria do funcional da densidade é que ele é o único sistema que nós sabemos a forma exata dos funcionais de troca e correlação, ou pelo menos com uma boa precisão. A idéia para usar esse modelo para aproximar $E_{X C}$, foi primeiramente proposto por Kohn e Sham em 1965 [59]. A suposição central deste modelo, é que nós podemos escrever $E_{X C}$ da seguinte maneira

$$
E_{X C}^{L D A}[\rho]=\int \rho(\vec{r}) \epsilon_{X C}(\rho(\vec{r})) d \vec{r}
$$

Aqui, $\epsilon_{X C}(\rho(\vec{r}))$ é a energia de troca e correlação por partícula, em um gás uniforme de elétrons, de densidade $\rho(\vec{r})$. Essa energia por partícula é ponderada com a probabilidade $\rho(\vec{r})$ de que existe de fato um elétron nesta posição do espaço. A quantidade $\epsilon_{X C}(\rho(\vec{r}))$ pode ser separada em duas contribuições, a pertencente 
à troca e a correlação, ou seja

$$
\epsilon_{X C}(\rho(\vec{r}))=\epsilon_{X}(\rho(\vec{r}))+\epsilon_{C}(\rho(\vec{r}))
$$

A parte de troca, $\epsilon_{X}(\rho(\vec{r}))$, que representa a energia de troca de um elétron em um gás uniforme de elétrons de uma densidade particular, foi originalmente derivada por Bloch e Dirac em meados de 1920 [60]

$$
\epsilon_{X}=-\frac{3}{4} \sqrt[3]{\frac{3 \rho(\vec{r})}{\pi}}
$$

Assim, a equação (3.44) é inserida na equação (3.42), que é a dependência na densidade da energia de troca. Esse funcional de troca é geralmente chamado de exchange de Slater e é abreviado por $S$. Não existe nenhuma expressão explícita para a parte da correlação $\epsilon_{C}$. Entretanto, existem valores fornecidos por simulações quânticas muito precisas de Monte Carlo para um gás homogêneo de elétrons feitas por Ceperley e Alder [61]. Vários autores apresentaram também, expressões analíticas do termo de troca, $\epsilon_{C}$, expressões essas baseadas em sofisticados esquemas de interpolação. Uma das expressões mais utilizadas é a apresentada por Vosko, Wilk e Nursair [62]. Enquanto que a mais recente e pode-se dizer a mais utilizada, é a dada por Perdew e Wang [63].

\subsubsection{A Aproximação Generalizada do Gradiente - GGA}

A aproximação local da densidade é insuficiente para se tratar problemas em química, onde a densidade não é uniforme. Por isso, que durante muitos anos a 
teoria do funcional da densidade foi somente aplicada na física do estado sólido e dificilmente apresentava algum resultado na química computacional. Em meados dos anos 80, a situação mudou drásticamente quando uma outra aproximação foi aplicada. A sugestão era, ao invés de usar somente a informação da densidade $\rho(\vec{r})$ em um ponto particular $\vec{r}$, usaríamos também a informação de um gradiente da densidade de carga, $\nabla \rho(\vec{r})$, para levarmos em conta a não-homogeneidade da verdadeira densidade eletrônica. Em outras palavras, interpretaríamos a aproximação local da densidade como um primeiro termo de uma expansão de Taylor da densidade uniforme e obteríamos melhores aproximações para o funcional de troca e correlação, $E_{X C}[\rho]$, estendendo a série com os próximos termos, assim nós teríamos

$$
E_{X C}^{G G A}[\rho]=\int d \vec{r} f(\rho(\vec{r}), \nabla \rho(\vec{r}))
$$

que inclui portanto as informações sobre a variação local (gradiente) da densidade. Existem diferentes aproximações GGA, correspondendo a diferentes escolhas para a função $f$. Essas funções são geralmente construídas para obedecer alguns vínculos.

Podemos criar construções específicas, como as de Perdew e Zunger (LDA) [64] e as GGA, $P W 91$ [63] e PBE [65]. 


\subsection{Condutância e Corrente: Via Funções de Green Fora do Equilíbrio - NEGF}

No presente trabalho de mestrado, foi utilizado também o formalismo de funções de Green fora do equilíbrio para o cálculo das propriedades de transporte dos sistemas a serem estudados. O programa utilizado para isto foi desenvolvido por um aluno do grupo SAMPA [66]. Utilizamos também uma outra implementação, feita pelo Dr. Alexandre Reilya Rocha, também do grupo SAMPA. Nesta seção iremos detalhar o formalismo utilizado nestes códigos, onde as implementações utilizam o formalismo de funções de Green fora do equilíbrio junto com o DFT (NEGF-DFT [67,68]) para calcular as propriedades de transporte do sistema.

Devido á complexidade deste método e o nosso objetivo ser somente utilizar ele para o cálculo das propriedades de transporte de carga dos nanotubos, nós iremos somente dar uma descrição das suas principais propriedades e implicações.

Este formalismo é muito poderoso e uma das maiores vantagens dele é que ele nos permite obter as matrizes densidade dos sistemas de forma auto-consistente para situações com condições de contorno aberta, estudando tanto sistemas dentro ou fora do equilíbrio. Assim, podemos estudar sistemas infinitos.

Nesta seção da dissertação, iremos apresentar as deduções com respeito ao transporte coerente de elétrons, onde os processos são não dissipativos. Existem generalizações desse método, onde são considerados outros tipos de transporte [67]. O formalismo apresentado aqui será seguindo o esquema proposto por Landauer [69]. 
O sistema a ser tratado com este formalismo, é constituído de uma região espalhadora que chamaremos de canal, ligada a dois contatos, leads ou eletrodos, um representado por uma fonte e outro por um dreno, ou melhor, os eletrodos esquerdo e direito. Cada um desses eletrodos está em um equilíbrio local, mas são mantidos a potenciais químicos um diferente do outro através de uma diferença de potencial aplicada de $V\left(\mu_{1}-\mu_{2}=q V\right)$. Esse não equilíbrio entre os eletrodos faz com que a fonte forneça elétrons para dentro da região espalhadora e o dreno retire elétrons deste, fazendo com que haja um fluxo de corrente no circuito externo.

Seja o seguinte sistema, figura (3.1):

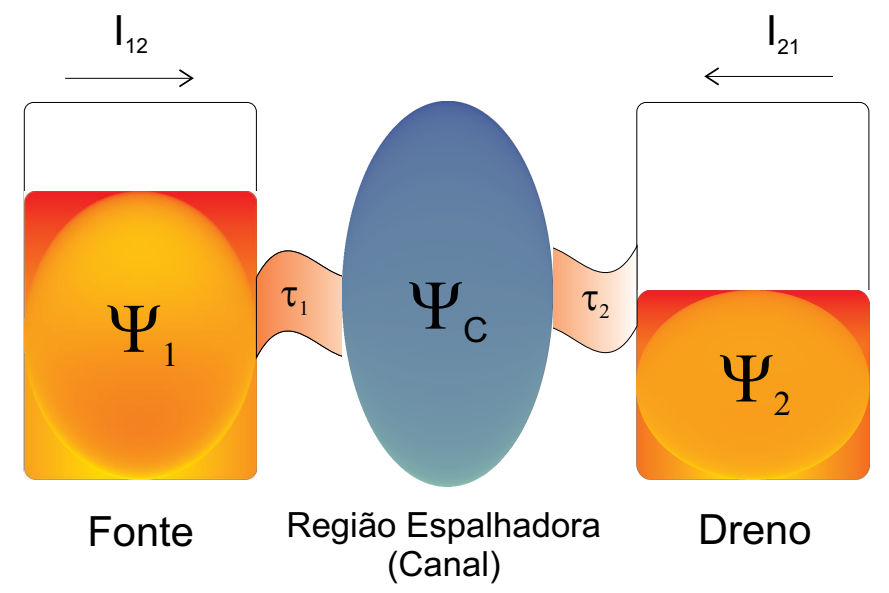

Figura 3.1: Esquema do sistema utilizado para o cálculo de transporte eletrônico.

Dado o sistema da figura (3.1), podemos escrever a equação de Schrödinger desse sistema na forma de matrizes, separando-se os subespaços dos contatos da parte espalhadora da seguinte forma:

$$
\left[\begin{array}{ccc}
H_{1} & \tau_{1}^{\dagger} & 0 \\
\tau_{1} & H_{c} & \tau_{2} \\
0 & \tau_{2}^{\dagger} & H_{2}
\end{array}\right]\left[\begin{array}{l}
\left|\psi_{1}\right\rangle \\
\left|\psi_{c}\right\rangle \\
\left|\psi_{2}\right\rangle
\end{array}\right]=E\left[\begin{array}{c}
\left|\psi_{1}\right\rangle \\
\left|\psi_{c}\right\rangle \\
\left|\psi_{2}\right\rangle
\end{array}\right]
$$


Na equação (3.46) $H_{1}$ e $H_{2}$ são os operadores Hamiltonianos dos eletrodos isolados, $H_{c}$ é o operador Hamiltoniano da região espalhadora e $\tau_{1}$ e $\tau_{2}$ são os Hamiltonianos de acoplamento entre os eletrodos e a região espalhadora. Podemos ver um esquema dessas grandezas na figura (3.1).

Para estudar esse tipo de sistema, introduzimos o conceito de funções de Green, pois a partir delas, nos é permitido calcular a resposta do sistema, quando é introduzido uma perturbação $(\nu)$ independente do tempo na equação de Schrödinger que descreve o sistema. Assim, será possível calcular a função de onda do sistema perturbado, sem resolver o problema de auto-valores. Para fazer isso, temos o seguinte. Seja a equação:

$$
\begin{aligned}
H|\psi\rangle & =E|\psi\rangle+\nu|\psi\rangle=E|\psi\rangle+|\nu\rangle \\
(E-H)|\psi\rangle & =-|\nu\rangle \\
|\psi\rangle & =-(E-H)^{-1}|\nu\rangle=-G(E)|\nu\rangle
\end{aligned}
$$

Daí, nós podemos definir a nossa função de Green como:

$$
G(E)=(E-H)^{-1}
$$

Dado isso, nós podemos retornar à equação (3.46) e obter uma igualdade para 
$\left|\psi_{2}\right\rangle$ como

$$
\begin{aligned}
H_{2}\left|\psi_{2}\right\rangle+\tau_{2}^{\dagger}\left|\psi_{c}\right\rangle & =E\left|\psi_{2}\right\rangle \\
\left(E-H_{2}\right)\left|\psi_{2}\right\rangle & =\tau_{2}^{\dagger}\left|\psi_{c}\right\rangle \\
\left|\psi_{2}\right\rangle & =g_{2}(E) \tau_{2}^{\dagger}\left|\psi_{c}\right\rangle
\end{aligned}
$$

onde $g_{2}$ é a função de Green do eletrodo 2 isolado. Podemos resolver este problema de maneira similar para a função de onda $\left|\psi_{1}\right\rangle$, assim,

$$
\begin{aligned}
H_{1}\left|\psi_{1}\right\rangle+\tau_{1}^{\dagger}\left|\psi_{c}\right\rangle & =E\left|\psi_{1}\right\rangle \\
\left(E-H_{1}\right)\left|\psi_{1}\right\rangle & =\tau_{1}^{\dagger}\left|\psi_{c}\right\rangle \\
\left|\psi_{1}\right\rangle & =g_{1}(E) \tau_{1}^{\dagger}\left|\psi_{c}\right\rangle
\end{aligned}
$$

onde $g_{1}$ é a função de Green do eletrodo 1 isolado.

Reescrevendo a equação (3.46) para incluir a matriz das funções de Green do sistema e assim, derivar os resultados dela. Fazendo isso, nos é permitido calcular a função de Green do canal (região espalhadora) sem que seja necessário calcular a função de Green do sistema todo, da maneira que é feita a seguir,

$$
\left[\begin{array}{ccc}
E-H_{1} & -\tau_{1}^{\dagger} & 0 \\
-\tau_{1} & E-H_{c} & -\tau_{2} \\
0 & -\tau_{2}^{\dagger} & E-H_{2}
\end{array}\right]\left[\begin{array}{ccc}
G_{11} & G_{1 c} & G_{12} \\
G_{c 1} & G_{c c} & G_{c 2} \\
G_{21} & G_{2 c} & G_{22}
\end{array}\right]=E\left[\begin{array}{ccc}
I & 0 & 0 \\
0 & I & 0 \\
0 & 0 & I
\end{array}\right]
$$

Disso, nós podemos obter as equações fornecidas pela segunda coluna da ma- 
triz de Green,

$$
\begin{gathered}
\left(E-H_{1}\right) G_{1 c}-\tau_{1}^{\dagger} G_{c c}=0 \\
-\tau_{1} G_{1 c}+\left(E-H_{c}\right) G_{c c}-\tau_{2} G_{2 c}=I \\
\left(E-H_{2}\right) G_{2 c}-\tau_{2}^{\dagger} G_{c c}=0
\end{gathered}
$$

Resolvendo as equações (3.52) e (3.54) para $G_{1 c}$ e $G_{2 c}$ e substituindo na equação (3.53), nós obtermos uma equação para $G_{c c}$,

$$
\begin{gathered}
-\tau_{1} g_{1} \tau_{1}^{\dagger} G_{c c}-\left(E-H_{c}\right) G_{c c}-\tau_{2} g_{2} \tau_{2}^{\dagger} G_{c c}=I \\
G_{c c}=\left(E-H^{c}-\Sigma_{1}-\Sigma_{2}\right)^{-1}
\end{gathered}
$$

Na equação (3.56), $\Sigma_{1}=\tau_{1} g_{1} \tau_{1}^{\dagger}$ e $\Sigma_{2}=\tau_{2} g_{2} \tau_{2}^{\dagger}$ são as auto-energias dos contatos.

A auto-energia possui um significado físico muito interessante, que pode ser deduzido transformando-a para as coordenadas temporais através de uma transformada de Fourier [67]. Nesse espaço da transformada de Fourier, podemos observar que a sua parte real provoca um deslocamento nos auto-valores, enquanto que a sua parte imaginária é responsável pelo tempo de vida do estado. Voltando ao espaço das energias, isso gera um alargamento da densidade de estados. Portanto, 
é comum definir a matriz de alargamento $\Gamma(E)$ como a parte anti-hermitiana da auto-energia da seguinte maneira,

$$
[\Gamma(E)]=i\left[\Sigma(E)-\Sigma^{\dagger}(E)\right]
$$

Seguindo esse formalismo, nós podemos escrever a densidade de estados em termos das funções de Green. Dessa maneira, seguindo a definição convencional da densidade de estados temos,

$$
D(E)=\sum_{\alpha} \delta\left(E-\epsilon_{\alpha}\right)
$$

onde a soma é feita sobre todos os auto-valores. Definindo a seguinte matriz, que é conhecida como função espectral,

$$
[A(E)]=2 \pi \delta(E[I]-[H])
$$

a densidade de estados pode ser escrita como o traço dessa matriz, como pode ser visto a seguir,

$$
D(E)=\frac{1}{2 \pi} \operatorname{Tr}[A(E)]
$$

A identidade (3.60) é bastante fácil de ser percebida se usarmos como base as auto-funções de $[H]$, onde tato $[H]$ como $[A]$ são matrizes diagonais. Como o traço de uma matriz é invariante por mudança de base, a identidade sempre será valida.

Por final, para chegar na representação de funções de Green para a densidade 
de estados, é necessário fazer uso de uma identidade matemática, expressando a função $\delta$ como uma Lorentziana no limite que o parâmetro $\eta$ vai zero, explicitado na equação (3.61),

$$
\begin{aligned}
& {[A(E)]_{\alpha \alpha}=2 \pi \delta\left(E-\epsilon_{\alpha}\right)=\left[\frac{2 \eta}{\left(E-\epsilon_{\alpha}\right)^{2}+\eta^{2}}\right]_{\eta \rightarrow 0^{+}}=} \\
& i\left[\frac{1}{E-\epsilon_{\alpha} i 0^{+}}-\frac{1}{E-\epsilon_{\alpha}-i 0^{+}}\right]=i\left[G(E)-G^{\dagger}(E)\right]_{\alpha \alpha}
\end{aligned}
$$

Nessa equação as funções de Green foram definidas de uma maneira levemente diferente da definida anteriormente em (3.48). Na verdade, deveríamos ter utilizado todo o formalismo para as funções de Green adiantada e retardada como definido na equação (3.61), onde uma é o complexo conjugado da outra. Porém, para um raciocínio mais simples, é suficiente considerar a definição fornecida em (3.48).

Retornando ao nosso desenvolvimento, é possível demonstrar que $\Gamma$ está relacionado com a função espectral da seguinte forma, para uma determinada função de Green $G$ do sistema,

$$
\begin{array}{r}
{[A(E)]=i\left[G(E)-G^{\dagger}(E)\right]} \\
\tau[A(E)] \tau^{\dagger}=i \tau\left[G(E)-G(E)^{\dagger}\right] \tau^{\dagger} \\
\tau[A(E)] \tau^{\dagger}=i\left[\tau G(E) \tau^{\dagger}-\tau G^{\dagger}(E) \tau^{\dagger}\right]=[\Gamma]
\end{array}
$$

onde $\tau$ e $\tau^{\dagger}$ são as matrizes genéricas de acoplamento, já previamente definidas.

Considerando o contato 1 completamente isolado, para uma determinada ener- 
gia teremos uma auto-função $\left|\psi_{1, n}\right\rangle$ que será completamente refletida na borda do contato. Ao se acoplar com o canal e com o contato 2, essa onda incidente que vem pelo contato 1 , gera uma função de onda resposta no sistema todo $\mid \psi_{R}$, que se espalha inclusive por ele mesmo. Dessa forma, poderíamos escrever a função de onda total do sistema como $\left|\psi_{1, n}\right\rangle+\left|\psi_{R}\right\rangle$. Olhando para a equação (3.46), podemos perceber que somente os operadores que se encontram na primeira coluna do Hamiltoniano atuarão sobre $\left|\psi_{1, n}\right\rangle$, já que esta só existe no eletrodo 1. Em compensação, todos os operadores agirão sobre $\left|\psi_{R}\right\rangle$, já que esta existe no sistema todo. Assim, podemos chegar a uma expressão para $\left|\psi_{R}\right\rangle$ da seguinte maneira,

$$
\begin{aligned}
\mathcal{H}\left(\left|\psi_{1, n}\right\rangle+\left|\psi_{R}\right\rangle\right) & =E\left(\left|\psi_{1, n}\right\rangle+\left|\psi_{R}\right\rangle\right) \\
H_{1}\left|\psi_{1, n}\right\rangle+\tau_{1}\left|\psi_{1, n}\right\rangle+\mathcal{H}\left|\psi_{R}\right\rangle & =E\left|\psi_{1, n}\right\rangle+E\left|\psi_{R}\right\rangle \\
(E-\mathcal{H})\left|\psi_{R}\right\rangle & =\tau_{1}\left|\psi_{1, n}\right\rangle \\
\left|\psi_{R}\right\rangle & =G \tau_{1}\left|\psi_{1, n}\right\rangle
\end{aligned}
$$

onde $\mathcal{H}$ é o Hamiltoniano de todo o sistema. Fizemos uso aqui do fato que $H_{1}\left|\psi_{1, n}\right\rangle=E\left|\psi_{1, n}\right\rangle$. Sendo assim, como na região espalhadora só temos $\psi_{R}$, nós podemos escrever,

$$
\left|\psi_{c}\right\rangle=G_{c c} \tau_{1}\left|\psi_{1, n}\right\rangle
$$

Agora, a fim de determinar $\left|\psi_{2}\right\rangle$ precisamos utilizar a relação (3.49). Assim, temos,

$$
\left|\psi_{2}\right\rangle=g_{2} \tau_{2}^{\dagger} G_{c c} \tau_{1} \mid \psi_{1, n}
$$


Finalmente, para determinar $\left|\psi_{1}\right\rangle$ temos que considerar a relação (3.50) e o fato que nele também há a própria $\left|\psi_{1, n}\right\rangle$, daí chegando à seguinte expressão,

$$
\left|\psi_{1}\right\rangle=\left|\psi_{1, n}\right\rangle+g_{1} \tau_{1}^{\dagger}\left|\psi_{c}\right\rangle=\left(1+g_{1} \tau_{1}^{\dagger} G_{c c} \tau_{1}\right)\left|\psi_{1, n}\right\rangle
$$

Quando estamos tratando sistemas fora do equilíbrio, como o nosso, a matriz densidade de carga e a corrente são as grandezas de maior interesse a serem determinadas.

A matriz densidade pode ser definida da seguinte forma,

$$
\rho=\sum_{\alpha} f\left(\epsilon_{\alpha}, \mu\right)\left|\psi_{\alpha}\right\rangle\left\langle\psi_{\alpha}\right|
$$

onde a soma é realizada sobre todos os estados do sistema com número de ocupação $f\left(\epsilon_{\alpha}, \mu\right)$. No equilíbrio a matriz densidade é facilmente calculada a partir da função espectral [67], porém fora do equilíbrio, é necessário fazer algumas observações.

Quando estudamos o caso fora do equilíbrio, existem dois potenciais químicos a ser considerado: um no eletrodo $1\left(\mu_{1}\right)$ e outro no eletrodo $2\left(\mu_{2}\right)$. Por esse motivo, podemos definir duas funções de Fermi-Dirac, $f_{1}$ e $f_{2}$, cada uma pertencente a cada eletrodo, que são dadas por,

$$
f_{i}\left(\epsilon_{\alpha}, \mu_{i}\right)=\frac{1}{1+e^{\left(\epsilon_{\alpha}-\mu_{i}\right) /\left(k_{B} T\right)}}, \quad i=1,2
$$

Assim, na região espalhadora, teremos uma contribuição para a densidade de carga proveniente do eletrodo 1 e outra do eletrodo 2. Usando as equações (3.64) 
e (3.60) e tomando $E$ como uma variável contínua, podemos escrever a densidade na região espalhadora (que contém os estados $k$ ) provocada pelo eletrodo $i$ da seguinte maneira,

$$
\begin{array}{r}
\rho_{c}^{i}=\int_{-\infty}^{\infty} d E D(E) f\left(E, \mu_{i}\right)\left|\psi_{c}\right\rangle\left\langle\psi_{c}\right|= \\
\int_{-\infty}^{\infty} d E f\left(E, \mu_{i}\right) \sum_{k} D(E) G_{c c} \tau_{i}\left|\psi_{i, k}\right\rangle\left\langle\psi_{i, k}\right| \tau_{i}^{\dagger} G_{c c}^{\dagger}= \\
\int_{-\infty}^{\infty} d E f\left(E, \mu_{i}\right) G_{c c} \tau_{i}\left(\sum_{k} D(E)\left|\psi_{i, k}\right\rangle\left\langle\psi_{i, k}\right|\right) \tau_{i}^{\dagger} G_{c c}^{\dagger}= \\
\int_{-\infty}^{\infty} d E f\left(E, \mu_{i}\right) G_{c c} \tau_{i} \frac{a_{i}}{2 \pi} \tau_{i}^{\dagger} G_{c c}^{\dagger}
\end{array}
$$

$\mathrm{Na}$ equação (3.69), $a_{i}$ representa a função espectral do eletrodo $i$ isolado. Usando a equação (3.62) podemos simplificar isso, e obter o seguinte,

$$
\rho_{c}^{i}=\frac{1}{2 \pi} \int_{-\infty}^{\infty} d E f\left(E, \mu_{i}\right) G_{c c} \Gamma_{i} G_{c c}^{\dagger}
$$

Afim de obtermos a densidade de carga total, temos que somar sobre os dois eletrodos e considerar a degenerescência de spin, dessa maneira, obtemos,

$$
\rho=\frac{2}{\pi} \int_{-\infty}^{\infty} d E \sum_{i} f\left(E, \mu_{i}\right) G_{c c} \Gamma_{i} G_{c c}^{\dagger}
$$

Uma outra grandeza que queremos obter dos nossos cálculos de transporte, é a corrente elétrica que flui no sistema. Para obter isso, iniciamos derivando a equação da continuidade para a região espalhadora, já que no estado estacionário, a probabilidade de encontrar um elétron na região espalhadora é conservada. Para isso, seja uma função de onda arbitrária, formada por uma combinação de $\psi_{1}, \psi_{2}$ 
e $\psi_{c}$. A probabilidade de encontrar um elétron na região espalhadora, nesses termos, seria então $\sum_{k}\langle\psi \mid k\rangle\langle k \mid \psi\rangle$, onde a soma é realizada sobre todo o subespaço da região espalhadora do sistema. A equação da continuidade possui a seguinte forma,

$$
\begin{aligned}
0 & =\sum_{k} \frac{\partial\langle\psi \mid k\rangle\langle k \mid \psi\rangle}{\partial t} \\
& =\sum_{k}\left(\frac{\partial\langle\psi|}{\partial t}|k\rangle\langle k \mid \psi\rangle+\langle\psi \mid k\rangle\langle k| \frac{\partial|\psi\rangle}{\partial t}\right)
\end{aligned}
$$

Tomando a equação de Schrödinger dependente do tempo, e introduzindo o operador Hamiltoniano somente com os elementos que levam as funções de onda dentro da região espalhadora, que é dado por $\mathcal{H}_{c}=H_{c}+\tau_{1}+\tau_{2}$, nós temos,

$$
\begin{aligned}
0 & =\frac{i}{\hbar} \sum_{k}\left(\langle\psi \mathcal{H}_{c} \underbrace{|k\rangle\langle k \mid \psi\rangle}_{\left|\psi_{c}\right\rangle}-\underbrace{\langle\psi \mid k\rangle\langle k|}_{\left\langle\psi_{c}\right|} \mathcal{H}_{c} \mid \psi\rangle\right) \\
& =\frac{i}{\hbar}\left(\left\langle\psi\left|\mathcal{H}_{c}\right| \psi_{c}\right\rangle-\left\langle\psi_{c}\left|\mathcal{H}_{c}\right| \psi\right\rangle\right) \\
& =\frac{i}{\hbar}\left(\left\langle\psi\left|H_{c}+\tau_{1}^{\dagger}+\tau_{2}^{\dagger}\right| \psi_{c}\right\rangle-\left\langle\psi_{c}\left|H_{c}+\tau_{1}+\tau_{2}\right| \psi\right\rangle\right) \\
& =\underbrace{\frac{i}{\hbar}\left(\left\langle\psi_{1}\left|\tau_{1}^{\dagger}\right| \psi_{c}\right\rangle-\left\langle\psi_{c}\left|\tau_{1}\right| \psi_{1}\right\rangle\right)}_{-i_{1} / e}+\underbrace{\frac{i}{\hbar}\left(\left\langle\psi_{2}\left|\tau_{2}^{\dagger}\right| \psi_{c}\right\rangle-\left\langle\psi_{c}\left|\tau_{2}\right| \psi_{2}\right\rangle\right)}_{-i_{2} / e}
\end{aligned}
$$

Na equação (3.72), $ß_{1} / e$ é a densidade de corrente na região espalhadora devido ao contato 1 e $-i_{2} / e$ é a proveniente do eletrodo 2. Dessa maneira, a expressão para a corrente em uma determinada energia é expressa por,

$$
i_{j}=-\frac{i e}{\hbar}\left(\left\langle\psi_{j}\left|\tau_{j}^{\dagger}\right| \psi_{c}\right\rangle-\left\langle\psi_{c}\left|\tau_{j}\right| \psi_{j}\right\rangle\right)
$$


Para obtermos a equação final da corrente, é necessário expressarmos as componentes da corrente, $i_{j}$, em função de $\mid \psi_{1, n}$ e depois em termos das matrizes $G$ e $\Gamma$, que já foram definidas. Dessa maneira, podemos usar as expressões (3.66), (3.65) e (3.64). Dessa maneira, a relação para a corrente na região espalhadora, proveniente do eletrodo 1 e acoplada ao eletrodo 2 por $\tau_{2}$ é dada por,

$$
\begin{aligned}
i_{2} & =-\frac{i e}{\hbar}\left(\left\langle\psi_{2}\left|\tau_{2}^{\dagger}\right| \psi_{c}\right\rangle-\left\langle\psi_{c}\left|\tau_{2}\right| \psi_{2}\right\rangle\right) \\
& =-\frac{i e}{\hbar}\left(\left\langle\psi_{1, n}\left|\tau_{1}^{\dagger} G_{c c}^{\dagger} \tau 2 g_{2}^{\dagger} \tau_{2}^{\dagger} G_{c c} \tau_{1}\right| \psi_{1, n}\right\rangle-\left\langle\psi_{1, n}\left|\tau_{1}^{\dagger} G_{c c}^{\dagger} \tau 2 g_{2} \tau_{2}^{\dagger} G_{c c} \tau_{1}\right| \psi_{1, n}\right\rangle\right) \\
& =-\frac{i e}{\hbar}\left\langle\psi_{1, n}\left|\tau_{1}^{\dagger} G_{c c}^{\dagger} \tau_{2}\left(g_{2}^{\dagger}-g_{2}\right) \tau_{2}^{\dagger} G_{c c} \tau_{1}\right| \psi_{1, n}\right\rangle \\
& =\frac{e}{\hbar}\left\langle\psi_{1, n}\left|\tau_{1}^{\dagger} G_{c c}^{\dagger} \Gamma_{2} G_{c c} \tau_{1}\right| \psi_{1, n}\right\rangle
\end{aligned}
$$

Integrando isso sobre a energia e somando sobre todos os $n$, considerando a degenerescência de spin e sabendo que todos os níveis são preenchidos pelo reservatório do eletrodo 1 , ou seja, obedecem a distribuição $f_{1}$, a expressão para a corrente no eletrodo 2 é dada por,

$$
\begin{aligned}
I_{2} & =\frac{2 e}{\hbar} \int_{-\infty}^{\infty} d E f\left(E, \mu_{1}\right) \sum_{m, n} D(E)\left\langle\psi_{1, n}\left|\tau_{1}^{\dagger}\right| m\right\rangle\left\langle m\left|G_{c c}^{\dagger} \Gamma_{2} \tau_{1}\right| \psi_{1, n}\right\rangle \\
& =\frac{2 e}{\hbar} \int_{-\infty}^{\infty} d E f\left(E, \mu_{1}\right) \sum_{m}\langle m| G_{c c}^{\dagger} \Gamma_{2} G_{c c} \tau_{1} \underbrace{\sum_{n} D(E)\left|\psi_{1, n}\right\rangle\left\langle\psi_{1, n} \mid m\right\rangle}_{a_{1} / 2 \pi} \\
& =\frac{2 e}{h} \int_{-\infty}^{\infty} d E f\left(E, \mu_{1}\right) \sum_{m}\left\langle m\left|G_{c c}^{\dagger} \Gamma_{2} G_{c c} \tau_{1} a_{1} \tau_{1}^{\dagger}\right| m\right\rangle \\
& =\frac{2 e}{h} \int_{-\infty}^{\infty} d E f\left(E, \mu_{1}\right) \operatorname{Tr}\left(G_{c c}^{\dagger} \Gamma_{2} G_{c c} \Gamma_{1}\right)
\end{aligned}
$$

onde $a_{1}$ é a função espectral do eletrodo 1 isolado. 
Seguindo o mesmo procedimento realizado para $I_{2}$, podemos encontrar $I_{1}$, porém com o sinal invertido. Feito isso, a fórmula para a corrente total, que é conhecida como equação de Landauer, pode ser escrita da seguinte maneira,

$$
\begin{aligned}
I & =\frac{2 e}{h} \int_{-\infty}^{\infty} d E\left(f\left(E, \mu_{1}\right)-f\left(E, \mu_{2}\right)\right) \operatorname{Tr}\left(G_{c c}^{\dagger} \Gamma_{2} G_{c c} \Gamma_{1}\right) \\
& =\frac{2 e}{h} \int_{-\infty}^{\infty} d E\left(f\left(E, \mu_{1}\right)-f\left(E, \mu_{2}\right)\right) T(E)
\end{aligned}
$$

onde a grandeza $T(E)$ é conhecida como transmitância ou função de transmissão.

Podemos entender essa grandeza fisicamente, podemos pensar nela como sendo uma medida da permeabilidade da região espalhadora ao fluxo de elétrons com energia $E$ vindos dos eletrodos. A transmitância é também diretamente proporcional à condutância o sistema e inversamente proporcional à resistência.

Normalmente, a transmitância é medida em unidades de $G_{0}$, que é dada por,

$$
G_{0}=\frac{2 e^{2}}{h}=(51.6 / \mu \Omega)^{-1}
$$

Cada modo, ou sub-banda pode transmitir até $1 G_{0}$ sendo interessante notar que no caso dos nanotubos metálicos usados nesse trabalho a condutância máxima na região próxima ao nível de Fermi é de $2 G_{0}$, já que existem somente duas bandas nessa região. 


\section{Capítulo 4}

\section{Resultados - Caracterização do Sistema Puro}

Neste capítulo, iremos apresentar os resultados obtidos durante o desenvolvimento do projeto de mestrado. Eles serão apresentados em ordem cronológica, ou seja, na seqüência em que foram sendo desenvolvidos. A primeira proposta foi o estudo sistemático do sistema nanotubo de carbono armchair na presença de monovacâncias, para entender a influência destes defeitos na estrutura geométrica (relaxação e reconstrução) e eletrônica (densidade de estados, estrutura de bandas e transporte de carga) desse. Seguindo o estudo das monovacâncias, e sabendo que esses defeitos apresentam uma mobilidade no nanotubo [70], nós apresentaremos os resultados da barreira de migração dessas no sistema, onde o objetivo é determinar qual seria um tempo característico para uma monovacância saltar de um sítio a outro do nanotubo. Seguindo com os resultados, no próximo capítulo, partiremos para a próxima proposta do nosso estudo, que é continuar o estudo dos defeitos pontuais, porém agora, defeitos formados pela retirada de 
mais de um átomo do sistema, ou seja, as multivacâncias. Esses cálculos foram motivados também pelos resultados obtidos com a monovacância, pois foi visto que essas possuem uma certa mobilidade no nanotubo, onde elas podem se encontrar e formar clusters de monovacâncias ou outros defeitos maiores. Sendo assim, teremos os mesmos resultados que para as monovacâncias - relaxação, reconstrução, bandas de energia, densidade de estados e transporte eletrônico. Além disso, apresentaremos para as multivacâncias algo que é muito importante, ou seja, qual é a estabilidade destes defeitos.

Antes de estudarmos propriamente o sistema formado pelas monovacâncias, precisamos caracterizar muito bem o que estaremos estudando, ou seja, o nanotubo de carbono armchair $(5,5)$.

Todo o estudo apresentado nessa dissertação, foi realizado com o nanotubo de carbono armchair $(5,5)$, cujo diâmetro é de $6.78 \AA$. Esse nanotubo foi escolhido devido a ele servir de modelo para vários outros estudos envolvendo tanto defeitos estruturais como os nossos [32], quanto outros tipos de defeitos, como os formados pela presença de átomos de outros tipos, como impurezas de nitrogênio [69], entre outros. Assim, precisamos saber todas as propriedades do sistema puro como o parâmetro de rede, a estrutura de bandas, densidade de estados e propriedades de transporte, para que depois possamos fazer a comparação do efeito dos defeitos.

Primeiramente otimizamos o sistema, a fim de obter o parâmetro de rede que minimiza a sua energia. A geometria da célula unitária foi construída, onde esta 
possui 20 átomos. Foi utilizado uma distância para a ligação entre os átomos de carbono de $1.424 \AA$. A célula unitária obtida é mostrada na figura (4.1).

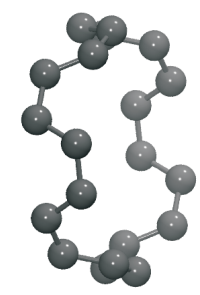

(a)

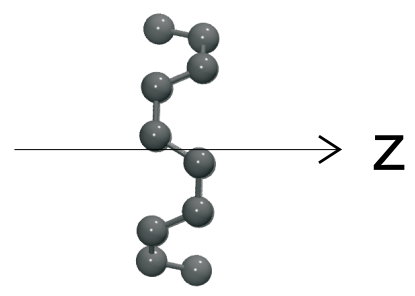

(b)

Figura 4.1: Célula unitária do nanotubo de carbono armchair $(5,5)$. (a) Vista em perspectiva da célula unitária; $(b)$ Vista lateral da célula unitária, onde o eixo indicado na figura por $z$ é o eixo de crescimento do nanotubo.

Foram realizados cálculos de energia total baseados em DFT, utilizando a aproximação GGA [63] para o termo de troca e correlação, com pseudopotenciais ultra-suaves [71]. Foi utilizada uma base em ondas planas até uma energia de corte de 286.74eV, implementado no código computacional VASP [72, 73]. Utilizamos o esquema de Monkhorst e Pack [74] para o sampling de pontos $k$, com $1 \times 1 \times 21$ para mapear a zona de Brillouin da célula unitária. Para o critério de força foi utilizado $2.5 \times 10^{-3} \mathrm{eV} / \AA$ e foi permitido que todos os átomos relaxassem.

Para a determinação do parâmetro de rede, o tamanho da caixa utilizada foi de $17.88 \AA$ nas direções $x$ e $y$, com $11 \AA$ de vácuo, para evitar que as imagens periódicas interajam entre si nessas direções. Variamos o comprimento em $z$ até encontrar o valor que minimiza a energia do sistema, conforme observamos na 
figura (4.2).

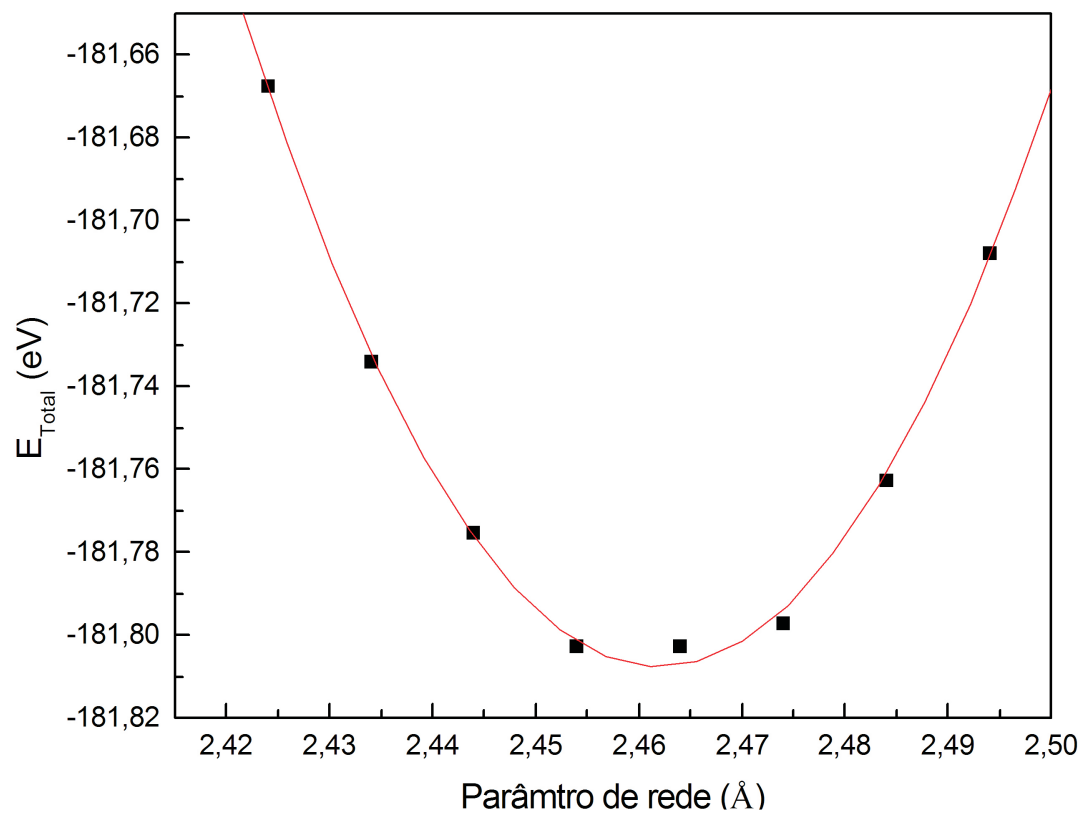

Figura 4.2: Parâmetro de rede do nanotubo de carbono armchair $(5,5)$.

Conforme a figura (4.2), o parâmetro de rede encontrado para este SWCNT foi de $2.464 \AA$ A O comprimento encontrado para a ligação entre os átomos de carbono foi encontrado como sendo $1.424 \AA$, que está em ótima concordância com o que é observado através de experimentos Raman, que é de $1.42 \AA$ [75].

Seguindo esta idéia de caracterizar o sistema primitivo, levantamos a sua estrutura de bandas e densidade de estados. As bandas de energia foram calculadas com 127 pontos $k$ na direção $\Gamma \rightarrow X$ da zona de Brillouin. A seguir temos a estrutura de bandas e densidade de estados calculadas para este nanotubo em questão, figura (4.3). 


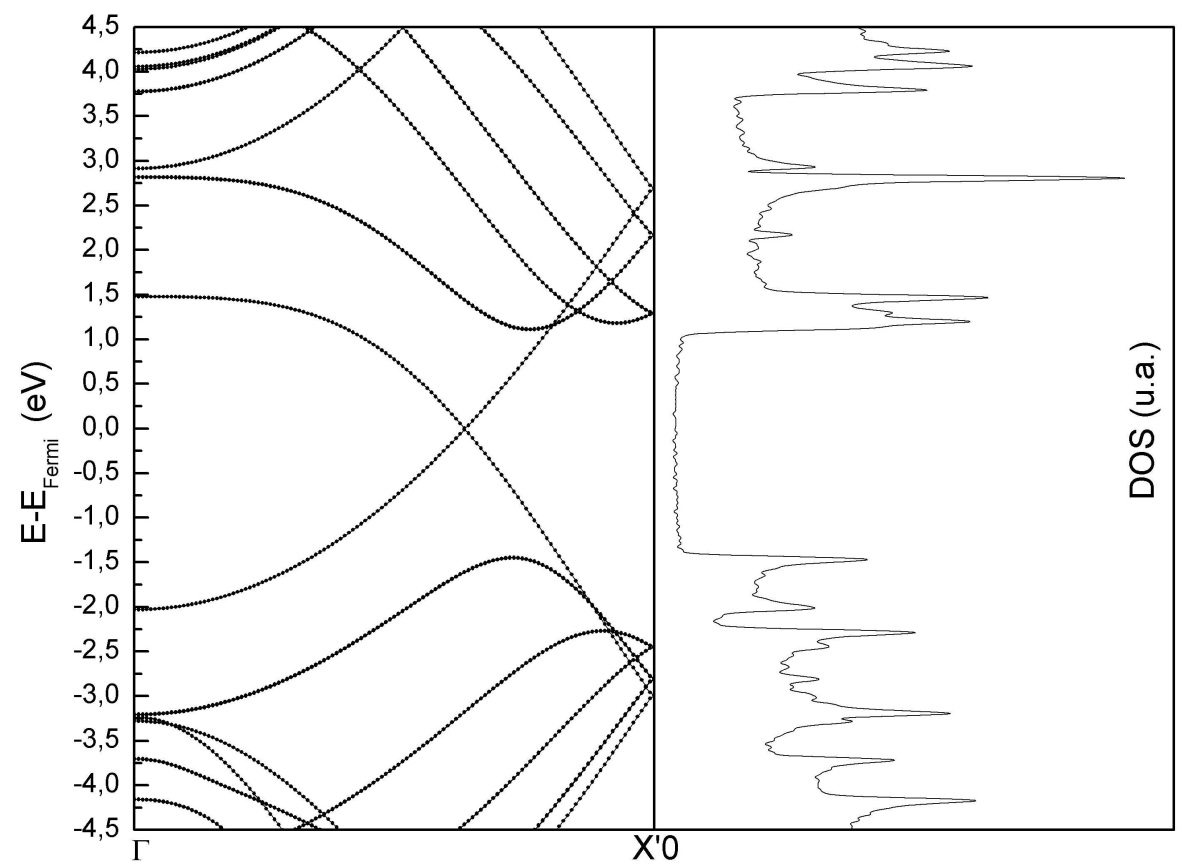

Figura 4.3: Bandas de energia e densidade de estados para o nanotubo de carbono armchair $(5,5)$. Do lado esquerdo da figura temos as bandas de energia e do lado direito a densidade de estados.

Olhando para essa estrutura de bandas e densidade de estados, nós podemos observar claramente o caráter metálico deste nanotubo, como já era de se esperar [76]. Nota se nesta figura, que as duas bandas ao redor do nível de Fermi não são degeneradas, enquanto que as outras são duplamente degeneradas. As bandas cruzam o nível de Fermi em $k=\frac{2 \pi}{3}$.

Tendo isto, o próximo passo na caracterização do nosso sistema puro, é obter as propriedades de transporte eletrônico. Para isso, realizamos cálculos via funções de Green que considera um sistema aberto onde a simetria translacional é quebrada e os efeitos dos eletrodos são levados em conta em termos das suas autoenergias $[66,77,78]$. Neste método a DFT é utilizada como uma teoria de campo 
médio, já que os auto-valores e as auto-funções de Kohn-Sham são consideradas como as funções de onda e os auto-valores do sistema real. O software utilizado foi o TRANSAMPA [66], desenvolvido pelo próprio grupo de pesquisa e é baseado no SIESTA [79].

Dessa maneira, calculamos a função transmissão para o nosso sistema puro, que é dada pelo gráfico (4.4),
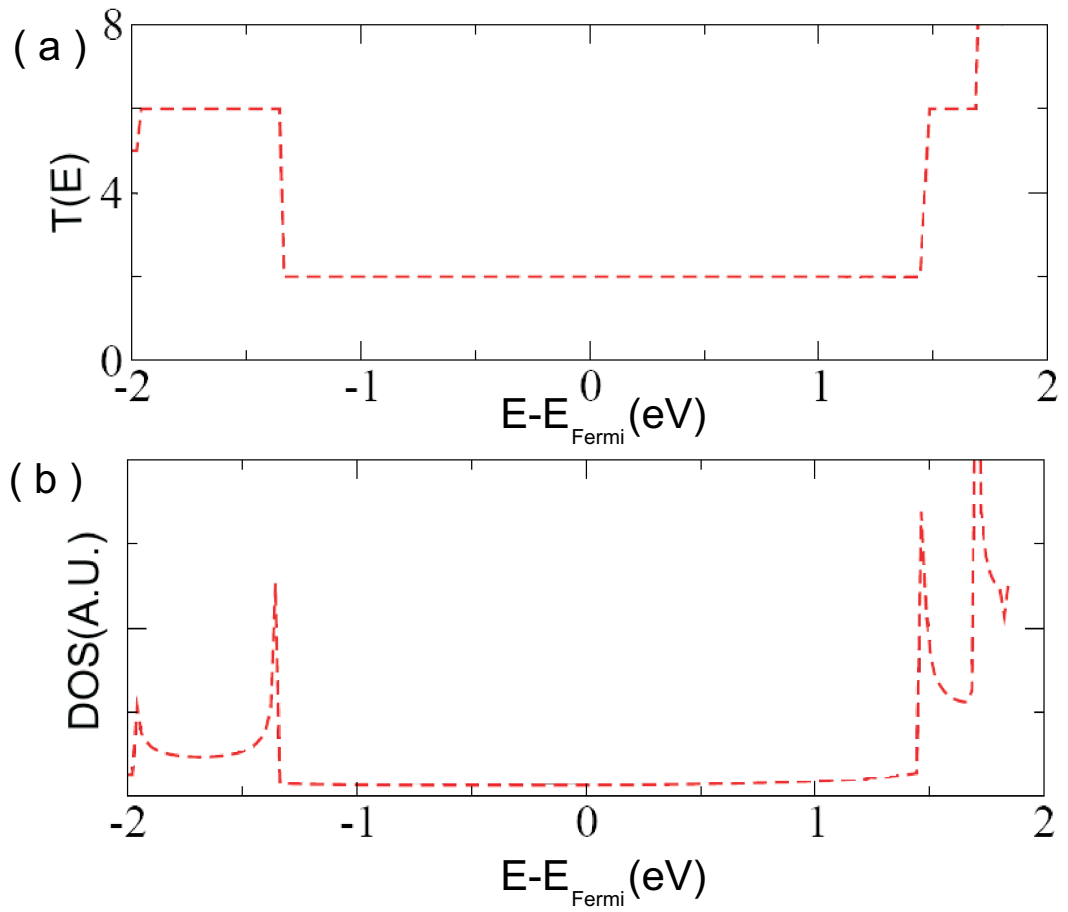

Figura 4.4: (a) Coeficiente de transmissão e (b) densidade de estados calculados para o sistema puro utilizando o método de funções de funções de Green.

A partir desses gráficos, podemos observar novamente através das duas figuras $(a)$ e $(b)$ o caráter metálico do sistema. A densidade de estados, calculada para o sistema puro com o método de funções de Green é idêntica à calculada com condições periódicas de contorno. Determinamos também o coeficiente de 
transmissão do nanotubo, nas vizinhanças do nível de Fermi, que é $2 G_{0}$.

Agora que caracterizamos todos os parâmetros importantes do sistema puro, passaremos para os resultados quando adicionamos o defeito. 


\section{Capítulo 5}

\section{Resultados - Monovacância}

Como um primeiro resultado, apresentaremos o processo de formação da monovacância no nanotubo de carbono armchair, evidenciando qual reconstrução é de mais baixa energia através da observação da sua energia de formação.

\subsection{Formação da Monovacância}

Primeiramente, antes de estudar as propriedades dos nanotubos de carbono com uma monovacância, vamos tentar entender o seu processo de formação. Olhando para a figura (5.1), temos:

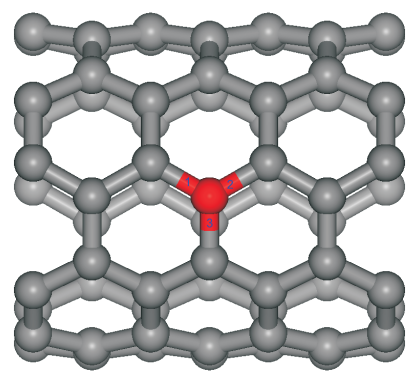

Figura 5.1: Nanotubo de Carbono $(5,5)$ - Armchair - Puro. O átomo de carbono em vermelho evidencia qual será retirado para a formação da monovacância. Os índices 1,2 e 3, identificam as suas ligações. 
Para criar a monovacância, nós retiramos um átomo de carbono do nanotubo - átomo em vermelho da figura (5.1) que a princípio pode ser escolhido aleatoriamente. Quando retiramos o átomo em vermelho da figura (5.1), nós obtemos a seguinte estrutura:

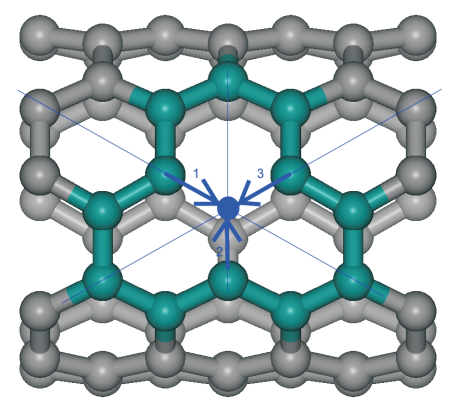

Figura 5.2: Nanotubo de Carbono $(5,5)$ - Armchair - Mono-vacância não relaxada.

As ligações 1, 2 e 3, da figura (5.1) possuem 2 elétrons. Quando retiramos o átomo (vermelho) e criamos uma vacância, fica 1 elétron desemparelhado em cada átomo que estava ligado com o átomo retirado. Estes elétrons são representados pelas setas 1, 2 e 3 na figura (5.2). Cada orbital pode se ligar com qualquer um dos dois adjacentes, fornecendo três possíveis recombinações. Podemos ter a ligação do orbital 1 com o 2, do 2 com o 3 e do 1 com o 3. Estas estruturas são representadas na figura (5.3):

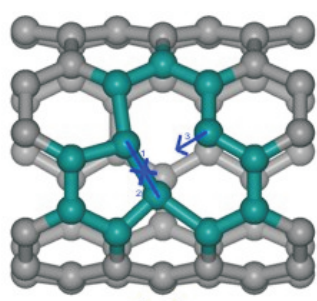

(a)

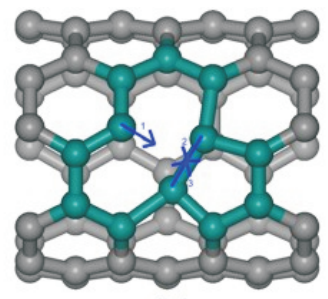

(b)

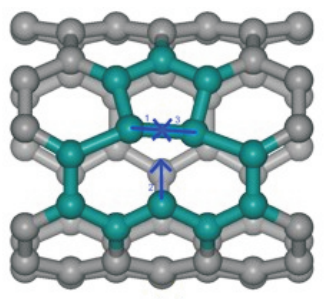

(c)

Figura 5.3: Nanotubos de Carbono $(5,5)$ - Armchair - Monovacâncias. 
Os sistemas $(a)$ e $(b)$ possuem a vacância inclinada em relação ao eixo do nanotubo, que quando tratada isoladamente, as duas são equivalentes, ou seja, são independentes da sua orientação. O sistema $(c)$ possui a vacância paralela ao eixo do nanotubo.

A primeira análise a fazer, é determinar qual dessas configurações é mais favorável. Basta observar a energia de formação de cada tipo - inclinada ou paralela. Foram realizados cálculos de energia total baseados em DFT utilizando a aproximação GGA [63], com pseudopotenciais ultra-suaves [71]. Foi utilizado uma base em ondas planas até uma energia de corte de $286.74 \mathrm{eV}$, implementado no código computacional VASP $[72,73]$. Para estudar a reconstrução preferencial utilizamos um nanotubo de carbono armchair $(5,5)$, na aproximação de supercélula. O sistema puro possui 140 átomos e o sistema com a monovacância 139, o que corresponde a 7 repetições da célula unitária. Foi utilizado o esquema de Monkhorst e Pack [74] para o sampling de pontos $k$, com $1 \times 1 \times 5$ na direção de crescimento do nanotubo. Todas as estruturas foram completamente relaxadas até atingir o critério de força de $2.5 \times 10^{-3} \mathrm{eV} / \AA$. As estruturas obtidas, completamente relaxadas são mostradas na figura (5.4).

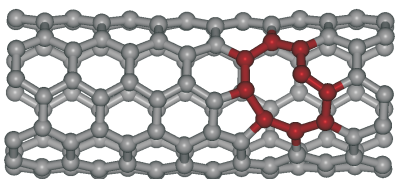

(a)

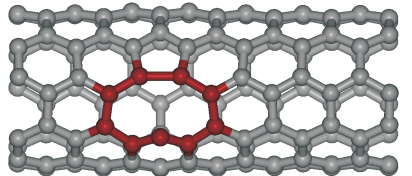

(b)

Figura 5.4: (a) Nanotubo de carbono mais monovacância. 
Realizados os cálculos de energia total, definimos a energia de formação de cada sistema, que é dada pela seguinte equação,

$$
E_{\text {For }}=E_{\text {Mono }}+E_{\text {Puro }}-\mu_{c}
$$

onde $E_{M o n o}$ é a energia total do sistema com o defeito, $E_{P \text { Pro }}$ é a energia total do sistema puro e $\mu_{c}$ é o potencial químico do carbono.

Os valores obtidos para a energia de formação foram de $5.65 \mathrm{eV}^{1}$ para o sistema do tipo (a) e (b) da figura (5.3) e $6.97 \mathrm{eV}$ para o sistema do tipo (c) da figura (5.3), onde a partir disso, concluímos que a reconstrução preferencial é a dos tipos (a) e (b), por possuírem energia de formação mais baixa.

Para observar isso de outra maneira, podemos olhar para a seguinte figura (5.5).

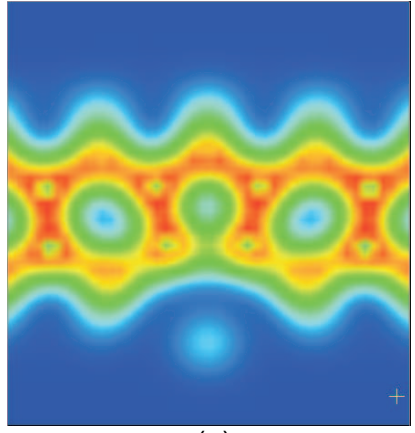

(a)

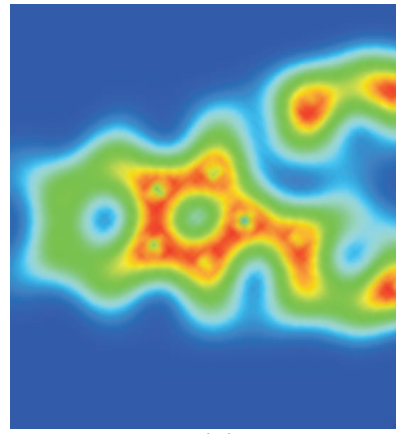

(b)

Figura 5.5: (a) Plano de Carga - Nanotubo de carbono (5,5) - Armchair - Configuração menos estável. (b) Plano de Carga - Nanotubo de carbono $(5,5)$ - Armchair - Configuração mais estável.

A partir da figura (5.5), nós observamos que a ligação do pentágono que se

\footnotetext{
${ }^{1}$ Este valor obtido está em boa concordância com outros valores presentes na literatura, conforme obtido na referência [70].
} 
forma na reconstrução $(a)$ é mais fraca do que a presente em $(b)$, mostrando novamente que o sistema preferencial é o formado pela monovacância inclinada. Concluímos que a reconstrução preferencial do sistema, ou seja, de energia de formação mais baixa, é quando a ligação nova, proveniente do pentágono, preserva alguma orientação das ligações presentes no nanotubo puro.

Dessa forma, com já sabemos qual a orientação da monovacância é preferencial no nanotubo de carbono, passamos agora ao estudo sistemático deste defeito, onde iniciaremos pela análise da energética dos sistemas.

\subsection{Energia de Formação das Monovacâncias}

Primeiramente, iremos analisar a energia de formação, dos sistemas nanotubo de carbono mais monovacâncias variando-se o número de células unitárias. Nesse estudo, variamos o número de células unitárias de 2 a 12, relaxando primeiramente o sistema puro e depois retirando um átomo do sistema puro para se criar a monovacância. Os cálculos de energia total foram realizados todos com o mesmo procedimento descrito na seção (5.1).

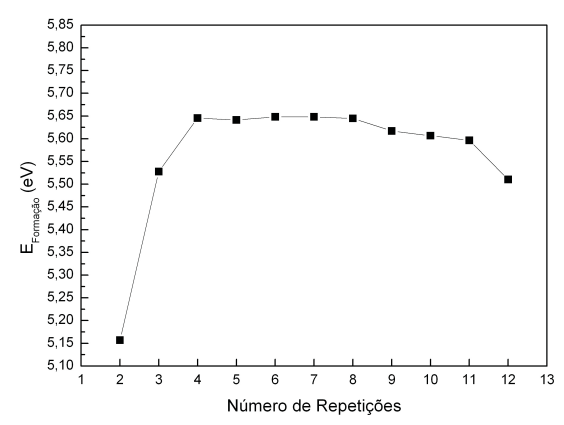

Figura 5.6: Energia de formação das monovacâncias. 
Olhando para este gráfico de uma maneira mais detalhada, podemos determinar algumas regiões e obter algumas conclusões a respeito do nosso sistema.

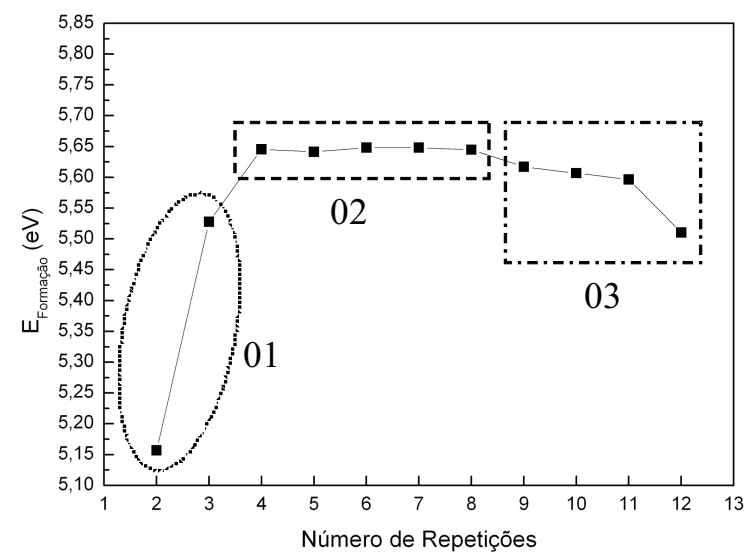

Figura 5.7: Energia de formação da mono-vacância para o nanotubo de carbono $(5,5)$ armchair - em função do número de repetições da célula unitária - aumento da distância vacância-vacância.

Na região 01, a energia de formação varia muito, pois possuímos praticamente uma vacância do lado da outra, sendo assim, a interação tanto da estrutura geométrica, quanto na estrutura eletrônica, é muito alta, exercendo uma grande influência na energia de formação do sistema. Na região 02, observamos um patamar na energia de formação onde isso pode ser uma evidência da baixa interação de uma vacância com a outra. Na região 03, a energia de formação começa a cair, onde isso pode ocorrer devido à diminuição da interação eletrostática de uma vacância com a outra somada a uma relaxação elástica da rede.

Vamos primeiro começar a entender a relaxação elástica da rede. Ela pode ser vista quando fazemos uma comparação entre qual foi o deslocamento dos átomos 
quando ocorre a reconstrução do sistema com o defeito. Para isso, tomamos a diferença entre as posições dos átomos do sistema na presença do defeito com os átomos correspondentes no sistema puro. Para ficar mais claro, podemos olhar para a figura (5.8).

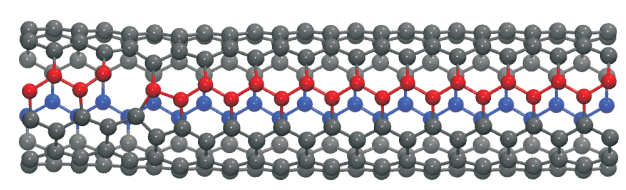

( a )

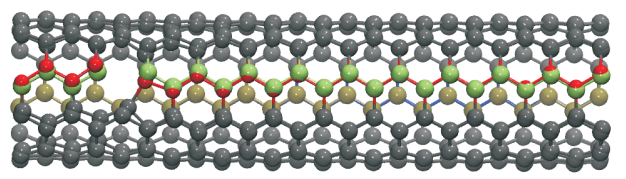

(c)

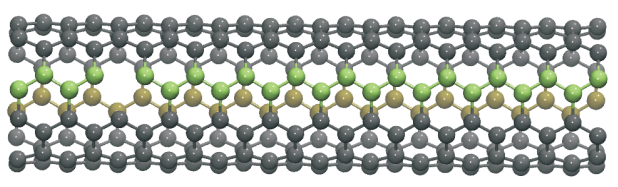

( b )

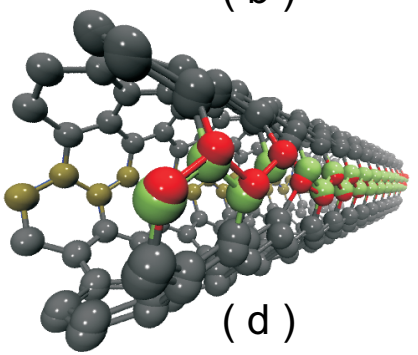

Figura 5.8: Nanotubo de carbono (12 células unitárias): (a)monovacância reconstruída, (b) puro com o átomo que cria a monovacância retirado; Superposição do nanotubo puro com o nanotubo com a monovacância, (c) vista lateral e (d) vista em perspectiva. As linhas coloridas nas figuras representam os átomos que será feita a comparação das distâncias.

Na figura (5.8-a) temos o sistema já reconstruído. Os átomos em vermelho representam os que estão na mesma linha do átomo do dangling bond e os em azul são os que estão na parede do lado oposto, onde a influência do defeito na geometria acredita-se ser menor. Em (5.8-b) temos o sistema puro, onde os átomos em verde representam a mesma linha de átomos em vermelho em $(a)$ e em bege são os correspondentes aos em azul. Na figura (5.8-c e d) temos o sistema com o defeito e puro superpostos para que fique mais claro a relaxação do sistema. Feito isso, calculamos quanto que cada átomo se movimenta depois da reconstrução. O 
resultado disso está na figura (5.9).

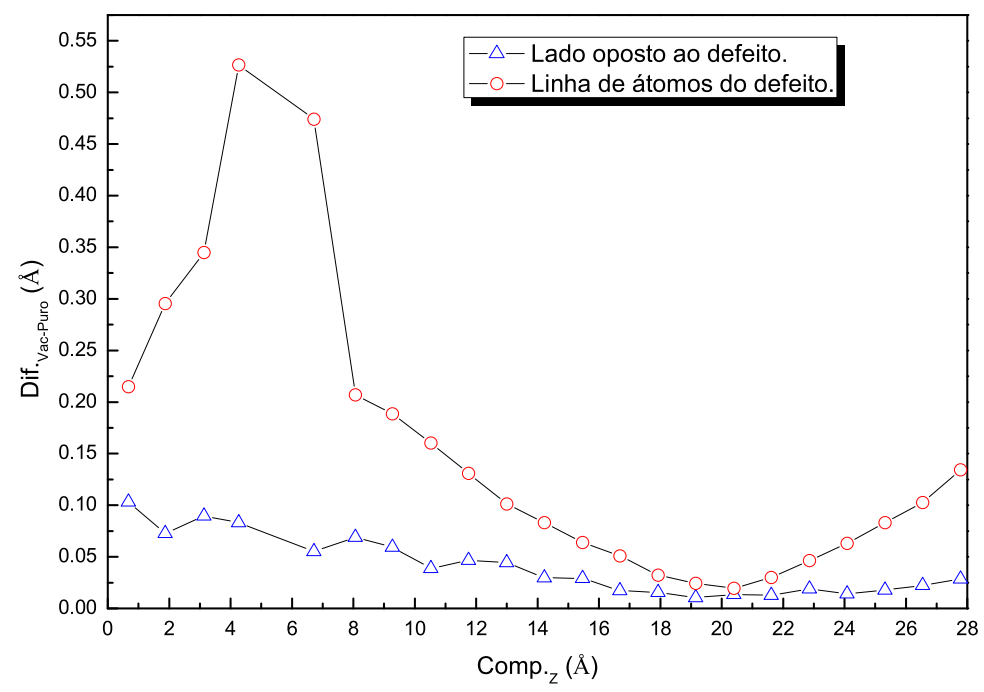

Figura 5.9: Distância entre os átomos do sistema puro e do sistema com o defeito, conforme explicado na figura (5.8)(Nanotubo com 12 células unitárias).

Como já era de se esperar, podemos observar da figura (5.9), que os átomos perto do defeito movimentam-se muito da posição original no sistema puro. Observamos também, que longe do defeito, a uma distância de $20.5 \AA$, os átomos na linha do defeito quase não se movimentam mais. Olhando para a movimentação dos átomos no lado oposto ao defeito, podemos ver que mesmo estando na parede oposta à do defeito, os átomos na região perto do defeito ainda se movimentam um pouco, porém a influência do defeito em grande parte é desprezível, como podemos ver no gráfico da figura (5.9).

Agora, para entender o que chamamos de relaxação da rede e termos uma idéia da distância mínima onde essa interação passa a ser desprezível, tomamos os menores deslocamentos dos átomos na linha do defeito, para todas as estruturas 
que calculamos, ou seja, de 2 a 12 células unitárias. Abaixo temos esta figura.

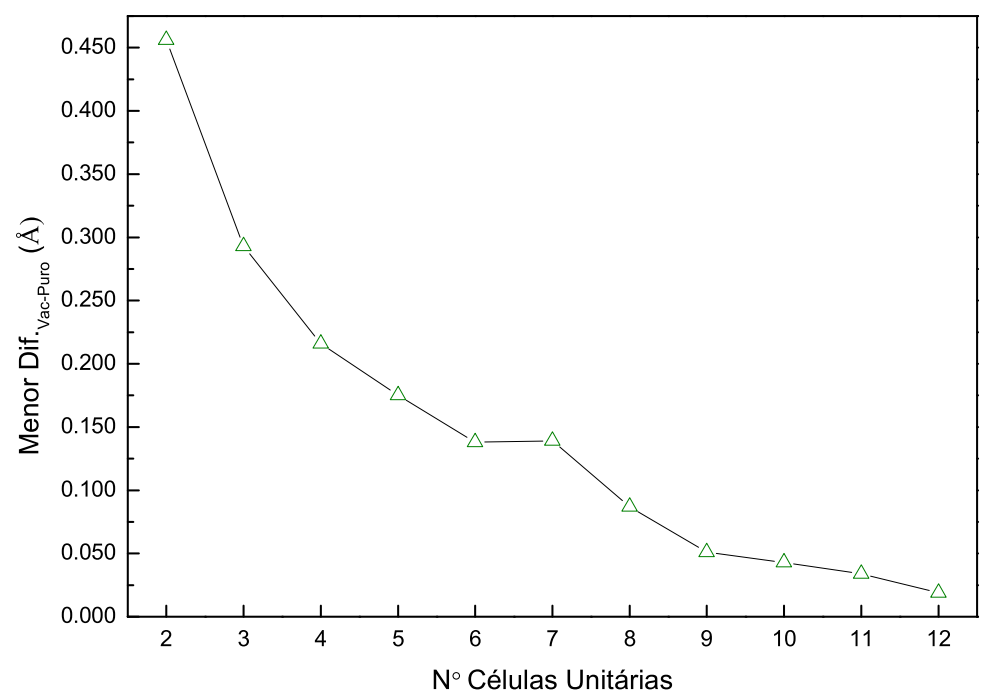

Figura 5.10: Menor deslocamento atômico na linha do dangling bond após a reconstrução do sistema.

Observando essa figura, nós temos também três regiões, onde podemos ter a mesma interpretação que a feita com a energia de formação. Mas o mais importante aqui, é notar que temos aquela redução na energia de formação, presente na região (3) da figura (5.7) pois a partir de 9 células unitárias, já temos uma região do sistema que pouco se movimenta no sistema relaxado, sendo por isso que chamamos relaxação da rede, ou seja, como os átomos em uma certa região se movimentam pouco, a energia adicionada devido ao stress da rede diminui, resultando na redução da energia de formação do sistema.

Com isso, já temos uma boa estimativa de qual é a distância mínima para que o defeito não interfira no restante do sistema, que é de 8 células unitárias ou $19.712 \AA$, onde os átomos se movimentam menos que $0.1 \AA$. Sendo assim, defi- 
nimos uma distância mínima para a interação do defeito com o restante da rede, no sentido da geometria do sistema, porém precisamos saber também qual é essa distância, com respeito à eletrônica do sistema, isto é, qual é a menor distância para que o potencial adicionado pelo defeito não interaja mais com a sua imagem periódica e com o restante do sistema. Isto será feito na seção (5.5).

\subsection{Bandas de Energia e Densidade de Estados}

Seguindo o nosso objetivo de estudar sistematicamente a influência da variação da densidade de defeitos no nanotubo de carbono, faremos agora a análise da estrutura eletrônica (densidade de estados e estrutura de bandas), variando-se a concentração dos defeitos.

As densidades de estados e estruturas de bandas dos sistemas que estudamos foram calculadas sob a luz da teoria do funcional da densidade implementadas no código VASP. Utilizamos condições periódicas de contorno, onde foi assumido um arranjo periódico das monovacâncias ao longo do nanotubo ${ }^{2}$. Em nossos cálculos utilizamos $286.74 \mathrm{eV}$ para a energia de corte, pseudopotenciais ultrasoft e uma aproximação GGA para o potencial de troca e correlação. Foi utilizado um sampling de 127 pontos $k$ na direção de crescimento do nanotubo, que corresponde às direções de alta simetria $\Gamma \rightarrow X$ na primeira zona de Brillouin.

A seguir, iremos mostrar na figura (5.11) as densidades de estados dos sistemas

\footnotetext{
${ }^{2}$ No caso do nanotubo de carbono com uma única monovacância na supercélula, o uso de condições periódicas de contorno implica que nós temos um sistema com os defeitos periodicamente espaçados.
} 
calculados (Gráficos fora de escala na DOS).
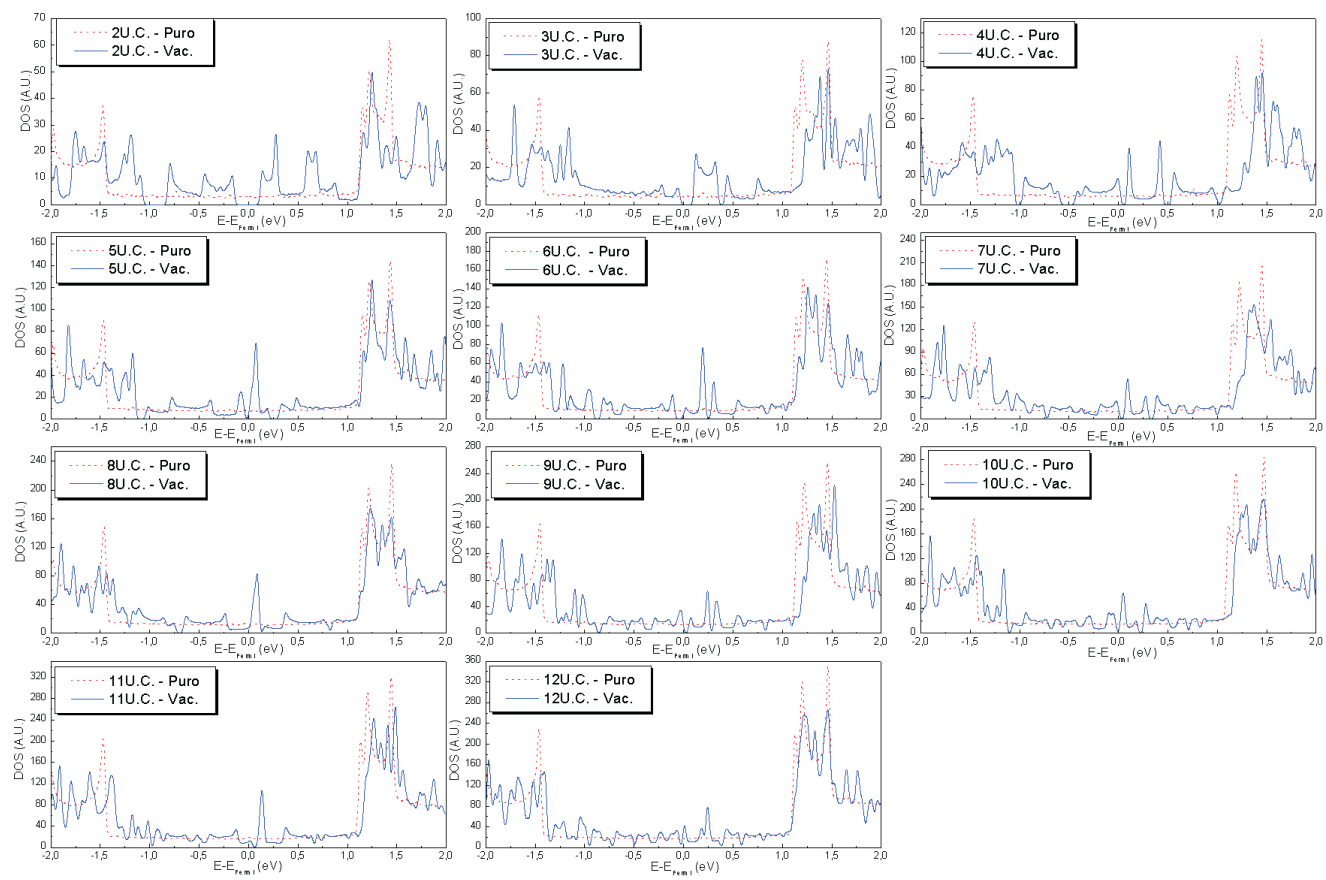

Figura 5.11: Densidade de estados dos sistemas nanotubo de carbono + monovacâncias, variando-se o número de células unitárias de 2 a 12.

Olhando para esses gráficos, podemos observar que todos eles, exceto os dos sistemas com 2, 3 e 4 células unitárias, apresentam um pico mais proeminente na região do nível de Fermi, sendo esse pertencente ao estado localizado no dangling bond proveniente da reconstrução de todo o sistema.

Os sistemas com 2, 3 e 4 células unitárias, não apresentam esse pico, pois a densidade de defeitos é grande e a interação entre um defeito e a sua imagem periódica perturbam de forma muito drástica a estrutura eletrônica desses sistemas. Para afirmarmos com certeza que o pico da DOS nos gráficos da figura (5.11) são devidos ao dangling bond, basta observarmos um gráfico de PDOS como o que 
temos na figura (5.12). A PDOS foi calculada para os átomos ao redor do defeito, conforme indicado na figura (5.12).

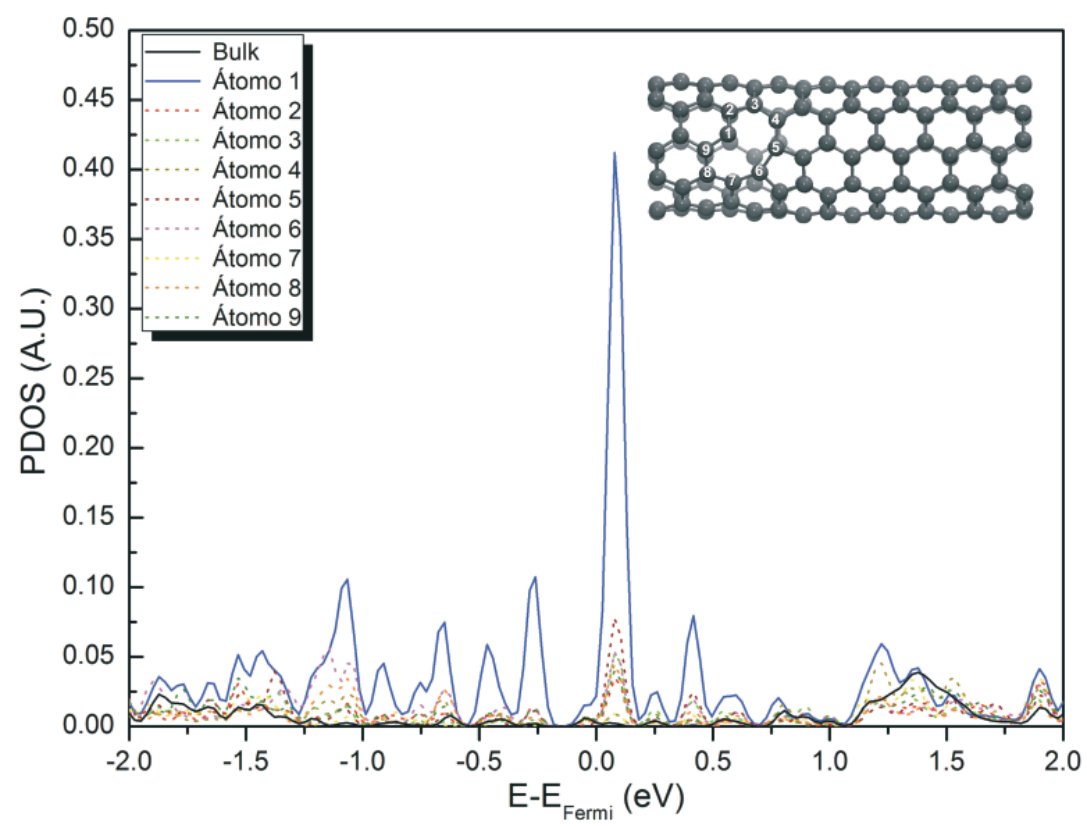

Figura 5.12: Densidade parcial de estados dos átomos de carbono ao redor do defeito em um nanotubo de carbono armchair $(5,5)$, calculada para um sistema com 8 células unitárias na aproximação de supercélula. Para o cálculo desta PDOS usamos o código VASP.

Reforçando a nossa afirmação de que o pico é devido ao átomo do DB, podemos observar o gráfico da densidade de estados projetada no átomo do DB e também um plot da densidade parcial de carga, figura (5.13), para o sistema da figura (5.12).Podemos observar também a partir da figura (5.13), que a $D B$ possui um caráter predominantemente $p$. 


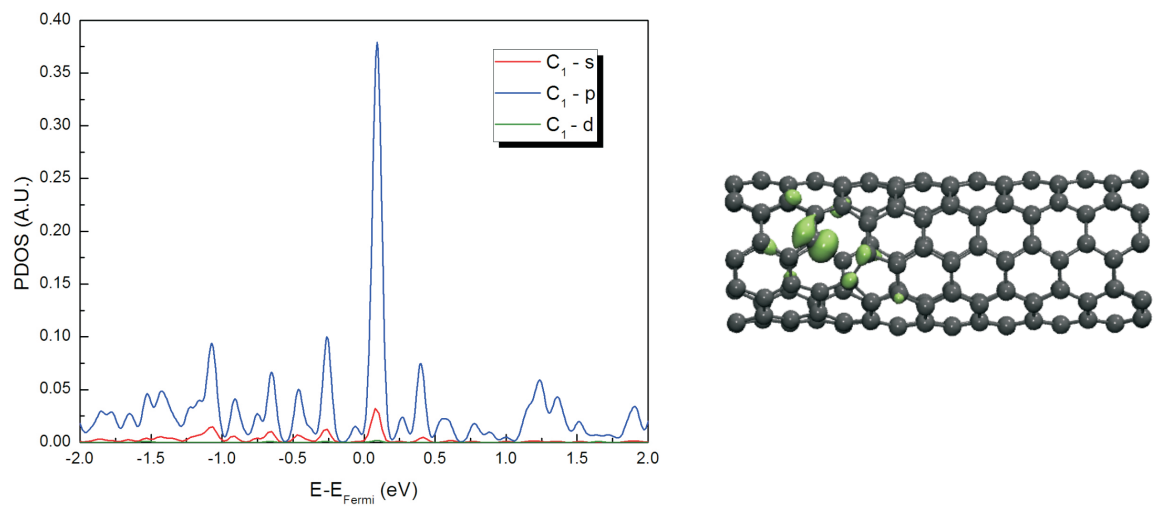

Figura 5.13: Densidade de estados projetada, no átomo da dangling-bond (átomo 1), para um nanotubo de carbono armchair $(5,5)$, calculada para um sistema com 8 células unitárias na aproximação de supercélula. Podemos observar ao lado, o plot da densidade de carga para essa energia.

Seguindo a nossa análise da estrutura eletrônica, olhando novamente para os gráficos das DOS, figura (5.11), observamos que a partir de 5 células unitárias, a DOS não apresenta nenhuma mudança significativa, o mesmo comportamento que a energia de formação apresentou. Todas apresentam o pico devido ao $D B$. Nós observamos também a presença em todas as DOS a perturbação devido ao defeito em todo o espectro de energia. Podemos ver isso, quando comparamos a DOS do sistema puro (linhas em vermelho tracejadas) com a DOS do sistema na presença do defeito (linhas preenchidas em azul).

Observando essa não mudança significativa das DOS, variando-se o número de células unitárias, podemos concluir parcialmente que a partir de 5 células unitárias um defeito praticamente não enxerga o outro, ou seja, a distância mínima para que um defeito não interaja com a sua imagem periódica é de $12.32 \AA$, mas isto ainda não é muito conclusivo, pois já observamos sa seção (5.2) a distância mínima 
para a interação estrutural é de 8 células unitárias. A assim é necessário um pouco mais de informação para que possamos chegar a essa distância mínima na parte eletrônica do sistema.

Retornando à nossa estrutura eletrônica, se realizarmos uma análise criteriosa do gráfico (5.11) e observando algumas estruturas de bandas, figura (5.14), nós podemos ver o surgimento de mini-gaps na densidade de estados e estrutura de bandas.

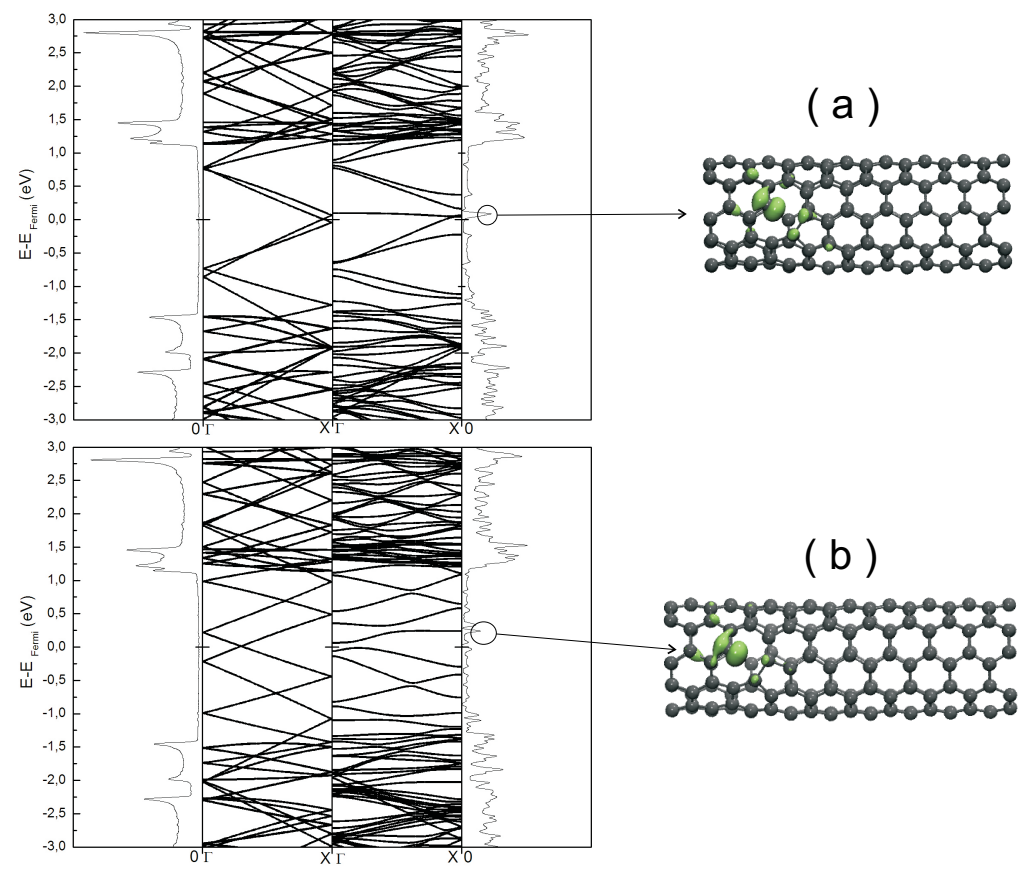

Figura 5.14: Bandas de energia, densidade de estados e plot de carga para os sistemas nanotubo de carbono mais monovacância com: (a) 8 células unitárias, (b) 9 células unitárias. As estruturas de bandas e DOS do lado esquerdo correspondem a do sistema puro e as do lado direito do sistema na presença do defeito. Os plots de carga apresentados são correspondentes à energia do pico da DOS e possuem isosuperfícies de $0.04 e / B o h r^{3}$, $0.01 e / B o h r^{3}$ respectivamente.

Os mini-gaps que aparecem nessas estruturas ocorrem pois no nosso caso o uso de condições periódicas de contorno, implica que temos um sistema com de- 
feitos periodicamente espaçados. Enquanto que a Hamiltoniana do sistema está muito bem escrita por esse método, o uso de condições periódicas de contorno nos leva a formação de uma banda de impureza, e no caso de um sistema metálico, ao surgimento de anti-cruzamentos na estrutura de bandas ${ }^{3}$.

Como a nossa sistemática de cálculo para esse sistema, nanotubo de carbono mais monovacância, foi sempre diminuir a densidade de vacâncias, é interessante sabermos qual o comportamento do sistema na presença de somente uma vacância, que é o que apresentaremos na seção seguinte.

\subsection{Densidade de Estados da Monovacância Isolada}

Se quisermos ir para limites de densidades muito baixas, ou como mencionado anteriormente saber qual o comportamento do sistema na presença de somente um defeito, temos que abrir mão do uso de condições periódicas de contorno, pois como também já foi dito, o uso de condições periódicas de contorno implica que temos um sistema com defeitos periodicamente espaçados, o que não é exatamente correto, pois enquanto que a Hamiltoniana desse sistema é muito bem descrita, o uso de condições periódicas de contorno nos leva a formação de bandas de impureza, e, no caso de um sistema metálico, ao surgimento de anti-cruzamentos na estrutura de bandas e mini-gaps na densidade de estados ${ }^{4}$.

Como agora nós queremos descrever um sistema na presença de somente uma monovacância, temos que descrever um sistema que não é periódico. Devemos

\footnotetext{
${ }^{3}$ Descreveremos melhor esses mini-gaps na seção (5.5).

${ }^{4}$ Artigo submetido à PRB.
} 
considerar um sistema aberto, ou seja, um nanotubo que apresente somente um defeito em toda a sua extensão.

Para isso, nós utilizamos o método descrito na seção de funções de Green, ou seja, utilizaremos funções de Green, onde o sistema consiste de uma região central onde se localiza o defeito, conectada por duas regiões semi-infinitas, conforme a figura (5.15).

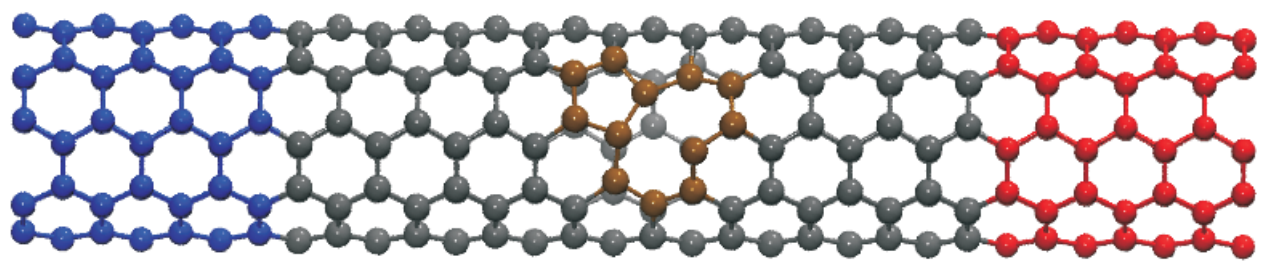

Figura 5.15: Esquema do sistema utilizado para o cálculo com funções de Green. A região em azul e vermelho são semi-infinitas.

Este mesmo sistema e método, é utilizado para calcular as propriedades de transporte do sistema, que apresentaremos na próxima seção.

A DOS desse sistema foi então calculada, utilizando a seguinte equação,

$$
\operatorname{DOS}(E)=\frac{1}{2 \pi} \operatorname{Tr}\left[\mathfrak{F} G_{S}(E) S_{S}\right]
$$

onde $G_{S}$ é a função de Green da região espalhadora na energia $E$ (região central) e é dada por,

$$
G_{S}(E)=\left[E S_{S}-H_{S}-\Sigma_{L}(E)-\Sigma_{R}(E)\right]^{-1}
$$

onde $H_{S}$ é a mesma Hamiltoniana utilizada no cálculo com condições periódicas de contorno.

A seguir, temos a DOS calculada para esse sistema, 


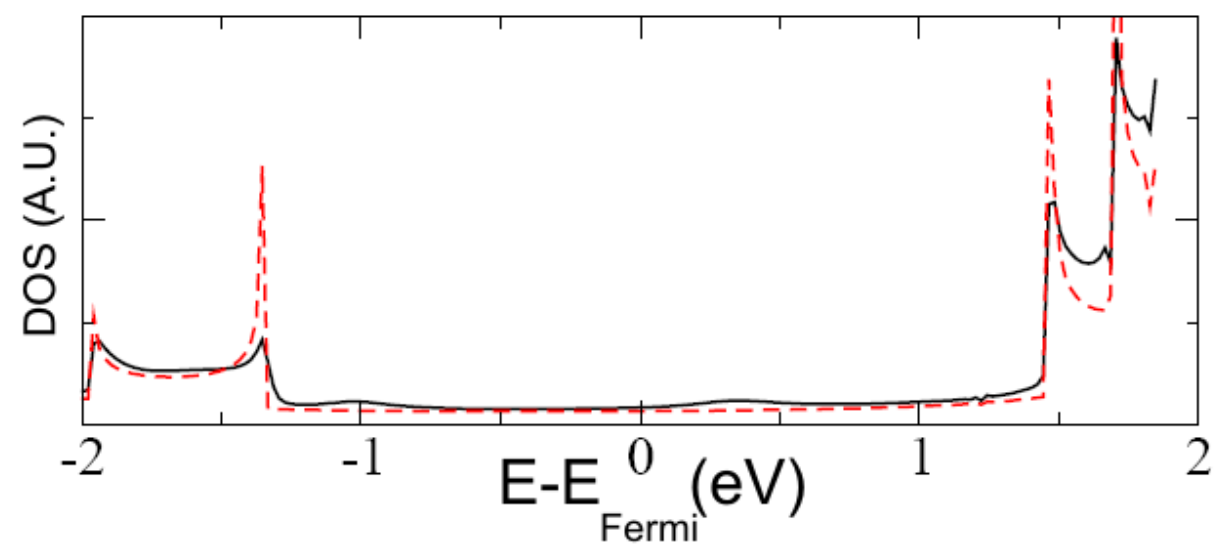

Figura 5.16: Densidade total de estados utilizando o método de funções de Green. Nós podemos notar aqui uma variação muito sensível perto da energia da dangling bond. Nesta imagem temos a DOS do sistema puro (linhas tracejadas em vermelho) e do sistema com defeito (linha preenchida em preto) superpostas.

Podemos observar então, que a DOS calculada via funções de Green, possui uma assinatura muito mais suave da dangling bond e também não apresenta os mini-gaps presente nos cálculos com condições periódicas de contorno.

Da mesma maneira que fizemos para a DOS, podemos calcular a PDOS com funções de Green, onde esta é dada pela seguinte equação,

$$
P D O S_{\mu}(E)=\frac{1}{2 \pi} \mathfrak{F}\left[G_{S}(E) S_{S}\right]_{\mu \mu}
$$

onde agora cada elemento da diagonal da equação (5.2), representa a densidade de estados projetada em um certo orbital.

Assim, quando calculamos a PDOS usando esse método, equação (5.4), os três picos da PDOS calculada com condições periódicas de contorno, figure (5.12), 
fundem-se em somente um ao redor de $100 \mathrm{meV}$ acima do nível de Fermi, figura (5.17). Nós podemos observar também que a densidade de estados projetada calculada dessa maneira é muito mais suave, quando comparada com a calculada via condições periódicas de contorno.

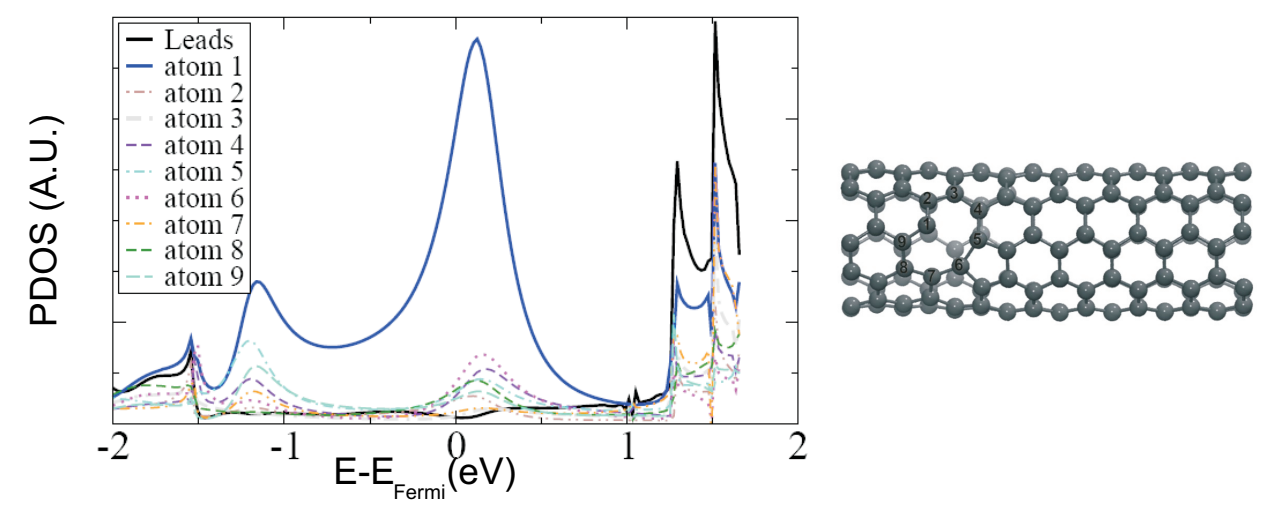

Figura 5.17: Densidade parcial de estados ao redor do defeito para um sistema aberto, calculada via funções de Green.

Dessa maneira, a análise baseada somente na densidade de estados calculada com condições periódicas de contorno pode ser um pouco equivocada. Devemos tomar cuidado em dizer que o sistema se torna isolante, quando observamos a abertura de um gap perto do nível de Fermi, como vimos em algumas densidades de estados da figura (5.11).

A origem dessas oscilações e mini-gap's na DOS e na PDOS, surge devido ao uso de condições periódicas de contorno, onde é introduzido um potencial periódico espalhador devido ao defeito [2]. Sendo assim, precisamos entender um pouco melhor sobre o efeito desse potencial introduzido, onde dedicaremos a próxima seção para essa finalidade. 


\subsection{Potencial das Monovacâncias}

Vamos analisar agora qual a influência do potencial inserido pelas monovacâncias. Para obter esse potencial, quando realizamos o cálculo da relaxação do sistema, nós obtivemos a partir do código VASP um arquivo que contém o potencial eletrostático em $e V$. O potencial que estudaremos em questão é uma média do potencial em $x$ e $y$ variando-se em $z$. Abaixo temos um gráfico que mostra a forma dos potenciais do sistema puro na presença da monovacância, figura 5.18.
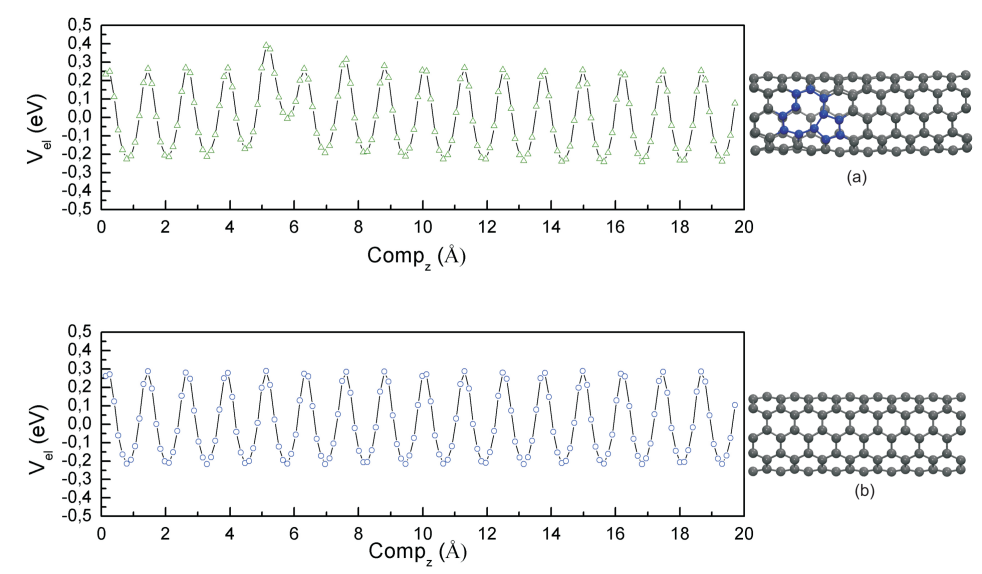

Figura 5.18: Potencial eletrostático característico de um nanotubo de carbono: (a) Potencial do sistema nanotubo mais monovacância; (b) Potencial do sistema nanotubo puro.

Dessa maneira, para entender qual é a contribuição somente do potencial inserido pelas monovacâncias, nós realizamos a diferença entre o potencial do sistema na presença do defeito e do puro. Fazendo isso, nós podemos estabelecer um critério para determinar um comprimento mínimo em que o potencial inserido pelo defeito irá deixar de perturbar o restante do sistema, complementando a análise que fizemos a partir da energia de formação e a partir da estrutura 
eletrônica (DOS e bandas). Sendo assim, temos abaixo os seguintes gráficos dos potenciais em função do número de células unitárias, ou seja, distanciando um defeito do outro.
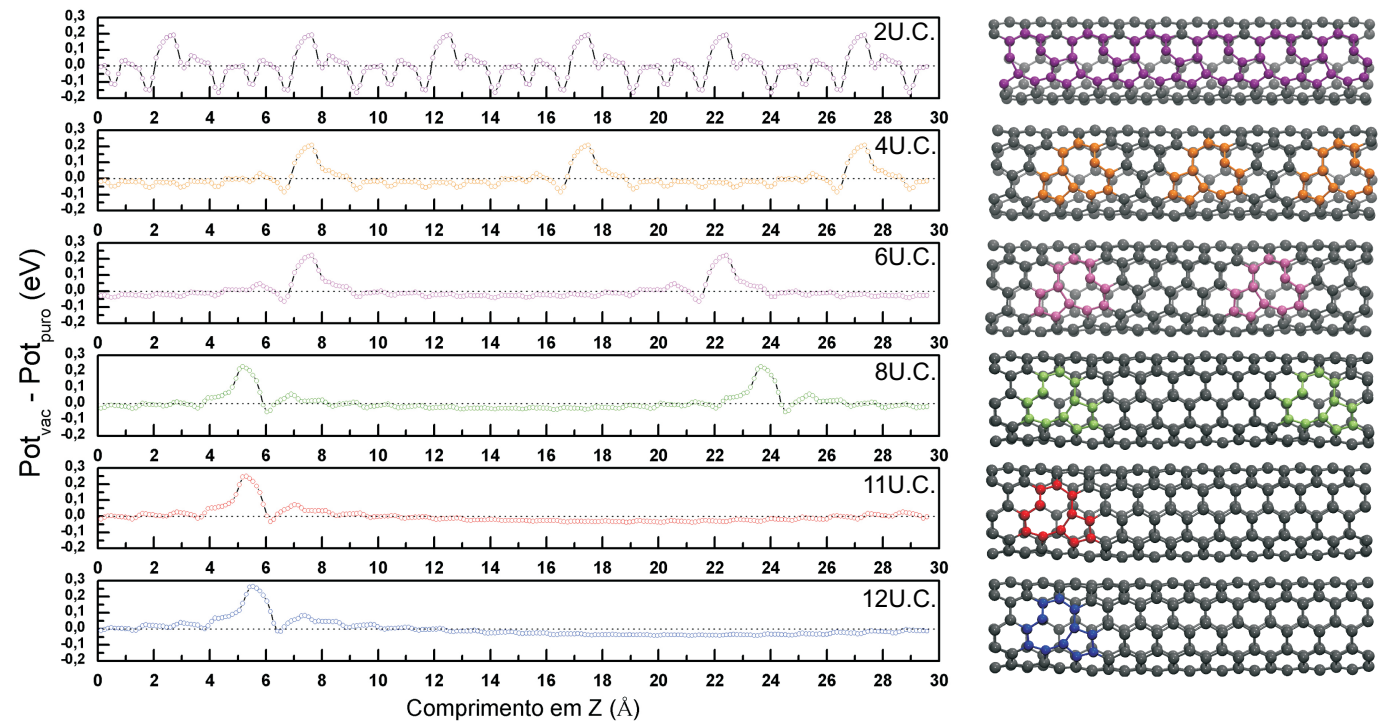

Figura 5.19: Diferença entre o potencial do sistema na presença das monovacâncias e do sistema puro, variando-se a distância entre um defeito e outro.

Observando esses gráficos, podemos ver claramente o potencial que é inserido pelo defeito no sistema e qual a propagação da sua perturbação. Se olharmos para o potencial de $2 U . C$. vemos claramente que a perturbação é muito grande, um defeito está praticamente do lado do outro, dessa maneira a influência desse potencial na estrutura eletrônica (DOS e bandas de energia) é muito grande, como podemos ver na figura (5.20). 


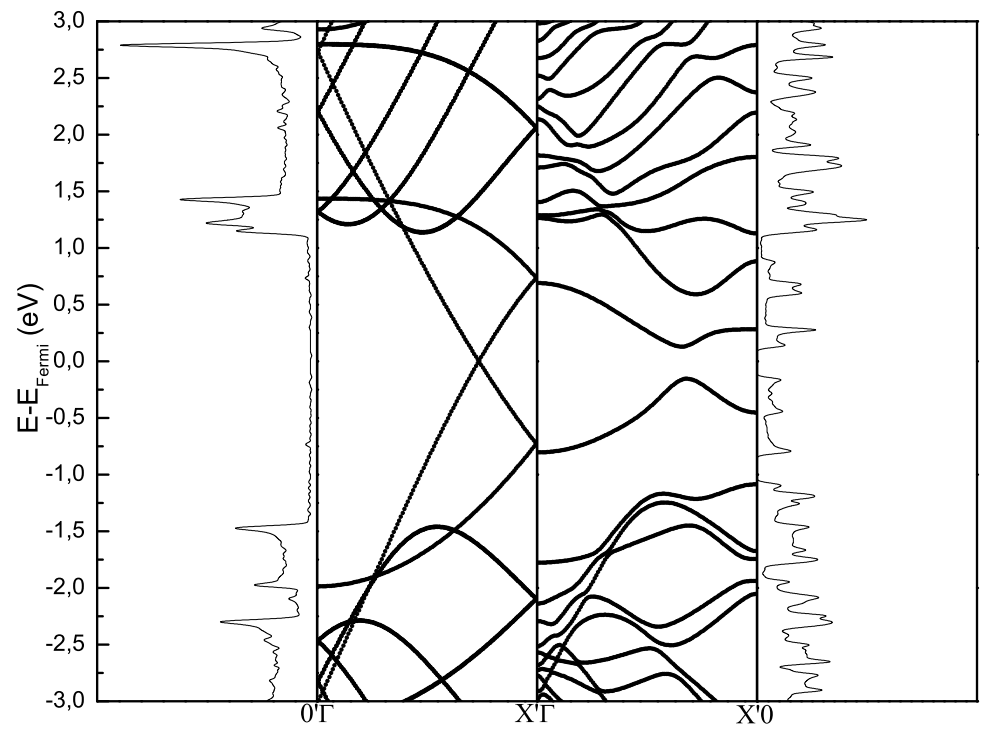

Figura 5.20: Densidade de estados e bandas de energia para o sistema nanotubo de carbono + monovacância, com um defeito a cada 2U.C.. Do lado esquerdo da figura temos a DOS e as bandas do sistema puro e do lado direito temos as bandas e a DOS do sistema com o defeito.

Quando aumentamos o número de células unitárias no sistema, distanciamos um defeito do outro, diminuindo dessa maneira a interação de um defeito com a sua imagem periódica. Podemos ver isso claramente, quando olhamos para a figura (5.19) nos gráficos das diferenças de potencial dos sistemas de $6,8,11$ e 12 células unitárias. Nesses sistemas fica claro que a partir de uma distância de $14.784 \AA ̊$, que corresponde a 6 células unitárias, um defeito praticamente não interage um com o outro, dessa maneira a perturbação do potencial inserido no sistema pelo defeito é minimizada. Podemos ver isso, olhando para as bandas e a DOS do sistema com 8U.C., figura (5.21). 


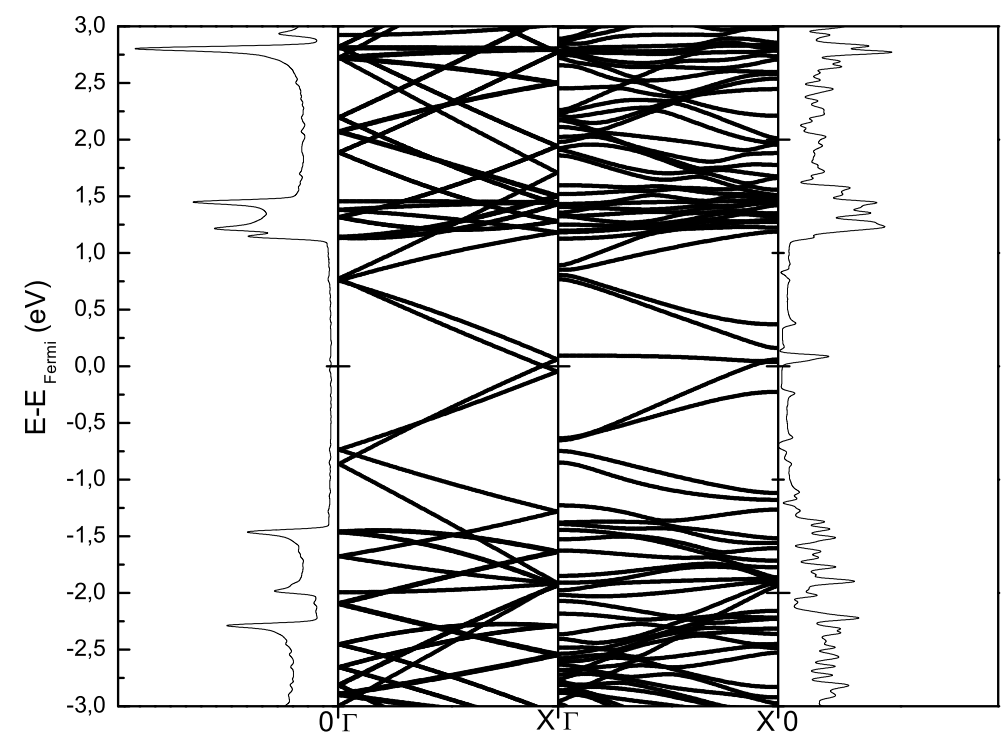

Figura 5.21: Densidade de estados e bandas de energia para o sistema nanotubo de carbono + monovacância, com um defeito a cada $8 U$.C.. Do lado esquerdo da figura temos a DOS e as bandas do sistema puro e do lado direito temos as bandas e a DOS do sistema com o defeito.

Fazendo uma comparação direta entre a estrutura de bandas do tubo puro (lado esquerdo da figura (5.21)) com as bandas do tubo com defeito (lado direito da figura (5.21)), nós observamos que as faixas de energia ao redor do nível de Fermi são muito semelhantes umas com as outras, onde temos o surgimento de um estado flat acima do nível de Fermi, que é devido ao DB presente no sistema reconstruído e identificado também na DOS desse sistema. Observamos também a presença de mini-gaps que surgem nos limites da zona de Brillouin devido à inserção de um potencial periódico do defeito [2].

Para melhorar o entendimento dessas aberturas de mini-gap's, podemos recor- 
dar da física do estado sólido [2], onde quando temos a presença de um potencial periódico $U(\mathbf{r})$, a expansão desse potencial em ondas planas, irá conter somente ondas planas com a periodicidade da rede e conseqüentemente vetores de onda que são vetores da rede recíproca, ou seja,

$$
U(\mathbf{r})=\sum_{\mathbf{K}} U_{\mathbf{K}} e^{i \mathbf{K} \cdot \mathbf{r}}
$$

onde $U_{\mathbf{K}}$ são os coeficientes de Fourier, que são relacionados com $U(\mathbf{r})$ por,

$$
U_{\mathbf{K}}=\frac{1}{v} \int_{\text {cell }} d \mathbf{r} e^{-i \mathbf{K} \cdot \mathbf{r}} U(\mathbf{r})
$$

Posto isso e sabendo que a adição desse potencial periódico determina uma abertura de $2\left|U_{\mathbf{k}}\right|$ das bandas de energia nos limites da zona de Brillouin, como podemos observar na figura (5.22), calcularemos este efeito para nossos sistemas.

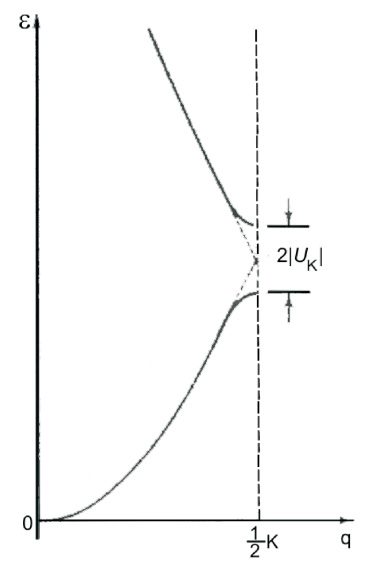

Figura 5.22: Plot de uma banda de energia genérica para um q paralelo à $\mathbf{K}$. Quando $\mathbf{q}=\frac{1}{2} \mathbf{K}$ as duas bandas são separadas por um bag de magnitude $2\left|U_{K}\right|$. As linhas pontilhadas são correspondentes ao sistema sem a presença desse potencial periódico. [2]

Sabendo dessas implicações da adição do potencial periódico no sistema, cal- 
culamos a transformada de Fourier para os nossos sistemas na presença do defeito onde obtivemos esse coeficiente de Fourier no ponto $\Gamma$. Dessa maneira podemos analisar a abertura das bandas dos nossos sistemas. Assim, temos o seguinte gráfico,
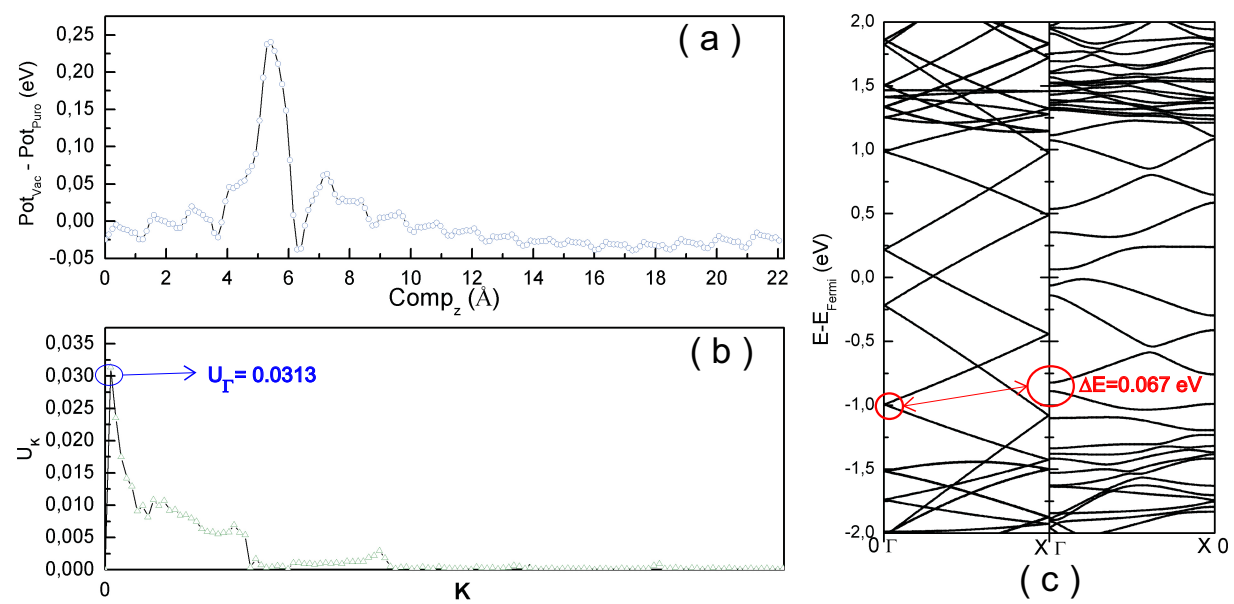

Figura 5.23: (a) Diferença entre o potencial do sistema com defeito e com o sistema puro para um nanotubo de carbono com 9 células unitárias; (b) Transformada de Fourier da diferença de potencial presente em (a), onde o coeficiente de Fourier $U_{\Gamma}=0.0313$; (c) Bandas de energia para o sistema nanotubo de carbono com 9 células unitárias, onde do lado esquerdo temos as bandas do sistema puro e do lado direito as bandas para o sistema com a monovacância.

Olhando para o gráfico da figura (5.23-(b)) podemos obter o coeficiente de Fourier no ponto $\Gamma$, para a diferença de potencial presente na figura (5.23-b). O valor obtido é de $U_{\Gamma}=0.0313$, dessa maneira, conforme demonstrado na figura (5.22), a separação das bandas de energia no ponto $\Gamma$, é dada por $\Delta E=$ $2\left|U_{\Gamma}\right| \mathrm{eV}=0.0626 \mathrm{eV}$. O valor obtido através da nossa estrutura de bandas, é de $\Delta E=0.067 \mathrm{eV}$, o que está em boa concordância com o que calculamos com a transformada de Fourier. 


\subsection{Propriedades de Transporte das Monovacâncias}

Feito todas as análises anteriores com respeito às características eletrônicas do sistema nanotubo de carbono mais monovacância, falta ainda estudarmos as propriedades de transporte eletrônico. Para isso utilizamos o método de funções de Green fora do equilíbrio, que considera um sistema aberto onde a simetria translacional é quebrada e os efeitos dos eletrodos são levados em conta em termos das auto-energias $[66,77,78]$. Para os cálculos das propriedades de transporte, foi seguido o esquema proposto por Caroli et al. [80].

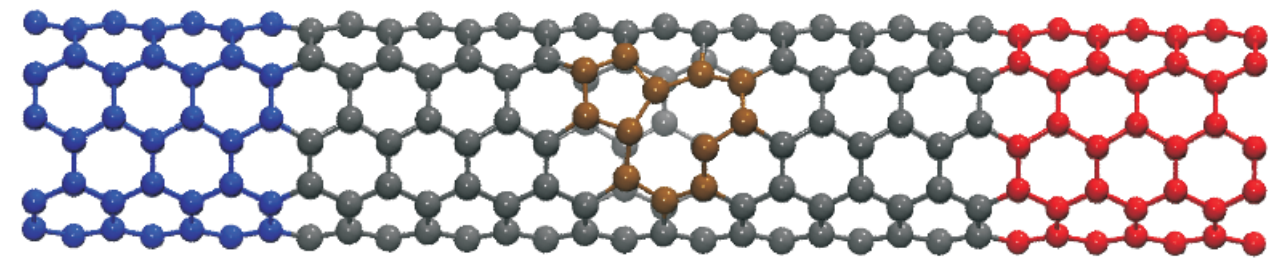

Figura 5.24: Esquema do sistema utilizado para o cálculo com funções de Green. A região em azul é o eletrodo esquerdo (fonte) e em vermelho é o eletrodo direito (dreno).

A figura (5.24) representa o setup utilizado tanto para o cálculo da DOS, como para o cálculo das propriedades de transporte. Esse sistema é dividido em três regiões fundamentais, que são os dois eletrodos semi-infinitos e uma região central de espalhamento. Essa região central de espalhamento foi definida da mesma maneira, quando utilizamos condições periódicas de contorno.

Resumidamente, o que estamos interessados agora é a função de Green na energia $E$ da região central de espalhamento, que é dada pela equação (5.3),

$$
G_{S}(E)=\left[E S_{S}-H_{S}-\Sigma_{L}(E)-\Sigma_{R}(E)\right]^{-1}
$$


onde $H_{S}$ e $S_{S}$ são as matrizes Hamiltoniana e de overlap para a região central de espalhamento, e $\Sigma_{L}(E)$ e $\Sigma_{R}(E)$ são as chamadas auto-energias do eletrodo esquerdo e direito, respectivamente.

Calculada essa função de Green, as propriedades de transporte do sistema são obtidas a partir da equação de Büttiker-Landauer [81],

$$
T(E)=\operatorname{Tr}\left[\Gamma_{L} G_{S} \Gamma_{R} G_{S}^{\dagger}\right]
$$

onde $\Gamma_{L / R}=i\left[\Sigma_{L / R}-\Sigma_{L / R}^{\dagger}\right]$ é a taxa em que os elétrons são espalhados para dentro ou para fora do nanotubo de carbono.

Assim, utilizando essas equações, a transmissão total para esse sistema é dada pela figura (5.25).

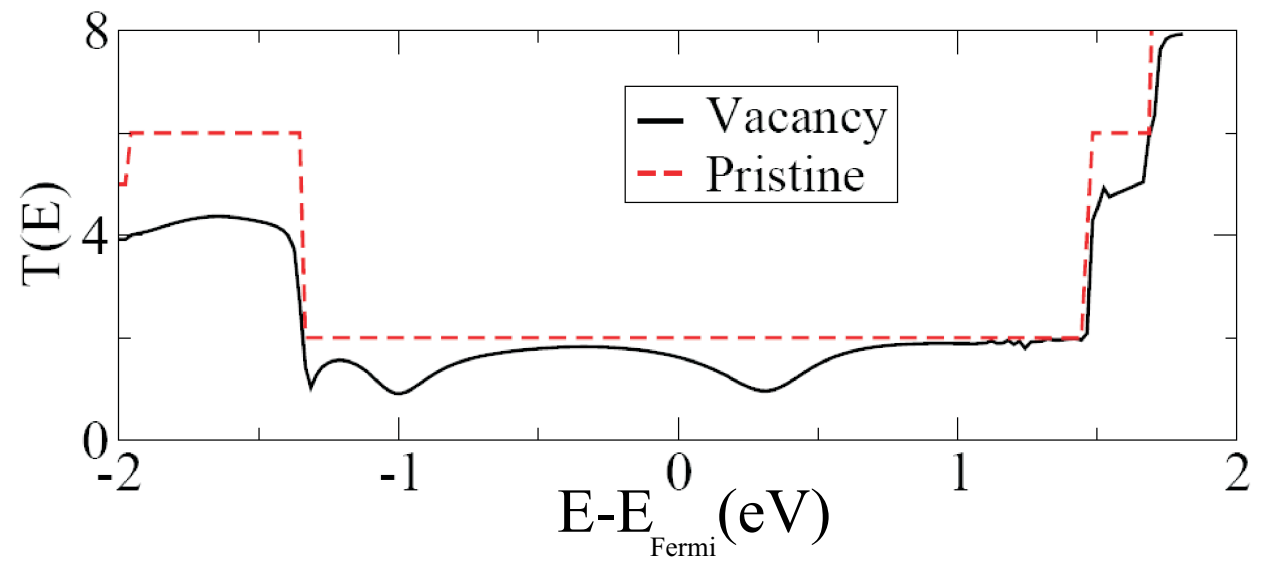

Figura 5.25: Coeficiente de transmissão total para o sistema puro em linha vermelha tracejada e para a monovacância em linha preta preenchida.

Nós podemos notar aqui que temos uma queda na transmitância do sistema em $250 \mathrm{meV}$ acima do nível de Fermi e em $1 \mathrm{eV}$ abaixo do nível de Fermi, enquanto que a condutância no nível de fermi é de $1.6 G_{0}$. Essas quedas na transmitância 
são devidas ao espalhamento no dangling bond do sistema, porém, mesmo com a presença do defeito, nosso sistema ainda continua apresentando o seu caráter metálico.

Terminamos aqui as nossas considerações sobre as propriedades eletrônicas do sistema, restando agora uma última análise com respeito à mobilidade da monovacância no nanotubo de carbono.

\subsection{Mobilidade da Monovacância}

Para estudarmos a mobilidade das monovacâncias nos nanotubos de carbono, precisamos determinar qual a barreira de migração da monovacância de um sítio para outro. Da literatura [70], temos:

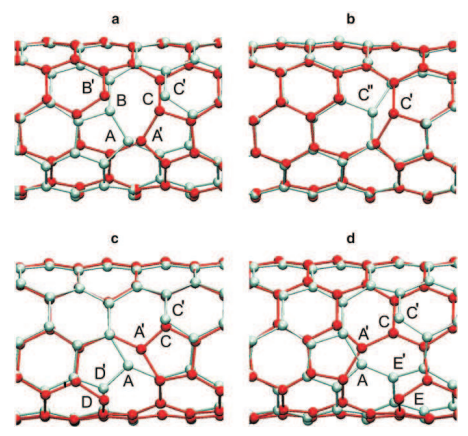

Figura 5.26: Migração da monovacância. (a) Troca horizontal do átomo da dangling bond do átomo B para o C. O átomo A se move ao longo do eixo do tubo. (b) Migração horizontal do átomo C. (c) Migração diagonal do átomo C. (d) Troca vertical do átomo da dangling bond do átomo B para o átomo C. O átomo A se move perpendicular ao eixo do tubo.

Estas migrações foram calculadas por Krasheninnikov et al., onde a menor barreira de migração é dada pelo processo $(b)$, com uma barreira de $0.52 \mathrm{eV}$ para o nanotubo $(4,4)$. Sendo assim, calculamos esta barreira para o nosso nanotubo 
de carbono, o $(5,5)$, utilizando a maneira de migração dada em (b).

Para calcular essa barreira, realizamos cálculos de primeiros princípios das estruturas iniciais e finais, implementadas no código VASP [72,73], que usa um conjunto de ondas planas como base, foi utilizados pseudopotenciais ultrasoft e utilizamos a aproximação GGA para o termo de troca e correlação. Para o cálculo da barreira de migração, foi utilizado o método NEB (nudge elastic band method) [82].

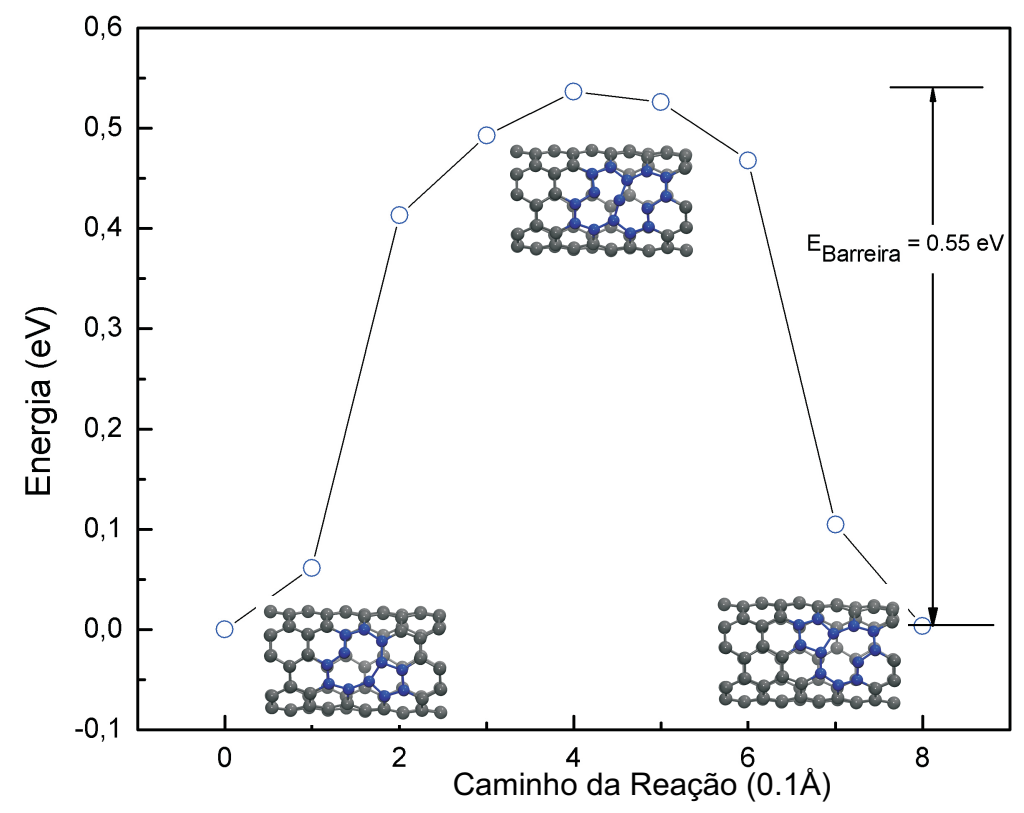

Figura 5.27: Barreira de migração da monovacância. Na figura, em (a) temos o estado inicial, em (b) o estado de transição e em (c) o estado final.

Conforme a figura (5.27), nós encontramos uma barreira de migração de $0.55 \mathrm{eV}$ para o nanotubo de carbono $(5,5)$, o que está em boa concordância com a literatura, pois Krasheninnikov et al. [70] reporta que quanto menor a curvatura do sistema, a barreira de migração aumenta o seu valor. 
De posse desse valor, podemos calcular qual é o tempo de transição da monovacância nesse sistema, onde este é dado por,

$$
\tau=\frac{1}{\Gamma}=10^{-13} e^{\frac{E_{\text {barr }}}{k_{B} T}}
$$

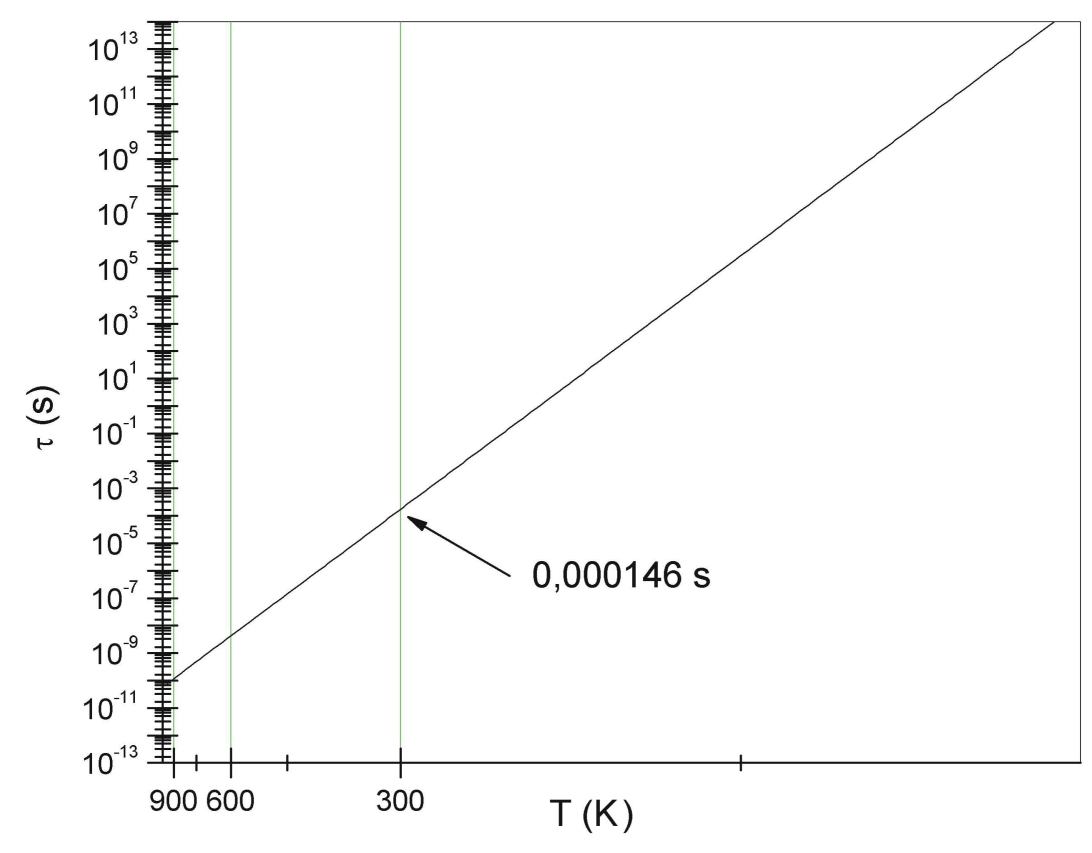

Figura 5.28: Tempo de transição da monovacância no nanotubo de carbono em função da temperatura.

A partir desse gráfico, nós obtivemos que à temperatura ambiente, uma monovacância leva um tempo de $0.146 \mathrm{~ms}$ para transitar de um sítio a outro, onde devido a isso ela pode ser considerada como um defeito que apresenta uma mobilidade muito grande. Essa grande mobilidade da monovacância pode gerar duas coisas. Primeiro, as monovacâncias podem caminhar rapidamente após a sua formação, para as extremidades dos nanotubos e se perderem, restando somente o nanotubo 
puro, onde esse pode ser um dos motivos pelo qual não se tem até hoje uma imagem de tal defeito em nanotubos de carbono. Segundo, essas monovacâncias podem se encontrar durante o movimento, formando clusters de monovacâncias ou defeitos maiores, como di-tri-..entre outros defeitos maiores. Assim, devido a essa segunda implicação, que dedicaremos os nossos próximos resultados, que é o estudo das multivacâncias.

\subsection{Conclusões - Monovacâncias}

Como nada na ciência experimental está livre de defeitos e imperfeições, até mesmo a ciência experimental dos nanotubos, sendo ela fina e muito precisa, também ocorrem defeitos. Quando se cresce os nanotubos de carbono, eles não estão livres dos defeitos, quando se estuda os nanotubos, criam-se defeitos. Logo, como estes sistemas nanoestruturados vem despertando ao longo dos anos um interesse muito grande tanto na nanociência quando à possíveis aplicações tecnológicas, só há duas saídas para o uso de tais nanoestruturas. Ou aprendemos a fabricá-las sem nenhum tipo de defeito, ou entendemos muito bem quais as suas propriedades na presença deles. Esta última, é a proposta dessa dissertação de mestrado.

Até o presente momento, fizemos uma análise sistemática do defeito mais simples possível, que é a retirada de um átomo do nanotubo de carbono. Este defeito é muito simples, porém a riqueza de fenômenos que acontecem é muito grande. Sendo assim, nós procuramos estudar tais sistemas, de uma maneira sistemática, através de cálculos ab initio as propriedades estruturais e eletrônicas desse de- 
feito. Determinamos qual seria o tipo mais estável, a sua influência na estrutura eletrônica, nas propriedades de transporte, na relaxação do sistema, entre outros.

Os principais resultados encontrados para esse sistema foram os seguintes:

1. A monovacância reconstrói-se preferencialmente na direção inclinada ao eixo do nanotubo de carbono. Nessa direção ela possui uma energia de formação $\approx 5.64 \mathrm{eV}$ e na direção paralela ao eixo ela possui uma energia de formação de $\approx 6.97 e V$ (Cálculos feitos com 7 células unitárias).

2. A energia de formação da monovacância no sistema nanotubo de carbono armchair $(5,5)$ possui uma variação expressiva, quando se aumenta a distância entre um defeito e outro. Com 2 células ela possui $E_{\text {form }} \approx 5.15 \mathrm{eV}$ subindo para um patamar de aproximadamente $5.65 \mathrm{eV}$ em uma região de 4 a 8 células unitárias, e depois caindo suavemente para $\approx 5.50 \mathrm{eV}$ em 12 células unitárias.

3. A partir de 8 células unitárias, já temos a presença no sistema de uma região do nanotubo que quase não sofre influência do defeito na sua relaxação. Por exemplo, um átomo no nanotubo a uma distância $19.712 \AA$ do defeito, quando o sistema relaxa, ele se movimenta por volta de $0.07 \AA ̊$, o que é uma distância muito pequena.

4. A partir de 5 células unitárias, todas as densidade de estados do sistema (calculadas com condições periódicas de contorno), na presença do defeito, apresentam o mesmo comportamento, onde há o surgimento de um pico, 
acima do nível de Fermi, que é proveniente do dangling bond resultante da reconstrução do sistema.

5. Através das diferenças das distâncias das reconstruções dos sistemas, concluímos que a partir de $19.712 \AA$ a propagação da relaxação estrutural do sistema é praticamente desprezível.

6. Através das diferenças dos potenciais adicionados pelo defeito, concluímos que a partir de $14.784 \AA$ um defeito praticamente não interage eletrônicamente com o outro.

7. A queda na energia de formação do sistema a partir de 8 células unitárias, é devido a uma relaxação estrutural da rede.

8. O uso de condições periódicas de contorno, acarreta no surgimento de minigaps na densidade de estados, que são resultantes da adição de um potencial periódico pelo defeito.

9. Foi demonstrado, que através de cálculos de funções de Green, que considera um sistema aberto, que esses mini-gaps não são observados.

10. A condutância do sistema na presença da monovacância, apresenta uma queda em $-1 \mathrm{eV}$ e em $+250 \mathrm{eV}$. A condutância no nível de Fermi é de $1.6 G_{0}$.

11. Estimamos o valor da barreira de migração com um valor de $0.55 \mathrm{eV}$, onde esta nos fornece um tempo aproximado de $\approx 0.16 \mathrm{~ms}$ a uma temperatura 
de $300 K$ para a migração do defeito de um sítio para outro. A partir disso concluímos que a monovacância é um sistema muito móvel, sendo essa característica responsável, ou pela não detecção de tais defeitos até hoje no tubo $^{5}$, ou pela formação de defeitos maiores, como as divacâncias.

Como perspectivas, para a continuidade deste trabalho, é interessante estudar as propriedades magnéticas destes defeitos, utilizando-se dessa mesma sistemática.

A realização de cálculos de Monte Carlo Cinético, pode nos fornecer o entendimento da evolução de tais defeitos no nanotubo.

\footnotetext{
${ }^{5}$ Não foi encontrada nenhuma referência ou evidência experimental desse defeito (monovacância) na literatura que estudamos.
} 


\section{Capítulo 6}

\section{Resultados - Multivacâncias}

Experimentalmente, o único tipo de multivacância de nosso conhecimento que é observada até hoje em nanotubos de carbono, é a divacância. Seguindo a nossa motivação e sabendo que a monovacância é móvel, onde a uma temperatura de $300 \mathrm{~K}$ ela demora por volta de $0.146 \mathrm{~ms}$ para saltar de um sítio a outro, pode haver várias dessas em um nanotubo onde elas poderão ocasionalmente se encontrar e reconstruírem-se em outras maiores, conforme citado no artigo de Saito, M., et al. [83]. Sendo assim, há uma possibilidade de que ocorram multivacâncias nos nanotubos. Por isso, realizamos cálculos ab initio, baseados em DFT para estudar tais sistemas.

Apresentaremos aqui os resultados das multivacâncias, primeiro caracterizando separadamente cada sistema estudado, e depois em uma outra seção, iremos apresentar os resultados coletivos de todas as multivacâncias. 


\subsection{Sistemas Estudados}

As multivacâncias estudadas, algumas foram construídas a partir de algumas já presentes em bibliografias de materiais carbonosos, como o grafeno e nanotubos de carbono, e outras seguindo uma idéia de como elas seriam a partir do encontro de várias monovacâncias. As multivacâncias que estudamos são todas do tipo buraco, possívelmente formadas a partir do encontro de várias monovacâncias. Existem também muiltivacâncias que são em linha, porém iremos apresentar elas em um apêndice. Todos os defeitos estudados estão descritos na tabela abaixo, (6.1).

\begin{tabular}{c|c|c|c}
\hline \hline Nome do Defeito & $N^{\circ}$ de At. Ret. & Índice & $N^{\circ}$ Repetições \\
\hline \hline Monovacância & 1 & $59-1 \mathrm{DB}$ & 2 à 12 \\
\hline Divacância (1) & 2 & 585 & 8 \\
\hline Divacância (2) & 2 & 555567777 & 8 e 9 \\
\hline Trivacância (1) Inclinada & 3 & $5510-1 \mathrm{DB}$ & 5 e 8 \\
\hline Trivacância (2) Paralela & 3 & $5510-1 \mathrm{DB}$ & 5 e 8 \\
\hline Tetravacância & 4 & 5559 & 5 e 8 \\
\hline Pentavacância & 5 & $55511-1 \mathrm{DB}$ & 5 e 8 \\
\hline Hexavacância & 6 & 555510 & 5 e 8 \\
\hline \hline
\end{tabular}

Tabela 6.1: Multivacâncias estudadas. A coluna índice representa o número e a quantidade de vezes que o polígono resultante da reconstrução do sistema aparece, e a coluna repetições é correspondente ao número de células unitárias utilizadas no cálculo. Todos os sistemas foram utilizados o nanotubo de carbono armchair $(5,5)$.

Todos os sistemas acima, foram relaxados, realizando-se cálculos de energia total baseados em DFT [56, 59] utilizando a aproximação GGA [63] para o termo de troca e correlação, com pseudopotenciais ultra suaves [71] e utilizando uma base em ondas planas até uma energia de corte de $286.74 \mathrm{eV}$, implementado no 
código computacional VASP $[72,73]$. Foi utilizado o esquema de Monkhorst e Pack [74] para o sampling de pontos $k$, com $1 \times 1 \times 5$ para mapear a zona de Brillouin da célula unitária. Para o critério de força foi utilizado $2.5 \times 10^{-3} \mathrm{eV} / \AA$ e foi permitido que todos os átomos relaxassem.

Obtidas as geometrias, calculamos todas as propriedades que estudamos anteriormente para a monovacância, como densidade de estados, bandas de energia, transporte eletrônico, entre outros. Esses resultados serão apresentados nas seções a seguir.

\subsection{Divacâncias}

Seguindo trabalhos presentes na literatura, como Amorin et al. [32], sabemos da existência de dois tipos de divacâncias, como as estruturas da figura (6.1).

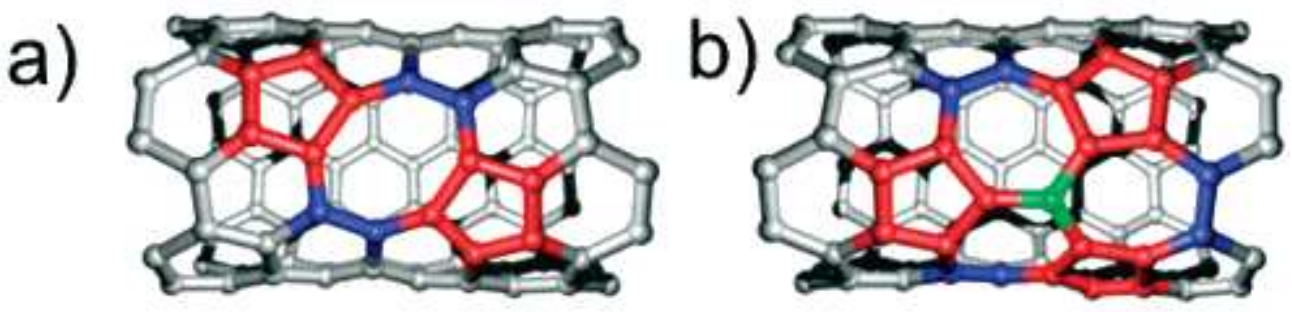

Figura 6.1: Divacâncias: (a) 585 e (b) 555777.

Na figura (6.1) nós temos os dois tipos de divacâncias reportados em artigos até hoje, sendo a do tipo 585 com energia de formação $4.1 \mathrm{eV}$ e a do tipo 555777 , que é formada a partir da rotação de uma ligação no defeito 585, possuindo energia de formação de $4.9 \mathrm{eV}$. Como a divacância 585 é a que possui energia de formação menor, tomamos ela como objeto de nosso estudo. Porém, durante o 
desenvolvimento do nosso estudo da divacância, percebemos a possibilidade de um novo tipo de defeito, que é formado pela rotação de duas ligações no defeito 585. Dessa maneira obtivemos a seguinte estrutura, figura (6.2).

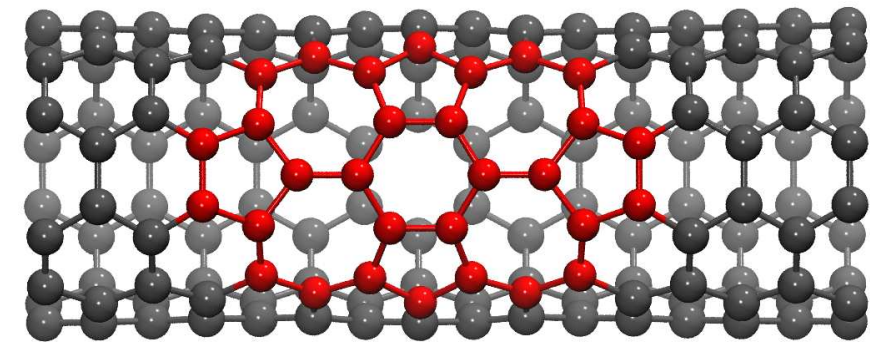

Figura 6.2: Nova divacância, obtida a partir de duas rotações de ligações da divacância 585 . Este novo defeito é indicado pelo nome de 555567777 , pois é formado por quatro pentágonos um hexágono e quatro heptágonos.

Estudamos o defeito 585 pois é o que possui energia de formação menor e também este novo defeito, o 555567777.

\subsubsection{Energia de Formação e Reconstrução para as Divacân- cias}

Primeiramente, iremos analisar a energia de formação, dos sistemas nanotubo de carbono mais divacâncias 585,555777 e $555567777^{1}$. Nesse estudo, utilizamos 8 células unitárias no cálculo do defeito 585,8 e 9 no defeito 555567777 e a partir da referência [32], obtivemos a energia de formação de 585 e 555777 com 9 células unitárias. Os cálculos de energia total foram realizados todos da mesma maneira como descrito na seção das monovacâncias. A seguir temos uma tabela,

\footnotetext{
${ }^{1}$ Para efeitos de comparação, alguns valores de energia de formação, os que não calculamos, foram obtido a partir da referência [32].
} 
(6.2.1), onde podemos observar os resultados da energia de formação para esses sistemas.

\begin{tabular}{ccc}
\hline \hline Tipo & Número de Células Unitárias & Energia de Formação (eV) \\
\hline 585 & 8 & 3.91 \\
585 & 9 & $3.90 *$ \\
555777 & 9 & $4.8 *$ \\
555565555 & 8 & 4.66 \\
555567777 & 9 & 4.56 \\
\hline \hline
\end{tabular}

Tabela 6.2: Energias de formação para as divacâncias. Resultados com o índice $*$ são obtidos a partir da referência [32].

A partir disso vemos claramente que a divacância 585 continua sendo o defeito com menor energia de formação, sendo mais favorável com respeito à 555567777 por $\approx 0.65 \mathrm{eV}$ e esta mais favorável por $\approx 0.25 \mathrm{eV}$ da 555777 . Este ganho na energia de formação quando comparamos o defeito 555567777 com o 555777 , é devido à alta simetria dele. Porém ele possui energia de formação maior que o 585 devido a sua grande extensão e também ao aumento da energia devido às rotações das ligações que tem que ser feitas.

Feito o estudo da energética das divacâncias, iniciaremos um estudo das estruturas de bandas e densidade de estados utilizando condições periódicas de contorno e condições abertas. Apresentaremos também os resultados de transporte de carga. 


\subsubsection{Bandas de Energia e Densidade de Estados - Condições Periódicas de Contorno}

As bandas de energia e densidades de estados foram calculadas da mesma maneira que fizemos para as monovacâncias.

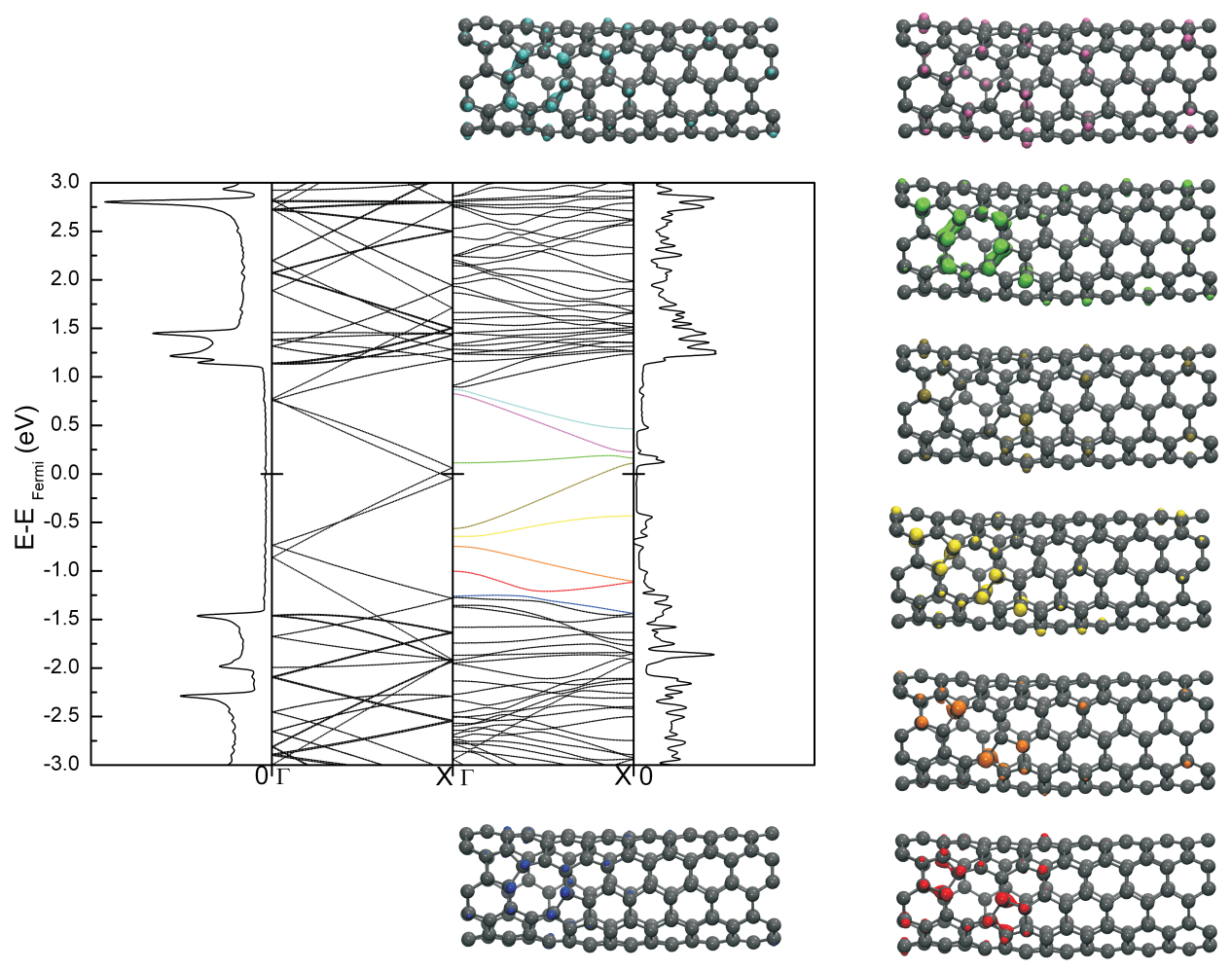

Figura 6.3: Bandas de energia, densidade de estados e plot de carga para os sistemas nanotubo de carbono mais divacância 585. As estruturas de bandas e DOS do lado esquerdo correspondem a do sistema puro e as do lado direito do sistema na presença do defeito. Os plots de carga apresentados são correspondentes à energias das regiões indicadas pelas cores e possuem isosuperfícies de $0.02 e / B o h r^{3}$.

A partir da figura (6.3), nós podemos observar na estrutura eletrônica do defeito 585, a presença de um pico acima do nível de Fermi em $0.15 \mathrm{eV}$. Este pico mais proeminente é devido a todo o defeito, como podemos observar a partir do 
plot de carga em verde claro à direita do gráfico das bandas e DOS.

Temos também a abertura de um gap em $-0.7 \mathrm{eV}$ abaixo do nível de Fermi, porém não podemos determinar ainda se é devido à presença do defeito, ou devido ao uso de condições periódicas de contorno.

Observando as bandas ao redor do nível de fermi, podemos ver que devido a adição do defeito, as bandas do sistema puro apresentam um caráter de impureza. Isso ocorre devido a localização da densidade de carga ao redor do defeito, como podemos observar através dos plots de carga apresentados na figura.

Para a divacância 555567777, figura (6.4), nós podemos observar na estrutura eletrônica do defeito 555567777, a presença de um estado "flat", que é proveniente do defeito, localizado um pouco abaixo do nível de Fermi, em $-0.52 \mathrm{eV}$. Observamos também, outro pico acima do nível de fermi em torno de $0.1 \mathrm{eV}$.

Todas essas estruturas "flats"estão relacionadas aos pentágonos do defeito, conforme notamos através da densidade de carga ao lado. Neste defeito observamos a abertura de um gap entre os níveis homo $\rightarrow$ homo $-1^{2}$

\footnotetext{
${ }^{2}$ Esses gap's precisam ainda ser confirmados se reais ou um artifício da conta devido ao uso de condições periódicas de contorno.
} 

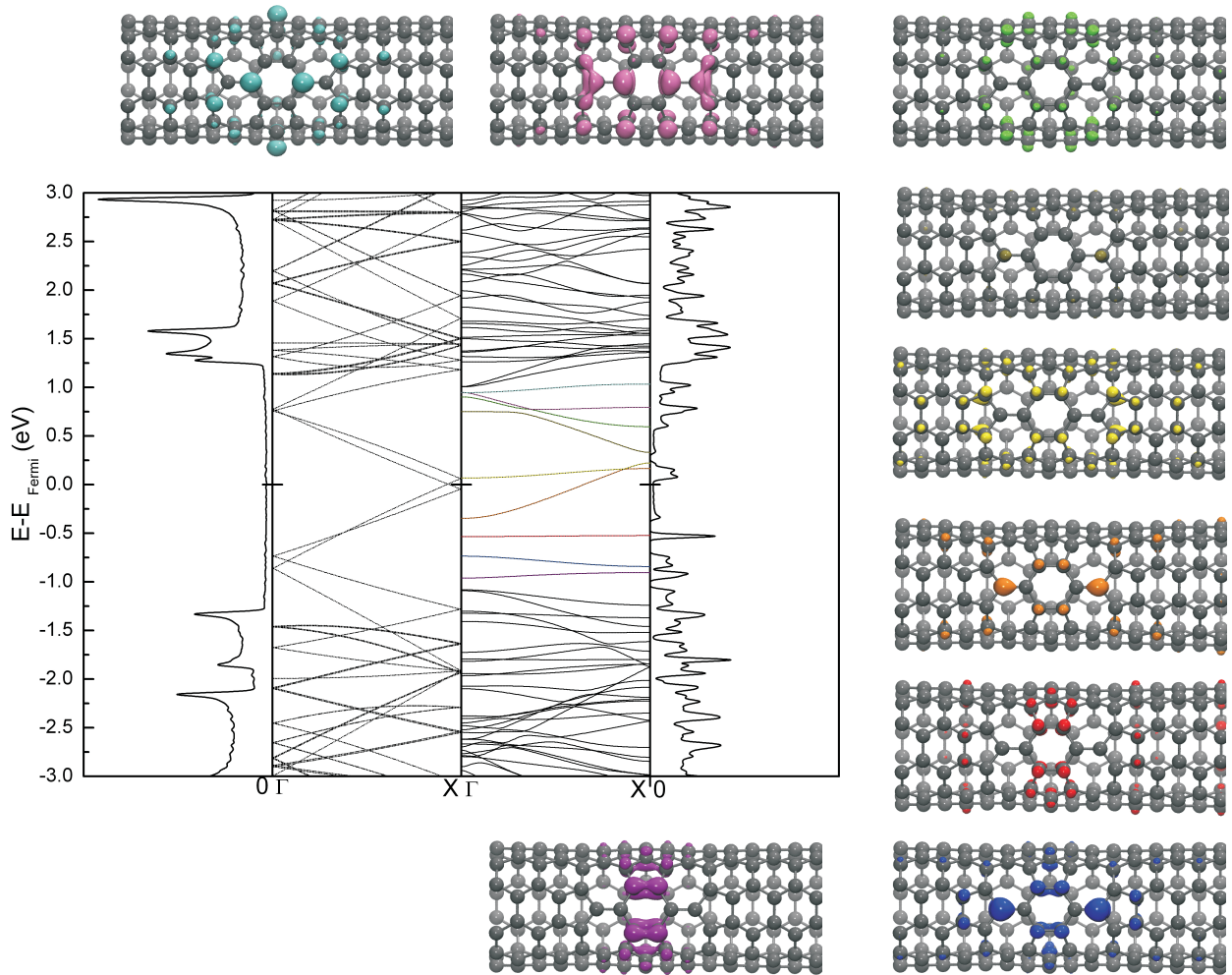

Figura 6.4: Bandas de energia, densidade de estados e plot de carga para os sistemas nanotubo de carbono mais divacância 555567777. As estruturas de bandas e DOS do lado esquerdo correspondem a do sistema puro e as do lado direito do sistema na presença do defeito. Os plots de carga apresentados são correspondentes à energias das regiões indicadas pelas cores e possuem isosuperfícies de $0.02 e / B o h r^{3}$.

\subsubsection{Densidade de Estados e Transporte - Defeito Isolado}

Agora, precisamos saber, quais são as propriedades de um defeito isolado no sistema. Para isso, deixamos de utilizar condições periódicas de contorno, pois com essa técnica, temos os defeitos periodicamente espaçados. Como já dito, com o uso de condições periódicas de contorno na presença um defeito, nós temos a formação de bandas de impureza, e no caso de um sistema metálico, o surgimento de anti-cruzamentos na estrutura de bandas e mini-gaps na densidade de estados. 
Assim, se quisermos somente um defeito temos que considerar um sistema aberto, onde teremos somente uma vacância em toda a sua extensão, conforme fizemos na seção de NEGF e nas seções pertinentes à monovacância.

Quando consideramos o sistema aberto e utilizamos o formalismo de funções de green fora do equilíbrio juntamente com o DFT, nos é permitido calcular as propriedades de transporte eletrônico dos defeitos. Podemos calcular também a densidade de estados (DOS) e as densidades de estados projetadas (PDOS). Assim, apresentaremos esses resultados para as divacâncias que estudamos.

Primeiro temos a transmitância e a DOS para a divacância 585, figura (6.5).

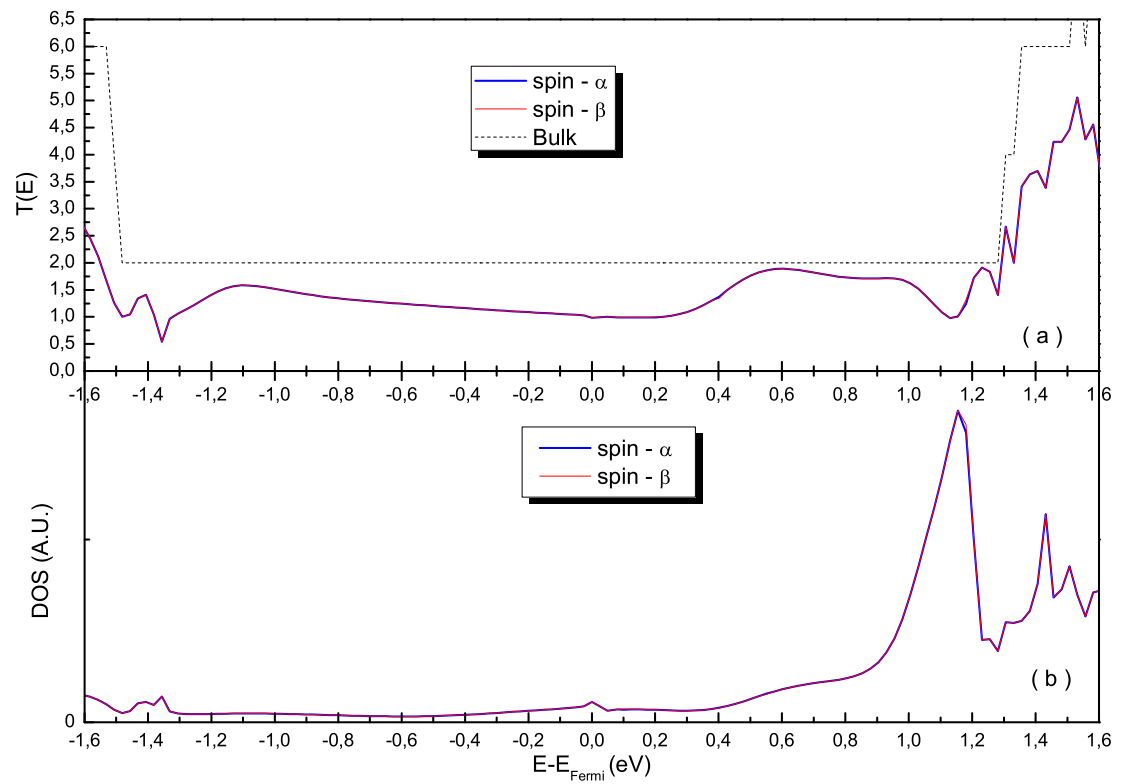

Figura 6.5: (a) Coeficiente de transmissão total para o sistema puro (linha preta tracejada) e coeficiente de transmissão por spin para a divacância 585. (b) Densidade de estados total por spin para a divacância 585 . 
Nós podemos observar em (6.5-a), que temos três quedas mais proeminentes na transmitância, uma em $-1.35 \mathrm{eV}$, outra mais suave ao redor de $0.2 \mathrm{eV}$ e outra em $1.13 \mathrm{eV}$. A condutância do sistema no nível de Fermi é de $\approx 1 G_{0}$, o que nos indica que nessa energia um canal de transmissão é completamente bloqueado. Não podemos deixar de notar, que nesse defeito a transmitância é completamente degenerada com respeito à polarização de spin, ou seja, a probabilidade de transmissão é igual para o canal up e down, onde em nosso sistema, indicamos esses canais por $\alpha$ e $\beta$.

Se olharmos para a DOS, figura (6.5-b), podemos ver claramente que a queda na transmissão em $1.13 \mathrm{eV}$ é devido a esse pico presente na DOS. As outras quedas, já temos um indicativo devido aos dois outros respectivos picos na DOS, porém estes são muito suaves, logo, para termos certeza e complementar o nosso entendimento, vamos observar a PDOS do sistema, onde daí poderemos precisar exatamente qual é causa dessas quedas na transmitância e qual a região do defeito que é responsável por isso.

A partir dessa PDOS, figura (6.6), observamos claramente os picos que são responsáveis pela diminuição na transmissão do sistema. Eles estão localizados nos átomos dos pentágonos, onde novamente temos a importância da reconstrução do sistema. Uma observação final é que nem na DOS e nem na PDOS temos presença de gap's de energia, logo, os gap's nos nossos cálculos utilizando condições periódicas de contorno são devidos à adição de um potencial periódico espalhador proveniente do defeito. 

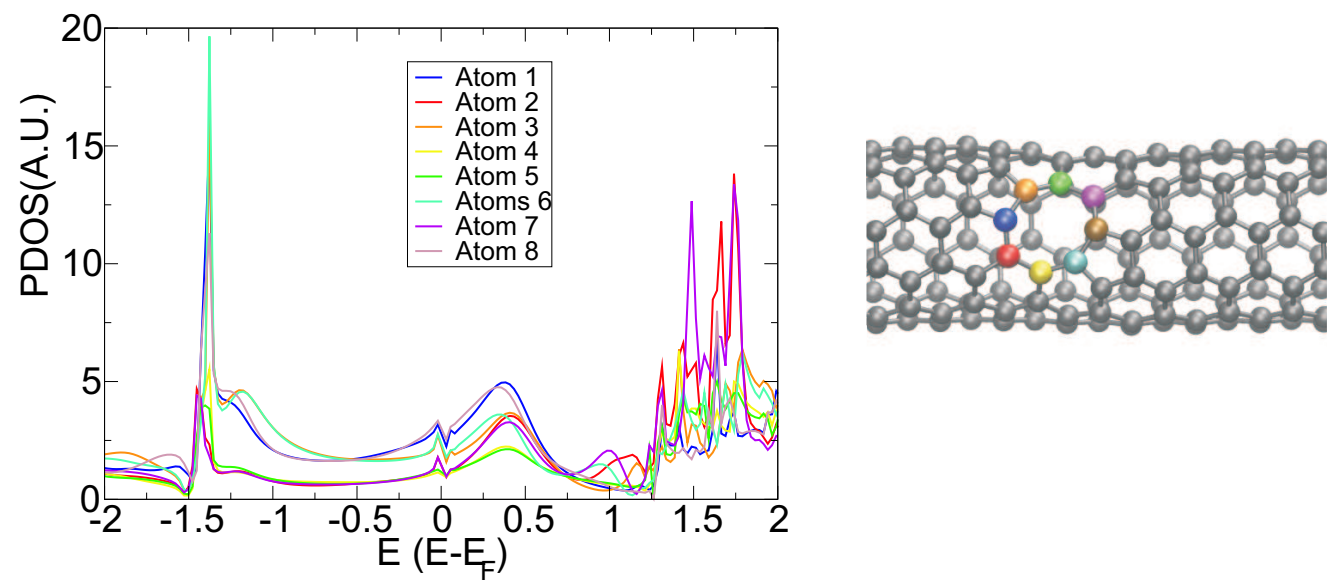

Figura 6.6: Densidade projetada de estados para os átomos do defeito 585.

Feito essa análise para a divacância 585, vamos entender o que acontece com a 555567777 .

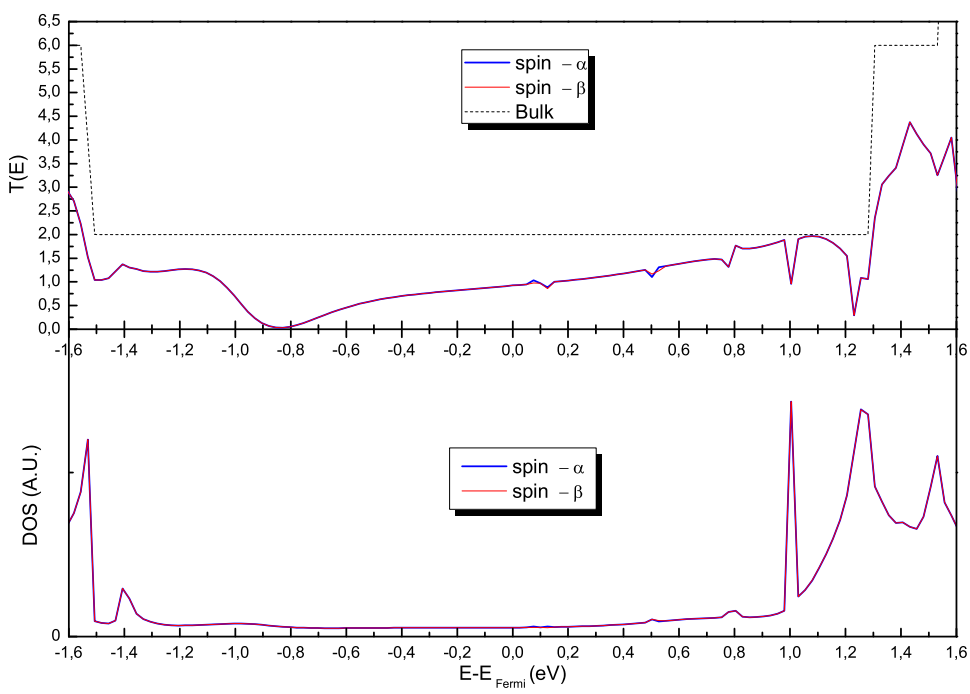

Figura 6.7: (a) Coeficiente de transmissão total para o sistema puro (linha preta tracejada) e coeficiente de transmissão por spin para a divacância 555567777. (b) Densidade de estados total por spin para a divacância 555567777 .

Aqui, podemos observar várias quedas mais evidentes da transmitância, umas 
suaves e outras não. São elas: $-1.47 \mathrm{eV},-0.84 \mathrm{eV}, 0.12 \mathrm{eV}, 0.5 \mathrm{eV}, 0.77 \mathrm{eV}$, $1.0 \mathrm{eV}$ e em 1.23. A condutância no nível de Fermi é $\approx 1 G_{0}$, o que nos indica que ainda existe um canal de transmissão. Olhando diretamente para a DOS, (6.7a), podemos observar claramente, que as duas últimas quedas na transmitância, são devido aos picos na densidade de estados na correspondente energia. Observamos também que o pico na DOS em $0.8 \mathrm{eV}$, mesmo ele sendo suave, causa uma diminuição da transmitância. Para observarmos qual é a causa das outras quedas na transmitância, precisamos olhar para a PDOS. Mas antes de entrarmos nesta questão, temos que neste defeito ocorre algo intrigante, e no mínimo interessante. Temos um pico na densidade de estados em $-1.4 \mathrm{eV}$, que não causa exatamente nada na transmissão. Observamos aqui, que a transmitância, como na divacância 585 é completamente degenerada com respeito à polarização de spin, ou seja, os canais up e down se comportam da mesma maneira.

A partir dessa PDOS, figura (6.8) observa-se claramente os picos que são responsáveis pelas duas quedas na transmitância nas energias $0.12 \mathrm{eV}$ e $0.5 \mathrm{eV}$. A queda na transmitância ao redor de $-0.2 \mathrm{eV}$, onde nessa energia a transmitância vai a zero, é devido a uma combinação de vários estados localizados. Atribuímos todos esses picos aos diversos pentágonos presente no defeito. Uma observação final, da mesma maneira que fizemos acima, mesmo com um defeito dessa extensão com todas essas reconstruções, o sistema continua sendo metálico e não temos nenhum gap de energia, como podemos observar da DOS e PDOS. 


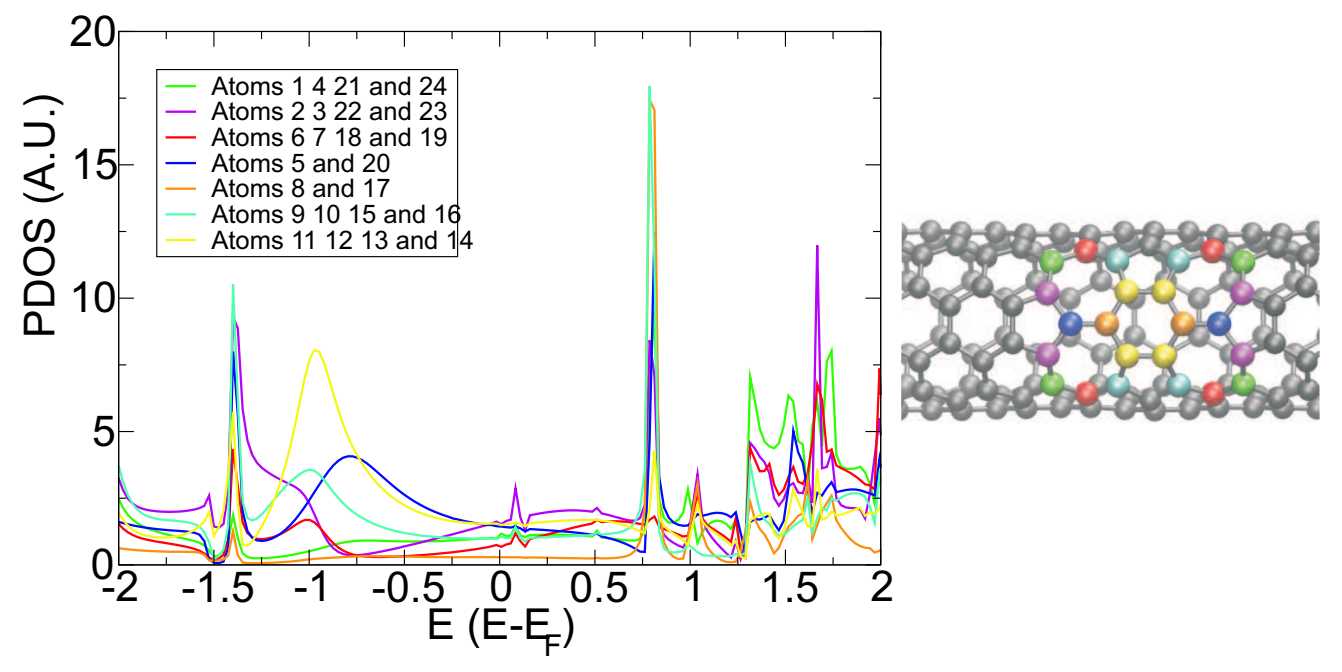

Figura 6.8: Densidade projetada de estados para os átomos do defeito 555567777.

\subsection{Trivacâncias}

Nós construímos dois tipos de trivacâncias, as duas apresentando após a reconstrução 1 "dangling bond"e dois pentágonos. Elas possuem diferentes orientações do defeito, conforme a figura (6.9).

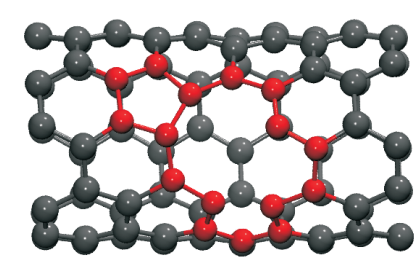

(a)

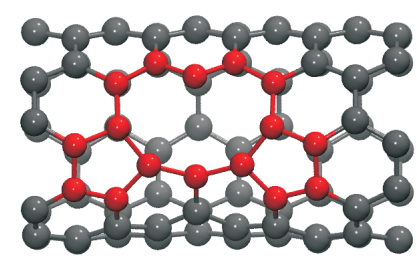

(b)

Figura 6.9: Trivacâncias: (a) $5510-1 D B-$ Inclinada e (b) $5510-1 D B-$ Paralela.

Construídos os defeitos, realizamos cálculos de energia total, para obter a energia de formação a fim de decidirmos qual possui energia mais favorável, ou seja, 
menor energia de formação. Após isso, tomado o defeito com menor energia de formação, realizamos todos os outros cálculos, como estruturas de bandas, densidade de estados e propriedades de transporte para esse sistema.

\subsubsection{Energia de Formação e Reconstrução para as Trivacân- cias}

Primeiramente, iremos analisar a energia de formação dos sistemas nanotubo de carbono mais trivacâncias 5510-1DB-Inclinada e 5510-1DB-Paralela. Nesse estudo, utilizamos 5 células unitárias na nossa supercélula para a escolha do defeito com menor energia de formação e após isso 8 células unitárias para o defeito mais favorável.

Os cálculos de energia total foram realizados todos da mesma maneira como descrito na seção das monovacâncias. A seguir, temos a tabela (6.3.1), onde podemos observar os resultados da energia de formação para esses sistemas.

\begin{tabular}{ccc}
\hline \hline Tipo & N $^{\circ}$ de Células Unitárias & $E_{f}(\mathrm{eV})$ \\
\hline $5510-1 D B-$ Inclinada & 5 & 9.07 \\
$5510-1 D B-$ Paralela & 5 & 7.50 \\
$5510-1 D B-$ Paralela & 8 & 7.46 \\
\hline \hline
\end{tabular}

Tabela 6.3: Energias de formação para as trivacâncias.

A trivacância $5510-1 D B-$ Paralela é a que possui energia de formação mais baixa. A explicação disso é devido a reconstrução do pentágono. Podemos observar isso a partir da figura (6.10).

Olhando para a figura (6.10), podemos concluir que o pentágono da trivacância 


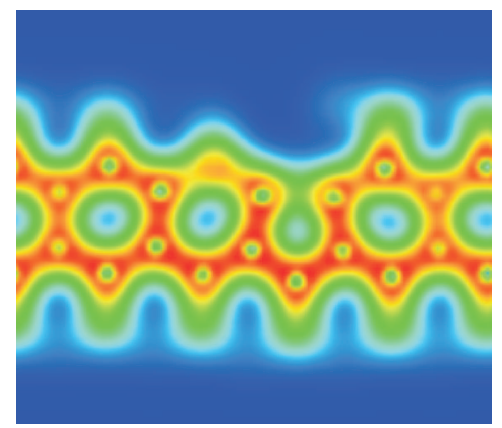

( a )

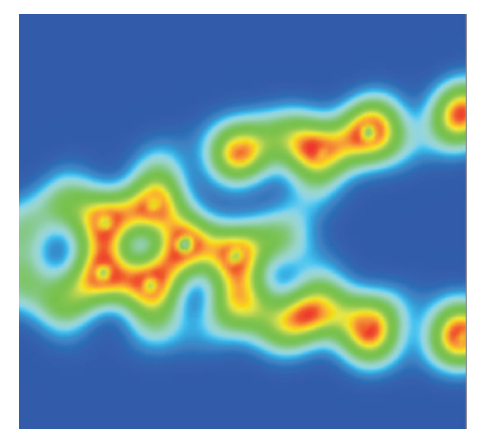

( b )

Figura 6.10: Plano de Carga: (a) Pentágono $5510-1 D B-$ Paralela e (b) pentágono $5510-1 D B-$ Inclinada.

paralela, possui a ligação mais forte que a inclinada, onde podemos ter a mesma conclusão que tivemos para a monovacância, que a reconstrução preferencial do sistema, é a que a ligação nova, proveniente do pentágono, preserva alguma orientação das ligações presentes no nanotubo puro. Assim, sabendo qual é a configuração mais favorável, passaremos agora ao estudo da estrutura eletrônica do sistema.

\subsubsection{Bandas de Energia e Densidade de Estados - Condições Periódicas de Contorno}

Nesta seção iremos apresentar os resultados obtidos para a estrutura eletrônica do sistema nanotubo de carbono mais trivacância 5510 - 1DB - Paralela, onde todos os cálculos foram realizados com 8 células unitárias, utilizando o mesmo procedimento que fizemos anteriormente para os outros defeitos.

A partir dessa figura, (6.11), notamos que na estrutura eletrônica desse defeito, tal como nas divacâncias, ocorre o surgimento de bandas de impureza criadas pela 
presença do defeito. Essas bandas de impureza são criadas a partir da localização da densidade de carga que o defeito gera. Podemos observar na estrutura de bandas 3 níveis "flats"(cores azul, vermelho e alaranjado) abaixo do nível de Fermi, ao redor de $-0.75 \mathrm{~V}$ e em $-1 \mathrm{eV}$, que são devidos aos pentágonos, figura (6.11), conforme podemos ver nos plots de carga. Observamos também o caráter $p$ do pico da densidade de estados no nível de Fermi, que está localizado no "dangling bond"do defeito. Nesse sistema existem gap's, que precisam também ser interpretados com um certo cuidado, para determinar se é devido realmente ao defeito ou ao uso de condições periódicas de contorno.

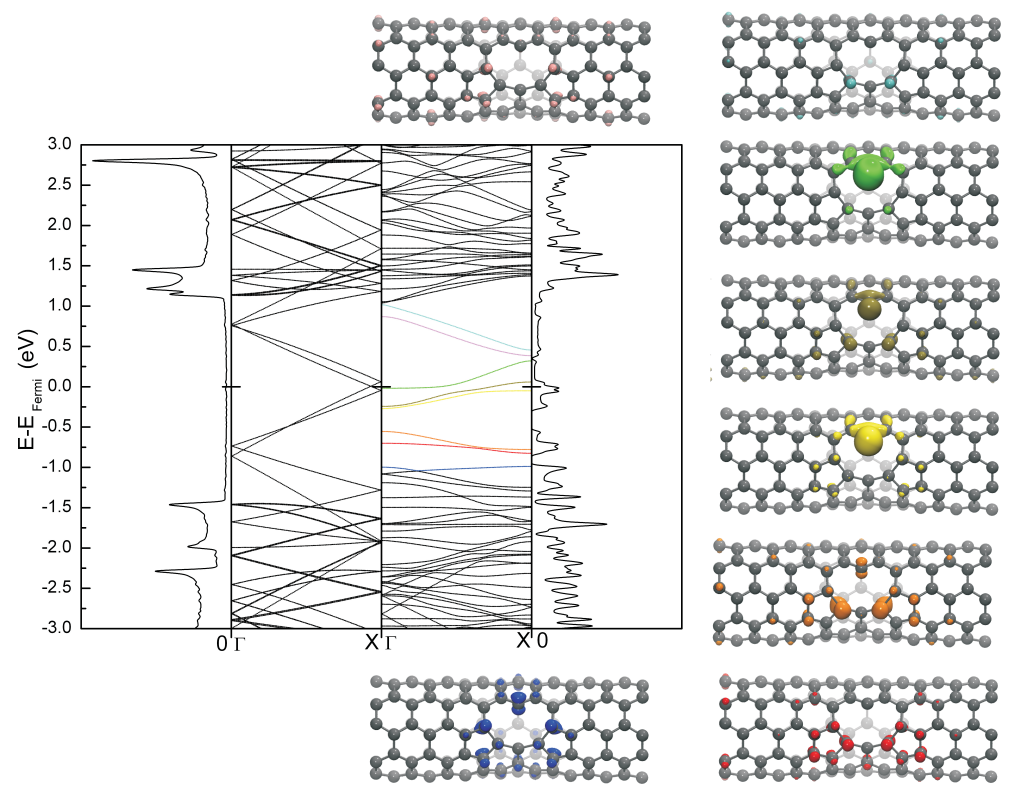

Figura 6.11: Bandas de energia, densidade de estados e plot de carga para os sistemas nanotubo de carbono mais trivacância $5510-1 D B-$ Paralela. As estruturas de bandas e DOS do lado esquerdo correspondem a do sistema puro e as do lado direito do sistema na presença do defeito. Os plots de carga apresentados são correspondentes à energias das regiões indicadas indicadas pelas cores e possuem isosuperfícies de $0.02 e / \mathrm{Bohr}^{3}$. 


\subsubsection{Densidade de Estados e Transporte - Defeito Isolado}

Nesta seção, temos os resultados calculados a partir dor formalismo de funções de Green para a trivacância. Apresentaremos aqui as curvas de transmitância e densidade de estados para este defeito.

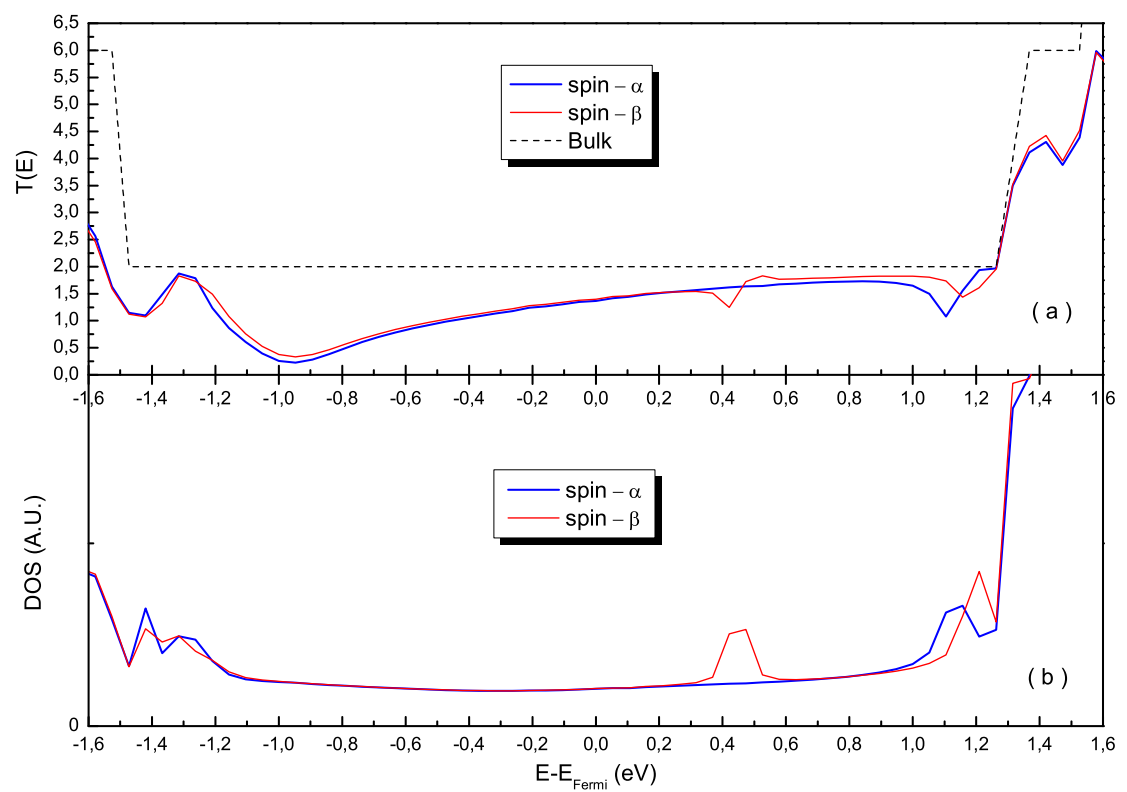

Figura 6.12: (a) Coeficiente de transmissão total para o sistema puro (linha preta tracejada) e coeficiente de transmissão por spin para a trivacância. (b) Densidade de estados total por spin para a trivacância.

Podemos observar na figura (6.12) que temos uma queda da transmitância em $-0.95 \mathrm{eV}$, que é devido à presença dos pentágonos da "dangling bond", resutantes da reconstrução. A transmitância desse sistema no nível de Fermi é de $\approx 1.2 G_{0}$. O transporte eletrônico, até a energia de $0.3 \mathrm{eV}$ se da através de canais de spin praticamente degenerados, porém devido a uma localização de estados de spin $\beta$ em $0.42 e V$ a probabilidade de transferência, é maior para os canais de spin $\alpha$ 
até a energia de $1.1 \mathrm{eV}$ onde agora ocorre uma localização de estados de spin $\alpha$ porém logo após temos um outro pico na DOS para spin $\beta$, onde a partir disso, a transmitância do sistema, fica novamente degenerada para os canais de spin.

\subsection{Tetravacância}

A tetravacância que construímos ${ }^{3}$, após a relaxação da sua estrutura, apresenta 3 pentágonos e uma região central com 9 lados, figura (6.13), por isso agora faremos referência a este defeito pelo nome de tetravacância 5559.

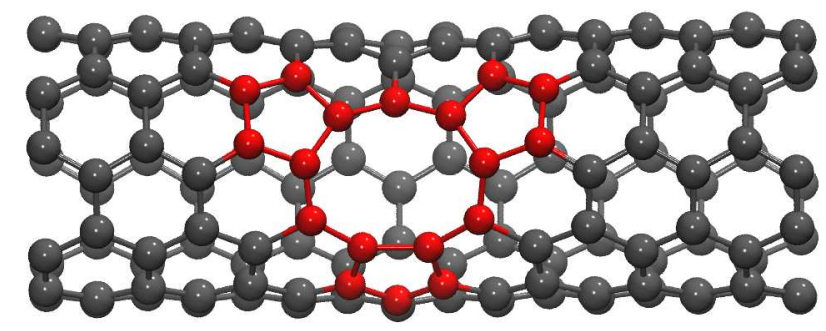

Figura 6.13: Tetravacância 5559.

Este defeito não possui nenhum "dangling bond"na sua estrutura final, porém possui um pentágono reconstruído com a ligação paralela ao eixo do nanotubo. Esta ligação é mais fraca do que as outras, como podemos ver em (6.34).

\subsubsection{Energia de Formação e Reconstrução da Tetravacância}

A energia de formação deste defeito, foi calculada da mesma maneira que foi feito para todos os defeitos anteriormente descritos, seção (5.1). Fizemos os

\footnotetext{
${ }^{3}$ Sistema construído a partir da nossa motivação, que é multivacâncias provenientes do encontro de monovacâncias - vacâncias com buraco.
} 


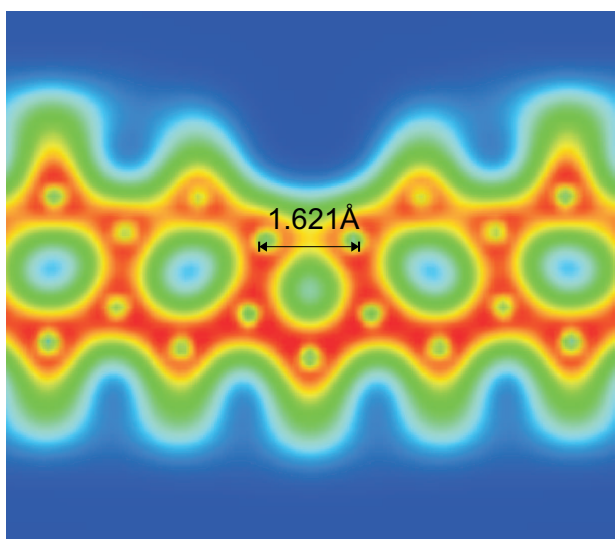

( a )

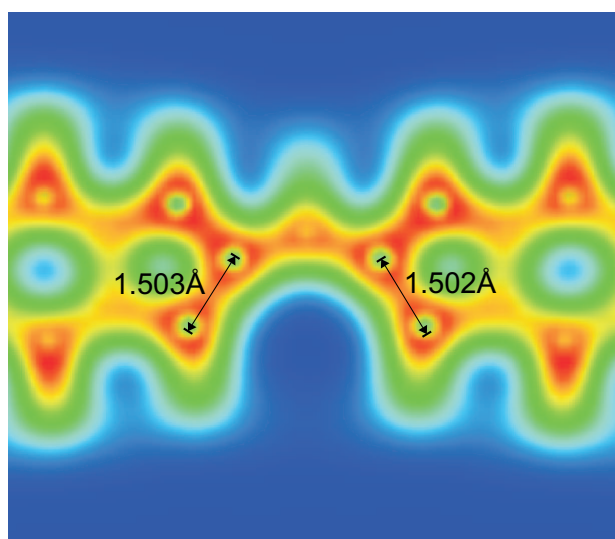

( b )

Figura 6.14: Plano de carga através dos pentágonos da tetravacância: (a) Pentágono paralelo ao eixo do nanotubo; (b) pentágonos inclinados.

cálculos da energia de formação para 5 e 8 células unitárias e encontramos $7.83 \mathrm{eV}$ e $7.28 \mathrm{eV}$ respectivamente. Atribuímos essa redução da energia de formação entre 5 e 8, devido à diminuição da interação tanto eletrônica quanto elástica entre o defeito e sua imagem periódica.

\subsubsection{Bandas de Energia e Densidade de Estados - Condições Periódicas de Contorno}

Nesta seção temos os resultados para as estrutura de bandas e densidade de estados do sistema tetravacância 5559. Todos os cálculos foram realizados com 8 células unitárias, utilizando o mesmo procedimento que na seção 5.3.

A partir dessa figura, (6.15), ao contrário dos defeitos estudados anteriormente, não temos nenhum pico mais proeminente na região do nível de Fermi, mas mesmo assim, os níveis nessa região apresentam um caráter de defeito, como notamos nos plots de carga. Observamos também, um pico na DOS na energia 
de $-0.75 \mathrm{eV}$, e como podemos ver pelo plot de carga, este pico é devido a uma localização de carga nos pentágonos do defeito. Novamente, temos um gap na região desse pico, porém não sabemos se é um gap real ou devido às condições de cálculo.
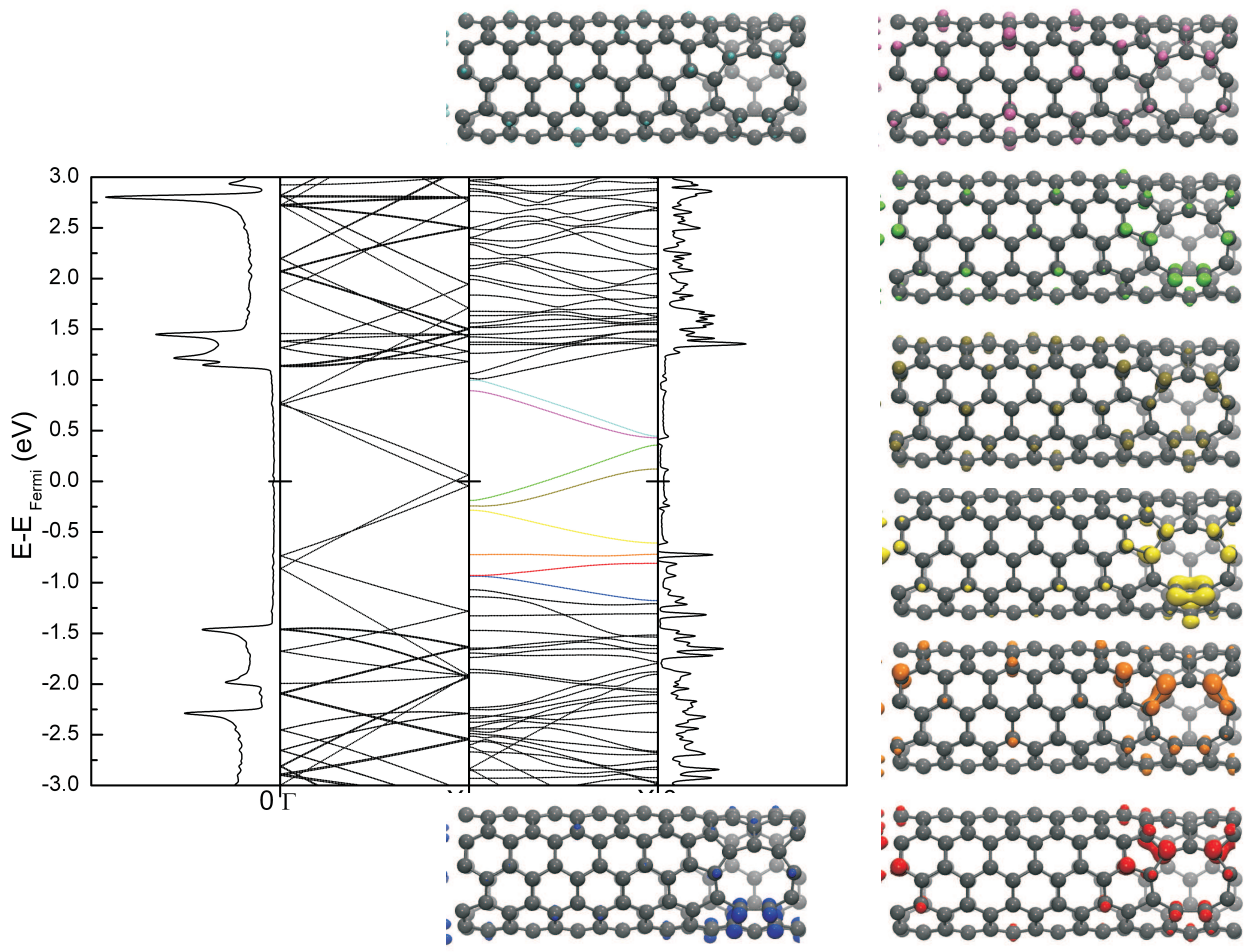

Figura 6.15: Bandas de energia, densidade de estados e plot de carga para o sistema nanotubo de carbono mais tetravacância 5559. As estruturas de bandas e DOS do lado esquerdo correspondem a do sistema puro e as do lado direito do sistema na presença do defeito. Os plots de carga apresentados são correspondentes à energias das regiões indicadas indicadas pelas cores e possuem isosuperfícies de $0.02 e / B o h r^{3}$.

\subsubsection{Densidade de Estados e Transporte - Defeito Isolado}

A seguir temos os resultados dos cálculos para a tetravacância isolada. Na tetravacância, figura (6.16), temos somente duas quedas na transmitância, uma 
em $-1.23 e V$ e outra em $-0,8 \mathrm{eV}$. A condutância no nível de Fermi é $\approx 1.48 G_{0}$. Olhando diretamente para a DOS, (6.16-a), podemos observar claramente, que o pico em $-1.23 \mathrm{eV}$ é responsável pela correspondente queda na transmitância. Mas, temos outra queda na transmitância em $-0.8 \mathrm{eV}$ que não conseguimos detectar através da DOS, para isso olhamos a PDOS, onde daí saberemos qual é a contribuição que causa esse efeito na transmitância. Como nas divacâncias a transmitância é completamente degenerada com respeito à polarização de spin, ou seja, os canais up e down se comportam da mesma maneira.

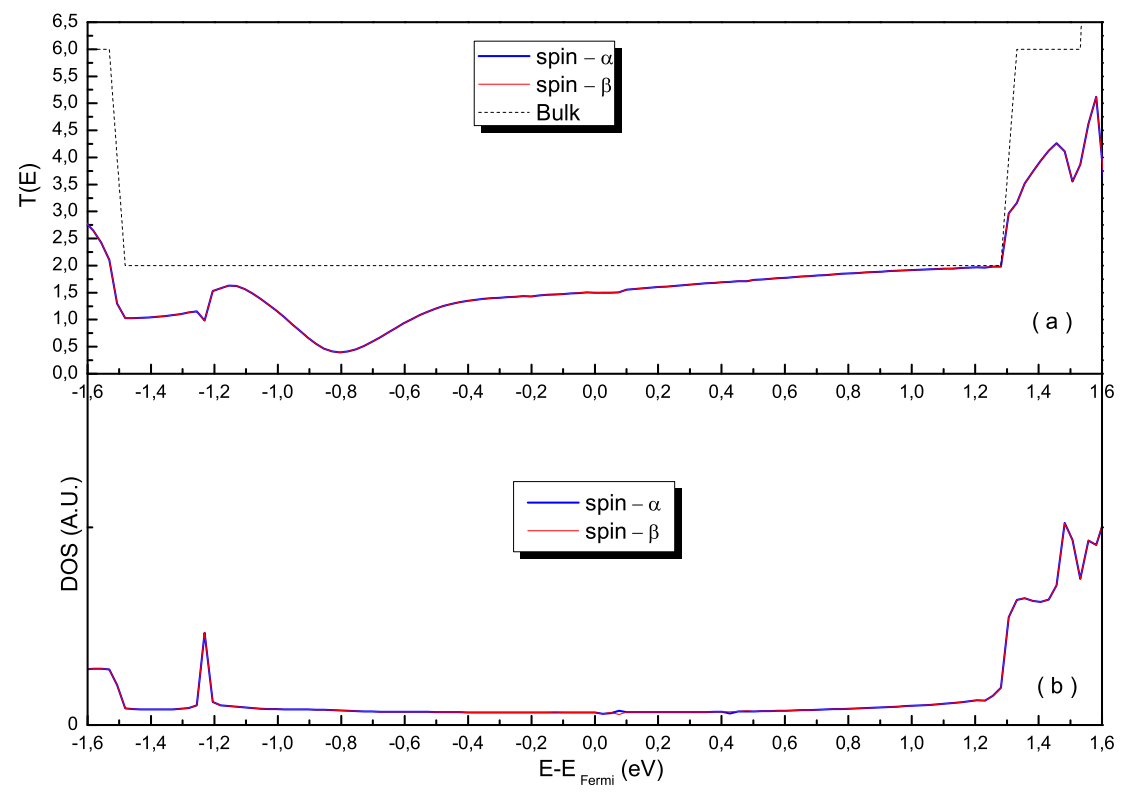

Figura 6.16: (a) Coeficiente de transmissão total para o sistema puro (linha preta tracejada) e coeficiente de transmissão por spin para a tetravacância. (b) Densidade de estados total por spin para a tetravacância.

A partir da PDOS, figura (6.17) observamos claramente que a queda na transmitância em $-0.8 \mathrm{eV}$ é devido aos picos na PDOS nessa energia. Atribuímos todos esses picos aos diversos pentágonos presente no defeito. Uma observação 
final, da mesma maneira que fizemos para todos os outros defeitos, é que o sistema continua sendo metálico. Não há nenhum gap de energia. Todos os gap's que aparecem com condições periódicas de contorno para este defeito, são devidos à adição de um potencial periódico espalhador proveniente do defeito.

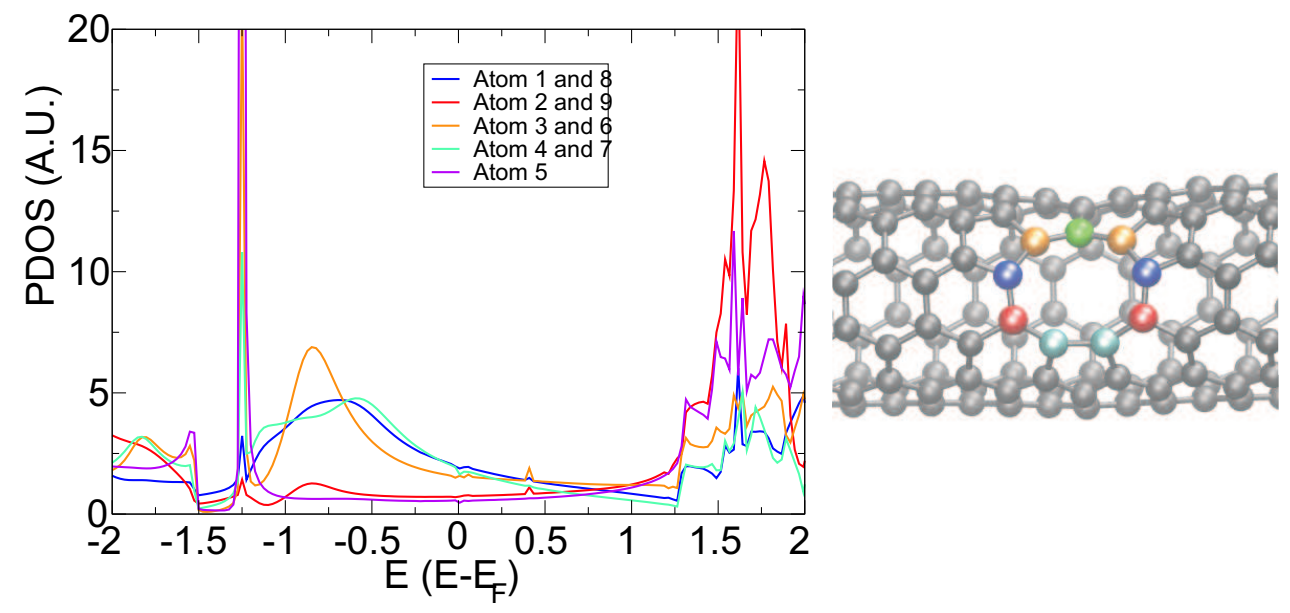

Figura 6.17: Densidade projetada de estados para os átomos do defeito - tetravacância.

\subsection{Pentavacância}

A pentavacância apresenta após a reconstrução da sua estrutura, 3 pentágonos e uma região central com 11 lados e uma "dangling bond", figura (6.13), por isso agora faremos referência a este defeito pelo nome de pentavacância $55511-1 D B$.

Observamos neste defeito após a reconstrução que ele possui uma forma muito semelhante à da monovacância, com a diferença de possuir 2 pentágonos a mais. 


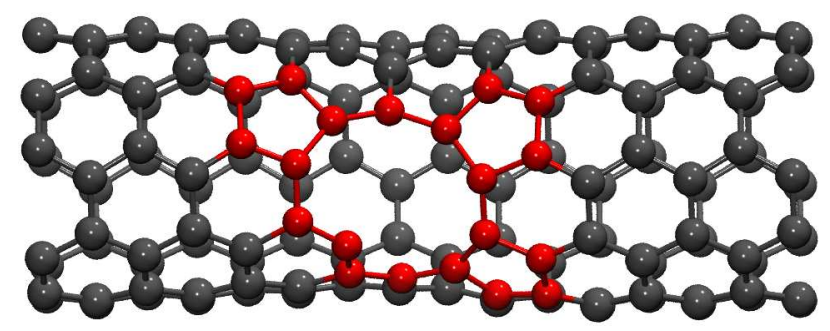

Figura 6.18: Pentavacância $55511-1 D B$.

\subsubsection{Energia de Formação da Pentavacância}

A energia de formação deste defeito, foi calculada da mesma maneira que foi feito para todos os defeitos anteriormente descritos, seção (5.1). Fizemos os cálculos para 5 e 8 células unitárias, e encontramos energias de formação de $9.62 \mathrm{eV}$ e $9.50 \mathrm{eV}$ respectivamente. Novamente a redução da energia de formação entre 5 e 8 , é devido à diminuição da interação tanto eletrônica quanto elástica entre o defeito e sua imagem periódica.

\subsubsection{Bandas de Energia e Densidade de Estados - Condições Periódicas de Contorno}

Nesta seção temos os resultados para as estrutura de bandas e densidade de estados do sistema pentavacância $55511-1 D B$. Todos os cálculos foram realizados com 8 células unitárias, utilizando o mesmo procedimento que na seção 5.3.

A partir dessa figura, (6.19), nós podemos observar que na estrutura eletrônica desse defeito temos picos ao redor do nível de Fermi, provenientes das bandas de impureza geradas pelo defeito, localizadas na "dangling bond"do sistema, como podemos observar nos plots de carga, lado direito da figura (6.19). Temos tam- 
bém, um pico na DOS na energia de $-0.75 \mathrm{eV}$, e como podemos ver pelo plot de carga, este pico é devido a uma localização de carga nos pentágonos do defeito. Novamente, temos um gap, onde ainda não podemos determinar precisamente se é um gap real ou devido às condições de cálculo. Mas como em todos os outros defeitos o caráter metálico do nanotubo continua sendo mantido.
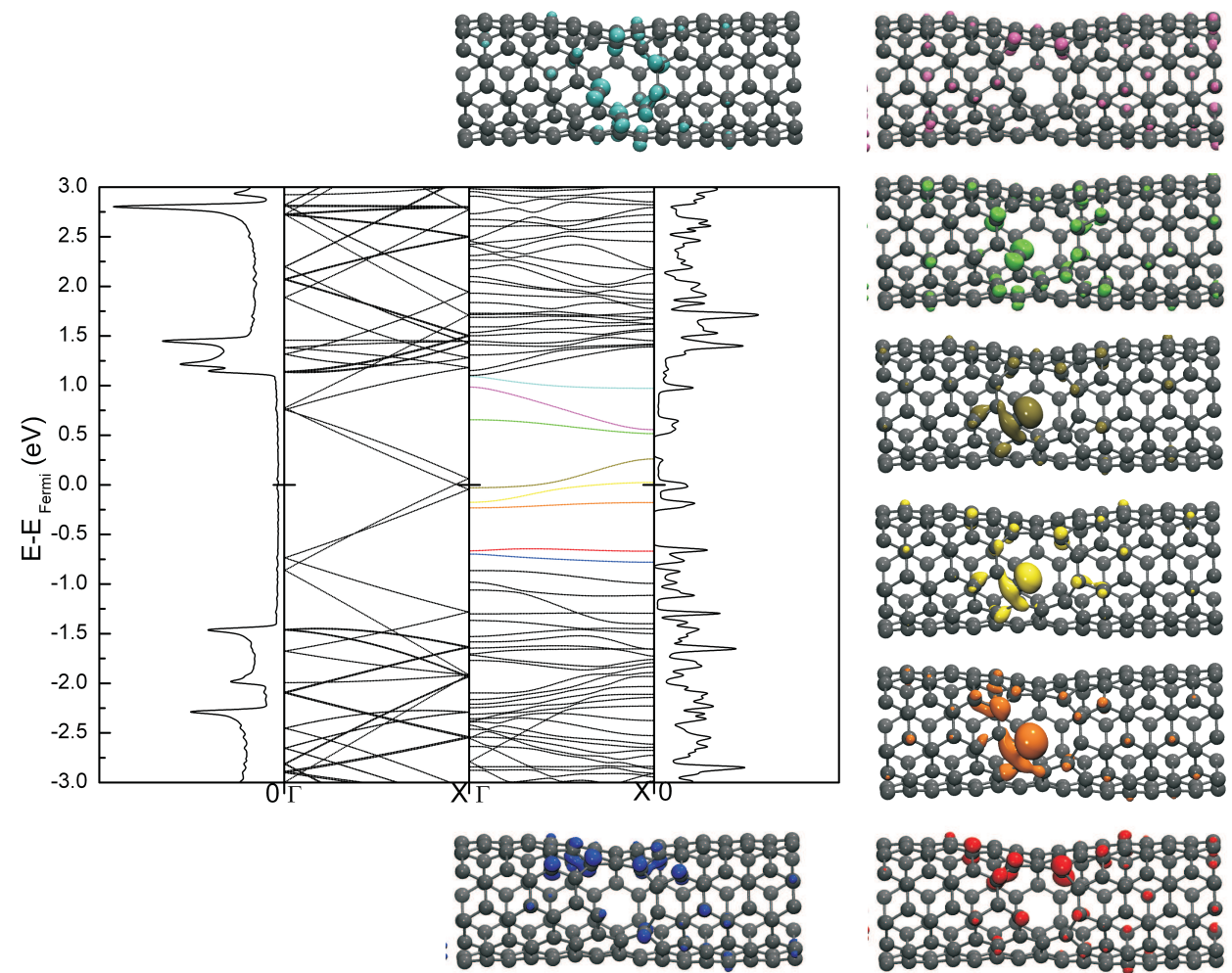

Figura 6.19: Bandas de energia, densidade de estados e plot de carga para o sistema nanotubo de carbono mais pentavacância $55511-1 D B$. As estruturas de bandas e DOS do lado esquerdo correspondem a do sistema puro e as do lado direito do sistema na presença do defeito. Os plots de carga apresentados são correspondentes à energias das regiões indicadas indicadas pelas cores e possuem isosuperfícies de $0.02 e / B o h r^{3}$. 


\subsubsection{Densidade de Estados e Transporte - Defeito Isolado}

Nesta seção, temos os resultados calculados a partir dor formalismo de funções de Green para a pentavacância. Podemos observar que temos uma queda da transmitância em $-0.9 \mathrm{eV}$, que da mesma maneira que concluímos para todos os outros defeitos, é devido à presença dos pentágonos da reconstrução, mas também tendo uma grande influência da "dangling bond"resultante. Observamos que o transporte eletrônico nesse sistema, ao contrário dos outros, que não possuíam nenhuma "dangling bond", se dá através de canais de spin polarizados. A partir de $0.1 \mathrm{eV}$ a transmitância se dá por canais de $\operatorname{spin} \beta$ até a energia de $0.7 \mathrm{eV}$, onde a partir desse ponto temos preferência ao canal de spin $\alpha$, e novamente em $1 \mathrm{eV}$ temos os dois canais de spin degenerados, como obtivemos para todos os outros sistema. A transmitância desse sistema no nível de Fermi é da ordem de $0.6 G_{0}$.

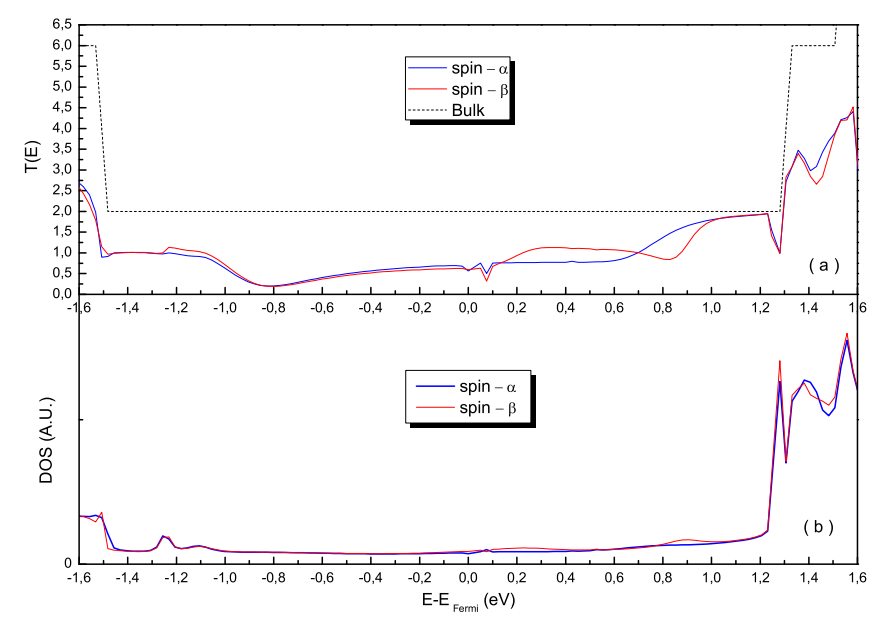

Figura 6.20: (a) Coeficiente de transmissão total para o sistema puro (linha preta tracejada) e coeficiente de transmissão por spin para a pentavacância. (b) Densidade de estados total por spin para a pentavacância. 


\subsection{Hexavacância}

A hexavacância que construímos, após a relaxação da sua estrutura, apresenta 4 pentágonos e uma região central com 10 lados, figura (6.21), por isso agora faremos referência a este defeito pelo nome de hexavacância 555510.

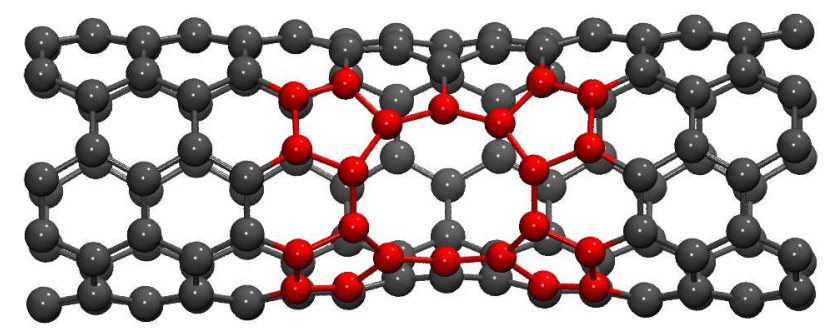

Figura 6.21: Hexavacância 555510.

Podemos observar, que este defeito não possui nenhuma "dangling bond"na sua estrutura final.

\subsubsection{Energia de Formação}

A energia de formação deste defeito, foi calculada da mesma maneira que foi feito para todos os defeitos anteriormente descritos. Fizemos os cálculos para $5 \mathrm{e}$ 8 células unitárias e encontramos $8.11 \mathrm{eV}$ e $7.88 \mathrm{eV}$ respectivamente. Atribuímos novamente essa redução da energia de formação entre 5 e 8 , devido à diminuição da interação tanto eletrônica quanto elástica entre o defeito e sua imagem periódica. 


\subsubsection{Bandas de Energia e Densidade de Estados - Condições Periódicas de Contorno}

Nesta seção temos os resultados para as estrutura de bandas e densidade de estados do sistema hexavacância 555510 . Todos os cálculos foram realizados com 8 células unitárias, utilizando o mesmo procedimento que para todos os outros defeitos.
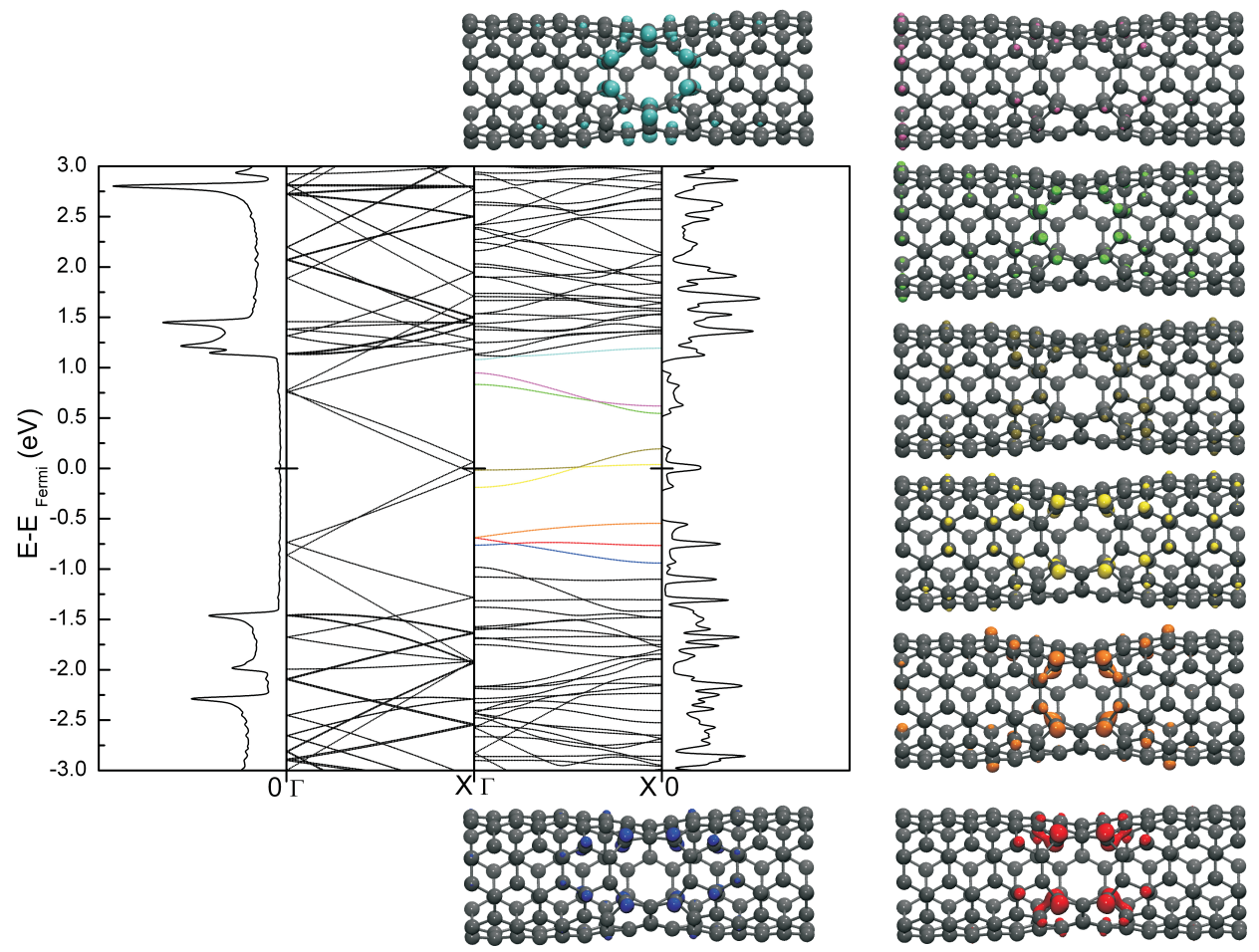

Figura 6.22: Bandas de energia, densidade de estados e plot de carga para o sistema nanotubo de carbono mais hexavacância 555510. As estruturas de bandas e DOS do lado esquerdo correspondem a do sistema puro e as do lado direito do sistema na presença do defeito. Os plots de carga apresentados são correspondentes à energias das regiões indicadas indicadas pelas cores e possuem isosuperfícies de $0.02 e / B o h r^{3}$.

A partir dessa figura, (6.22), nós podemos observar que na estrutura eletrônica desse defeito, nós temos um pico no nível de Fermi, ao contrário dos defeitos 
estudados anteriormente, este pico não é devido a "dangling bonds", mas é proveniente da presença de uma banda de impureza devido à presença do defeito, como podemos observar nos plots de carga. Observamos também, um pico na DOS na energia de $-0.75 \mathrm{eV}$, e como podemos ver pelo plot de carga, este pico é devido a uma localização de carga nos pentágonos do defeito. Novamente, temos um gap na região acima e abaixo desse pico, onde ainda não podemos determinar precisamente se é um gap real ou devido às condições de cálculo, porém o caráter metálico nanotubo continua preservado.

\subsubsection{Densidade de Estados e Transporte - Defeito Isolado}

A seguir temos os resultados dos cálculos baseados em funções de Green para a hexavacância.

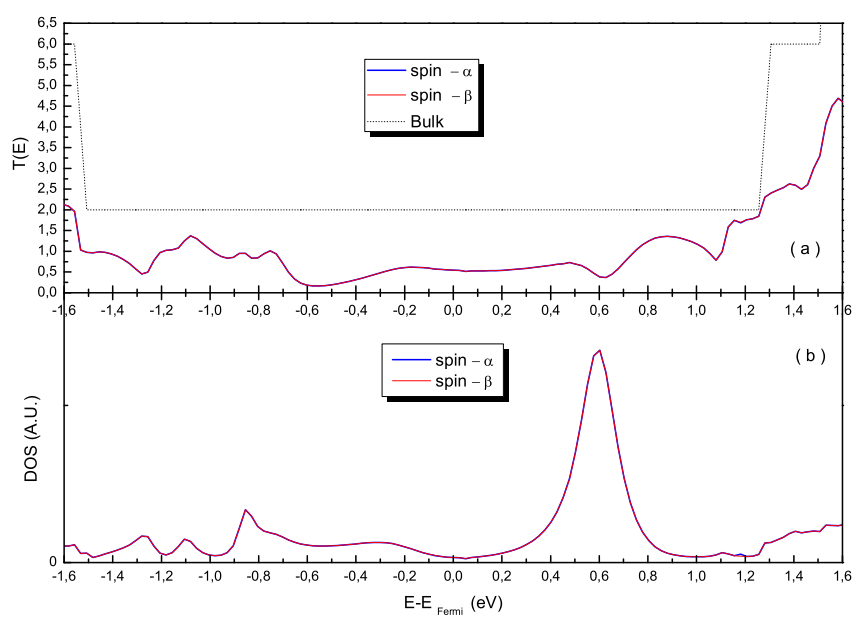

Figura 6.23: (a) Coeficiente de transmissão total para o sistema puro (linha preta tracejada) e coeficiente de transmissão por spin para a hexavacância. (b) Densidade de estados total por spin para a hexavacância.

Podemos observar a transmitância da hexavacância, possui uma grande vari- 
ação nesse intervalo de energia que é mostrado na figura (6.23). Nós observamos quedas na transmissão em $-1.27 \mathrm{eV}, 0.92 \mathrm{eV},-0.81 \mathrm{eV},-0.56 \mathrm{eV}, 0.61 \mathrm{eV} \mathrm{e}$ $1.08 \mathrm{eV}$. Olhando diretamente para a DOS, figura (6.23), já sabemos que o pico na densidade de estados em $0.61 \mathrm{eV}$ é responsável pela variação da transmitância nessa energia. Nós podemos tirar mais conclusões com respeito à transmitância, olhando somente para a DOS, mas vamos deixar para fazer isso a partir da PDOS. No nível de Fermi, a condutância apresenta um valor de $\approx 0.5 G_{0}$. Observamos também, que devido a não presença de "dangling bonds"no sistema devido à alta reconstrução da rede, nós não observamos nenhuma polarização de spin, ou seja, os canais de spin são completamente degenerados, ao contrário do que foi reportado por Louie, S. et al. [84].

Olhando agora para a PDOS, temos:
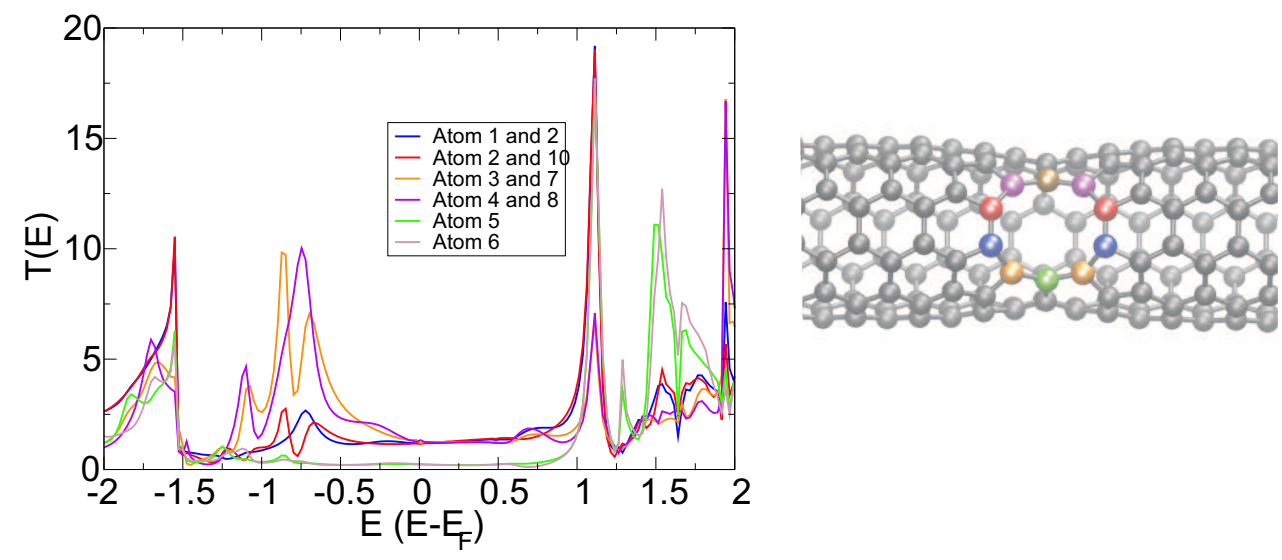

Figura 6.24: Densidade projetada de estados para os átomos do defeito - hexavacância.

A partir dessa PDOS, nós podemos determinar agora, com certeza o porque da grande oscilação da transmitância, com diminuições consideradas. Temos a 
partir da PDOS, que entre $-1.2 \mathrm{eV}$ e $-0.4 \mathrm{eV}$, ocorre a localização de uma grande quantidade de estados, sendo isso responsável pelas quedas na transmissão. Uma outra região onde observamos uma queda na transmitância, mas não conseguimos concluir nada a partir da DOS, é em $1.08 \mathrm{eV}$, porém, a partir da PDOS, constatamos que há a presença de estados localizados, evidenciados pelos picos nessa energia, sendo estes responsáveis pela queda do coeficiente de transmissão nessa região. Reforçando, não observamos nenhum tipo de transporte polarizado, todos os canais são completamente degenerados. Uma observação final, da mesma maneira que fizemos para todos os outros defeitos, é que o sistema continua sendo metálico. Nenhum gap de energia é criado, como podemos observar da DOS e PDOS, assim, todos os gap's de energia que aparecem nos cálculos com condições periódicas de contorno para este defeito, são devidos à adição do potencial periódico espalhador proveniente do defeito.

\subsection{Estabilidade dos Defeitos}

Defeitos como vacâncias e clusters de $n$-vacâncias $\left(V_{n}\right)$, possuem efeitos muitos importantes em várias propriedades de muitos materiais, como Si [85], GaAs [86] e materiais baseados no carbono, como o grafite $[41,87,88]$, entre outros.

Como já vimos anteriormente em nossos resultados, podemos ter a presença de vários tipos de defeitos nos nanotubos de carbono [20,32,43,70,89], por isso, se o principal objetivo é utilizar os nanotubos para a confecção de nanodispositivos, 
é muito importante o controle dos tipos de defeitos que estarão presentes.

Os tipos de defeitos presentes nos nanotubos de carbono consistem das Stone Wales [89], monovacâncias e multivacâncias [39,41,43, 87, 90-93], adatoms [88, 94] e pares de adatoms e vacâncias [95]. Todos esses tipos de defeitos foram e são ainda extensivamente estudados, tanto teoricamente quanto experimentalmente. A nossa proposta aqui é apresentar um estudo detalhado da estabilidade das $n$-vacâncias para o nanotubo de carbono armchair.

É esperado que vacâncias de tamanhos maiores (multivacâncias) podem ser formadas como resultado da difusão de vacâncias menores. Desde que essas vacâncias afetam drasticamente as propriedades eletrônicas e mecânicas do bulk, o seu estudo é muito importante. Neste caso, o número mágico é uma quantidade física fundamental. Ele indica o tamanho de uma multivacância estável. Estudos anteriores, já trataram destes números mágicos para alguns semicondutores [85,86], e para o grafeno [96]. Agora, o que faremos é mostrar que estes números mágicos também existem para os nanotubos de carbono. Mas antes de continuarmos com nossos resultados, vamos tentar entender um pouco sobre este assunto de números mágicos.

Estudos anteriores com aniquilação de pósitrons em grafite, sugeriram que a hexavacância, $V_{6}$, possuindo uma forma de anel, era a forma mais etável [87], sendo assim, o número mágico é 6 . Essa estabilidade foi explicada com sucesso pelo modelo de contagem de "dangling bonds"(DBCM), em que o número de "dangling bonds" $N_{D B}$ diminuía quando a vacância se tornava mais estável. Este 
modelo teve sucesso também em estudos com multivacâncias em silício [85]. Porém cálculos recentes de primeiros princípios em grafeno, indicaram que pentágonos são formados após a reconstrução do sistema [93]. Nesses cálculos, concluíram que vacâncias pares eram energéticamente favoráveis às ímpares. Saito, mostrou em um de seus trabalhos [96], que para o grafeno também existem os números mágicos, e são 2, 4 e 6, mostrando também que a estabilidade do defeito depende dos pentágonos formados na reconstrução do sistema, reformulando assim, o modelo de contagem de "dangling bonds", adicionando a este o efeito dos pentágonos, escrevendo o modelo de contagem de pentágonos e "dangling bonds"(PDBCM). Dessa maneira, a nossa proposta é obter estes números mágicos, determinando assim quais os defeitos são mais estáveis para os nanotubos de carbono.

Uma primeira tentativa de determinarmos qual seria o defeito mais estável, é olhar para a sua energia de formação, conforme a figura (6.25).

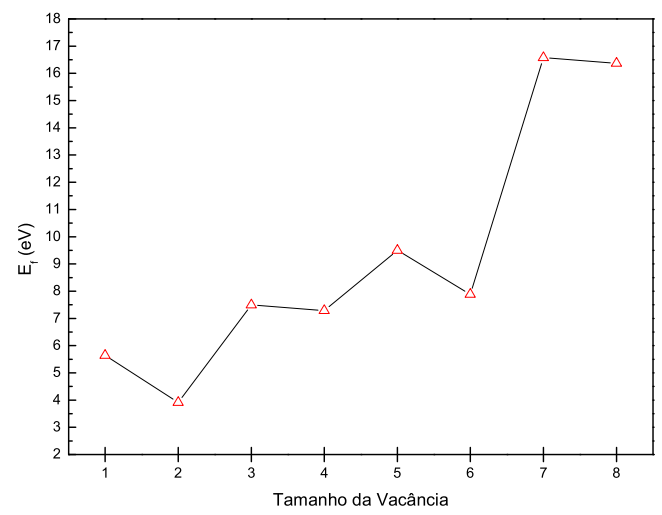

Figura 6.25: Energia de formação das multivacâncias estudadas calculadas a partir de DFT-GGA. 
Olhando para esse gráfico, diríamos logo que a vacância $V_{2}$ é a mais estável. Porém, não podemos esquecer que para dizer se é mais estável ou não, temos que comparar ela com as outras. Dessa maneira, uma outra tentativa, seria fazer uma comparação com respeito ao número de átomos que foram retirados do sistema, ou seja, tomarmos a energia de formação de cada sistema e dividir pelo número de átomos retirados. Assim estabeleceríamos uma comparação com a monovacância. A seguir temos a energia de formação por átomo de carbono retirado, figura (6.26).

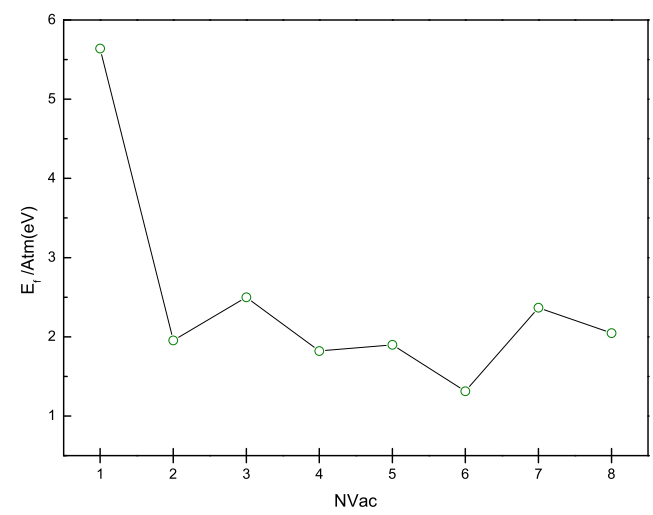

Figura 6.26: Energia de formação por átomo retirado das multivacâncias estudadas.

Esta informação já é um pouco mais conclusiva. Porém podemos pensar: E se tivermos uma tetravacância e uma monovacância no sistema? Para onde ele vai preferir evoluir? E somente uma tetra? Ele vai querer virar duas di? Assim, precisamos definir um método mais preciso e confiável para determinar realmente qual tipo de defeito é mais estável no sistema.

Para isso, vamos relembrar primeiramente os sistemas que estudamos e os que iremos acrescentar agora no nosso estudo que são as vacâncias $V_{7}$ e $V_{8}$. Na figura (6.27), temos as multivacâncias sem reconstrução atômica e na figura (6.28) temos 
as já reconstruídas.

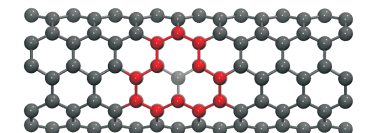

(a)

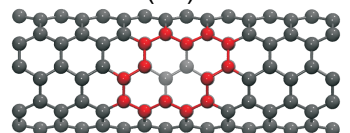

(b)

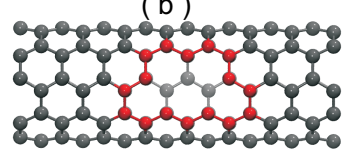

( C )

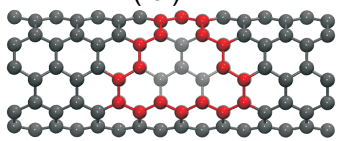

(d)

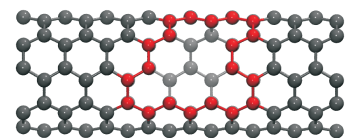

(e)

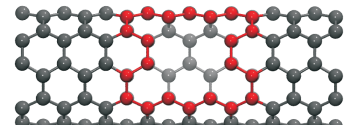

(f)

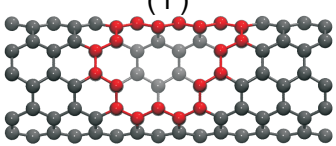

( g )

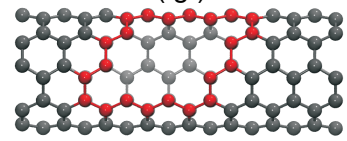

( h )

Figura 6.27: Multivacâncias sem reconstrução: (a) $V_{1}$; (b) $V_{2}$; (c) $V_{3}$ (d) $V_{4}$; (e) $V_{5}$; (f) $V_{6} ;$ (g) $V_{7} ;$ (h) $V_{8}$.

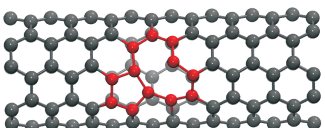

(a)

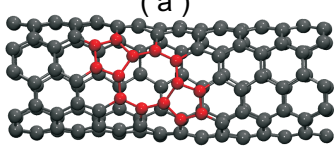

(b)

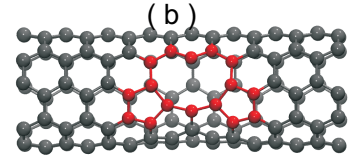

(c)

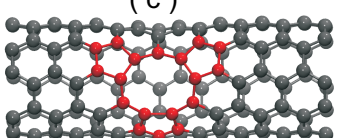

(d)

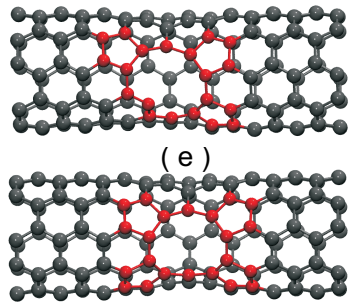

( f )

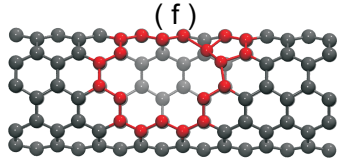

( g )

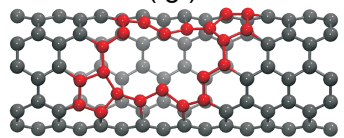

( h )

Figura 6.28: Multivacâncias com reconstrução: (a) $V_{1}$; (b) $V_{2}$; (c) $V_{3}$ (d) $V_{4}$; (e) $V_{5}$; (f) $V_{6}$; (g) $V_{7}$; (h) $V_{8}$. 
Feito isso, temos que definir um método confiável para a determinação da estabilidade das multivacâncias. Para isso, vamos definir duas energias de dissociação, para cada, $V_{n}$.

A primeira é definida da seguinte maneira,

$$
D_{1}(n)=E_{f}(n-1)+E_{f}(1)-E_{f}(n)
$$

que é correspondente à seguinte reação:

$$
V_{n} \rightarrow V_{n-1}+V_{1}
$$

A segunda energia de dissociação é definida como,

$$
D_{2}(n)=E_{f}(n+1)+E_{f}(n-1)-2 F_{f}(n)
$$

que corresponde à reação:

$$
2 V_{n} \rightarrow V_{n-1}+V_{n+1}
$$

onde $E_{f}(n)$ indica a energia de formação da $V_{n}$. A primeira definição, corresponde à dissociação da vacância $V_{n}$ em uma vacância $V_{n-1}$ mais uma monovacância $\left(V_{1}\right)$. A segunda definição corresponde à reação de duas vacâncias $V_{n}$ virando uma $V_{n-1}$ e uma $V_{n+1}$. Dessa maneira, temos o seguinte: 

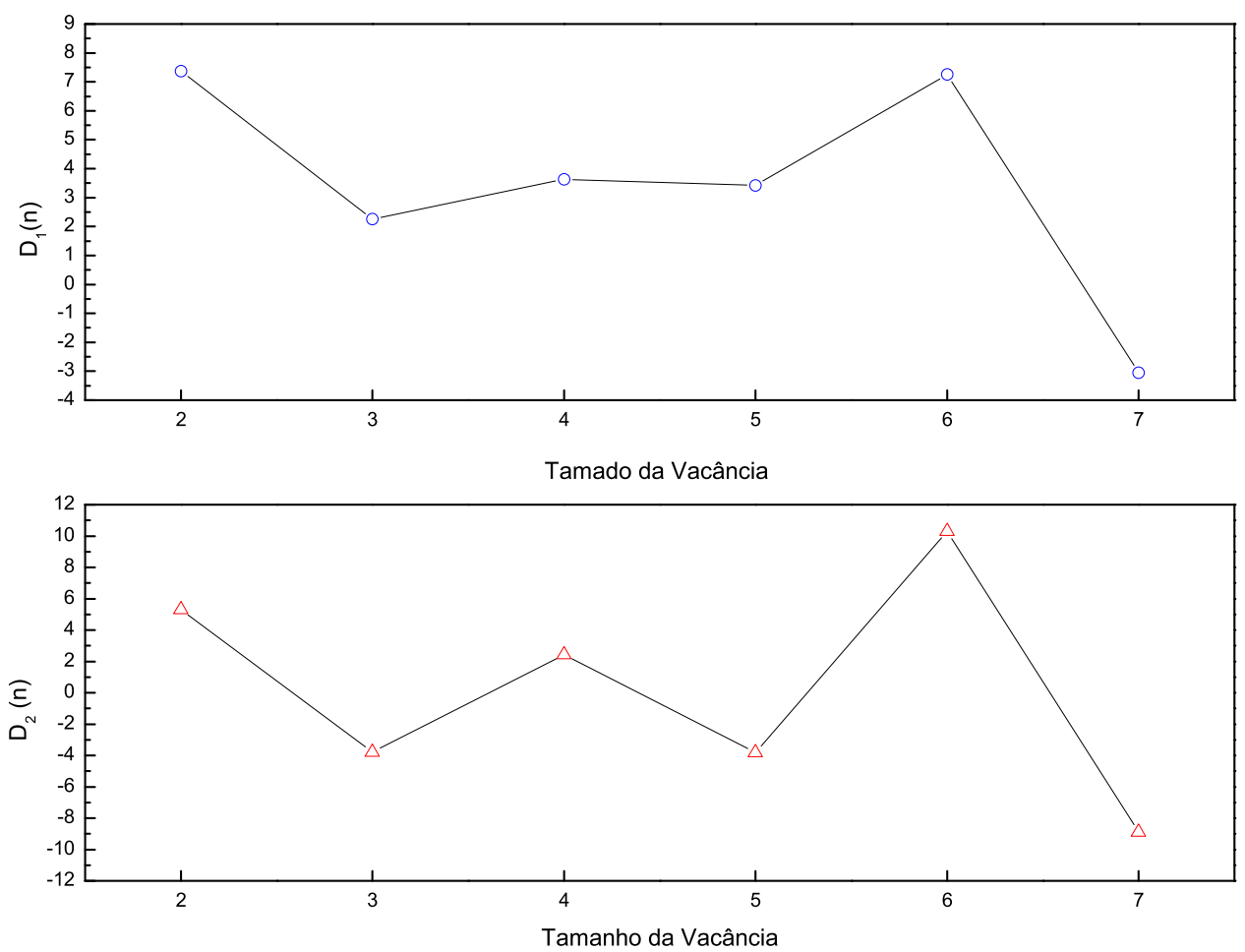

Figura 6.29: Energias de dissociação. (a) Energia de dissociação calculada com a equação (6.1); (b) Energia de dissociação calculada com a equação (6.3).

A partir de ambas as figuras (6.29-(a) e (b)) observamos picos nas energias de dissociação em $V_{2}, V_{4}$ e $V_{6}$. Concluímos que os números mágicos são 2,4 e 6 . Isso nos indica que as vacâncias $V_{2}, V_{4}$ e $V_{6}$ são estáveis no nanotubo, ao contrário da conclusão que teríamos se olhássemos somente para a energia de formação do sistema.

Agora surge uma pergunta: Porque esses defeitos são os mais estáveis? O que é que determina a estabilidade desses defeitos? Qual é o principal fator presente que estabiliza os defeitos? Será que é a aniquilação das "dangling bonds"é o 
principal fator? Será que é devido aos pentágonos?

Para entender isso, vamos primeiramente analisar o modelo que somente leva em conta as "dangling bonds", que é reportado na literatura como "Modelo de Contagem de "Dangling Bonds"(DBCM)". Para isso, precisamos determinar algumas quantidades. A primeira, é o ganho de energia do sistema devido à relaxação, que é definida como a diferença da energia do sistema reconstruído com a energia do sistema com o defeito perfeito (sem reconstruir). Se tomarmos essa energia de relaxação e dividirmos pelo número de pentágonos no sistema reconstruído, teremos a energia de ligação de um pentágono. Nós podemos definir também a energia por "dangling bond", que é a energia de formação do defeito perfeito (sem reconstrução) dividida pelo número de "dangling bonds". Essas grandezas são resumidas na tabela a seguir, (6.7).

\begin{tabular}{ccccccccc}
\hline \hline & $V_{1}$ & $V_{2}$ & $V_{3}$ & $V_{4}$ & $V_{5}$ & $V_{6}$ & $V_{7}$ & $V_{8}$ \\
\hline$E_{\text {relax }}(\mathrm{eV})$ & 2.305 & 5.51 & 5.04 & 7.06 & 7.18 & 10.13 & 2.61 & 5.04 \\
$N_{\text {pent }}$ & 1 & 2 & 2 & 3 & 3 & 4 & 1 & 2 \\
$N_{D B}$ & 3 & 4 & 5 & 6 & 7 & 8 & 7 & 8 \\
$E_{\text {pent }}(\mathrm{eV})$ & 2.30 & 2.75 & 2.52 & 2.35 & 2.39 & 2.53 & 2.61 & 2.52 \\
$E_{D B}(\mathrm{eV})$ & 2.64 & 2.35 & 2.50 & 2.39 & 2.38 & 2.25 & 2.74 & 2.67 \\
$C-C_{\text {pent }} \AA$ & 1.54 & 1.51 & 1.53 & 1.54 & 1.52 & 1.51 & 1.52 & 1.54 \\
\hline \hline
\end{tabular}

Tabela 6.4: Energias de formação e relaxação para os pentágonos e "dangling bonds". O valor da distância $C-C$ dos pentágonos é uma média entre todos os pentágonos do sistema. 
Definido essas energias, podemos escrever o modelo de contagem de "dangling bonds"(DBCM). Para esse modelo, basta termos uma média da energia por "dangling bond", que é $\approx 2.49 \mathrm{eV}$. Assim, a partir desse modelo a energia de formação é dada por:

$$
E_{D B C M}=2.49 N_{D B}
$$

onde $N_{D B}$ é o número de "dangling bonds"para o sistema não relaxado. Saito, et al. [96] também escreve um outro modelo para a energia de formação porém ele leva em conta os pentágonos e as dangling bonds, conhecido como "Modelo de Contagem de Pentágonos e "Dangling Bonds"(PDBCM)". Para isso, definimos uma média das energias por pentágono entre todos os defeitos, que é $\approx 2.50 \mathrm{eV}$. Assim, o modelo que considera tanto as "dangling bonds"como a reconstrução dos pentágonos (PDBCM), pode ser escrito como:

$$
E_{P D B C M}=2.49 N_{D B}-2.5 N_{P B}
$$

onde $N_{P B}$ é o número de pentágonos do sistema reconstruído.

A seguir, temos as energias de formação calculadas com os dois modelos, comparadas com os nossos cálculos DFT-GGA.

Aqui, podemos observar duas coisas. Primeiro, se considerarmos somente as "dangling bonds", esse modelo falha, onde a discrepância na energia de formação é muito grande. Segundo, adicionando a correção devido aos pentágonos a concordância entre o modelo PDBCM com as nossas energias calculadas com DFT-GGA. 


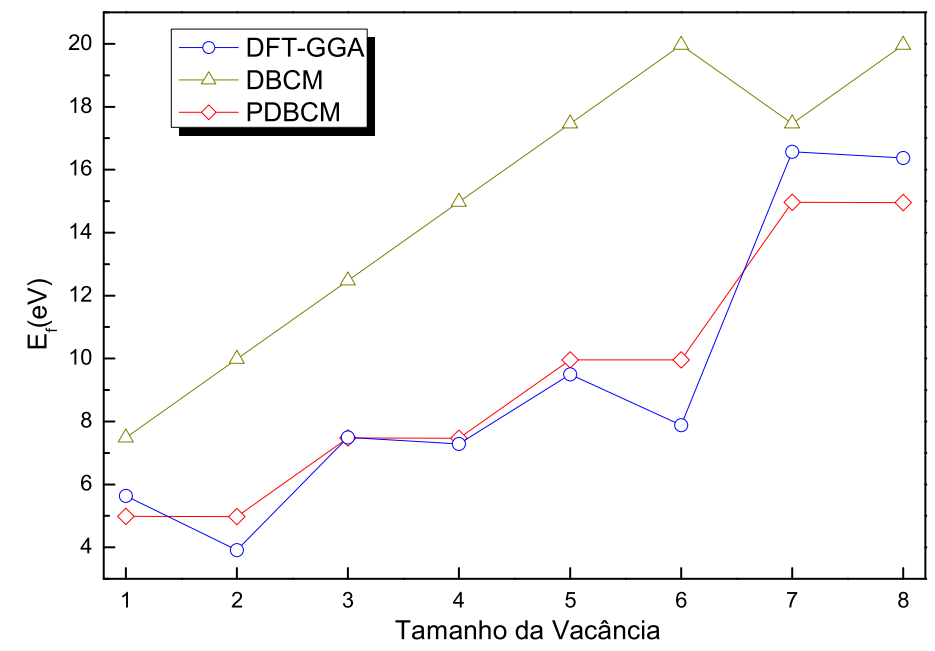

Figura 6.30: Energia de formação dos defeitos calculadas a partir dos cálculos DFT-GGA, DFT-GGA-DBCM e DFT-GGA-PDBCM.

Podemos observar as energias de dissociação para determinar se esses modelos acima reproduzem os números mágicos que encontramos.
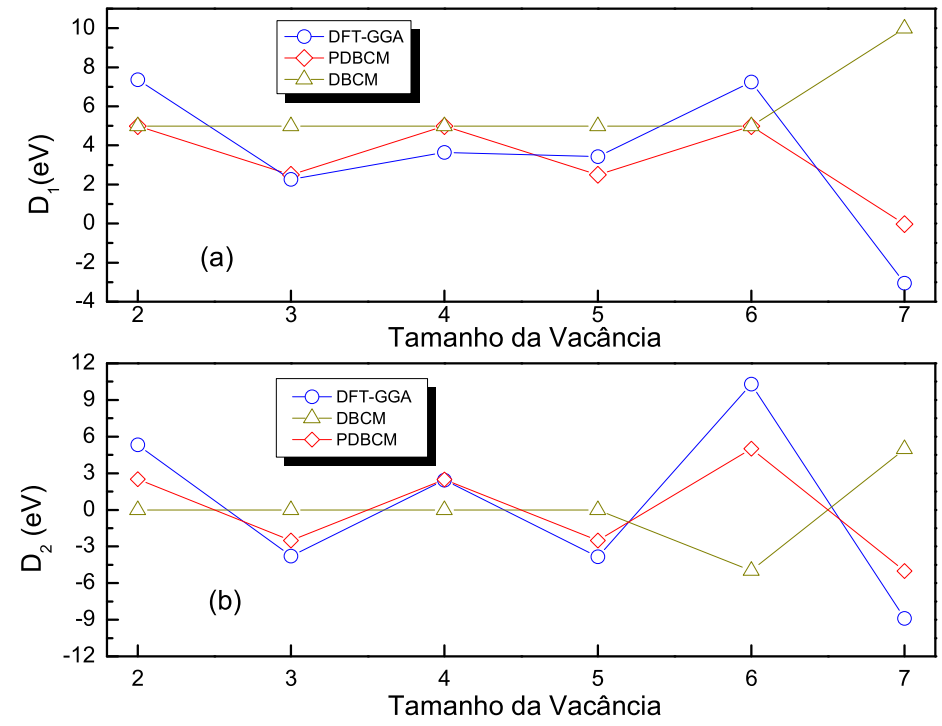

Figura 6.31: Energias de dissociação. (a) Calculada com a equação (6.1) para os novos modelos; (b) Energia de dissociação calculada com a equação (6.3) para os novos modelos. 
Assim, podemos novamente concluir aqui, que o modelo de contagem de "dangling bonds"falha nas duas energias de dissociação, enquanto que o modelo que leva em consideração também os pentágonos reproduz muito bem os nossos cálculos com DFT-GGA. Concluímos também que os números mágicos para as multivacâncias nos nanotubos de carbono são 2,4 e 6 .

Estes modelos escritos acima, consideram sempre uma média entre todos os defeitos calculados, o que é algo não muito interessante, pois ele não pode ser utilizado como um modelo de previsão, sendo assim, vamos propor um novo modelo, onde esse possa ser utilizado para serem feitas previsões qualitativas com respeito à energia de formação e estabilidade dos defeitos nos nanotubos de carbono.

O nosso modelo irá seguir a mesma linha de pensamento dos modelos descritos acima, onde a reconstrução e aniquilação das "dangling bonds"são as principais variáveis responsáveis pela energia de formação do sistema. Mas no nosso modelo vamos utilizar somente dois tipos de defeitos. Um onde tenha a presença de "dangling bonds"e pentágonos e outro onde só ocorra os pentágonos. O nosso modelo irá consistir das seguintes variáveis:

$$
\begin{aligned}
E_{f}(n) & \Rightarrow(\text { DB }) N_{D B N R e l a x}+(\text { Pentagonos }) N_{P B}+ \\
+ & (\text { FormaDefeito }) \frac{\left(1-N_{D B R e l a x}\right)}{\left(N_{\text {Lados }}-N_{P B}\right)} \\
+ & (\text { DeformDB }) \frac{N_{\text {DBRelax }}}{\left(N_{\text {Lados }}-N_{P B}\right)}
\end{aligned}
$$

Precisamos agora determinar quantitativamente essas contribuições através dos nossos dois defeitos, onde utilizamos aqui a monovacância e a divacância. 
O primeiro termo é uma média da energia por "dangling bond", que no nosso caso será $\approx 2.50 \mathrm{eV}$ vezes o número de "dangling bonds"do sistema não relaxado. O segundo termo é o ganho de energia que o sistema terá devido à reconstrução do defeito em pentágonos, para isso tomamos o negativo do valor da energia de ligação de um pentágono, determinada a partir da divacância, onde só temos pentágonos, que é $\approx 2.76 \mathrm{eV}$. Seguindo a mesma idéia que a reconstrução do sistema favorece a energia de formação, temos que levar em conta a forma final do defeito, ou seja o número de lados desse defeito. O termo (FormaDefeito) pode ser obtido através da energia de relaxação da divacância, que é $\approx 5.52 \mathrm{eV}$. O último termo $($ Deform $D B$ ) é a energia que a "dangling bond"restante adiciona no sistema na reconstrução do sistema - deformação que acarreta no átomo da "dangling bond"sempre sair para fora do nanotubo. Este termo podemos obter do valor da energia de relaxação da monovacância que é $\approx 2.31 \mathrm{eV}$. Assim, a nossa equação final fica:

$E_{f}(n)=2.50 N_{D B N \text { Relax }}-2.76 N_{P B}-5.52 \frac{1-N_{\text {DBRelax }}}{N_{\text {Lados }}-N_{P B}}+2.31 \frac{N_{\text {DBRelax }}}{N_{\text {Lados }}-N_{P B}}$

As energias de formação para todos os defeitos calculada a partir dessa equação é então: 

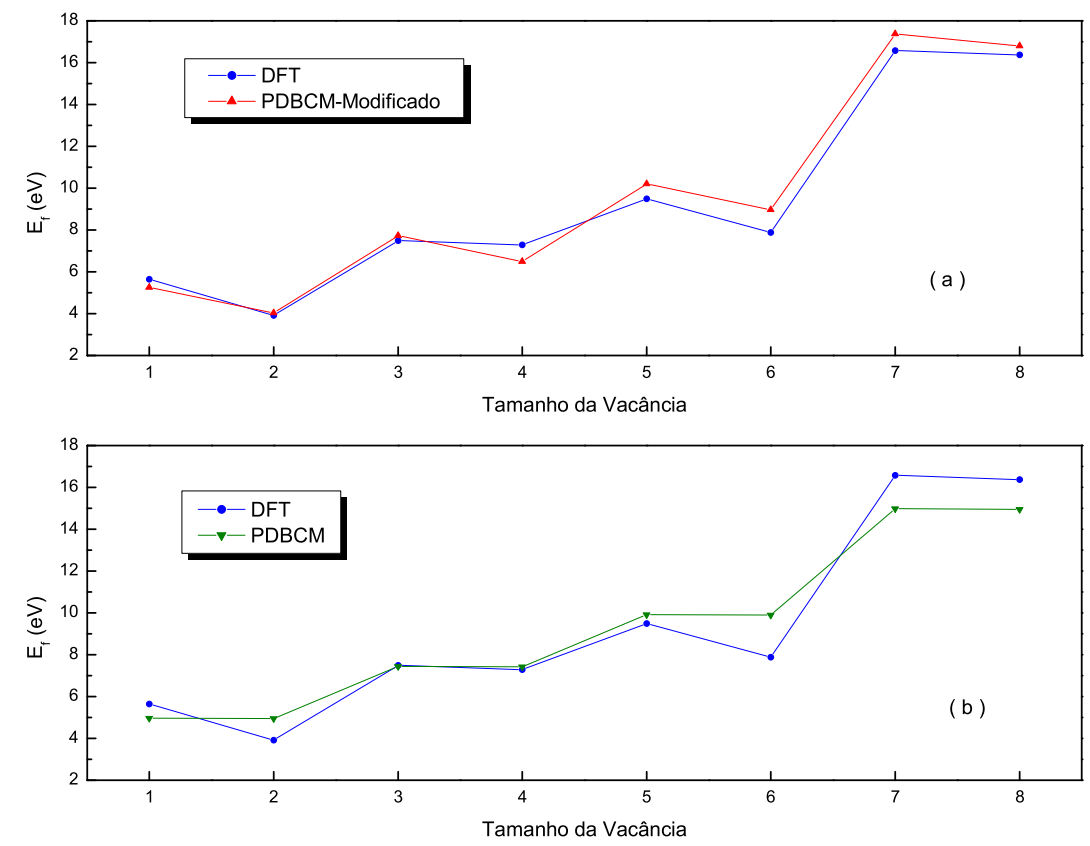

Figura 6.32: Energias de formação: (a) calculada a partir do modelo PDBCM-Modificado, equação (6.8); (b) Energia de formação calculada a partir do modelo PDBCM, equação (6.6).

Nós podemos observar aqui, que as modificações que fizemos na energia de formação estão é ótima concordância com a calculada a partir de nossos cálculos DFT. O que é ainda mais interessante, é que o nosso modelo, considera somente a monovacância e a divacância, onde podemos concluir, que este modelo serve como uma previsão quantitativa com respeito a ordem de grandeza da energia de formação dos defeitos, sem mesmo precisar calcular nenhum deles. Este modelo não fornece o valor exato da energia de formação, pois para isso, teríamos de considerar o comprimento das ligações dos pentágonos, pois essa variação de comprimentos possui uma influência muito grande na energia de formação, como podemos ver através da tendência do comprimento da ligação dos pentágonos por 
tamanho da vacância, figura (6.33).

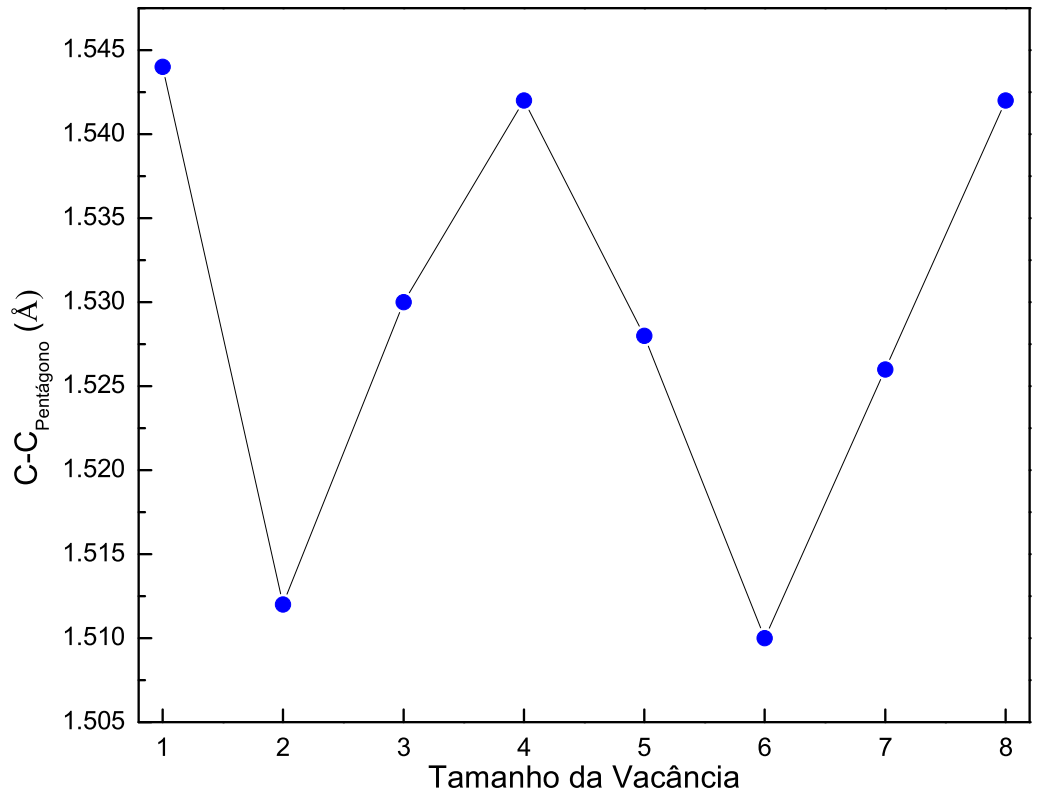

Figura 6.33: Comprimento da ligação médio dos pentágonos presentes nos defeitos.

Olhando para esse gráfico, podemos observar claramente a influência do comprimento da ligação dos pentágonos na energia de formação e estabilidade do defeito. Observamos isso na tetravacância, que possui um comprimento médio da ligação dos pentágonos muito grande, o que não corresponde com a nossa interpretação, mas isso pode ser explicado devido à tetravacância possuir uma ligação de pentágono paralela ao eixo do tubo e essa não ser muito forte, dessa maneira possuindo um comprimento maior, como podemos ver na figura (6.34). 


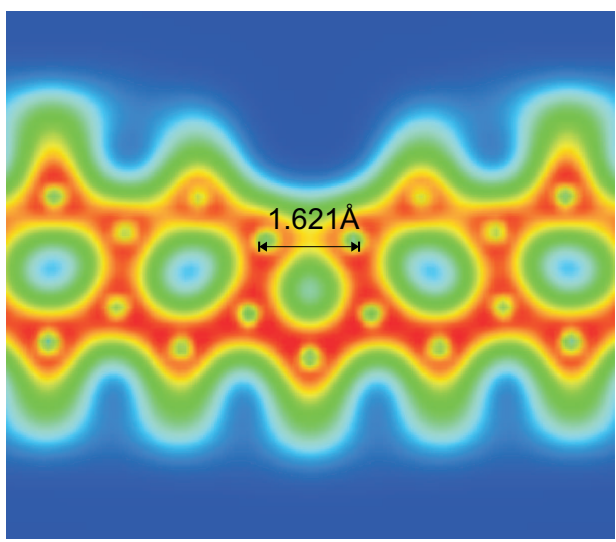

( a )

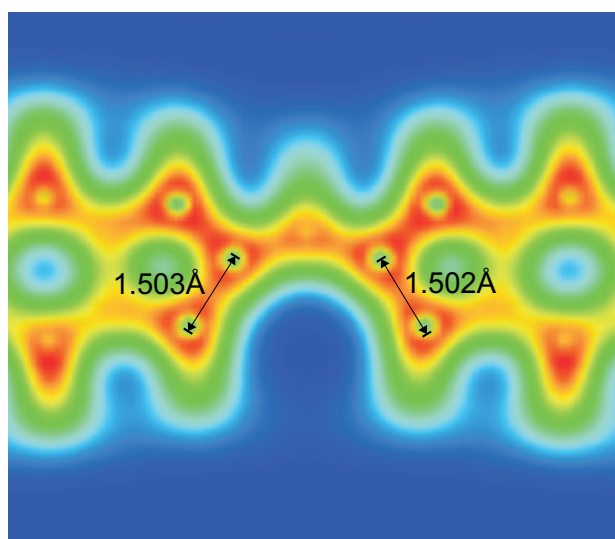

(b)

Figura 6.34: Plano de carga através dos pentágonos da tetravacância: (a) Pentágono paralelo ao eixo do nanotubo; (b) pentágonos inclinados.

Assim, para uma melhoria no nosso modelo para energia de formação e estabilidade dos defeitos, seria incluir algum tipo de relação entre o comprimento dos pentágonos devido à reconstrução dos defeitos, porém da maneira que está agora, já funciona muito bem, como um modelo qualitativo e quantitativo. Qualitativo no sentido que representa muito bem a ordem de grandeza da energia de formação dos defeitos e quantitativo na determinação dos números mágicos, conforme podemos observar através da energia de dissociação calculada com esse nosso modelo, figura (6.35). 

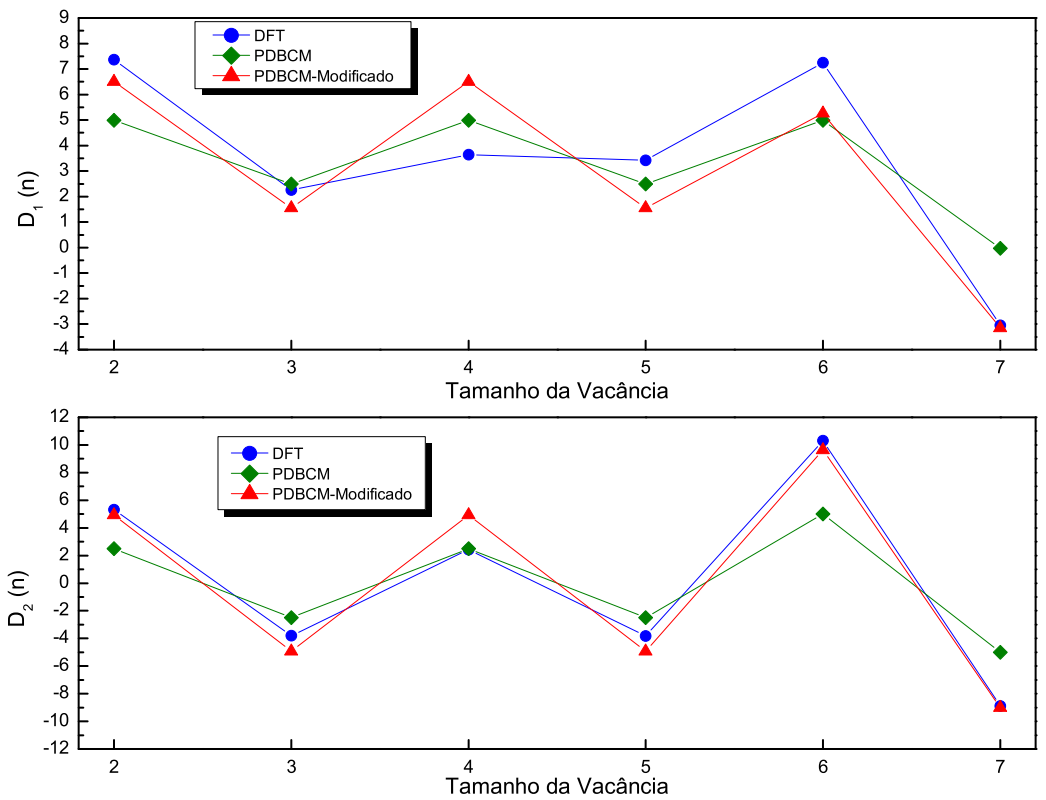

Figura 6.35: Energias de dissociação. (a) Calculada com a equação (6.1); (b) Energia de dissociação calculada com a equação (6.3). Em azul calculada com DFT-GGA, verde a partir do modelo PDBCM e em vermelho através do nosso modelo, PDBCM-Modificado.

Assim, podemos concluir que o nosso modelo funciona muito bem, representando a energia de formação e novamente nos indicando que as vacâncias mais estáveis são as $V_{2}, V_{4}$ e $V_{6}$, onde os números mágicos são então, 2,4 e 6 . E reforçando novamente, nosso modelo serve como um modelo de previsão, pois sabemos tudo com respeito à estabilidade somente precisando calcular a divacância e a monovacância.

\subsection{Conclusões - Multivacâncias}

Nesta seção, iremos apresentar as conclusões do trabalho com as multivacâncias. Aqui nós realizamos um estudo sistemático de defeitos do tipo multivacân- 
cias, partindo da divacância até a hexavacância, onde tratamos a reconstrução, estrutura eletrônica, transporte eletrônico e estabilidade de todos os defeitos.

Os principais resultados para esses defeitos são:

\section{Divacâncias}

1. A partir do estudo da energia de formação das divacâncias, concluímos que a 585 continua sendo a do tipo mais favorável no sistema, possuindo uma energia de formação de $\approx 0.6 \mathrm{eV}$ mais baixa dentre as outras divacâncias;

2. Observamos que através de duas "bond-rotation"no defeito 585, nós obtivemos um outro tipo de divacância, a 555567777; ainda não descrita na literatura. Esta possui uma configuração altamente simétrica com respeito à forma do defeito. Possuindo uma energia de formação $\approx 0.65 \mathrm{eV}$ mais alta que a 585, porém é energéticamente mais favorável com respeito à 555777 por $\approx 0.25 \mathrm{eV}$

3. Observando a estrutura de bandas dos defeitos 585 e 555567777 notamos o surgimento de estados "flat's"ao redor do nível de Fermi. Estes são devido à uma localização de carga nos pentágonos do defeito;

4. Quando olhamos para a estrutura de bandas e densidade de estados calculadas com condições periódicas de contorno observamos a presença de gap's. Da mesma maneira que ocorre com a monovacância, tais gap's são devido ao potencial periódico inserido pelo defeito. Quando observamos 
a DOS calculadas com funções de Green estes gap's de energia desaparecem, reforçando a idéia de que estes são artifícios da imposição da simetria translacional;

5. A transmitância dessas divacâncias apresenta várias quedas devido a interferências destrutivas de estados localizados no defeito;

6. Os canais de spin são completamente degenerados;

\section{Trivacâncias}

1. Estudando a reconstrução do sistema após a retirada de três átomos, obtivemos duas possíveis configurações para a trivacância. Uma possuindo um conformação inclinada com respeito ao eixo de crescimento do nanotubo e outra paralela. A mais favorável é a configuração onde a nova ligação dos pentágonos é sempre inclinada com relação ao eixo do tubo. A trivacância paralela ao eixo do tubo, possui uma energia de formação de $\approx 2.5 \mathrm{eV}$ mais baixa que a configuração inclinada. Esta diferença grande de energia é devido a não-reconstrução da ligação do pentágono paralelo;

2. A partir do cálculo da estrutura de bandas e DOS para o defeito paralelo, observamos o surgimento de bandas de impureza, devido a localização de carga ao redor do defeito e no "dangling bond"presente no sistema. 
3. Através da análise da densidade de carga do pico da densidade de estados no nível de Fermi, observamos que ele está localizado no "dangling bond";

4. Na DOS desse sistema, temos também a presença de "gap's", que também são devidos ao uso de condições periódicas de contorno.

5. Os canais de spin desse defeito são degenerados, com uma pequena diferença entre spins $\alpha$ e $\beta$ em $0.3 \mathrm{eV}$ e $1.1 \mathrm{eV}$;

\section{Tetravacância}

1. A tetravacância apresenta uma estrutura com 3 pentágonos e uma região central com 9 lados. A sua energia de formação é de $7.28 \mathrm{eV}$ para 8 células unitárias. Observamos nesse sistema, a presença de um pentágono paralelo ao eixo do nanotubo, que possui uma ligação maior que a dos inclinados. Esta ligação é responsável pelo aumento da energia de formação desse sistema;

2. Não temos nenhum pico na DOS ao redor do nível de Fermi, mesmo estando todos os estados nessa região localizados no defeito;

3. Seguindo a mesma conclusão para os defeitos anteriores, observamos gap's de energia quando realizamos o cálculo com condições periódicas de contorno. 
4. A condutância no nível de Fermi desse é de $\approx 1.48 G_{0}$. Esta possui uma queda no seu valor em $-1.23 \mathrm{eV}$, que é devido a uma interferência destrutiva de estados localizados nos pentágonos de defeito;

5. Os canais de spin são completamente degenerados;

\section{Pentavacância}

1. A pentavacância apresenta uma estrutura com 3 pentágonos, uma região central com 11 lados e um "dangling bond". A sua energia de formação é de $9.50 \mathrm{eV}$ para 8 células unitárias;

2. Devido a presença do defeito, temos o surgimento de bandas de impureza, que estão localizadas na região do defeito, principalmente no "dangling bond";

3. Novamente, observamos o surgimento de gap's de energia espúrios quando realizamos o cálculo com condições periódicas de contorno.

4. A condutância no nível de Fermi é de $\approx 0.6 G_{0}$. A função de transmissão possui uma queda no seu valor em $0.8 \mathrm{eV}$ abaixo do nível de Fermi devido a uma interferência destrutiva de estados localizados nos pentágonos e no "dangling bond";

5. Como na trivacância, os canais de spin são degenerados, com uma pequena diferença entre os spins $\alpha$ e $\beta$ na região entre $0.1 \mathrm{eV}$ e $1 \mathrm{eV}$ 


\section{Hexavacância}

1. A hexavacância após a reconstrução apresenta 4 pentágonos e uma forma central com 10 lados;

2. A energia de formação para a hexavacância 555510 com 8 células unitárias é de $7.88 \mathrm{eV}$;

3. A presença do defeito no sistema, gera bandas de impureza, que são localizadas no defeito;

4. Devido a presença de um potencial espalhador periódico inserido pelo defeito, ocorre o surgimento de gap's de energia no entorno do nível de Fermi, que não são vistos quando calculados com condições de contorno abertas, onde estes gap's são relacionados com um artifício do cálculo;

5. A transmitância desse sistema possui uma grande variação em toda a região do nível de Fermi, onde ai possui um valor de $0.5 G_{0}$. Estas quedas na transmissão são devidas a localização de estados no defeito;

6. A transmissão eletrônica neste sistema se dá por canais de spin completamente degenerados;

\section{Estabilidade dos Defeitos}


1. Através do estudo sistemático dos defeitos, encontramos que a divacância 585 é a que possui energia de formação mais baixa: $3.9 \mathrm{eV}$ para 9 células unitárias;

2. Quando comparamos todos os defeitos com a monovacância, dividindo a energia de formação deles pelo número de átomos retirados, obtemos que a hexavacância possui a menor energia;

3. Através do fato que a divacância possui energia de formação mais baixa, podemos falar que ela é mais estável, porém temos também que a hexavacância possui energia mais baixa, quando comparamos os defeitos com a monovacância, onde podemos dizer que ela é a mais estável. Assim, a única conclusão que temos a partir desses resultados é que precisamos de um método melhor para dizer com certeza qual é o defeito mais estável no sistema;

4. Ao estudarmos as energia de dissociação dos defeitos, obtivemos que a divacância, a tetravacância e a hexavacância são os defeitos mais estáveis no sistema;

5. Os defeitos em nanotubos de carbono, também apresentam números mágicos como em muitos outros sistemas. Eles são 2, 4 e 6;

6. Observamos através do modelo PDBCM que os pentágonos provenientes da reconstrução do sistema exercem uma influência muito grande no valor da energia de formação e estabilidade dos defeitos; 
7. Propusemos um novo modelo para o cálculo da energia de formação dos defeitos, baseados somente em parâmetros obtidos a partir da monovacância e divacância, onde observamos que ele reproduz muito bem tanto o comportamento do valor da energia de formação quando à estabilidade dos defeitos. Concluímos daí, que ele é um bom modelo de previsão para defeitos em nanotubos de carbono; 


\section{Capítulo 7}

\section{Conclusões Gerais}

Neste trabalho estudamos defeitos do tipo vacâncias em nanotubos de carbono armchair $(5,5)$ via cálculos de primeiros princípios. Realizamos uma análise sistemática das monovacâncias a fim de entender qual a influência da densidade destas nas propriedades estruturais e eletrônicas do nanotubo. Observamos que tais propriedades possuem uma certa dependência com a densidade de defeitos e que a partir de $19.712 \AA$ os dois tipos de interações entre as vacâncias (estrutural e eletrônica) são praticamente desprezíveis. Determinamos uma barreira de migração para a monovacância de $0.55 \mathrm{eV}$ e esta nos fornece um tempo aproximado de $0.146 \mathrm{~ms}$ a uma temperatura de $300 \mathrm{~K}$ para que um defeito salte de um sítio para outro na rede do nanotubo. Estabelecida está grande mobilidade da monovacância, construímos as multivacâncias do tipo buraco, que são formadas eventualmente pelo encontro de várias monovacâncias. Determinamos que a divacância, a tetravacância e a hexavacância são os defeitos mais estáveis no nanotubo. Através dos cálculos de bandas e DOS, observamos o surgimento de gap's 
de energia espúrios, devido a imposição da simetria translacional no sistema. A partir de cálculos de funções de Green, que considera um sistema aberto, estes gap's não são observados. 


\section{Apêndice A}

\section{Multivacâncias Lineares}

Apresentaremos neste apêndice outros tipos de multivacâncias que não fazem

parte do objetivo dessa dissertação de mestrado, mas que são importantes para o entendimento dos defeitos em nanotubos de carbono.

Denominamos essas multivacâncias de lineares, pois ao invés de retirarmos átomos do sistema a fim de criar um buraco, nós retiramos átomos em linha, onde resulta de um defeito mais extenso.

As multivacâncias lineares que calculamos são a tetra, a penta e a hexa. A seguir temos os resultados.

\section{A.1 Tetravacância Linear}

Nesta seção, apresentaremos os resultados de energia de formação, estrutura eletrônica e transporte de carga para a tetravacância linear. 


\section{A.1.1 Reconstrução e Energia de Formação da Tetravacância Linear}

Este tipo de defeito é formado pela retirada de quatro átomos em linha do nanotubo de carbono, da maneira que temos na figura (A.1).

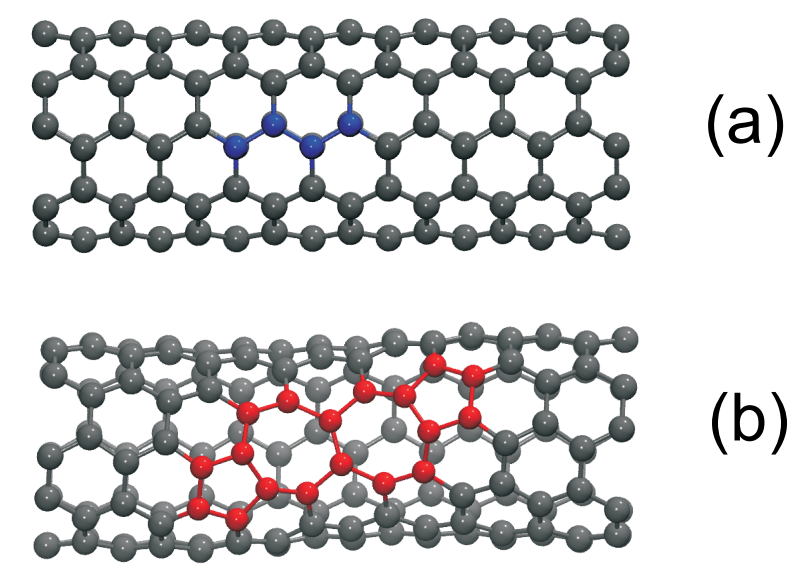

Figura A.1: (a) Nanotubo de carbono puro, onde os átomos em azul indicam a linha de átomos que serão retirados para a criação do defeito;(b) Nanotubo com a tetravacância linear reconstruída, onde os átomos em vermelho indicam o defeito 5577.

Reconstruído o sistema, observamos uma alta reconstrução, com a formação de dois pentágonos e dois heptágonos. Este defeito possui energia de formação de $5.95 \mathrm{eV}$, o que se compararmos com a tetravacância do tipo buraco que calculamos anteriormente, possui energia de formação mais baixa por $1.33 \mathrm{eV}$.

\section{A.1.2 Bandas de Energia e Densidade de Estados - Condições Periódicas de Contorno}

Agora, iremos apresentar as bandas de energia e densidade de estados calculadas com condições periódicas de contorno para essa tetravacância 5577 . 


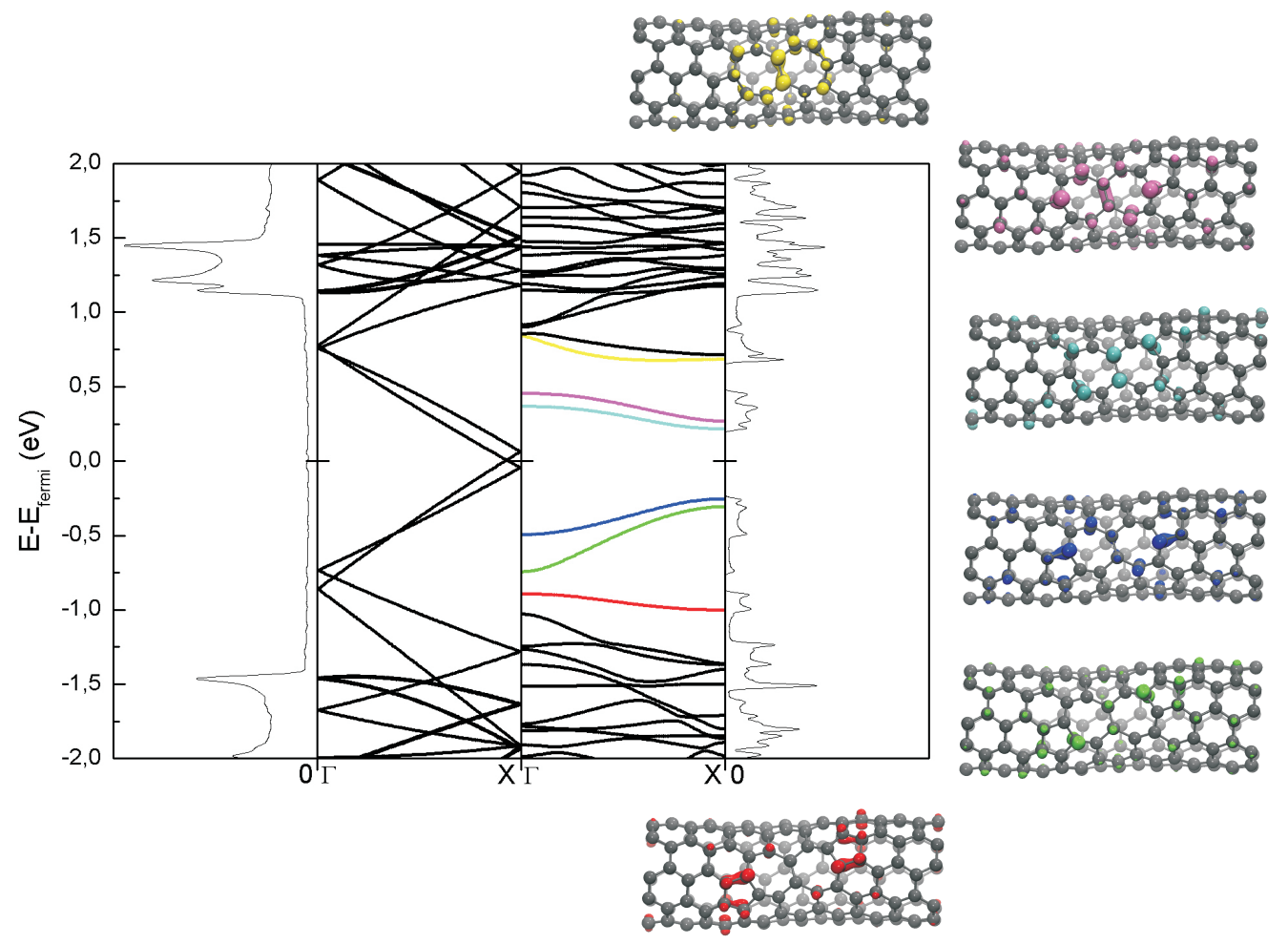

Figura A.2: Bandas de energia, densidade de estados e plot de carga para os sistemas nanotubo de carbono mais tetravacância 5577. As estruturas de bandas e DOS do lado esquerdo correspondem a do sistema puro e as do lado direito do sistema na presença do defeito. Os plots de carga apresentados são correspondentes à energias das regiões indicadas pelas cores e possuem isosuperfícies de $0.02 e / B o h r^{3}$.

Observando a estrutura de bandas do defeito na figura (A.2), temos que devido a uma localização de carga no defeito, temos o surgimento de bandas de impureza em todos os níveis ao redor do nível de Fermi. Essas bandas de impureza criam anti cruzamentos, dando origem ao gap que temos no nível de Fermi. Nota-se a partir da DOS desse defeito, que não temos nenhum pico mais proemimente, porém todos os estados na região do nível de Fermi estão localizados no defeito, tanto nos pentágonos quanto nos heptágonos. 


\section{A.1.3 Densidade de Estados e Transporte Eletrônico - Defeito Isolado}

Deixando agora de utilizar condições periódicas de contorno, calculamos as propriedades eletrônicas da tetravacância linear 5577 utilizando o método de funções de Green fora do equilíbrio, onde é considerado um sistema aberto. Os resultados são os seguintes, figura (A.3):

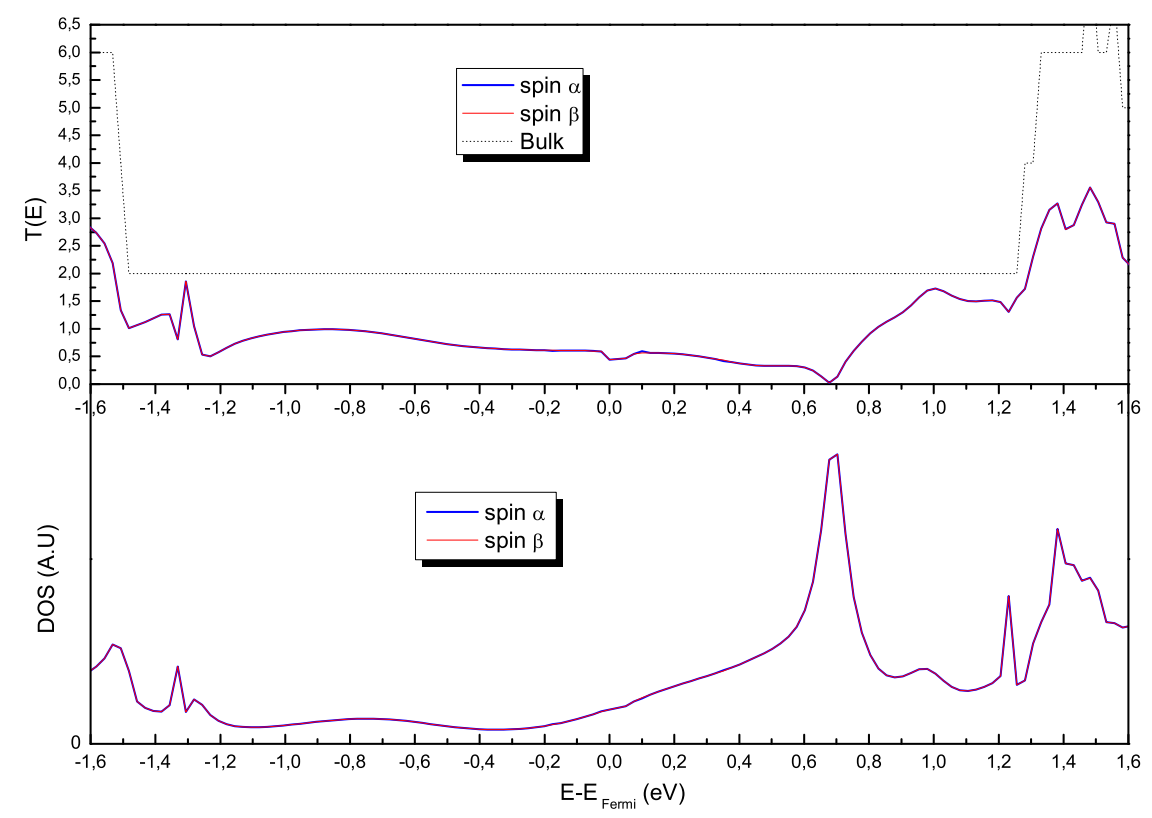

Figura A.3: (a) Coeficiente de transmissão total para o sistema puro (linha preta tracejada) e coeficiente de transmissão por spin para a tetravacância 5577. (b) Densidade de estados total por spin para a divacância 5577 .

Olhando para esse gráfico, observamos várias quedas na transmitância, que são devido à localizações de estados no defeito, ou seja, o defeito apresenta um potencial espalhador, que bloqueia alguns canais de transmissão. Olhando para a DOS da figura (A.3), nós observamos um pico em $0.7 \mathrm{eV}$, que é responsável por um bloqueio total dos canais de transmissão, porém mesmo com essa queda da 
transmitância para zero, o sistema continua metálico como observamos através da condutância desse sistema no nível de Fermi que é de $0.47 G_{0}$. A transmissão eletrônica nesse sistema se dá através de canais de spin completamente degenerados.

É importante notar, neste sistema, que temos na DOS com condições periódicas de contorno, figura (A.2), a abertura de um grande gap no nível de Fermi, porém, este não é presente na DOS calculadas com funções de Green, figura (A.3), onde confirmamos que este gap é devido ao uso de condições periódicas de contorno como observamos para todos os outros defeitos calculados.

\section{A.2 Pentavacância Linear}

Seguindo o nosso estudo com os defeitos lineares, temos agora a pentavacância. Apresentaremos aqui a reconstrução do defeito e a estrutura eletrônica deste, calculadas com condições periódicas de contorno ${ }^{1}$.

\section{A.2.1 Reconstrução e Energia de Formação da Pentavacância Linear}

Esta pentavacância é formada pela retirada de quatro átomos de carbono em linha e um átomo paralelo à essa linha, conforme temos na figura (A.4).

Após a reconstrução do sistema, temos um defeito que apresenta dois pentágonos, dois hexágonos, um sistema central com nove lados e um dangling bond.

\footnotetext{
${ }^{1}$ Não foram realizados cálculos com condições abertas, devido à falta de tempo computacional, pois esses defeitos foram propostos no final do período do mestrado
} 


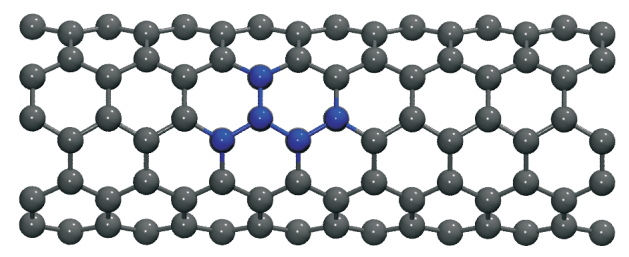

(a)

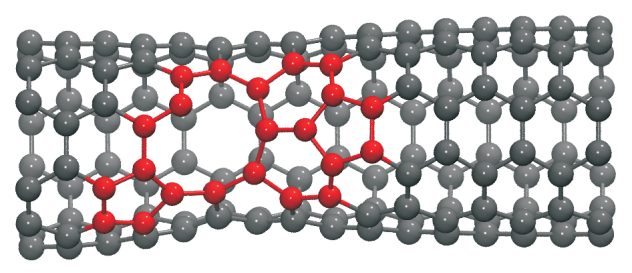

(b)

Figura A.4: (a) Nanotubo de carbono puro, onde os átomos em azul indicam a linha de átomos que serão retirados para a criação do defeito;(b) Nanotubo com a pentavacância linear reconstruída, onde os átomos em vermelho indicam o defeito $55669-1 D B$.

Este defeito possui energia de formação $9.36 \mathrm{eV}$ que é $0.14 \mathrm{eV}$ mais favorável com a pentavacância que apresentamos anteriormente.

\section{A.2.2 Bandas de Energia e Densidade de Estados - Condições Periódicas de Contorno}

Agora, iremos apresentar as bandas de energia e densidade de estados calculadas com condições periódicas de contorno para essa pentavacância linear $55669-1 D B$.

Observando a estrutura de bandas do defeito na figura (A.5), temos que devido a uma localização de carga no defeito, temos o surgimento de bandas de impureza em todos os níveis ao redor do nível de Fermi. Essas bandas de impureza criam anti cruzamentos, dando origem a gap's, porém nesse sistema, não temos a abertura de um gap no nível de Fermi. Quando olhamos para a DOS e para as bandas do defeito, observamos que os picos na DOS, são devidos a uma forte localização 


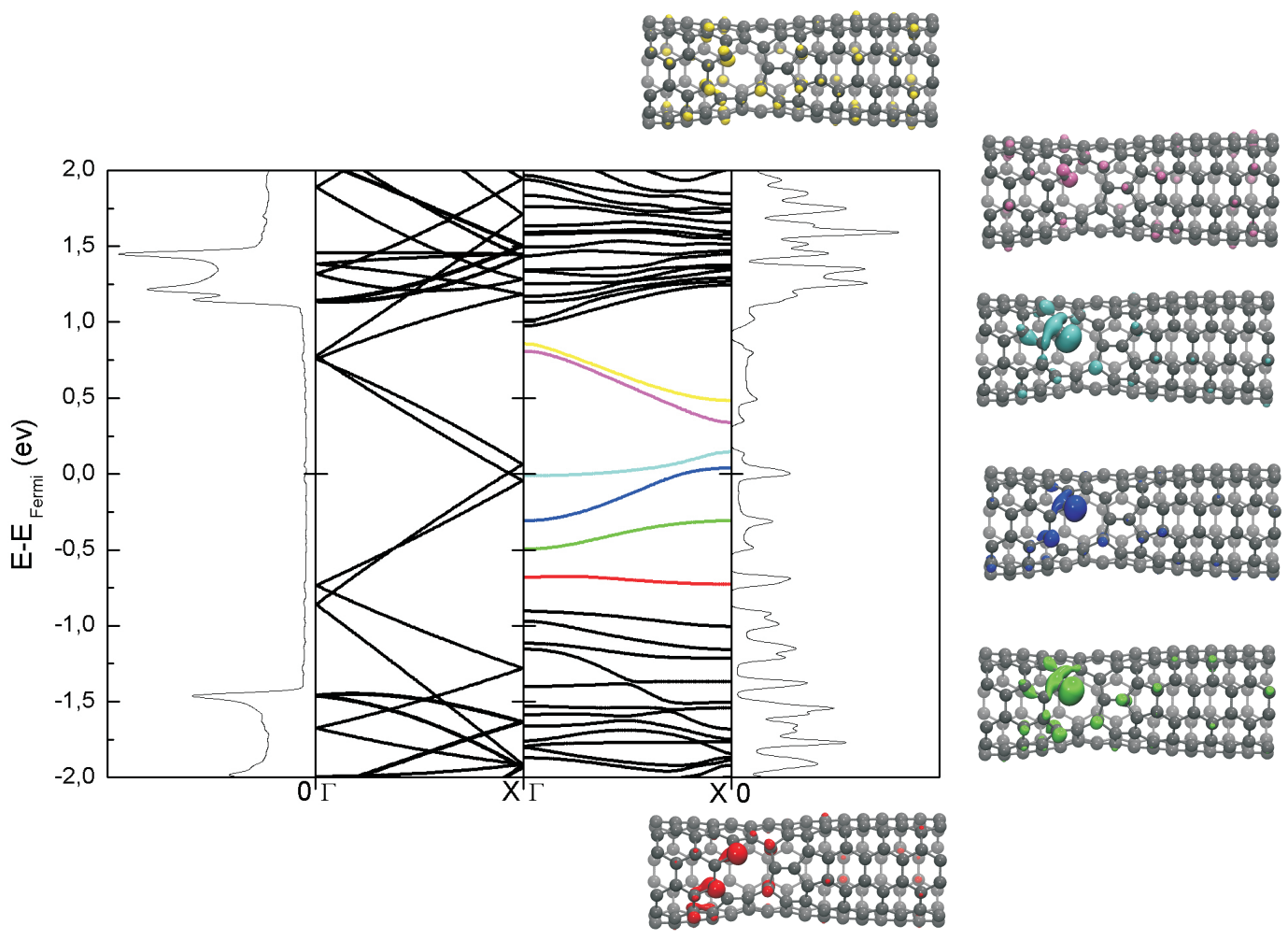

Figura A.5: Bandas de energia, densidade de estados e plot de carga para os sistemas nanotubo de carbono mais pentavacância $55669-1 D B$. As estruturas de bandas e DOS do lado esquerdo correspondem a do sistema puro e as do lado direito do sistema na presença do defeito. Os plots de carga apresentados são correspondentes à energias das regiões indicadas pelas cores e possuem isosuperfícies de $0.02 e / B o h r^{3}$.

de carga no dangling bond do defeito, conforme pormos observar através dos plots de carga no lado direito da figura (A.5).

\section{A.3 Hexavacância Linear}

Finalmente, apresentaremos agora, a hexavacância linear. Como fizemos para a pentavacância linear, apresentaremos os resultados da reconstrução do sistema, energia de formação do defeito e estrutura eletrônica calculadas com condições 
periódicas de contorno ${ }^{2}$.

\section{A.3.1 Reconstrução e Energia de Formação da Hexavacância Linear}

A hexavacância linear, é formada a partir da retirada de seis átomos de carbono em linha, resultando após a reconstrução do seguinte sistema apresentado na figura (A.6).
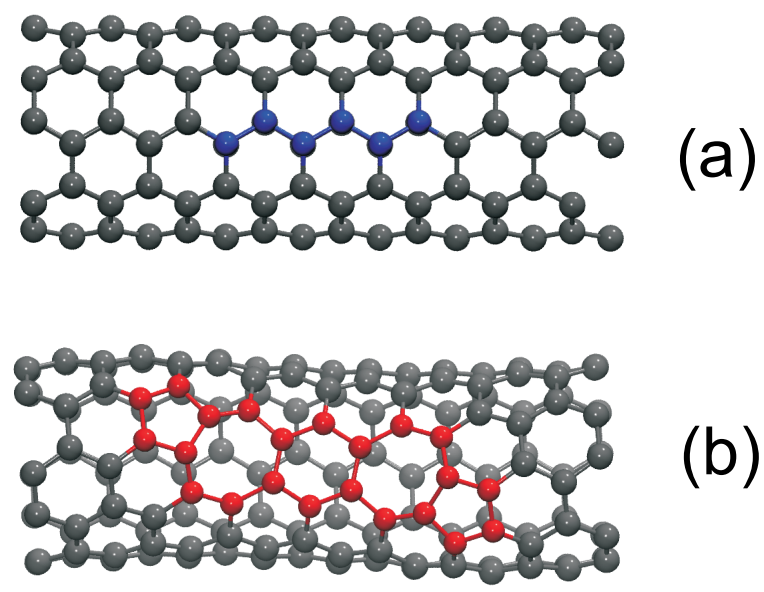

Figura A.6: (a) Nanotubo de carbono puro, onde os átomos em azul indicam a linha de átomos que serão retirados para a criação do defeito;(b) Nanotubo com a hexavacância linear reconstruída, onde os átomos em vermelho indicam o defeito 55677.

Este sistema após a reconstrução apresenta dois pentágonos, dois heptágonos e um hexágono central, conforme podemos ver na figura (A.6). Este defeito possui energia de formação $7.09 \mathrm{eV}$ que é $0.79 \mathrm{eV}$ mais favorável que a hexavacância em forma de buraco que calculamos anteriormente, porém, este defeito nos dá uma intuição de que se continuarmos aumentando o tamanho do defeito em linha,

\footnotetext{
${ }^{2}$ Não foram feitos cálculos de transporte nem DOS com condições abertas, devido à falta de tempo entre a proposta dos defeitos e o fim do mestrado.
} 
teremos na verdade somente dois defeitos formados por um pentágono e um heptágono, separados um do outro, com a presença de um tubo de diâmetro menos no centro. Discutiremos isso um pouco mais pra frente.

\section{A.3.2 Bandas de Energia e Densidade de Estados - Condições Periódicas de Contorno}

Agora, iremos apresentar as bandas de energia e densidade de estados calculadas com condições periódicas de contorno para essa hexavacância linear.

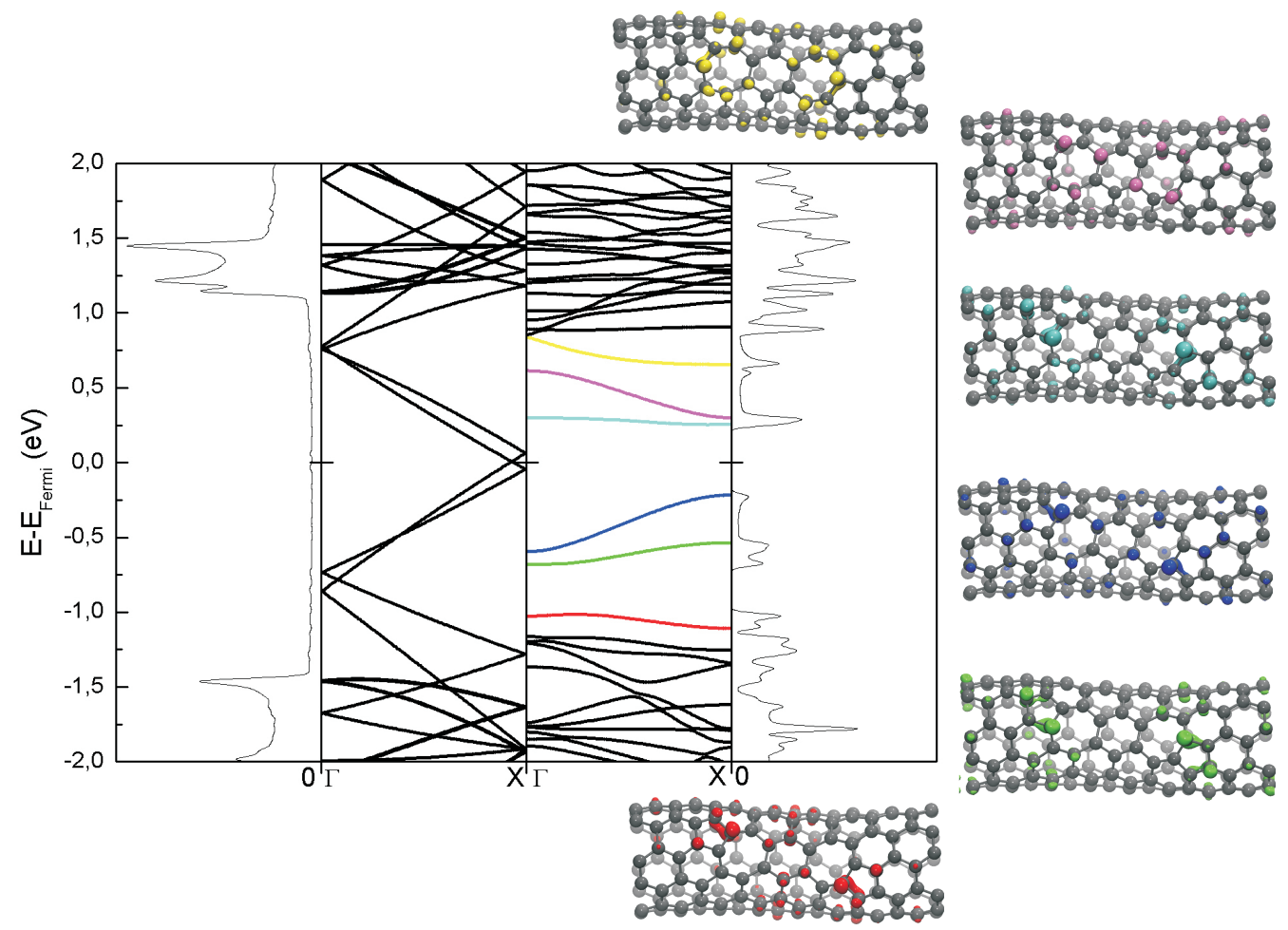

Figura A.7: Bandas de energia, densidade de estados e plot de carga para os sistemas nanotubo de carbono mais hexavacância 55677. As estruturas de bandas e DOS do lado esquerdo correspondem a do sistema puro e as do lado direito do sistema na presença do defeito. Os plots de carga apresentados são correspondentes à energias das regiões indicadas pelas cores e possuem isosuperfícies de $0.02 e / B o h r^{3}$. 
Observando a estrutura de bandas do defeito na figura (A.7), temos que devido a uma localização de carga em todo o defeito, temos o surgimento de bandas de impureza em todos os níveis ao redor do nível de Fermi. Essas bandas de impureza criam anti cruzamentos, dando origem ao gap que temos no nível de Fermi. Nota-se a partir da DOS desse defeito, que temos um pico em $0.29 \mathrm{eV}$, que se observamos através do plot de carga do lado direito da figura (A.7) em azul, ele está localizado nos átomos dos pentágonos presentes na reconstrução. Este estado em azul claro e o em vermelho, são dois níveis quase flat's, e os dois estão localizados nos pentágonos do defeito.

\section{A.4 Conclusões e Perspectivas}

1. Todos os defeitos lineares propostos neste apêndice, possuem energia de formação mais baixa com respeito aos defeitos propostos na forma de buraco;

2. A extensão da reconstrução desses defeitos é muito maior que os defeitos em forma de buraco;

3. Se comparadas as estruturas de bandas e DOS dos defeitos em forma de buraco com a dos lineares, é evidente que a perturbação causada pelos lineares é muito maior, isto devido à grande extensão destes defeitos, sendo necessário o uso de uma supercélula muito maior para minimizar a interação de um defeito com o outro, porém existem algumas limitações com- 
putacionais, que impedem esta prática;

Como perspectivas para trabalhos futuros, utilizando essas multivacâncias lineares, é no estudo de junções de tubos de diferentes diâmetros, para explicar estruturas como mostradas na figura (A.8) [28,97].
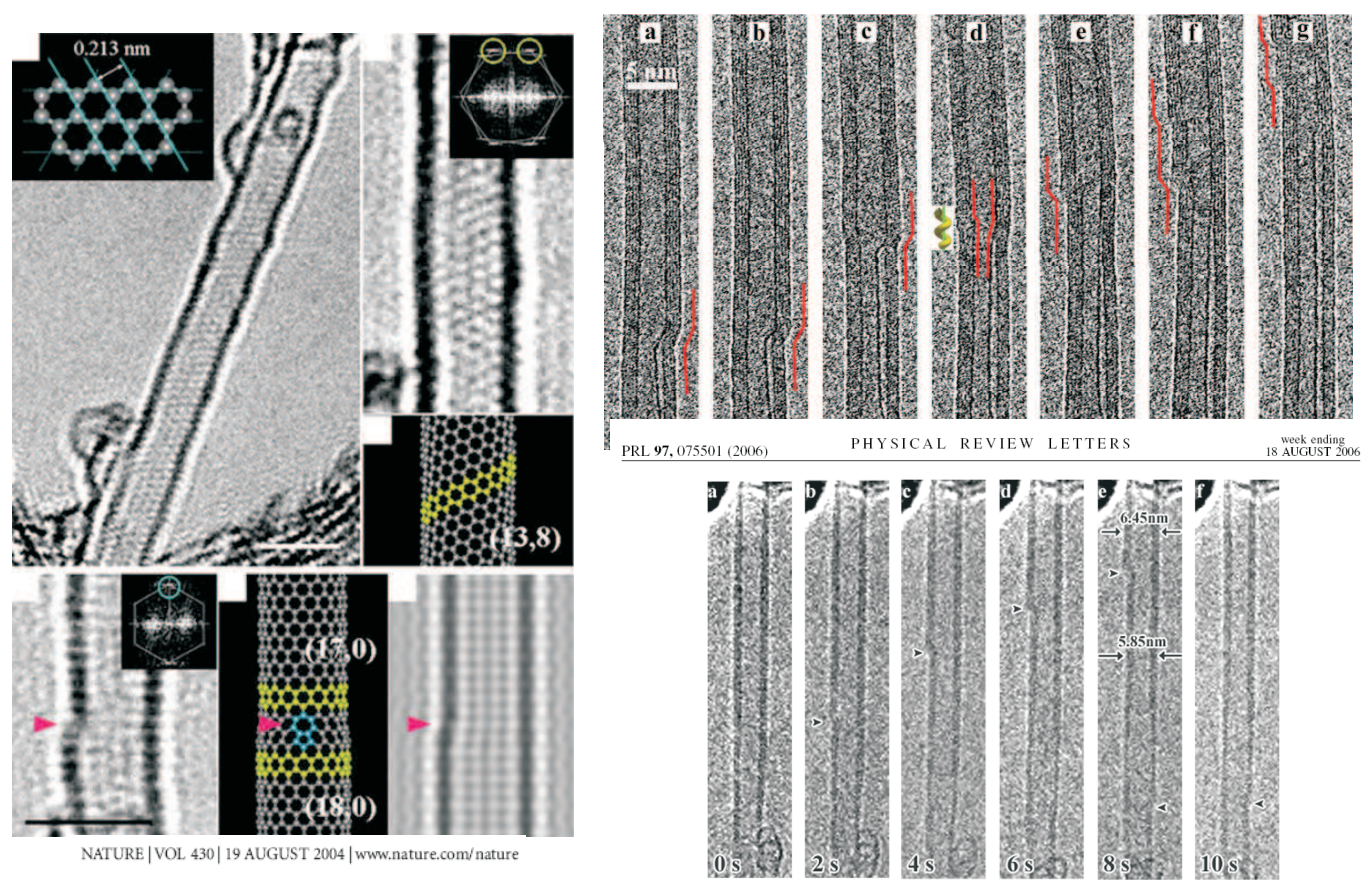

Figura A.8: Exemplos de junções criadas por esses tipos de defeitos com pares de pentágonos e heptágonos

E dessa maneira, uma proposta para isso, seria estudar sistemas como o da figura (A.9)

Assim, conforme podemos observar dessa figura, e das outras vacâncias lineares, quando aumentamos o tamanho do defeito linear, eu crio na verdade dois pares de pentágonos e heptágonos, que fazem a junção de dois tubos, um de diâmetro maior e outro menor. Ressaltando que as propriedades eletrônicas dos 


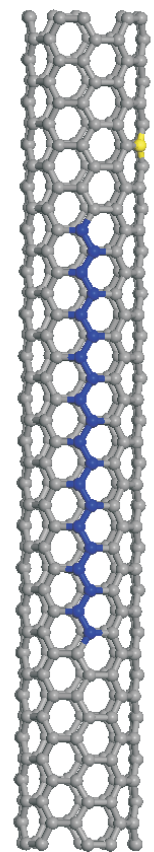

(a)

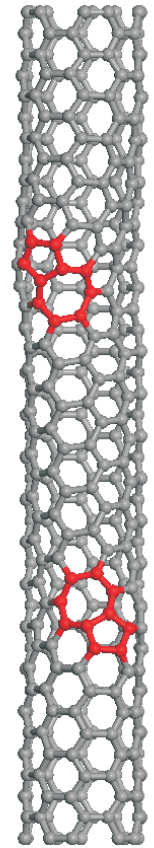

(b)

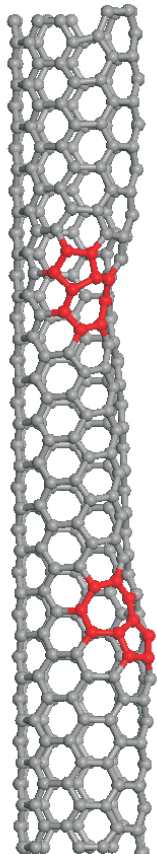

(c)

Figura A.9: Proposta de uma vacância de número 20; (a) átomos em azul mostram os átomos retirados do sistema; (b) Vista frontal dos pares de pentágonos e heptágonos; (c) Vista lateral do defeito, evidenciando a diferença de diâmetros entre os dois tubos;

nanotubos de carbono estão intimamente ligadas com o diâmetro desse, temos a possibilidade de realizar uma junção entre um tubo condutor e um semicondutor, utilizando somente pares de pentágonos e heptágonos. 


\section{Apêndice B}

\section{Trabalhos Relacionados com a Dissertação}

1. 2008 - Seminário promovido pelo Programa de Pós-Graduação em Física da Universidade Estadual de Maringá Apresentação: Nanociência e Nanotecnologia - Estudo de defeitos em nanotubos de carbono via teoria do funcional da densidade;

11 de Março de 2008, Maringá, Paraná, Brasil.

2. 2007 - II Encontro Anual da Rede Theo-Nano Apresentação: Vacâncias em Nanotubos de Carbono; 29 e 30 de Novembro de 2007, São Paulo, São Paulo, Brasil.

3. 2008 - APS March Meeting Transport properties of single vacancies in nanotubes; 10 a 14 de Março, New Orleans, Louisiana, EUA.

\section{Artigos}


1. "Transport properties of single vacancies in nanotubes"

Rocha, A.R., Padilha,J.E., Fazzio,A. and da Silva, A. J. R.;

Physical Review B (B15) Vol (77) Issue (15). (ACEITO);

2. "Multivacancies in carbon nanotubes"em preparação; 


\section{Referências Bibliográficas}

[1] A. V. Rode, S. T. Hyde, E. G. Gamaly, and et al. Applied Physics A - Materials Science and Processing, 69:755, 1999.

[2] N. Ashcroft and D. Mermin. Solid State Physics. 1976.

[3] W. Saslow and T. K. Bergstresser M. L. Cohen. Physical Review Letters, $16: 324,1966$.

[4] H. W. Kroto, J. R. Heath, S. C. O’Brien, R. F. Curl, and year = R. E. Smalley.

[5] S. Iijima and T. Ichihashi. Nature, 363:603, 1993.

[6] D. S. Bethune, C. H. Kiang, M. S. de Vries, G. Gorman, R. Savoy, J. Vazquez, and R. Beyers. Nature, 363:605, 1993.

[7] S. Iijima. Nature, 56:354, 1991.

[8] R. A. Jishi, L. Venkataraman, M. S. Dresselhaus, , and G. Dresselhaus. Phys. Rev. B, 51:11176, 1995.

[9] S. J. Tans, M. H. Devoret, H. Dai, A. Thess, R. E. Smalley, L. J. Geerligs, , and C. Dekker. Nature, 386:474, 1997. 
[10] A. Thess and et al. Science, 273:483, 1996.

[11] B. I. Yakobseon and R. E. Smalley. American Scientifist, 85:324, 1997.

[12] C. Journet and et al. Nature, 388:756, 1997.

[13] M. A. J. Veld and et al. Scince, 273:483, 1996.

[14] G. Binning and H. Rohrer. Rev. Mod. Phys., 59:615, 1987.

[15] G. Binning, H. Rohrer, Ch. Gerber, and E. Weibel. Phys. Rev. Lett., 50:120, 1983.

[16] R. J. Hamers, R. M. Tromp, and J. E. Demuth. Phys. Rev. B, 34:5343, 1986.

[17] H. Ohtani, R. J. Wilson, S. Chiang, and E. M. Nate. Phys. Rev. Lett., 60:2398, 1988.

[18] G. Binning, K. H. Frank, H Fuchs, N. Garcia, B. Reihl, H. Rohrer, F. Salvan, and A. R.Williams. Phys. Rev. Lett., 55:991, 1985.

[19] G. Binnig, C. F. Quate, and Ch. Gerber. Phys. Rev. Lett., 56:9, 1986.

[20] A. V. Krasheninnikov and F. Banhart. Nature Materials, 6:723-733, 2007.

[21] M. Nastasi, J. Mayer, and J. Hirvonen. Ion-Solid Interactions: Fundamentals and Applications. 1996.

[22] D. Ugarte. Nature, 359:707-709, 1992.

[23] F. Banhart and P. M. Ajayan. Nature, 382:433-435, 1996. 
[24] B. W. Smith, M. Monthioux, and D. E. Luzzi. Nature, 396:323-323, 1998.

[25] A. Kis and et al. Nature Materials, 3:153-157, 2004.

[26] G. Gómez-Navarro and et al. Nature Materials, 4:534-539, 2005.

[27] M. Terrones, H. Terrones, F. Banhar, J. C Charlier, and P. M. Ajayan. Science, 288:1226-1229, 2000.

[28] A. Hashimoto, K. Suenaga, A. Gloter, K. Urita, and S. Iijima. Nature, 430:870-873, 2003.

[29] W. Mickelson, S. Aloni, W. Q. Han, J. Cumings, and A. Zettl. Science, 300:467-469, 2003.

[30] M. Terrones and et al. Phys. Rev. Lett., 89:075505, 2002.

[31] J. Kotakoski, A. V. Krasheninnikov, and K. Nordlund. Phys. Rev. B, 74:245420, 2006.

[32] R. G. Amorim, A. Fazzio, A. Antonelli, F. D. Novaes, and A. J. R. da Silva. Nano Letters, 7(8):2459-2462, 2007.

[33] S. Berber and A. Oshiyama. Physica B, 376-377:272-275, 2006.

[34] K. Suenaga, H. Wakabayashi, M. Koshino, Y. Sato, K. Urita, and S. Iijima. Nature, 2:358-360, 2007.

[35] P. M. Ajayan, V. Ravikumar, and J. C. Charlier. Phys. Rev. Lett., 81(7):1437$1440,1998$. 
[36] J. C. Charlier. Acc. Chem. Res., 35:1063-1069, 2002.

[37] A. J. Lu and C. B. Pan. Phys. Rev. Lett., 92:105504, 2004.

[38] J. Rossato, R. J. Baierle, A. Fazzio, and R. Mota. Nano Letters, 5:197-200, 2005.

[39] A. V. Krasheninikov, P. O. Lehtinen, A. S. Foster, and R. M. Nieminen. Chem. Phys. Lett., 418:132-136, 2006.

[40] P. O. Lehtinen, A. S. Foster, Y. Ma, A. V. Krasheninikov, and R. M. Nieminen. Phys. Rev. Lett., 93:187202, 2004.

[41] A. El-Barbary, R. H. Telling, C. P. Ewels, M. I. Heggie, and P. R. Briddon. Phys. Rev. B, 68:144107, 2003.

[42] A. V. Krasheninnikov. Solid State Commun., 118:361-365, 2001.

[43] A. V. Krasheninnikov, K. Nordlund, M. Sirviö, E. Salonen, and J. Keinonen. Phys. Rev. B, 63:245405, 2001.

[44] Z. Osváth and et al. Phys. Rev. B, 72:045429, 2005.

[45] M. R. Carvalho. Dissertação de Mestrado. Universidade de São Paulo, São Paulo, 2007.

[46] H. Stahl, J. Appenzeller, R. Martel, P. Avouris, and B. Lengeler. Phys. Rev. Lett., 85:5186-5189, 2000. 
[47] F. Villalpando-Paez, A. H. Romero, G. Monoz-Sandoval, and et al. Chem. Phys. Lett., 386:137, 2004.

[48] L. H. Thomas. Proc. Camb. Phil. Soc., 23:542, 1927.

[49] E. Fermi. Z. Physik, 48:73, 1928.

[50] I. Z. da Silva. Tese de Doutorado. Universidade de São Paulo, São Paulo, 2006.

[51] J. D. M. Viana, A. Fazzio, and S. Canuto. Teoria Quântica de Moléculas e Sólidos. Simulação Computacional. Editora Livraria da Física, São Paulo, 2004.

[52] P. A. M. Dirac. Proc. Camb. Phil. Soc., 26:376, 1930.

[53] E. P. Wigner. Trans. Faraday Soc., 34:678, 1938.

[54] P. Hohenberg and W. Kohn. Phys. Rev. B, 136:864, 1964.

[55] P. Hohenberg and W. Kohn. Phys. Rev. A, 140:11, 1965.

[56] P. Hohenberg and W. Kohn. Phys. Rev., 136:B864, 1964.

[57] W. Koch and M. C. Holthausen. A Chemist ̌̌s Guide to Density Functional Theory.

[58] R. Parr and W. Yang. Density Functional Theory of Atoms and Molecules. Oxford University Press, 1994. 
[59] W. Kohn and L. J. Sham. Phys. Rev., 140:A1133, 1965.

[60] P. A. M. Dirac. Proc. Camb. Phil. Soc., 26:376, 1930.

[61] D. M. Ceperley and B. J. Alder. Phys. Rev. Lett., 45:566, 1980.

[62] S. H. Vosko, L. Wilk, and M. Nusair. Can. J. Phys., 58:1200, 1980.

[63] J. P. Perdew and Y. Wang. Phys. Rev. B, 45:13244, 1992.

[64] J. P. Perdew and A. Zunger. Phys. Rev. B, 23:5048, 1981.

[65] J. Perdew, K. Burke, and M. Ernzerhof. Phys. Rev. Lett., 77:3865, 1996.

[66] F. D. Novaes, A. J. R. da Silva, and A. Fazzio. Braz. J. Phys., 36:799, 2006.

[67] S. Datta. Quantum Transport: Atom to Transistor, pages Cambrigde University Press, Cambrigde, 2005.

[68] Y. Xue, S. Datta, and M. A. Ratner. Chem. Phys, 281:151, 2002.

[69] M. Paulsson. cond-mat, 0210519, 2004.

[70] A. V. Krasheninnikov, P. O. Lehtinen, A. S. Foster, and R. M. Nieminen. Chem. Phys. Lett., 418:132-136, 2006.

[71] L. Vanderbilt. Phys. Rev. B, 32:8412, 1985.

[72] G. Kresse and J. Hafner. Phys. Rev. B, 47:588, 1993.

[73] G. Kresse and J. Furthmüller. Phys. Rev. B, 54:11169, 1996. 
[74] H. J. Monkhorst and J. D. Pack. Phys. Rev. B, 13:5188, 1976.

[75] R. Saito, G. Dresselhaus, and M. S. Dresselhaus. Physical Properties of Carbon Nanotubes. Imperial College Press, chap. 10, 1st ed., 1998.

[76] R. Saito, G. Dresselhaus, and M. S. Dresselhaus. Physical Properties of Carbon Nanotubes. Imperial College Press, 1st ed., 1998.

[77] M. Brandbyge, J. L. Mozos, P. Ordejon, J. Taylor, and K. Stokbro. Phys. Rev. B, 65:165401, 2002.

[78] A. R. Rocha, V. M. Garcia-Suarez, S. Bailey, C. Lambert, J. Ferrer, and S. Sanvito. Phys. Rev. B, 73:085414, 2006.

[79] J. M. Soler et al. J. Phys.: Condens. Matter, 14:2745, 2002.

[80] C. Caroli, R. Combescot, P. Nozieres, and D. Saint-James. J. Phys. C, 5:21, 1972.

[81] M. Büttiker, Y. Imry anda R. Landauer, and S. Pinhas. Phys. Rev. B, 31:6207, 1985.

[82] H. Jónsson, G. Mills, and G. K. Schenter. Surf. Sci., 324:305, 1995.

[83] M. Saito, K. Yamashita, and T. Oda. Japanese Jounal of Applied Physics, 46:L1185-L1187, 2007.

[84] Y-W., M. L. Cohen, and S. G. Louie. 2007. 
[85] D. J. Chadi and K. J. Chang. Phys. Rev. B, 38:1523, 1988.

[86] T. E. M. Staab, M. Haugk, Th. Frauenheim, and H. S. Leipner. Phys. Rev. Lett., 83:5519, 1999.

[87] Z. Tang, M. Hasegawa, T. Shimamura, Y. Nagai, T. Chiba, Y. Kawazoe, M. Takenaka, E. Kuramoto, and T. Iwata. Phys. Rev. Lett., 82:2532, 1999.

[88] K. Nordlund, J. Keinonen, and T. Mattila. Phys. Rev. Lett., 77:699, 1996.

[89] A. J. Stone and D. J. Wales. Chem. Phys. Lett., 128:501, 1986.

[90] R. H. Telling, C. P. Ewels, A. A. El-Barbary, and M. I. Heggie. Nat. Mater, $2: 333,2003$.

[91] R. H. Telling, C. P. Lehtinen, A. S. Foster, A. Ayuela, and R. M. Nieminen. Phys. Rev. B, 69:73402, 2004.

[92] K. Yamashita, M. Saito, and T. Oda. Jpn. J. Appl. Phys., 45:6534, 2006.

[93] J. M. Carlsson and M. Scheffler. Phys. Rev. Lett., 96:046806, 2006.

[94] P. O. Lehtinen, A. S. Foster, A. Ayuela, A. Krasheninnikov, K. Nordlund, and R. M. Nieminen. Phys. Rev. Lett., 91:17202, 2003.

[95] C. P. Ewels, R. H. Telling, A. A. El-Barbary, M. I. Heggie, , and P. R. Briddon. Phys. Rev. Lett., 91:25505, 2003.

[96] M. Saito, K. Yamashita, and T. Oda. Jpn. J. Appl. Phys., 47:L1185-L1187, 2007. 
[97] J. Y. Huang, S. Chen, Z. F. Ren, Z. Q. Wang, D. Z. Wang, M. Vaziri, Z. Suo, G. Chen, , and M. S. Dresselhaus. Science, 300:467-469, 2003. 